\title{
Contemporary determinants of outcome after colorectal surgery
}

Citation for published version (APA):

Cakir, H. (2020). Contemporary determinants of outcome after colorectal surgery: adherence in enhanced recovery and visceral obesity. [Doctoral Thesis, Maastricht University]. Ridderprint BV. https://doi.org/10.26481/dis.20200110hc

Document status and date:

Published: 01/01/2020

DOI:

10.26481/dis.20200110hc

Document Version:

Publisher's PDF, also known as Version of record

\section{Please check the document version of this publication:}

- A submitted manuscript is the version of the article upon submission and before peer-review. There can be important differences between the submitted version and the official published version of record.

People interested in the research are advised to contact the author for the final version of the publication, or visit the DOI to the publisher's website.

- The final author version and the galley proof are versions of the publication after peer review.

- The final published version features the final layout of the paper including the volume, issue and page numbers.

Link to publication

\footnotetext{
General rights rights.

- You may freely distribute the URL identifying the publication in the public portal. please follow below link for the End User Agreement:

www.umlib.nl/taverne-license

Take down policy

If you believe that this document breaches copyright please contact us at:

repository@maastrichtuniversity.nl

providing details and we will investigate your claim.
}

Copyright and moral rights for the publications made accessible in the public portal are retained by the authors and/or other copyright owners and it is a condition of accessing publications that users recognise and abide by the legal requirements associated with these

- Users may download and print one copy of any publication from the public portal for the purpose of private study or research.

- You may not further distribute the material or use it for any profit-making activity or commercial gain

If the publication is distributed under the terms of Article $25 \mathrm{fa}$ of the Dutch Copyright Act, indicated by the "Taverne" license above, 
Contemporary determinants of outcome after colorectal surgery: adherence in enhanced recovery and visceral obesity 
(C) Hamit Cakir, Maastricht 2020

No part of this book may be reproduced or transmitted in any form or by any means, without prior permission in writing by author, or when appropriate, by the publishers of the publications.

Layout: Tiny Wouters

Cover design: Denny Stoekenbroek

Production: Ridderprint B.V.

ISBN: 978-94-6380-646-6

Printing and disseminations of this thesis was financially supported by Maastricht University, Maatschap Heelkunde Zuyderland, ABN-AMRO, Applied Medical, Pfizer and Nutricia Specialized Nutrition. 


\title{
Contemporary determinants of outcome after colorectal surgery: adherence in enhanced recovery and visceral obesity
}

\author{
ter verkrijging van de graad van doctor aan de Universiteit Maastricht, \\ op gezag van de Rector Magnificus, Prof. Rianne M. Letschert \\ volgens het besluit van het College van Decanen, \\ in het openbaar te verdedigen op \\ vrijdag 10 januari 2020 om 14:00 uur
}

door

Hamit Cakir 


\section{Promotor}

Prof. dr. C.H.C. Dejong

\section{Copromotor}

Dr. A.P.J. Houdijk

\section{Beoordelingscommissie}

Prof. dr. L.P.S. Stassen (voorzitter)

Prof. dr. H.J. Bonjer (Amsterdam UMC, locatie VUmc)

Prof. dr. M.W. de Haan

Dr. A.G.M. Hoofwijk (Zuyderland MC, locatie Sittard-Geleen)

Dr. J. Melenhorst 
Voor mijn ouders, annem ve babam icin 



\section{Contents}

$\begin{array}{lll}\text { Part I Introduction } & 9\end{array}$

Chapter 1 General introduction and outline of the thesis 11

Part II Enhanced Recovery After Surgery 25

Chapter 2 Adherence to Enhanced Recovery After Surgery and length of stay 27 after colonic resection.

Chapter 3 Eight years of experience with Enhanced Recovery After Surgery in patients with colon cancer: Impact of measures to improve adherence.

Part III Risk factors affecting recovery after colorectal surgery for patients treated according to an ERAS protocol

Chapter 4 Risk of anastomotic leakage with non-steroidal anti-inflammatory drugs within an enhanced recovery program.

Chapter 5 The new Body Mass Index as a predictor of postoperative complications in elective colorectal cancer surgery.

Chapter 6 Visceral obesity determined by CT scan and outcomes after colorectal surgery; a systematic review and meta-analysis.

Chapter 7 Visceral obesity, body mass index and risk of complications after colon cancer resection: A retrospective cohort study.

Chapter 8 Visceral obesity, muscle mass and outcome in rectal cancer surgery after neo-adjuvant chemo-radiation.

Part IV Summary

Chapter 9 General discussion and summary

Addendum

Nederlandse samenvatting

Turkse samenvatting

Valorisation 163

Dankwoord

List of publications

Curriculum Vitae 

Part I

Introduction 



\section{Chapter 1}

\section{General introduction and outline of the thesis}

Based on ERAS: Improving outcome in the cachectic HPB patient.

J Surg Oncol. 2017;116(5):617-622. Review. 



\section{General introduction}

Until recently, colorectal surgery was principally performed by laparotomy. Perioperative care was rather conservative, which was in part based on limited diagnostic and therapeutic options if complications occurred. During the last decades, care for the colorectal patient underwent some major improvements such as the introduction of laparoscopic procedures and the implementation of Enhanced Recovery After Surgery (ERAS) programs.

\section{Enhanced recovery after surgery (ERAS)}

In the 1990's, surgery underwent important changes not only because of improved surgical techniques, but also due to improved anesthetic and analgesic techniques. A multidisciplinary approach to perioperative care was instituted and this together with the development of laparoscopic surgery, led to earlier recovery in ambulatory surgery. Programs incorporating these practice changes were called "fast track" programs and this approach converted many multi-day admission surgeries in 1-day surgery operations. In 1997 Hendrik Kehlet, a surgeon in Denmark, introduced a multimodal evidence-based program to fasten postoperative recovery, which was called "multimodal rehabilitation". ${ }^{1}$ He emphasized that multimodal interventions in preoperative, intraoperative and postoperative care may lead to early recovery after surgical procedures by maintaining pre-operative organ function, and reducing the stress response following surgery. Thereby length of hospital stay and costs were reduced after various surgical procedures including colorectal surgery. ${ }^{1}$ Stress induced organ dysfunction, pain, nausea and vomiting, ileus, hypoxemia and sleep disturbances, fatigue, immobilization and semi-starvation, drains and nasogastric tubes with fasting regimes were identified as key factors contributing to slow recovery.

After these years, broad variation existed in the acceptance of this innovative approach among colorectal surgeons and most did not adhere to the program. In 2000, the Enhanced Recovery After Surgery (ERAS) study group was established as a collaboration of five specialised departments of surgery (Denmark, UK, Norway, Sweden and the Netherlands). The ERAS group reviewed the clinical management and outcomes of colorectal surgery in these five centres of which only the Danish centre had implemented the fast track program at that time. ${ }^{2} 451$ consecutive patients underwent an open colorectal resection, 118 patients in the "fast track" centre in Denmark and 333 patients in the other four "traditional care" hospitals. The length of stay (LOS) was significantly shorter in the "fast track" centre in Denmark compared to the other 
"traditional care" hospitals. The ERAS care in Denmark had no influence on morbidity and 30-day mortality, but was associated with higher re-admission rates, particularly if length of stay had been reduced to 2-3 days. In 2005, the group developed an evidencebased ERAS protocol for patients undergoing colonic surgery. ${ }^{3}$

The main components of the ERAS programs are intensive preoperative counselling, the absence of bowel preparation and premedication, no preoperative fasting, the intake of carbohydrate-loaded liquids until 2 hours before surgery, tailored anaesthesiology encompassing thoracic epidural anaesthesia and short-acting anaesthetics, perioperative high inspired oxygen concentrations, avoidance of perioperative fluid overload, small incisions, non-opioid pain management, avoidance of drains, tubes and catheters, standard laxatives and pro-kinetics, and early and enhanced postoperative feeding and mobilization (Figure 1.1). ${ }^{4}$

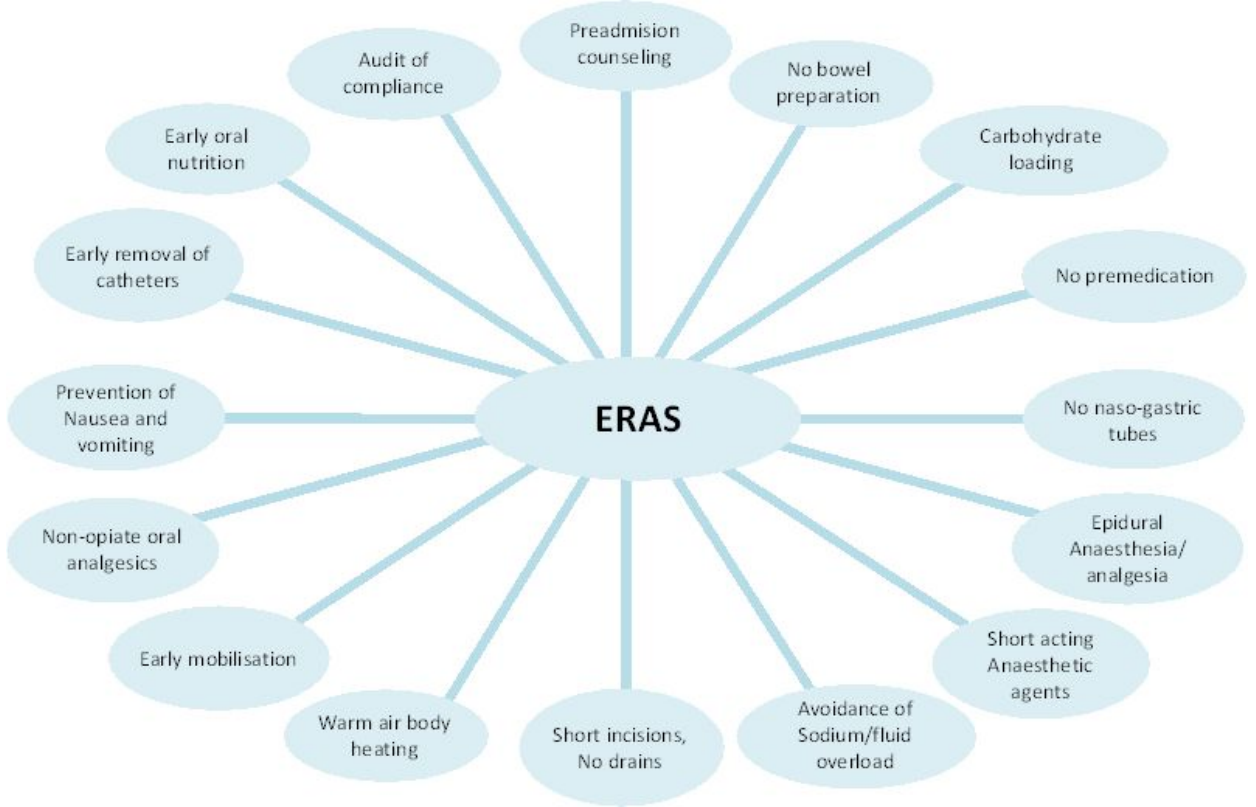

Figure 1.1 Elements of ERAS (Permission from Eslam Elshafey).

Since its introduction, several studies have demonstrated that the ERAS programs compared with traditional care are associated with earlier recovery and shorter LOS after colonic resection. ${ }^{5}$ Recently, the effect of treatment within an ERAS program 
compared to traditional care on four outcome parameters (mortality, morbidity, LOS, hospital readmissions) after mainly colonic surgery was reported in two systematic reviews. ${ }^{6,7}$ The mortality in patients undergoing surgery within an ERAS program was $0.4 \%$ compared to $1.3 \%$ in patients within a traditional care program. This difference was not significant, but there was a significant reduction of postoperative morbidity in patients undergoing surgery within an ERAS program of about $48 \%$ compared to traditional care. Length of stay was shorter in patients within an ERAS program compared with patients undergoing surgery within a traditional care program. Finally, there was no difference in readmission rates among patients within an ERAS program compared with patients treated using a traditional care program. ${ }^{6,7}$

Even though the elements in ERAS programs are based on best evidence, these protocols have not been widely adopted. In 2003, the ERAS collaboration studied perioperative care in the five institutions mentioned before. ${ }^{8}$ A questionnaire was sent to the head surgeons of all intestinal surgical centers. This study showed that perioperative care in colorectal cancer varied widely and did not comply with evidence based practice in northern Europe. These findings were confirmed in a study by Kehlet et al. ${ }^{9}$ The ERAS collaboration also studied outcomes of the ERAS program in the five institutions and showed that a protocol as such is not enough to achieve enhanced recovery and a decrease in length of stay. It was recommended that better organization of care may be required to achieve a more substantial reduction in length of stay. ${ }^{10}$ Clearly, effective implementation and compliance have been shown to be important factors for the success of an ERAS program. Although ERAS programs have been widely studied internationally, little has been published on compliance with such protocols. A previous study showed that morbidity and LOS were reduced more if there was a higher levels of compliance with an ERAS program. ${ }^{11,12}$ In the LAFA-trial, a compliance of $60 \%$ was reported in both laparoscopic and open colonic surgery. ${ }^{13}$ In contrast, the study of Ahmed et al. showed that a high compliance to an ERAS program did not lead to better outcome in elective colorectal surgery. ${ }^{11}$ These results are conflicting to some extent and more research is needed on the relation between adherence to ERAS variables and postoperative outcome.

Surgery provokes a stress response which is associated with metabolic changes. Postoperative hyperglycemia is caused by insulin resistance. Increased insulin resistance and glucose levels are associated with complications and mortality after major abdominal surgery. ${ }^{14,15}$ The risk increases with higher insulin resistance or glucose levels. Several elements in the ERAS protocol affect insulin resistance and glucose levels. These include absence of bowel preparation and preoperative carbohydrate treatment. ${ }^{16,17}$ Surgical injury also induces an inflammatory response. ${ }^{18-21}$ 
One of the aims of an ERAS program is to reduce the surgical stress response with the use of the multimodal interventions. A randomised controlled trial was conducted in 597 consecutive patients who underwent elective colorectal resection, either in an ERAS program (299 patients) or in conventional care (298 patients). In this study, outcomes relating to nutritional, metabolic and stress index on postoperative day 1 and 5 were measured. ${ }^{22}$ The HOMA-IR (insulin resistance index) of the ERAS group was lower than that of the control group $(P<0.001)$. The cortisol level of the control group was elevated on both postoperative days. The cortisol level of the ERAS group remained stable until postoperative day 5 . A reduced postoperative stress response was seen in the ERAS group as witnessed by reduced levels of TNF- $\alpha, \mathrm{IL}-1 \beta, \mathrm{IL}-6$, and IFN- $\gamma$.

There is limited literature on the impact of an ERAS program on health costs after colonic surgery. Recently, the Dutch multicenter LAFA trial examined the costs after colonic resection within an ERAS program compared to traditional care. ${ }^{13}$ They found no differences between these groups. Despite these results, it is a fact that an ERAS program reduces complications and LOS which may result in cost benefits.

\section{Risk factors affecting recovery after colorectal surgery for patients treated according to an ERAS protocol}

The coordinated approach of ERAS allows for groups and individual patients to be better compared for risk factors that are hard to study in less homogenous groups. In a sense, ERAS has contributed to the possibility of identifying new risk factors that may impact recovery after colorectal surgery. Due to better protocol adherence in the ERAS concept and setting up databases to monitor this, other aspects of usual medical care have become apparent like the impact of NSAID's on anastomotic leaks. Again, the structured ERAS database allows for analysing the impact of potential new risk factors on outcome variables. Recently, the impact of body composition, especially visceral fat and the amount of muscle mass has gained interest as factors influencing outcome after colorectal surgery.

\section{Laparoscopic surgery}

Laparoscopic colorectal surgery was introduced in 1991 by Jacobs et al. ${ }^{23}$ Since then minimally invasive colorectal surgery has become more popular and is more and more 
used to reduce the surgical trauma compared to conventional open surgery. Laparoscopic colorectal surgery leads to less morbidity, less postoperative pain, a faster postoperative recovery, and shorter hospital stay compared to open colorectal surgery without compromising the oncological outcome. ${ }^{24}$ When laparoscopy and ERAS are combined, major morbidity and hospital stay are reduced. ${ }^{25}$ The reduction in morbidity seems to be due to laparoscopy rather than ERAS, this may show that laparoscopy offers additional advantages that neutralize ERAS advantages in complication rates. ${ }^{25}$

\section{Visceral obesity}

Obesity is a rapidly increasing global health problem. The index most frequently used to categorize overweight and obesity is the Body Mass Index (BMI), developed by the Belgian scientist Adolphe Quetelet in the 1830 s as a simple measure for classifying people's weight. The BMI is easily calculated as weight in kilograms divided by height in meters squared $\left(\mathrm{kg} / \mathrm{m}^{2}\right)^{26}$ According to the World Health Organization (WHO), overweight is defined as a BMI $>25 \mathrm{~kg} / \mathrm{m}^{2}$ and obesity as a BMI $>30 \mathrm{~kg} / \mathrm{m}^{2}{ }^{27}$ In 2014 , The WHO classified $67 \%$ of the population in the United States and $63 \%$ of the United Kingdom as overweight or obese. ${ }^{28}$ Fat is deposited in two compartments; subcutaneously and viscerally. Visceral fat is more metabolically active than subcutaneous adipose tissue. ${ }^{29}$ The amount of visceral fat is related to the extent of the metabolic syndrome, a pro-inflammatory state associated with insulin resistance. ${ }^{30-34} \mathrm{~A}$ previous study among patients who underwent colectomy for cancer, showed that morbid obesity (BMI $>35 \mathrm{~kg} / \mathrm{m}^{2}$ ) was associated with a higher prevalence of surgicalsite infections, wound dehiscence, pulmonary embolism and renal failure. ${ }^{35}$ Another study found that obesity $\left(\mathrm{BMI}>30 \mathrm{~kg} / \mathrm{m}^{2}\right)$ was associated with a higher conversion rate and longer hospital stay in laparoscopic colectomies. ${ }^{36}$ However, the BMI formula, as a risk profiler for postoperative outcome, has been challenged for some time and the focus now has turned to the impact of the accumulation of visceral fat. ${ }^{37-38}$ One of the aims of this thesis was to investigate if a modified BMI would be a better outcome predictor after colorectal surgery. Visceral obesity has been associated with the development of colorectal cancer and worse outcome after colorectal surgery and other forms of abdominal surgery. ${ }^{39-46}$ Visceral obesity is a risk factor for longer hospital stay after colorectal surgery. ${ }^{47-49}$ It also leads to higher numbers of wound hernia, pulmonary and cardiovascular complications, longer operative times and lower diseasefree survival after major colorectal surgery. ${ }^{49-51}$ It is important to identify the risk factors for obesity, because of the increasing number of these people. 


\section{Sarcopenia and sarcopenic obesity}

The number of elderly patients in need for surgery is continuously increasing. This includes patients with cancer needing surgical treatment. Fifty percent of patients with colorectal cancer are above the age of $70 .^{52}$ Many of these elderly people lose weight, which in the end may result in sarcopenia. Sarcopenia is characterized by a decreased muscle mass caused by ageing or disease which is accompanied by inflammation, metabolic dysregulations and protein breakdown such as in cancer. Sarcopenia is a signal of frailty and has been reported to be associated with more postoperative morbidities, prolonged hospital stay, delayed recovery from surgery, and worse oncologic outcomes. ${ }^{53-59}$ Sarcopenia is mostly assessed by measurement of muscle area at the level of the third lumbar spine at a CT-scan. ${ }^{60}$

The combination of sarcopenia and obesity leads to a phenotype called sarcopenic obesity. Sarcopenic obesity may result in worse outcome and survival in patients undergoing pulmonary, gastrointestinal and pancreatic cancer surgery. ${ }^{61-63}$ 


\section{Aims and outline of this thesis}

As outlined in this chapter, ERAS programs are now in common use in colorectal surgery. However, adherence seems to be essential after the implementation of such a program. Obesity is becoming an increasing health problem, being related to worse outcomes after colorectal resections and maybe also be considered to cause colorectal cancer. With the increasingly older population requiring surgery, cancer- or age-related weight loss resulting in sarcopenia also becomes a more and more common problem.

The subject of the first part of this thesis, Chapter $\mathbf{2}$ and 3, is the cause and impact of differences in adherence rates to the ERAS protocol variables. In recent decades, perioperative care for colorectal surgical patients has improved drastically. In addition to the technical innovation of laparoscopic surgery, Enhanced Recovery After Surgery (ERAS) programmes have been implemented which were designed to reduce perioperative stress factors and hence speed up recovery after colorectal surgery. These programmes have resulted in a much more coordinated and unified approach to perioperative care of the colorectal patient. However, differences in adherence rates to the proposed changes between surgeons and institutions may jeopardize this unified approach to perioperative care of the colorectal cancer patient. When successful, better coordination of perioperative care between surgeons and institutions opens up the possibility of identification and study of other variables that may impact outcome after colorectal surgery.

The second part of this thesis, Chapter 4-8, addresses the risk factors impacting recovery after colorectal surgery for patients treated according to an ERAS protocol. Along with the implementation of ERAS programs in colorectal surgery, non-steroidal anti-inflammatory drugs (NSAIDs) have been introduced to reduce opioid usage. ${ }^{64}$ However, several retrospective studies have recently indicated an association between postoperative NSAID use and anastomotic leakage in colorectal surgery. Although this association is not fully understood or confirmed, several surgical centres have ceased to use NSAIDs for postoperative analgesia after colorectal surgery if an anastomosis is planned. $^{65,66}$

In Chapter 4, we investigated the risk of anastomotic leakage related to NSAIDs within an enhanced recovery program. In Chapter 5, we investigated whether assessment of obesity using the "new" BMI formula is a better predictor of postoperative complications after colorectal surgery compared to the "old" BMI. In Chapter 6, the literature regarding the influence of visceral obesity measured by CT-scan, on postoperative complications and mortality for colorectal surgery was reviewed and appraised in a systematic review and meta-analysis. In Chapter 7, the effect of visceral 
obesity (measured by CT) on the incidence of postoperative complications and length of hospital stay was studied in patients with colonic cancer related to their BMI.

It is important to identify the factors, which can influence visceral obesity, because of the increasing number of obese people. Thus, we also analyzed the influence of chemoradiation on visceral obesity, sarcopenia and their effect on postoperative outcome in Chapter 8.

Finally, Chapter 9 provides a general discussion and interpretation of the data presented in this thesis. 


\section{References}

1. Kehlet $\mathrm{H}$. Multimodal approach to control postoperative pathophysiology and rehabilitation. $\mathrm{Br} \mathrm{J}$ Anaesth 1997;78(5):606-17. Review.

2. Nygren J, Hausel J, Kehlet H, Revhaug A, Lassen K, Dejong C, Andersen J, von Meyenfeldt M, Ljungqvist $\mathrm{O}$, Fearon KC. A comparison in five European Centres of case mix, clinical management and outcomes following either conventional or fast-track perioperative care in colorectal surgery. Clin Nutr 2005; 24(3):455-61.

3. Fearon KC, Ljungqvist O, Von Meyenfeldt M, Revhaug A, Dejong CH, Lassen K, Nygren J, Hausel J, Soop $\mathrm{M}$, Andersen J, Kehlet $\mathrm{H}$. Enhanced recovery after surgery: a consensus review of clinical care for patients undergoing colonic resection. Clin Nutr 2005;24(3):466-77. Review.

4. Debarros M, Steele SR. Perioperative protocols in colorectal surgery. Clin Colon Rectal Surg 2013;26(3): 139-45.

5. Eskicioglu C, Forbes SS, Aarts MA, Okrainec A, McLeod RS. Enhanced recovery after surgery (ERAS) programmes for patients having colorectal surgery: a meta-analysis of randomized trials. J Gastrointest Surg 2009;13:2321-9.

6. Varadhan KK, Neal KR, Dejong CH, Fearon KC, Ljungqvist O, Lobo DN. The Enhanced Recovery After Surgery (ERAS) pathway for patients undergoing major elective open colorectal surgery: a metaanalysis of randomized controlled trials. Clin Nutr 2010;29(4):434-40.

7. Spanjersberg WR, Reurings J, Keus F, van Laarhoven CJ. Fast track surgery versus conventional recovery strategies for colorectal surgery. Cochrane Database Syst Rev 2011;16(2):CD007635..

8. Lassen K, Hannemann P, Ljungqvist O, Fearon K, Dejong CH, von Meyenfeldt MF, Hausel J, Nygren J, Andersen J, Revhaug A; Enhanced Recovery After Surgery Group. Patterns in current perioperative practice: survey of colorectal surgeons in five northern European countries. BMJ 2005;330(7505): 1420-1.

9. Kehlet $\mathrm{H}$, Williamson R, Büchler MW, Beart RW. A survey of perceptions and attitudes among European surgeons towards the clinical impact and management of postoperative ileus. Colorectal Dis 2005;7(3): 245-50.

10. Maessen J, Dejong CH, Hausel J, Nygren J, Lassen K, Andersen J, Kessels AG, Revhaug A, Kehlet H, Ljungqvist $\mathrm{O}$, Fearon KC, von Meyenfeldt MF. A protocol is not enough to implement an enhanced recovery programme for colorectal resection. Br J Surg 2007;94(2):224-31.

11. Ahmed J, Khan S, Lim M, Chandrasekaran TV, MacFie J. Enhanced recovery after surgery protocols compliance and variations in practice during routine colorectal surgery. Colorectal Dis 2012;14: 1045-51.

12. Gustafsson UO, Hausel J, Thorell A, Ljungqvist O, Soop M, Nygren J. Adherence to the enhanced recovery after surgery protocol and outcomes after colorectal cancer surgery. Arch Surg 2011;146: 571-7.

13. Vlug MS, Wind J, Hollmann MW, Ubbink DT, Cense HA, Engel AF, et al. Laparoscopy in combination with fast track multimodal management is the best perioperative strategy in patients undergoing colonic surgery: a randomized clinical trial (LAFA-study). Ann Surg 2011; 254(6): 868-75.

14. Jackson RS, Amdur RL, White JC, Macsata RA. Hyperglycemia is associated with increased risk of morbidity and mortality after colectomy for cancer. J Am Coll Surg 2012;214(1):68-80.

15. Sato H, Carvalho G, Sato T, Lattermann R, Matsukawa T, Schricker T. The asso-ciation of preoperative glycemic control, intraoperative insulin sensitivity, and outcomes after cardiac surgery. J Clin Endocrinol Metab 2010;95(9):4338-44.

16. Ljungqvist O. Insulin resistance and outcomes in surgery. J Clin Endocrinol Metab 2010;95(9):4217-9.

17. Ljungqvist O. Jonathan E. Rhoads lecture 2011: insulin resistance and enhanced recovery after surgery. JPEN J Parenter Enteral Nutr 2012;36(4):389-98.

18. Van den Berghe G, Wouters P, Weekers F, Verwaest C, Bruyninckx F, Schetz M, et al. Intensive insulin therapy in the critically ill patients. N Engl J Med 2001;345(19):1359-67.

19. Finfer S, Chittock DR, Su SY, Blair D, Foster D, Dhingra V, et al. Intensive versus conventional glucose control in critically ill patients. N Engl J Med 2009;360(13):1283-97. 
20. Furnary AP, Zerr KJ, Grunkemeier GL, Starr A. Continuous intravenous insulin infusion reduces the incidence of deep sternal wound infection in diabetic patients after cardiac surgical procedures. Ann Thorac Surg 1999;67(2):352-60.

21. Krinsley JS. Effect of an intensive glucose management protocol on the mortality of critically ill adult patients. Mayo Clin Proc 2004;79(8):992-1000.

22. Ren L, Zhu D, Wei Y, Pan X, Liang L, Xu J, Zhong Y, Xue Z, Jin L, Zhan S, Niu W, Qin X, Wu Z, Wu Z. Enhanced Recovery After Surgery (ERAS) program attenuates stress and accelerates recovery in patients after radical resection for colorectal cancer: a prospective randomized controlled trial. World J Surg 2012;36(2):407-14.

23. Jacobs M, Verdeja JC, Goldstein HS. Minimally invasive colon resection (laparoscopic colectomy). Surg Laparosc Endosc 1991;1:144-50.

24. Kuhry E, Schwenk W, Gaupset R, Romild U, Bonjer J. Long-term outcome of laparoscopic surgery for colorectal cancer: a cochrane systematic review of randomised controlled trials. Cancer Treat Rev 2008; 34(6):498-504 Review.

25. Spanjersberg WR, van Sambeeck JD, Bremers A, Rosman C, van Laarhoven CJ. Systematic review and meta-analysis for laparoscopic versus open colon surgery with or without an ERAS programme. Surg Endosc 2015;29(12):3443-53.

26. Rossner S. Adolphe quetelet (1796-1874). Obes Rev 2007;8:183.

27. Ogden CL, Carroll MD, Kit BK, Flegal KM. Prevalence of obesity and trends in body mass index among us children and adolescents, 1999-2010. JAMA 2012;307:483-90.

28. Lennon H, Sperrin M, Badrick E, Renehan AG. The obesity paradox in cancer: a review. Curr Oncol Rep 2016;18:56-91.

29. Fox CS, Massaro JM, Hoffmann U, et al. Abdominal visceral and subcutaneous adipose tissue compartments. Circulation 2007;116(1):39-48.

30. Fujioka S, Matsuzawa Y, Tokunaga K, et al. Contribution of intra-abdominal fat accumulation to the impairment of glucose and lipid metabolism in human obesity. Metabolism 1987;36: 54-9.

31. Després JP. Is visceral obesity the cause of the metabolic syndrome? Ann Med 2006; 38(1): 52-63.

32. Després JP, Lemieux I. Abdominal obesity and metabolic syndrome. Nature 2006;444(7121):881-7. Review.

33. Fasshauer M \& Paschke R. Regulation of adipocytokines and insulin resistance. Diabetologia 2003;46 1594-603.

34. Greenberg AS \& McDaniel ML. Identifying the links between obesity, insulin resistance and beta-cell function: Potential role of adipocyte-derived cytokines in the pathogenesis of type 2 diabetes. Eur J Clin Invest 2002;32(Suppl.3):24-34.

35. Merkow RP, Bilimoria KY, McCarter MD, Bentrem DJ. Effect of body mass index on short-term outcomes after colectomy for cancer. J Am Coll Surg 2009;208:53-61.

36. Costa B, Queiroz F, Lamounier P, Lacerda Filho A, Paiva R, França P, et al. Body mass index as a predictor of complications and conversion in patients undergoing laparoscopic colectomy. J Coloproctol 2011;31:330-3.

37. Bouchard C, Després JP, Mauriège $P$. Genetic and nongenetic determinants of regional fat distribution. Endocr Rev 1993;14(1):72-93, Review.

38. Burton RF. Why is the body mass index calculated as mass/height2, not as mass/height3? Ann Hum Biol 2007;34:656e63.

39. Dai Z, Xu YC, Niu L. Obesity and colorectal cancer risk: a meta-analysis of cohort studies. World J Gastroenterol 2007;13 (31):4199-206.

40. Tsujinaka S, Konishi F, Kawamura YJ, SaitoM, Tajima N, Tanaka O, Lefor AT. Visceral obesity predicts surgical outcomes after laparoscopic colectomy for sigmoid colon cancer. Dis Colon Rectum 2008; 51(12):1757-65.

41. Ueda J, Ichimiya H, Okido M, KatoM. The impact of visceral fat accumulation on laparoscopy-assisted distal gastrectomy for early gastric cancer. J Laparoendosc Adv Surg Tech A 2009;19(2):157-62.

42. YoshikawaK, ShimadaM, Kurita N, Iwata T, Nishioka M,Morimoto S, Miyatani T, Komatsu M, Mikami C, Kashihara H. Visceral fat area is superior to body mass index as a predictive factor for risk with laparoscopy-assisted gastrectomy for gastric cancer. Surg Endosc 2011;25(12):3825-30. 
43. MiyakiA, Imamura K, Kobayashi R, TakamiM,Matsumoto J. Impact of visceral fat on laparoscopyassisted distal gastrectomy. Surgeon 2013;11(2):76-81.

44. Tokunaga M, Hiki N, Fukunaga T, Ogura T, Miyata S, Yamaguchi T. Effect of individual fat areas on early surgical outcomes after open gastrectomy for gastric cancer. Br J Surg 2009;96(5):496-500.

45. Shimizu A, Tani M, KawaiM, Hirono S,MiyazawaM, Uchiyama K, Yamaue H (2011) Influence of visceral obesity for postoperative pulmonary complications after pancreaticoduodenectomy. J Gastrointest Surg 2011;15(8):1401-10.

46. Hagiwara M, Miyajima A, Hasegawa M, Jinzaki M, Kikuchi E, Nakagawa K, Oya M. Visceral obesity is a strong predictor of perioperative outcome in patients undergoing laparoscopic radical nephrectomy. BJU Int 2012;110(11): E980-E984

47. Ballian N, Lubner MG, Munoz A, Harms BA, Heise CP, Foley EF, et al. Visceral obesity is associated with outcomes of total mesorectal excision for rectal adenocarcinoma. J Surg Oncol 2012;105:365-70.

48. Tapper R, Dixon L, Frampton C, Frizelle F. Impact of obesity on the cost of major colorectal surgery. Br J Surg 2013;100:293-8.

49. Gendall KA, Raniga S, Kennedy R, Frizelle FA. The impact of obesity on outcome after major colorectal surgery. Dis Colon Rectum 2007;50:2223-37.

50. Nitori N, Hasegawa H, Ishii Y, Endo T, Kitagawa Y. Impact of visceral obesity on short-term outcome after laparoscopic surgery for colorectal cancer: a single Japanese center study. Surg Laparosc Endosc Percutan Tech 2009;19(4):324-7.

51. Moon HG, Ju YT, Jeong CY, Jung EJ, Lee YJ, Hong SC, Ha WS, Park ST, Choi SK. Visceral obesity may affect oncologic outcome in patients with colorectal cancer. Ann Surg Oncol 2008;15(7):1918-22.

52. Snijders HS, Wouters MW, van Leersum NJ, Kolfschoten NE, Henneman D, de Vries AC, Tollenaar RA, Bonsing BA. Meta-analysis of the risk for anastomotic leakage, the postoperative mortality caused by leakage in relation to the overall postoperative mortality. Eur J Surg Oncol 2012;38:1013-9.

53. Reisinger KW, van Vugt JL, Tegels JJ, Snijders C, Hulsewe KW, Hoofwijk AG, Stoot JH, VonMeyenfeldtMF, Beets GL, Derikx JP,Poeze M. Functional compromise reflected by sarcopenia, frailty, and nutritional depletion predicts adverse postoperative outcome after colorectal cancer surgery. Ann Surg 2015; 261(2):345-52.

54. Huang DD, Wang SL, Zhuang CL, Zheng BS, Lu JX, Chen FF, Zhou CJ, Shen X, Yu Z. Sarcopenia, as defined by lowmuscle mass, strength and physical performance, predicts. complications after surgery for colorectal cancer. Colon Dis 2015;17(11):256-64.

55. Lieffers JR, Bathe OF, Fassbender K, Winget M, Baracos VE. Sarcopenia is associated with postoperative infection anddelayed recovery from colorectal cancer resection surgery. Br J Cancer 2012;107(6): 931-6.

56. Peng PD, van Vledder MG, Tsai S, de Jong MC, Makary M, Ng J, Edil BH, Wolfgang CL, Schulick RD, Choti MA, Kamel I, Pawlik TM. Sarcopenia negatively impacts short-term outcomes in patients undergoing hepatic resection for colorectal liver metastasis. HPB (Oxford) 2011;13(7):439-46 .

57. Miyamoto $Y$, Baba Y, Sakamoto Y, Ohuchi M, Tokunaga R, Kurashige J, Hiyoshi Y, Iwagami S, Yoshida N, Yoshida $\mathrm{M}$,Watanabe $\mathrm{M}$, Baba $\mathrm{H}$. Sarcopenia is a negative prognostic factor after curative resection of colorectal cancer. Ann Surg Oncol 2015;22(8):2663-8.

58. Boer BC, de Graaff F, Brusse-Keizer M, Bouman DE, Slump CH, Slee-ValentijnM, Klaase JM. Skeletal musclemass and quality as risk factors for postoperative outcome after open colon resection for cancer. Int J Color Dis 2016;31(6):1117-24.

59. Malietzis G, Aziz O, Bagnall NM, Johns N, Fearon KC, Jenkins JT. The role of body composition evaluation by computerized tomography in determining colorectal cancer treatment outcomes: a systematic review. Eur J Surg Oncol 2015;41(2):186-96.

60. Shen W, Punyanitya M, Wang Z, et al. Total body skeletal muscle and adipose tissue volumes: estimation from a single abdominal crosssectional image. J Appl Physiol 2004;97:2333-8.

61. Prado CM, Lieffers JR, McCargar LJ, Reiman T, Sawyer MB, Martin L, et al. Prevalence and clinical implications of sarcopenic obesity in patients with solid tumours of the respiratory and gastrointestinal tracts: a population-based study. Lancet Oncol. 2008;9:629-35.

62. Tan BH, Birdsell LA, Martin L, Baracos VE, Fearon KC. Sarcopenia in an overweight or obese patient is an adverse prognostic factor in pancreatic cancer. Clin Cancer Res. 2009; 15:6973-9. 
63. Martin L, Birdsell L, Macdonald N, Reiman T, Clandinin MT, McCargar LJ, et al. Cancer cachexia in the age of obesity: skeletal muscle depletion is a powerful prognostic factor, independent of body mass index. J Clin Oncol. 2013; 31:1539-47.

64. Gustafsson UO, Scott MJ, Schwenk W, Demartines N, Roulin D, Francis N, McNaught CE, MacFie J, Liberman AS, Soop M, Hill A, Kennedy RH, Lobo DN, Fearon K, Ljungqvist O; Enhanced Recovery After Surgery Society. Guidelines for perioperative care in elective colonic surgery: Enhanced Recovery After Surgery $\left(\right.$ ERAS $^{\circledR}$ ) Society recommendations. Clin Nutr. 2012 Dec; 31(6):783-800. Review.

65. Klein M, Gögenur I, Rosenberg J: Postoperative use of non-steroidal anti-inflammatory drugs in patients with anastomotic leakage requiring reoperation after colorectal resection: cohort study based on prospective data. BMJ 2012; 345:e6166.

66. Gorissen KJ, Benning D, Berghmans T, Snoeijs MG, Sosef MN, Hulsewe KW, Luyer MDI: Risk of anastomotic leakage with non-steroidal anti-inflammatory drugs in colorectal surgery. Br J Surg 2012; 99: 721-7. 
Part ||

Enhanced Recovery After Surgery 



\section{Chapter 2}

\section{Adherence to Enhanced Recovery After Surgery and length of stay after colonic resection}

H. Cakir, M.F.M. van Stijn, A.M.F. Lopes Cardozo, B.L.A.M. Langenhorst, W.H. Schreurs, T.J. van der Ploeg, W.A. Bemelman, A.P.J. Houdijk Colorectal Dis 2013;15(8):1019-1025 


\section{Abstract}

\section{Aim}

The Enhanced Recovery After Surgery (ERAS) programme is a multimodal approach to improve peri-operative care in colon surgery. The aim of this study was to report on the adherence to and outcomes of ERAS in the first years after implementation.

\section{Method}

Data of patients undergoing elective colon resections for malignancy in 2006 until 2010 were compared with patients receiving conventional care in 2005. Retrospective analysis was performed including length of stay (LOS), protocol adherence and complications. The predictive values of ERAS items and baseline characteristics on LOS and complications were analysed using univariate and multivariate analysis.

\section{Results}

Length of stay (LOS) was significantly shorter in 2006 and 2007 ( $P \leq 0.009$ and $P \leq 0.004)$ but not in 2008 and 2009. The mean adherence rate to the ERAS items was $84.1 \%$ in 2006 and 2007 and $72.4 \%$ in 2008 and 2009 (P<0.001). In 2005, 2008 and 2009 LOS was significantly shorter for laparoscopically operated patients than for patients with open resections $(P<0.002, P<0.001$ and $P<0.004$ respectively). Multivariate analysis showed that age, laparoscopic surgery, removal of nasogastric tube before extubation, mobilization within $24 \mathrm{~h}$ after surgery, starting nonsteroidal anti-inflammatory drugs at day 1 and removal of thoracic epidural analgesia at day 2 were independent predictors of LOS.

\section{Conclusion}

Strict adherence to the ERAS protocol was associated with reduced LOS and improved outcome in elective colon surgery for malignancy. These benefits were lost when protocol adherence was lower. Embedding the ERAS protocol into an organization and repetitive education are vital to sustain its beneficial effects on LOS and outcome. 


\section{Introduction}

The Enhanced Recovery After Surgery (ERAS) programme is a multimodal approach to optimize the perioperative management of patients scheduled for surgery. ${ }^{1,2}$ Several randomized controlled trials of ERAS have shown a reduction in complication rates and length of stay (LOS) in patients undergoing colon surgery. ${ }^{3}$ The programme consists of evidence-based changes in preoperative, intra-operative and postoperative treatments. Multidisciplinary involvement makes several aspects of the programme vulnerable to failure, which probably explains the differences in early adherence rates to ERAS components reported in the literature. ${ }^{4-6}$ Which of these components are most important is not clear and is a matter of ongoing research. Long-term success of the protocol is reliant on continuous registration and analysis of the adherence rate to each individual ERAS item. In order to monitor the effects of the protocol in our institute, the relevant data have been entered into a database from the start of the ERAS programme. The present study reports on the success and failure of the programme and on the importance of protocol adherence in relation to clinical outcome and LOS in elective colon cancer surgery during the first 4 years after implementation.

\section{Method}

\section{Study design}

Prospectively collected data on the effect of the ERAS programme on outcome and LOS in elective colon cancer patients was studied retrospectively. In 2006, ERAS was introduced at the Medical Center Alkmaar, a large Dutch teaching hospital, after a multidisciplinary training programme. All data of consecutive patients above 18 years of age who followed the ERAS programme between January 2006 and January 2010 were studied. The data of patients treated in the year 2005 served as a control, because the ERAS programme had not been implemented at that time. In all patients, a colonic resection was performed with or without primary anastomosis. Exclusion criteria were patients who underwent acute colonic resection, total mesorectal excision surgery or colostomy closure. One observer evaluated the medical files for any complication or readmission that occurred after discharge within 30 days of the operation. The mean adherence to a specific ERAS item in 1 year was defined as the percentage of patients in whom the item was successfully implemented. All patients were discharged if they complied with the following discharge criteria: adequate pain control with oral 
analgesics, ability to tolerate solid food, passage of first flatus or first stool and acceptance of discharge by the patient.

\section{Statistical analysis}

The statistical analyses were performed using the Statistical Package for the Social Sciences (SPSS) version 16.0 (SPSS, Chicago, Illinois, USA). ANOVA was used for comparison of the continuous variables. Chi-squared analysis was used to compare dichotomous or categorical variables. A $P$-value $<0.05$ was considered significant. LOS was calculated from the day of surgery until the day of discharge. Before statistical analysis, the LOS data were log transformed because the distribution was not normal. For the univariate analysis, linear regression analysis or logistic regression analysis for the five baseline characteristics and all individual fast-track items was used. A $P$-value $<0.05$ was considered significant. The variables with $P$-value $<0.05$ in the univariate analysis were entered into a multivariate linear regression analysis. Regression coefficients of significant predictive parameters are given with their $95 \%$ confidence intervals.

\section{Results}

\section{Patient characteristics, length of stay and ERAS items}

\section{Years 2006 and 2007}

Patient characteristics and LOS are listed in Table 2.1. The LOS in 2006 and 2007 was significantly shorter than in $2005(P<0.009$ and $P<0.004)$. No significant differences were found in the patient characteristics between 2006 and 2007 vs. 2005. Table 2.2 shows that in the years 2006 and 2007 the ERAS items were implemented with a mean adherence rate of $84.1 \%$.

Years 2008 and 2009

For the years 2008 and 2009, the reduction in LOS compared with 2005 was no longer achieved ( $P<0.154$ and $P<0.731$ respectively) (Table 2.1 ). The mean adherence to the ERAS items significantly declined in the years 2008 and 2009 compared with the years 2006 and 2007 (72.4\% vs. 84.1\%, P<0.001) (Table 2.2). In 2008 and 2009, better adherence was achieved only for omitting bowel preparation and applying forced body heat intra-operatively $(P<0.007$ and $P<0.008)$. For the following items a lower 
adherence rate was noted: preoperative carbohydrate loading $(P<0.001)$, the use of anti-emetics $(P<0.001)$, postoperative mobilization within $24 \mathrm{~h}$ after surgery $(P<0.003)$, the use of laxatives $(P<0.001)$ and nonsteroidal anti-inflammatory drugs (NSAIDs) on the first postoperative day $(P<0.004)$. In addition, fewer thoracic epidural catheters were removed within 3 days $(P<0.001)$. Compared with 2006, 2007 and 2008 more patients with cardiac comorbidity underwent operation in $2009(P<0.02)$ (Table 2.1). Other baseline characteristics showed no significant difference.

Table $2.1 \quad$ Patient characteristics.

\begin{tabular}{lcccccc}
\hline & $\begin{array}{c}2005 \\
(n=67)\end{array}$ & $\begin{array}{c}2006 \\
(n=72)\end{array}$ & $\begin{array}{c}2007 \\
(n=69)\end{array}$ & $\begin{array}{c}2008 \\
(n=83)\end{array}$ & $\begin{array}{c}2009 \\
(n=92)\end{array}$ & $\begin{array}{c}2005-2009 \\
(n=383)\end{array}$ \\
\hline LOS (days) & $7.0(2-30)$ & $5.5(2-33)^{*}$ & $5.0(2-27) \dagger$ & $6.0(1-51) \neq$ & $7.0(3-117) \S$ & $6.0(1-117) \mathfrak{9}$ \\
Age (years)** & $71.9 \pm 11.1$ & $71.1 \pm 12.5$ & $71.2 \pm 10.4$ & $68.4 \pm 13.1$ & $70.7 \pm 11.4$ & $70.3 \pm 11.9$ \\
Male sex (\%) & $40(59.7 \%)$ & $39(54.2 \%)$ & $35(50.7 \%)$ & $47(56.6 \%)$ & $45(48.9 \%)$ & $206(53.8 \%)$ \\
BMI (kg/m)** & $25.1 \pm 3.6$ & $25.5 \pm 3.6$ & $26.2 \pm 4.4$ & $25.0 \pm 3.4$ & $26.3 \pm 5.2$ & $25.7 \pm 4.3$ \\
Laparoscopie & $8(11.9 \%)$ & $29(40.3 \%)$ & $27(39.1 \%)$ & $26(31.3 \%)$ & $23(25.0 \%)$ & $113(29.5 \%)$ \\
Right colectomy & $33(49.3 \%)$ & $40(55.6 \%)$ & $30(43.5 \%)$ & $38(45.8 \%)$ & $43(46.7 \%)$ & $184(48.0 \%)$ \\
Left colectomy & $32(47.8 \%)$ & $29(40.3 \%)$ & $36(52.2 \%)$ & $42(50.6 \%)$ & $46(50 \%)$ & $185(48.3 \%)$ \\
Comorbidity total (\%) & $31(46.3 \%)$ & $40(55.6 \%)$ & $39(56.5 \%)$ & $40(48.2 \%)$ & $56(60.9 \%)$ & $206(53.8 \%)$ \\
Cardiac & $24(35.8 \%)$ & $17(23.6 \%)$ & $16(23.2 \%)$ & $16(19.3 \%)$ & $36(39.1 \%)++$ & $109(28.5 \%)$ \\
Pulmonary & $5(7.5 \%)$ & $5(6.9 \%)$ & $8(11.6 \%)$ & $8(9.6 \%)$ & $7(7.6 \%)$ & $33(8.6 \%)$ \\
Hypertension & $4(6.0 \%)$ & $20(27.8 \%)$ & $12(17.4 \%)$ & $24(28.9 \%)$ & $27(29.3 \%)$ & $87(22.7 \%)$ \\
Diabetes & $7(10.4 \%)$ & $5(6.9 \%)$ & $6(8.7 \%)$ & $11(13.3 \%)$ & $5(5.4 \%)$ & $34(8.9 \%)$ \\
\hline
\end{tabular}

LOS: length of stay, BMI: body mass index. ${ }^{*} 2005$ vs. 2006: $P=0.009 ;+2005$ vs. 2007: $P=0.004 ; \ddagger 2005$ vs. 2008: $P=0.154$; $\S 2005$ vs.2009: $P=0.731$; 2008 vs. 2009: $P<0.016$; $++2006,2007,2008$ vs.2009: $P<0.02$;

$* *$ Values are mean $\pm \mathrm{SD}$. LOS is median (minimum - maximum).

Table 2.2 Adherence to the ERAS items.

\begin{tabular}{lccccc}
\hline ERAS elements & $2006(n=72)$ & $2007(n=69)$ & $2008(n=83)$ & $2009(n=92)$ & $P$-value \\
\hline Carbohydrate-loaded drink & $63(87.5 \%)$ & $59(85.5 \%)$ & $52(62.7 \%)$ & $60(65.2 \%)$ & $<0.001^{*}$ \\
Bowel preparation & $2(2.8 \%)$ & $5(7.2 \%)$ & $0(0.0 \%)$ & $0(0.0 \%)$ & $0.007^{*}$ \\
Thoracic epidural analgesia & $68(94.4 \%)$ & $66(95.7 \%)$ & $78(94.0 \%)$ & $88(95.7 \%)$ & 0.947 \\
Anti-emetics & $35(48.6 \%)$ & $65(94.2 \%)$ & $15(18.1 \%)$ & $19(20.7 \%)$ & $<0.001^{*}$ \\
Vasopressors & $65(90.3 \%)$ & $54(78.3 \%)$ & $70(84.3 \%)$ & $81(88.0 \%)$ & 0.187 \\
Forced body heating & $71(98.6 \%)$ & $62(89.9 \%)$ & $82(98.8 \%)$ & $90(97.8 \%)$ & $0.008^{\dagger}$ \\
Removal of nasogastric tube & $67(93.1 \%)$ & $63(91.3 \%)$ & $70(84.3 \%)$ & $85(92.4 \%)$ & 0.214 \\
before extubation & & & & & \\
No use of abdominal drains & $68(94.4 \%)$ & $60(87.0 \%)$ & $73(88.0 \%)$ & $83(90.2 \%)$ & 0.449 \\
Mobilization within 24 h after surgery & $58(80.6 \%)$ & $50(72.5 \%)$ & $55(66.3 \%)$ & $50(54.3 \%)$ & $0.003^{\ddagger}$ \\
Start laxative day 1 & $64(88.9 \%)$ & $50(72.5 \%)$ & $50(60.2 \%)$ & $48(52.2 \%)$ & $<0.001^{*}$ \\
Start NSAIDs day 1 & $62(86.1 \%)$ & $45(65.2 \%)$ & $50(60.2 \%)$ & $63(68.5 \%)$ & $0.004^{\S}$ \\
Removal of thoracic epidural analgesia & $46(65.7 \%)$ & $47(68.1 \%)$ & $46(56.1 \%)$ & $37(40.2 \%)$ & $0.001^{9}$ \\
at day 2 & & & & &
\end{tabular}

ERAS: Enhanced Recovery After Surgery; NSAIDs, nonsteroidal anti-inflammatory drugs. * Significance was found for 2008 and 2009 vs. 2006 and 2007; † Significance was found for 2008 vs. 2007; ¥ Significance was found for 2009 vs. 2006; § Significance was found for 2008 vs. 2006 and 2007; ๆ Significance was found for 2009 vs. 2006 and 2007. 


\section{Complications}

Except for urinary tract infection (UTI), no differences in complications were found between the years 2008 and 2009 and the years 2006 and 2007. More UTIs were seen in 2009 compared with the other years $(P<0.001)$. In addition, more re-operations were seen in the last 2 years than in the first 2 years $(P<0.001)$. No differences were found in readmission rate between the years. Univariate analysis showed no correlation between any ERAS components and anastomotic leakage and UTI. Multivariate analysis showed a significant correlation with the following items and the development of pulmonary infection: mobilization not achieved within $24 \mathrm{~h}$ after surgery $(P=0.022)$, not starting laxative at day $1(P=0.029)$ and removal of thoracic epidural catheters after 3 days $(P=0.036)$ (Table 2.3). Univariate analysis showed a correlation with the carbohydrate-loaded drink and mobilization within $24 \mathrm{~h}$ after surgery being predictive of the development of wound infection, but after multivariate analysis the association with the carbohydrate drink was lost and that with mobilization within $24 \mathrm{~h}$ was just short of significance $(P<0.053)$. Multivariate analysis showed the following items to be correlated with the development of ileus: right-sided colectomy $(P=0.026)$, mobilization not achieved within $24 \mathrm{~h}$ after surgery $(P=0.042)$, not starting laxative at day 1 $(P=0.029)$ and removal of thoracic epidural catheters after 3 days $(P=0.001)$.

Table 2.3 Univariate and multivariate logistic regression analysis on complications (log transformation).

\begin{tabular}{|c|c|c|c|c|}
\hline & Odds ratio, $B(95 \% \mathrm{Cl})$ & $P$-value & $\begin{array}{c}\text { Adjusted odds ratio, } \\
B(95 \% \mathrm{Cl})\end{array}$ & $P$-value \\
\hline \multicolumn{5}{|l|}{ Pulmonary infection } \\
\hline \multicolumn{5}{|l|}{ Baseline characteristics } \\
\hline Laparoscopic surgery & $4.784(1.084 ; 21.120)$ & 0.039 & $3.054(0.659 ; 14.146)$ & 0.154 \\
\hline \multicolumn{5}{|l|}{ Fast-track elements } \\
\hline Mobilization within $24 \mathrm{~h}$ after surgery & $5.427(0.074 ; 0.610)$ & 0.001 & $3.583(1.201 ; 10.688)$ & 0.022 \\
\hline Start laxative day 1 & $3.326(1.135 ; 8.412)$ & 0.011 & $3.075(1.124 ; 8.416)$ & 0.029 \\
\hline $\begin{array}{l}\text { Removal of thoracis epidural analgesia } \\
\text { at day } 2\end{array}$ & $5.705(1.862 ; 17.482)$ & 0.002 & $3.509(1.087 ; 11.324)$ & 0.036 \\
\hline \multicolumn{5}{|l|}{ Wound infection } \\
\hline \multicolumn{5}{|l|}{ Fast-track elements } \\
\hline Carbohydrate-loaded drink & $2.073(1.006 ; 7.259)$ & 0.049 & $2.211(0.802 ; 6.094)$ & 0.125 \\
\hline Mobilization within $24 \mathrm{~h}$ after surgery & $3.164(1.168 ; 8.571)$ & 0.023 & $2.729(0.985 ; 7.563)$ & 0.053 \\
\hline \multicolumn{5}{|l|}{ lleus } \\
\hline \multicolumn{5}{|l|}{ Baseline characteristics } \\
\hline Right-sided colectomy & $0.390(0.185 ; 0.825)$ & 0.014 & $0.402(0.181 ; 0.897)$ & 0.026 \\
\hline \multicolumn{5}{|l|}{ Fast-track elements } \\
\hline Mobilization within $24 \mathrm{~h}$ after surgery & $4.087(2.003 ; 8.339)$ & $<0.001$ & $2.230(1.031 ; 4.825)$ & 0.042 \\
\hline Start laxative day 1 & $2.409(1.204 ; 4.819)$ & 0.013 & $2.329(1.089 ; 4.978)$ & 0.029 \\
\hline $\begin{array}{l}\text { Removal of thoracis epidural analgesia } \\
\text { at day } 2\end{array}$ & $4.780(2.173 ; 10.516)$ & $<0.001$ & $4.274(1.805 ; 10.120)$ & 0.001 \\
\hline
\end{tabular}

Only the items with significance in the univariate analysis are shown. 


\section{Laparoscopic resections and ERAS}

In 2005 we started laparoscopic colon resections on a small scale and noticed a significantly reduced LOS compared with open resections (Table 2.4; $P=0.002$ ). During the first 2 years of the introduction of ERAS this difference in LOS between laparoscopic surgery and open surgery was lost (2006, $P=0.629 ; 2007, P=0.092)$. However, for the years 2008 and 2009, during which there was less compliance with the ERAS protocol, we once more found a significant difference in LOS in favour of laparoscopic surgery (2008, $P<0.001 ; 2009, P=0.004)$.

Table 2.4 Laparoscopic surgery.

\begin{tabular}{lccr}
\hline & $\begin{array}{c}\text { Contiventional } \\
\text { (days)* }\end{array}$ & $\begin{array}{c}\text { Laparoscopic } \\
\text { (days)* }\end{array}$ & $P$-value \\
\hline 2005 & $8.0(3-30)$ & $4.0(2-18)$ & 0.002 \\
2006 & $6.0(2-20)$ & $5.0(2-33)$ & 0.629 \\
2007 & $5.0(2-27)$ & $4.0(2-21)$ & 0.092 \\
2008 & $7.5(3-51)$ & $3.0(1-29)$ & $<0.001$ \\
2009 & $8.0(3-62)$ & $5.0(3-117)$ & 0.004 \\
\hline
\end{tabular}

* Value is median (minimum-maximum).

\section{Length of stay}

Univariate and multivariate linear regression analysis was done to study the association of five baseline characteristics and the ERAS elements with LOS for each separate year and for all years combined. The following items were significantly associated with LOS on univariate analysis (Table 2.5): age, laparoscopic surgery, carbohydrate-loaded drink, removal of nasogastric tube before extubation, starting laxatives at day 1 , mobilization within $24 \mathrm{~h}$ after surgery, starting NSAIDs on day 1 and removal of thoracic epidural analgesia on day 2 . On multivariate analysis the following were independent predictors of LOS, when analysing all the years in total: age $(P=0.024)$, laparoscopic surgery $(P=0.024)$, removal of nasogastric tube before extubation $(P=0.002)$, mobilization within $24 \mathrm{~h}$ after surgery $(P<0.001)$, starting NSAIDs on day $1(P=0.02)$ and removal of thoracic epidural analgesia on day $2(P<0.001)$. 


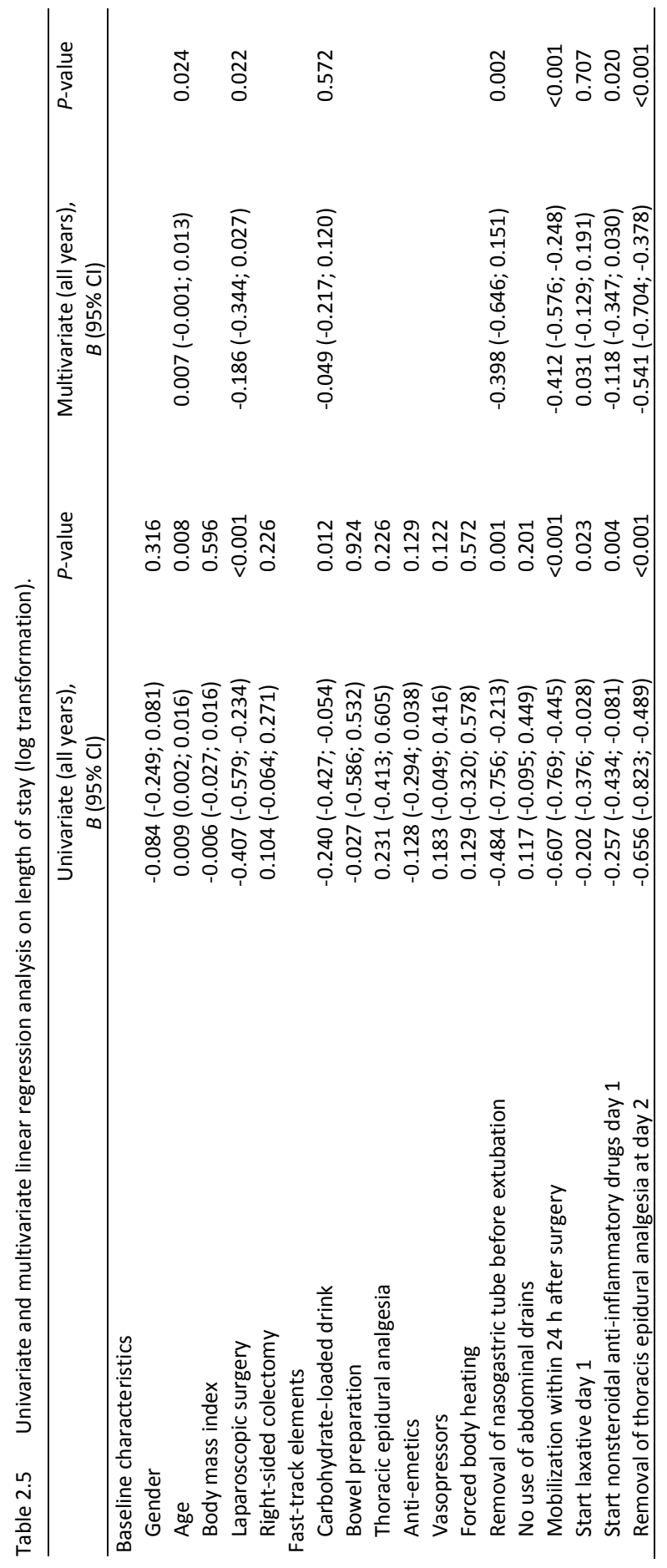




\section{Discussion}

Our study has shown an association between ERAS adherence and complications and LOS following elective colonic resection. To our knowledge, this is the first detailed report on the effects of the rise and fall of compliance to the ERAS programme in a single institute. The high mean adherence rate in the first 2 years (84.1\%) was associated with a shorter LOS than found in the two following years with a lower adherence rate $(72.1 \%)$. Our early data confirm the results of studies reporting beneficial effects of ERAS in the first year of implementation. ${ }^{7,8}$ Studies with longer follow-up, however, show lower initial adherence rates in the first year with an increase in the following years. ${ }^{8}$ In our setting, the very high initial adherence rate and success may be explained by a long training period before programme implementation. At a still acceptable mean adherence rate, compliance was lost on certain key elements of the programme, and therefore LOS increased. The specific ERAS items with lower adherence may explain the relapse in LOS and outcome in 2008 and 2009. Fewer preoperative carbohydrate-loaded drinks were administered during the last 2 years, which may suggest an association with the increase in LOS. This would be in keeping with reports that carbohydrate containing drinks reduce postoperative insulin resistance and speed up recovery. ${ }^{9,10}$ However, multivariate analysis did not show a significant correlation between the carbohydrate drink, LOS and complications. Antiemetics are reported to help the patient resume an oral diet earlier and decrease LOS. $^{11}$ In the present study, this could not be confirmed despite the significant association with the development of pulmonary infection and ileus. The reduction in the rate of mobilization within $24 \mathrm{~h}$ after surgery did show a correlation with LOS as well as with pulmonary infection, wound infection $(P=0.053)$ and ileus. This was the most consistent finding, and is in line with results of others on early mobiliz ation and shorter hospital stay. ${ }^{12}$ In terms of pain relief, a high adherence rate was achieved for the use of the epidural catheter. The epidural catheter was removed less quickly in the year 2009 compared with the years 2006 and 2007. Early removal of the epidural catheter was significantly related to a decrease in LOS, pulmonary infection and ileus. This may have been related to the decline in the use of NSAIDs on postoperative day 1 , which was also correlated with LOS. The epidural catheter may be removed sooner with the early use of oral analgesics such as NSAIDs, whose anti-inflammatory effect may be of benefit in major abdominal surgery and in earlier restoration of bowel function. ${ }^{13}$ Overall, our results underscore the conclusions of a recent meta-analysis that the ERAS concept can reduce postoperative complications and LOS after colon surgery. ${ }^{14}$ Compliance with the ERAS programme is a multidisciplinary responsibility, and differences between disciplines can be detected in our data. ERAS items that were the 
responsibility of the surgeon (no bowel preparation, no use of drains, removal of nasogastric tube) and anaesthesiologist (vasopressor use, use of thoracic epidurals, forced body heating) did not lose their high initial adherence rates. The items with loss of compliance over the years were part of the postoperative care package that is the responsibility of the nursing staff in our unit. This confirms reports on the low compliance with protocols in the early postoperative phase ${ }^{15}$ and difficulties in changing nursing practice. ${ }^{16}$ Laparoscopic colon surgery has been associated with reduced LOS in comparison with open resections. ${ }^{17,18}$ In line with this, our multivariate analysis showed a significant correlation between laparoscopic surgery and LOS. However, this was true only for the pre-ERAS year 2005 and the years of lower compliance with the protocol, 2008 and 2009. This is explained by the ERAS-induced reduction in LOS for the open resections in 2006 and 2007. The LOS in the laparoscopic group did not change because of ERAS, and no differences were found between the years. The present study was not designed to investigate the effects of laparoscopic vs. open surgery within an enhanced recovery programme, and results should be interpreted in the setting of the high and low ERAS adherence rates. Indeed, in a recent four-group randomized trial Vlug et al. showed that even within an enhanced recovery programme laparoscopic surgery may reduce LOS compared with open surgery. ${ }^{19}$ However, the LOS of 5 days they report in the laparoscopic enhanced recovery group does not differ from the present data. Age was an independent predictor of LOS in the multivariate analysis in our study. This is in accordance with the results of a study by Hendry et al. $^{20}$, who concluded that age was an independent predictor of delayed mobilization and prolonged LOS but that it was not an independent determinant of morbidity or mortality. No previous studies have identified early mobilization, the use of NSAIDs and early removal of thoracic epidural analgesia as independent predictors of LOS. However, these findings are easily explained by the fact that all these items are variables which help the patients to mobilize earlier and which shorten the LOS. Although whether LOS is a good parameter to monitor the success of the programme has been questioned, all the ERAS items may theoretically contribute to a quicker recovery after surgery. ${ }^{15}$ In line with our results, several studies have shown that ERAS care after colorectal surgery results in reduced LOS compared with traditional care. ${ }^{4,7}$ For this reason, LOS may be a good surrogate marker for the effectiveness of the protocol. Together, the changes in the ERAS programme seem to be beneficial, but not much is known about the influence of each individual item. Data on the importance of the various ERAS components are scarce. In a retrospective case review, Ahmed et al. determined the factors that have maximum effect on accelerating recovery after open colorectal surgery. ${ }^{21}$ Univariate and multivariate analysis showed that American Society of Anesthesiologists grade, avoidance of oral opiates and the duration of use of 
epidurals were associated with shorter LOS. $^{21}$ In a recent report, Varadhan et al. showed that the implementation of four or more elements of the ERAS programme reduced LOS by more than 2 days and decreased the complication rate by $50 \%$ in patients undergoing major colorectal surgery. ${ }^{14}$ However, they did not show which of these elements were important. There are reasons to believe that all components of the ERAS programme work synergistically. ${ }^{8}$ Furthermore, when analysing the effect of individual items on LOS it is clear that some of the ERAS items can influence each other, which causes difficulties in interpretation. These interrelationships could limit the value of the univariate analyses and may explain the differences found in the literature. A limitation of the present study is that analysis was retrospective and results should be interpreted as such. However, database entry was done prospectively, which minimized data loss. Our data show that compliance with the ERAS elements is crucial for a shorter LOS and fewer complications in patients undergoing elective colon resections for malignancy. ERAS programme adherence is complex because of its multidisciplinary character; it is sensitive to change and continuous monitoring and feedback are required to ensure ongoing success. In an era of increasing numbers of protocols and regulations, hospital administrations should take responsibility to ensure these multidisciplinary protocols are continuously implemented in an organization, because without adherence the care and cost benefits are easily lost. 


\section{References}

1. Gouvas N, Tan E, Windsor A, Xynos E, Tekkis PP. Fast-track vs standard care in colorectal surgery: a meta-analysis update. Int J Colorectal Dis 2009;24:1119-31.

2. Kehlet H. Fast-track colorectal surgery. Lancet 2008;371:791-3.

3. Eskicioglu C, Forbes SS, Aarts MA, Okrainec A, McLeod RS. Enhanced recovery after surgery (ERAS) programmes for patients having colorectal surgery: a meta-analysis of randomized trials. J Gastrointest Surg 2009;13:2321-9.

4. Gustafsson UO, Hausel J, Thorell A et al. Adherence to the enhanced recovery after surgery protocol and outcomes after colorectal cancer surgery. Arch Surg 2011;146:571-7.

5. Varadhan KK, Lobo DN, Ljungqvist $\mathrm{O}$. Enhanced recovery after surgery: the future of improving surgical care. Crit Care Clin 2010;26:527-47.

6. Grol R, Grimshaw J. From best evidence to best practice: effective implementation of change in patients' care. Lancet 2003;362:1225-30

7. Nygren J, Hausel J, Kehlet $\mathrm{H}$ et al. A comparison in five European Centres of case mix, clinical management and outcomes following either conventional or fast-track perioperative care in colorectal surgery. Clin Nutr 2005;24:455-61.

8. Basse L, Thorbol JE, Lossl K, Kehlet H. Colonic surgery with accelerated rehabilitation or conventional care. Dis Colon Rectum 2004;47:271-7.

9. Nygren J, Soop M, Thorell A, Sree NK, Ljungqvist O. Preoperative oral carbohydrates and postoperative insulin resistance. Clin Nutr 1999;18:117-20.

10. Nygren J, Soop M, Thorell A et al. Preoperative oral carbohydrate administration reduces postoperative insulin resistance. Clin Nutr 1998;17:65-71.

11. Kehlet H, Dahl JB. Anaesthesia, surgery, and challenges in postoperative recovery. Lancet 2003;362: 1921-8.

12. Delaney CP, Zutshi M, Senagore AJ et al. Prospective, randomized, controlled trial between a pathway of controlled rehabilitation with early ambulation and diet and traditional postoperative care after laparotomy and intestinal resection. Dis Colon Rectum 2003;46:851-9.

13. Xu Y, Tan Z, Chen J, Lou F, Chen W. Intravenous flurbiprofen axetil accelerates restoration of bowel function after colorectal surgery. Can J Anaesth 2008;55:414-22.

14. Varadhan $\mathrm{KK}, \mathrm{Neal} \mathrm{KR}$, Dejong $\mathrm{CH}$ et al. The enhanced recovery after surgery (ERAS) pathway for patients undergoing major elective open colorectal surgery: a meta-analysis of randomized controlled trials. Clin Nutr 2010;29:434-40.

15. Maessen JM, Dejong CH, Kessels AG, von Meyenfeldt MF. Length of stay: an inappropriate readout of the success of enhanced recovery programmes. World J Surg 2008;32:971-5.

16. Price B. Strategies to help nurses cope with change in the healthcare setting. Nurs Stand 2008;22:50-6.

17. Gibson $M$, Byrd C, Pierce $C$ et al. Laparoscopic colon resections: a five-year retrospective review. Am Surg 2000;66:245-8.

18. Hong D, Tabet J, Anvari M. Laparoscopic vs. open resection for colorectal adenocarcinoma. Dis Colon Rectum 2001;44:10-8.

19. Vlug MS, Wind J, Hollmann MW et al. Laparoscopy in combination with fast track multimodal management is the best perioperative strategy in patients undergoing colonic surgery: a randomized clinical trial (LAFA-study). Ann Surg 2011;254:868-75.

20. Hendry PO, Hausel J, Nygren J et al. Determinants of outcome after colorectal resection within an enhanced recovery programme. Br J Surg 2009;96:197-205.

21. Ahmed J, Lim M, Khan S, McNaught C, Macfie J. Predictors of length of stay in patients having elective colorectal surgery within an enhanced recovery protocol. Int J Surg 2010;8:628-32. 


\section{Chapter 3}

Eight years of experience with Enhanced Recovery After Surgery in patients with colon cancer: Impact of measures to improve adherence 


\section{Abstract}

\section{Background}

Perioperative treatment of patients with colorectal cancer according to the Enhanced Recovery After Surgery (ERAS) protocol has proven to reduce complications and duration of stay. However, strict adherence remains a challenge and the benefits may decrease with lower adherence. In this study, we report on 8 years of adherence to the ERAS protocol and its effect on postoperative outcome in patients with colon cancer.

\section{Methods}

In 2006, the ERAS protocol was introduced for treatment of colon cancer patients in the Medical Center Alkmaar, a large teaching hospital. Patients scheduled for elective colon cancer resection were included in this study. Adherence to ERAS items was monitored and along with clinical data prospectively gathered in a database. In 2011, several measures to improve adherence were implemented.

\section{Results}

In total, 816 patients were included. Mean adherence rate was $73 \%$ in 2006 and 2007, $66 \%$ in 2008 and 2009, 63\% in 2010 and 2011, and 82\% in 2012 and 2013. There was a shorter duration of stay in the years with high adherence (5.7 days) compared with the years with low adherence ( 7.3 days; $P<.001)$. The ERAS items that were the strongest predictors for a shorter duration of stay were no nasogastric tube, early mobilization, early oral nutrition, early removal of epidural, early removal of catheter, and nonopioid oral analgesia.

\section{Conclusion}

It is possible to improve adherence to the ERAS protocol and related outcomes with specific measures. Adherence to the ERAS protocol was related inversely to duration of stay. Only postoperative items of the ERAS protocol were predictive for a shorter duration of stay. Keeping adherence optimal remains an ongoing challenge that requires repeated training and dedicated personnel. 


\section{Introduction}

Enhanced Recovery After Surgery (ERAS) is a multimodal perioperative care pathway designed to achieve early recovery for patients undergoing major surgery. Current ERAS protocols include preoperative, intraoperative, and postoperative measures using a multidisciplinary approach. ${ }^{1}$ The focus lies on maintaining homeostasis and regaining mobility and oral fluid and food intake as soon as possible. The use of the ERAS pathway has proven to reduce duration of stay and the complication rate after colorectal resections. ${ }^{2,3}$ Despite the obvious benefits of the ERAS program, its implementation and adherence to the protocol remain a challenge. The participation of a number of specialists and the ward staff is required for successful implementation and long-term success of the protocol. ${ }^{4,5}$ In a previous study, we showed that strict adherence to the ERAS protocol is associated with a decreased duration of stay and better outcome after colon cancer surgery. These benefits were lost when adherence decreased. ${ }^{5}$ To improve adherence and postoperative outcome, we introduced a set of specific measures in 2011. We hypothesized that with specific measures adherence to the ERAS protocol could be improved to the high level of the first years after introduction in 2006. The goal of the current study was to report on 8 years of adherence to the ERAS protocol, its effect on postoperative outcome in patients with colon cancer and the effects of the measures to improve adherence.

\section{Methods}

\section{Study design}

In 2006, ERAS was introduced at the Medical Center Alkmaar after a multidisciplinary training program. All data for adult patients scheduled for elective colonic cancer resection between January 2005 and January 2014 were collected prospectively in a database. The year 2005 served as a control. Exclusion criteria were acute operation, benign disease, rectal resection, and colostomy closure.

\section{ERAS items}

Description of the ERAS protocol that is used in the Medical Center Alkmaar is shown in Table 3.1. 
Table 3.1 ERAS protocol in the Medical Center of Alkmaar.

\begin{tabular}{|c|c|}
\hline ERAS item & Details \\
\hline \multicolumn{2}{|l|}{ Preoperative } \\
\hline No bowel preparation & Unless low anterior resection after radiotherapy \\
\hline Carbohydrate-loaded drink & $2 \times 200 \mathrm{~mL}$ Nutricia, unless diabetes $>3 \mathrm{~h}$ before surgery \\
\hline $\begin{array}{l}\text { Intraoperative } \\
\text { Thoracic epidural analgesia }\end{array}$ & $\begin{array}{l}\text { Colon resections: T6-T8, sigmoid resections T8-T10 Chirocaine } 0.5 \%+ \\
\text { sufenta/catapressan/sufenta forte }\end{array}$ \\
\hline Maintenance of normothermia & $\begin{array}{l}\text { Ranger (dry heat warmer of IV fluids) and/or warm touch (blanket with } \\
\text { warmed air) }\end{array}$ \\
\hline Vasopressors & $\begin{array}{l}\text { During anesthesia to maintain blood pressure and prevent salt and water } \\
\text { overload }\end{array}$ \\
\hline Routine antiemetics & Started at the end of the operative procedure, ondansetron $4 \mathrm{mg}$ \\
\hline \multicolumn{2}{|l|}{ Postoperative } \\
\hline No nasogastric tube & Removal of the nasogastric tube before extubation \\
\hline Early mobilization & Mobilization within $24 \mathrm{~h}$ \\
\hline Oral magnesium & $\begin{array}{l}\text { Started at the first day after surgery, unless defunctioning ileostoma, } \\
1,500 \mathrm{mg} \text { once daily }\end{array}$ \\
\hline Nonopioid oral analgesia & Diclofenac $50 \mathrm{mg} 3$ times a day, started on postoperative day 2 \\
\hline Early oral nutrition & Successful restart of oral nutrition within $48 \mathrm{~h}$ after surgery \\
\hline Early removal of epidural & Within $48 \mathrm{~h}$ after surgery \\
\hline Early removal of catheter & Within $56 \mathrm{~h}$ after surgery \\
\hline $\begin{array}{l}\text { Standard care } \\
\text { Preadmission counseling }\end{array}$ & By specialized nurse-practitioners \\
\hline \multicolumn{2}{|l|}{ No prolonged fasting } \\
\hline Antibiotic prophylaxis & $1,500 \mathrm{mg}$ cefuroxim, $500 \mathrm{mg}$ metronidazol \\
\hline Thromboprophylaxis & Fraxiparin 2,850 IU once daily \\
\hline Short-acting anesthetic agents & Propofol $20 \mathrm{mg} / \mathrm{mL}$ \\
\hline
\end{tabular}

ERAS, Enhanced Recovery After Surgery; IV, intravenous.

\section{Measures to improve adherence}

Our first evaluation of ERAS from 2006 to 2010 showed an increase and decrease in adherence. ${ }^{5}$ For this reason, in 2011 a specialized nurse-practitioner was installed to improve adherence to the protocol on the surgical ward and to improve continuity of care. In 2012, regular teaching sessions were organized for surgical ward personnel. Case managers were introduced to ensure the quality of the entire perioperative care pathway. They attend the multidisciplinary conference on surgical indication and join the morning rounds to ensure ERAS protocol adherence. Every patient is informed about the ERAS protocol at the preoperative outpatient clinic visit. Within 3 days after discharge, a nurse-practitioner calls the patient and fills out a checklist for complications. 


\section{Postoperative outcomes}

\section{Duration of hospital stay}

Duration of stay was calculated by subtracting date of discharge from date after operation. Patients were discharged if they met the following criteria: adequate pain control with oral analgesics, ability to tolerate solid food, passage of flatus or stool, and acceptance of discharge by the patient.

\section{Occurrence of postoperative complications}

Postoperative ileus was defined as prolonged inability to pass flatus and stool resulting in nausea and vomiting and requiring the use of a nasogastric tube and/or total parenteral nutrition. Surgical site infection was defined as any evidence of infection (erythema, purulent discharge, tenderness) requiring antibiotic treatment and or opening of the wound. Abscess was defined as an infected abdominal or pelvic fluid collection. Urinary tract infection was defined as a symptomatic infection requiring antibiotics. Pneumonia was defined as a combination of clinical signs and a new infiltrate on chest x-ray requiring intravenous antibiotic treatment. Anastomotic leakage was defined as a combination of clinical signs (pain, fever, tachycardia, peritonitis, feculent or purulent drainage), radiographic signs (free abdominal fluid or gas collections on CT scan) and intraoperative findings (enteric spillage, anastomotic disruption).

\section{Statistical analysis}

Patient and operation characteristics were described as numbers with percentages in case of nominal variables and means with standard deviations in case of continuous variables. The adherence to a single ERAS item was described as the percentage of patients in whom the item was implemented successfully. Duration of stay was not distributed normally and was transformed logarithmically before analysis. After analysis, back-transformation of the means resulted in geometric means, which can be interpreted as median values. Differences in nominal and ordinal variables between consecutive years were analyzed using the Chi-square test or Fisher exact test where appropriate. Differences in continuous variables were analyzed using 1-way analysis of variance.

Logistic regression analysis was used to determine the independent association of patient characteristics (age, sex, body mass index, comorbidity), laparoscopic resection, and all ERAS items on postoperative complications. Linear regression analysis was used to determine the independent association of patient characteristics, laparoscopic resection, and ERAS items on the logarithmically transformed variable duration of stay. Transformation of the resulting regression coefficient from these analyses resulted in a 
ratio of geometric means, which can be interpreted as ratio of medians. The variables with a significant predictive value in univariate analysis were entered into multivariate regression analysis. The statistical analyses were performed using the Statistical Package for the Social Sciences (SPSS) version 20.0 (SPSS, IBM, Armonk, NY).

\section{Results}

\section{Patient characteristics}

In total, 816 patients were included in this study. Patient and operation characteristics are shown in Table 3.2. Mean age was $71 \pm 11$ years. Of all patients, 431 (52.8\%) were male. Mean body mass index was $25.5 \pm 4.1 \mathrm{~kg} / \mathrm{m}^{2}$. Comorbidity included cardiac comorbidity in 261 patients (32.0\%), pulmonary comorbidity in 88 patients $(10.8 \%)$, hypertension in 251 patients (30.8\%), and diabetes in 90 patients (11.0\%). Tumor stage was divided in stage 1 ( $n=131 ; 16.1 \%)$, stage 2 ( $n=359 ; 44.0 \%)$, stage 3 ( $n=233 ; 28.6 \%)$, and stage $4(n=86 ; 10.5 \%)$. In 7 patients $(0.9 \%)$, the diagnosis was a carcinoid tumor of the appendix or an extra-intestinal malignancy. Laparoscopic resections increased gradually from 3 of 57 (5.3\%) in 2005 to 59 of 122 (48.4\%) in 2013.

Table 3.2 Patient and operation characteristics.*

\begin{tabular}{|c|c|c|c|c|c|c|c|c|c|c|}
\hline Characteristic & $\begin{array}{l}2005 \\
n=57 \\
n(\%)\end{array}$ & $\begin{array}{l}2006 \\
n=75 \\
n(\%)\end{array}$ & $\begin{array}{l}2007 \\
n=82 \\
n(\%)\end{array}$ & $\begin{array}{l}2008 \\
n=87 \\
n(\%)\end{array}$ & $\begin{array}{c}2009 \\
n=103 \\
n(\%)\end{array}$ & $\begin{array}{c}2010 \\
n=102 \\
n(\%)\end{array}$ & $\begin{array}{l}2011 \\
n=86 \\
n(\%)\end{array}$ & $\begin{array}{c}2012 \\
n=102 \\
n(\%)\end{array}$ & $\begin{array}{c}2013 \\
n=122 \\
n(\%)\end{array}$ & $\begin{array}{c}P_{-} \\
\text {value }\end{array}$ \\
\hline Male sex & $33(58)$ & $38(51)$ & $44(54)$ & $47(54)$ & $52(51)$ & $59(58)$ & $43(50)$ & $50(49)$ & $65(53)$ & .938 \\
\hline Age $\ddagger$ & $72(11)$ & $72(13)$ & $72(11)$ & $70(13)$ & $71(11)$ & $70(11)$ & $72(11)$ & $72(12)$ & $70(10)$ & .740 \\
\hline Body mass index $\ddagger$ & $25(4)$ & $26(3)$ & $26(4)$ & $24(4)$ & $26(5)$ & $25(4)$ & $26(4)$ & $25(4)$ & $25(3)$ & .013 \\
\hline \multicolumn{11}{|l|}{ Comorbidity } \\
\hline Cardiac & 22 (39) & $21(28)$ & $25(31)$ & $20(23)$ & $38(37)$ & $30(29)$ & $23(27)$ & $44(43)$ & $38(31)$ & .098 \\
\hline Pulmonary & $5(9)$ & $5(7)$ & $10(12)$ & $7(8)$ & $9(9)$ & $11(11)$ & $11(13)$ & $15(15)$ & $15(12)$ & .743 \\
\hline Hypertension & $4(7)$ & $18(24)$ & $18(22)$ & $29(33)$ & $33(32)$ & $42(41)$ & $27(31)$ & $46(45)$ & $34(28)$ & $<.001$ \\
\hline Diabetes & $5(9)$ & $8(11)$ & $9(11)$ & $15(17)$ & $7(7)$ & $13(13)$ & $13(15)$ & $11(11)$ & $9(7)$ & .339 \\
\hline Tumor stage & & & & & & & & & & $<.001$ \\
\hline 1 & $2(3.5)$ & $9(12)$ & $23(28)$ & $9(11)$ & $14(14)$ & $11(11)$ & $19(22)$ & 19 (19) & $25(21)$ & \\
\hline 2 & $27(47)$ & $48(65)$ & $26(32)$ & $40(47)$ & $44(43)$ & $43(43)$ & $43(50)$ & $42(42)$ & $46(38)$ & \\
\hline 3 & $19(33)$ & $15(20)$ & $25(31)$ & $28(33)$ & $28(28)$ & $26(26)$ & $20(23)$ & $33(33)$ & $39(32)$ & \\
\hline 4 & $9(16)$ & $2(3)$ & $8(10)$ & $8(9)$ & $16(16)$ & $20(20)$ & $4(4.7)$ & $7(7)$ & $12(10)$ & \\
\hline $\begin{array}{l}\text { Laparoscopic } \\
\text { resection }\end{array}$ & $3(5.3)$ & $23(31)$ & $23(28)$ & $22(25)$ & $23(22)$ & $7(7)$ & $47(55)$ & $39(38)$ & $59(48)$ & $<.001$ \\
\hline Resection type & & & & & & & & & & .392 \\
\hline Right/ileocoecal & $25(44)$ & $37(49)$ & $31(38)$ & $40(46)$ & $49(48)$ & $55(54)$ & $46(53)$ & $52(51)$ & $62(51)$ & \\
\hline Left/sigmoid & $29(51)$ & $34(45)$ & $46(56)$ & $43(49)$ & $50(48)$ & $42(41)$ & $35(41)$ & $38(37)$ & $55(45)$ & \\
\hline Other & $3(5)$ & $4(5)$ & $5(6)$ & $4(5)$ & $4(4)$ & $5(5)$ & $5(6)$ & $12(12)$ & $5(4)$ & \\
\hline
\end{tabular}

* Values in parentheses are percentages. $+P=$ Chi-square test except age and body mass index (1-way analysis of variance). $¥$ Values are mean (standard deviation). 


\section{ERAS adherence}

The adherence to the preoperative, intraoperative, and postoperative ERAS protocol is shown in Figure 3.1. In 2006 and 2007, the protocol was implemented successfully and adherence was high. After this period, adherence decreased. The greatest decrease was seen in the use of carbohydrate-loaded drinks, routine anti-emetics, oral magnesium, and non-opioid oral analgesia. In the period between 2011 and 2013, adherence to 8 items (carbohydrate-loaded drinks, thoracic epidural analgesia, maintenance of normothermia, vasopressors, oral magnesium, non-opioid oral analgesia, early removal of epidural, and early removal of catheter) was significantly higher, resulting in the large increase in mean overall adherence. The inverse relationship between overall adherence and duration of stay is shown in Figure 3.2.

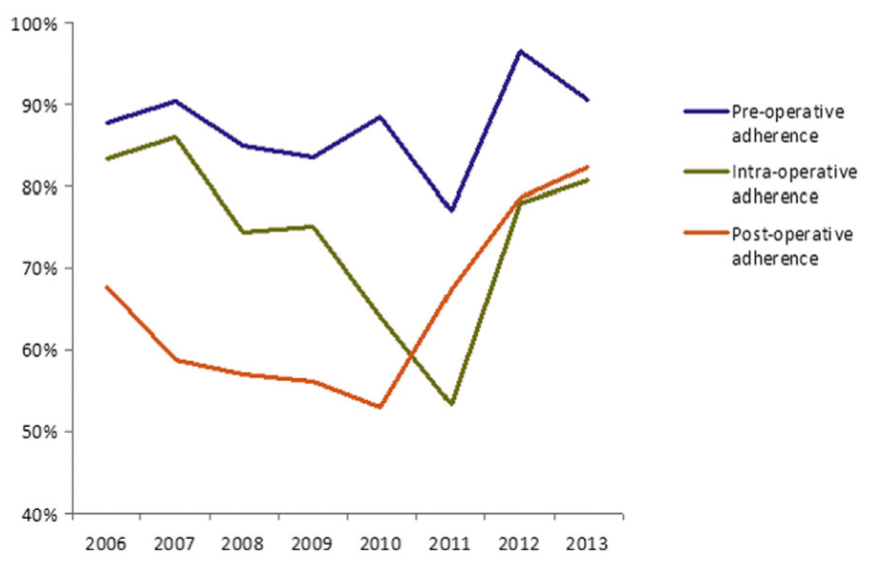

Figure 3.1 Adherence to preoperative, intraoperative, and postoperative items of the ERAS protocol.

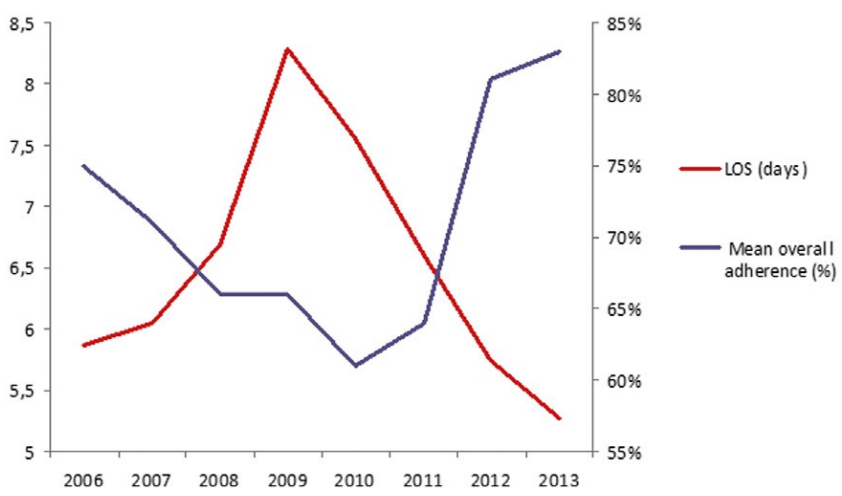

Figure 3.2 Relationship between length of stay (LOS)y and adherence. yLOS is presented as geometric mean. In 2011, an ERAS dedicated nurse-practitioner was installed. 


\section{Postoperative outcome}

Duration of stay and postoperative complications are shown in Table 3.3. There was a significant decrease in duration of stay between 2005 and 2006 (8.5 vs. 5.7 days; $P<.001)$. In all years after introduction of the ERAS protocol, duration of stay was significantly shorter than 2005, except for 2009 and 2010 (these years were not significantly different from 2005). Median duration of stay gradually declined from 8.5 days in 2005 until 5.1 days in $2013(P<.001)$.

We compared the years with high adherence $(71-83 \%$ in 2006, 2007, 2012, 2013) with the years with low adherence (61-66\% in 2008-2011). There was a significantly shorter duration of stay in the years with high adherence (5.7 vs. 7.3 days; $P<.001$ ). Individual complications were not significantly different between these groups, although there was a trend for fewer urinary tract infections (11/380 [2.9\%] vs. 20/378 [5.3\%]; $P=.096$ ) and less pneumonia (27/380 [7.1\%] vs. $41 / 378$ [10.8\%]; $P=.072)$ in the years with high adherence.

Table 3.3 Postoperative outcome.*

\begin{tabular}{|c|c|c|c|c|c|c|c|c|c|c|}
\hline & $\begin{array}{c}2005 \\
(n=57) \\
n(\%)\end{array}$ & $\begin{array}{c}2006 \\
(n=75) \\
n(\%)\end{array}$ & $\begin{array}{c}2007 \\
(\mathrm{n}=82) \\
\mathrm{n}(\%)\end{array}$ & $\begin{array}{c}2008 \\
(n=87) \\
n(\%)\end{array}$ & $\begin{array}{c}2009 \\
(n=103) \\
n(\%)\end{array}$ & $\begin{array}{c}2010 \\
(n=102) \\
n(\%)\end{array}$ & $\begin{array}{c}2011 \\
(\mathrm{n}=86) \\
\mathrm{n}(\%)\end{array}$ & $\begin{array}{c}2012 \\
(\mathrm{n}=102), \\
\mathrm{n}(\%)\end{array}$ & $\begin{array}{c}2013 \\
(n=122) \\
n(\%)\end{array}$ & $\begin{array}{c}P \text { - } \\
\text { value }\end{array}$ \\
\hline $\begin{array}{l}\text { Duration of } \\
\text { stay (d) }\end{array}$ & $8.5(1.8)$ & $5.7(1.9)$ & $6.4(2.0)$ & $6.7(2.1)$ & $8.3(2.2)$ & $7.5(2.0)$ & $6.6(2.1)$ & $5.8(2.1)$ & $5.1(2.1)$ & $<.001$ \\
\hline $\begin{array}{l}\text { Anastomotic } \\
\text { leakage }{ }^{\dagger}\end{array}$ & $2(3.5)$ & $0(0.0)$ & $2(2.4)$ & $6(6.9)$ & $8(7.8)$ & $5(4.9)$ & $7(8.1)$ & 15 (14.7) & $9(7.4)$ & .009 \\
\hline $\begin{array}{l}\text { Surgical site } \\
\text { infection }\end{array}$ & $4(7.0)$ & $4(5.3)$ & $3(3.7)$ & $3(3.4)$ & $8(7.8)$ & $15(14.7)$ & $2(2.3)$ & $7(6.9)$ & $7(5.8)$ & .033 \\
\hline Abscess & $1(1.8)$ & $0(0.0)$ & $1(1.2)$ & $1(1.1)$ & $5(4.9)$ & $1(1.0)$ & $3(3.5)$ & $1(1.0)$ & $4(3.3)$ & .336 \\
\hline Ileus & $6(10.5)$ & $7(9.3)$ & $13(16)$ & $8(9.2)$ & $16(15.5)$ & $7(6.9)$ & $14(16.3)$ & $16(15.7)$ & $8(6.6)$ & .129 \\
\hline Pneumonia & $3(5.3)$ & $2(2.7)$ & $5(6.1)$ & $2(2.3)$ & $16(17.5)$ & $11(10.8)$ & 10 (11.6) & $10(9.8)$ & $10(8.3)$ & .007 \\
\hline $\begin{array}{l}\text { Urinary tract } \\
\text { infection }\end{array}$ & $2(3.5)$ & $1(1.3)$ & $2(2.4)$ & $4(4.6)$ & $5(4.9)$ & $10(9.8)$ & $1(1.2)$ & $3(2.9)$ & $5(4.1)$ & .108 \\
\hline Readmission & $4(7.0)$ & $6(8.0)$ & $4(4.9)$ & $6(6.9)$ & $5(4.9)$ & $10(9.8)$ & $10(11.6)$ & $13(13)$ & $12(10.1)$ & .455 \\
\hline Mortality $\ddagger$ & $1(1.8)$ & $2(2.7)$ & $5(6.1)$ & $2(2.3)$ & $8(7.8)$ & $10(9.8)$ & $3(3.5)$ & $6(5.9)$ & $2(1.7)$ & .076 \\
\hline
\end{tabular}

* Values in parentheses are percentages except for duration of stay, which is geometric mean \pm standard deviation. + Percentage of patients with primary anastomosis. ¥ Deceased during surgical admission.

The results of the univariate and multivariate regression analysis are shown in Table 3.4. Factors that significantly improved postoperative outcome in multivariate analysis included carbohydrate-loaded drinks, no nasogastric tube, early oral nutrition, early mobilization, early removal of urinary catheter, early removal of epidural, and nonopioid oral analgesia. Factors that significantly increased duration of stay and the risk at postoperative complications in multivariate analysis included age, body mass index and sex (male sex, anastomotic leakage and ileus; female sex, urinary tract infections). 
Table 3.4 Predictive factors for postoperative outcome.*

\begin{tabular}{|c|c|c|c|c|}
\hline Predictive factor & $\begin{array}{c}\text { Univariate analysis } \\
\text { Risk estimate }(95 \% \mathrm{CI})\end{array}$ & $P$ value & $\begin{array}{c}\text { Multivariate analysis } \\
\text { Risk estimate }(95 \% \mathrm{Cl})\end{array}$ & $P$ value \\
\hline \multicolumn{5}{|l|}{ Anastomotic leakage } \\
\hline Male sex & 2.09 (1.16-3.79) & .014 & $1.96(1.08-3.56)$ & .028 \\
\hline Early removal of catheter & $0.41(0.23-0.72)$ & .001 & $0.42(0.24-0.75)$ & .003 \\
\hline \multicolumn{5}{|l|}{ Surgical site infection } \\
\hline Body mass index & $1.07(1.00-1.14)$ & .049 & $1.08(1.01-1.16)$ & .028 \\
\hline Carbohydrate-loaded drinks & $0.40(0.21-0.76)$ & .005 & $0.51(0.26-0.99)$ & .048 \\
\hline No nasogastric tube & $0.30(0.15-0.59)$ & .001 & $0.37(0.18-0.78)$ & .009 \\
\hline Early mobilization & $0.35(0.19-0.64)$ & .001 & & \\
\hline Nonopioid oral analgesia & $0.48(0.27-0.87)$ & .016 & & \\
\hline Early removal of catheter & $0.42(0.23-0.75)$ & .004 & & \\
\hline Laparoscopic resection & $0.33(0.15-0.76)$ & .008 & & \\
\hline \multicolumn{5}{|l|}{ Abscess } \\
\hline Early mobilization & $0.25(0.09-0.68)$ & .006 & $0.25(0.09-0.68)$ & .006 \\
\hline \multicolumn{5}{|l|}{ lleus } \\
\hline Male sex & $1.79(1.15-2.81)$ & .010 & $1.68(1.05-2.69)$ & .031 \\
\hline Early mobilization & $0.55(0.36-0.85)$ & .007 & & \\
\hline Nonopioid oral analgesia & $0.64(0.41-0.99)$ & .046 & & \\
\hline Early removal epidural & $0.47(0.28-0.80)$ & .006 & & \\
\hline Early oral nutrition & $0.35(0.22-0.56)$ & $<.001$ & $0.51(0.29-0.85)$ & .011 \\
\hline Early removal of catheter & $0.26(0.16-0.41)$ & $<.001$ & $0.37(0.21-0.63)$ & $<.001$ \\
\hline \multicolumn{5}{|l|}{ Pneumonia } \\
\hline Male sex & $1.85(1.11-3.08)$ & .019 & & \\
\hline Age & $1.04(1.01-1.06)$ & .004 & & \\
\hline Cardiac comorbidity & $2.23(1.36-3.64)$ & .001 & & \\
\hline Pulmonary comorbidity & $2.22(1.18-4.18)$ & .013 & & \\
\hline Early mobilization & $0.39(0.24-0.64)$ & $<.001$ & & \\
\hline Early oral nutrition & $0.53(0.32-0.88)$ & .015 & & \\
\hline Early removal of catheter & $0.26(0.15-0.44)$ & $<.001$ & $0.31(0.17-0.58)$ & $<.001$ \\
\hline \multicolumn{5}{|l|}{ Urinary tract infection } \\
\hline Female sex & $2.31(1.10-4.83)$ & .026 & $2.44(1.13-5.28)$ & .023 \\
\hline Carbohydrate-loaded drinks & $0.44(0.19-0.99)$ & .047 & $0.44(0.19-0.99)$ & .047 \\
\hline \multicolumn{5}{|l|}{ Duration of stay } \\
\hline Age & $1.01(1.006-1.015)^{\dagger}$ & $<.001$ & $1.006(1.002-1.009)^{\dagger}$ & .003 \\
\hline Pulmonary comorbidity & $1.25(1.06-1.48)+$ & .009 & & \\
\hline No bowel preparation & $0.75(0.63-0.88)+$ & .001 & & \\
\hline No drains & $0.80(0.68-0.93)+$ & .005 & & \\
\hline No nasogastric tube & $0.64(0.55-0.73)+$ & $<.001$ & $0.87(0.75-0.99)^{\dagger}$ & .041 \\
\hline Early mobilization & $0.59(0.53-0.65)+$ & $<.001$ & $0.84(0.75-0.84)^{\dagger}$ & .003 \\
\hline Oral magnesium & $0.79(0.71-0.88)+$ & $<.001$ & & \\
\hline Nonopioid oral analgesia & $0.75(0.66-0.83)+$ & $<.001$ & $0.89(0.81-0.97)^{\dagger}$ & .012 \\
\hline Early removal epidural & $0.62(0.56-0.69)+$ & $<.001$ & $0.85(0.77-0.94)^{\dagger}$ & .002 \\
\hline Early oral nutrition & $0.63(0.57-0.69)+$ & $<.001$ & $0.86(0.78-0.95)^{\dagger}$ & .004 \\
\hline Early removal of catheter & $0.49(0.45-0.55)+$ & $<.001$ & $0.64(0.57-0.71)^{\dagger}$ & $<.001$ \\
\hline Laparoscopic resection & $0.71(0.63-0.79)+$ & $<.001$ & & \\
\hline
\end{tabular}

* Odds ratio unless stated otherwise. + Ratio of geometric means. 


\section{Discussion}

This study reports on a long follow-up ( 8 years) of the ERAS program in a large number of patients (816) electively operated for colon cancer. After a training period, the ERAS protocol was successfully introduced in 2006 in the Medical Center Alkmaar. Adherence was high in 2006 and 2007, but decreased between 2008 and 2011, probably owing to a lack of repetitive education and trained personnel. Only after specific measures at the outpatient clinic and the surgical ward, adherence improved again in 2012 and 2013. This study shows that with specific measures it is possible to increase adherence significantly. Key factors include repeated training sessions and the presence of trained nurse-practitioners at all stages in perioperative care. In addition, this study confirms the relationship between the ERAS protocol and duration of stay. It shows that, with high adherence, duration of stay decreased and that with low adherence, duration of stay increased. Multivariate regression analysis showed that no nasogastric tube, early mobilization, early oral nutrition, early removal of epidural, early removal of catheter, and non-opioid oral analgesia were the most predictive ERAS items for a shorter duration of stay.

Our results compare well with the published literature. A recent meta-analysis of randomized, controlled trials comparing ERAS care with conventional care showed a significant reduction in duration of stay, overall morbidity, and nonoperative complications (cardiovascular, respiratory, urinary tract infections) in patients treated within an ERAS protocol. ${ }^{6}$ Our results also contribute to the existing evidence that there is a significant association between adherence to the ERAS protocol and postoperative outcome. A review article by Ahmed et al. ${ }^{4}$ showed that there is a significant variation in the applied ERAS components and the compliance to them in daily practice. However, greater compliance was associated with a decreased duration of stay. ${ }^{4}$ Another study by Gustafsson et al. ${ }^{7}$ showed that an increase in adherence from 40.3 to $70.6 \%$ resulted in a significant improvement of postoperative outcome. In our previous study, the high initial adherence (84.1\%) resulted in a reduced duration of stay that increased when adherence dropped to $72.4 \%{ }^{5}$. The anastomotic leak rate in the last years of our cohort are somewhat higher than expected from elective colon surgery. We have looked into this issue, but we could not find a relation between early discharge, readmission, or patient characteristics and anastomotic leakage. After multivariate analyses, male sex was associated with a greater risk for postoperative complications (anastomotic leakage, ileus), even though rectal cases were excluded. This is an unexplained phenomenon seen in other studies about colon surgery as well. ${ }^{8-11}$ Because the ERAS protocol and laparoscopic surgery were both developed to maintain homeostasis and to speed up recovery, it is likely that the increase in laparoscopic 
resections over the years contributed to the reduction in duration of stay in our study. In a large, multicenter study on the effect of ERAS in laparoscopic versus open in colon cancer surgery the shortest duration of stay was achieved in the group combining laparoscopic surgery with the ERAS protocol. ${ }^{12}$ Because laparoscopic surgery preserves homeostasis better, it is suggested that laparoscopic resection should be considered a standard aspect of the ERAS protocol when feasible. ${ }^{13}$ In contrast with the literature, our present regression analysis showed that some ERAS protocol items have a greater impact on postoperative outcome than laparoscopic resection that is even lost in multivariable analysis. This may be explained by the fact that laparoscopic resection further facilitates the execution of several postoperative ERAS protocol items.

Suggestions to improve adherence include the use of a specific ward, dedicated anaesthesiologists, a leader responsible for coordination of updates and training, regular auditing, and dissemination of results. ${ }^{4}$ In addition, it is useful to analyse barriers and facilitators for implementation and adherence. ${ }^{14}$ Lack of repetitive education about the ERAS protocol has an important impact on adherence. This education is specifically important among doctors and nurses on the surgical ward, because there are often changes in personnel in this group and usually the youngest members of the team are responsible for actual execution of daily care. In this study we show that, in our setting, installing a dedicated ERAS nurse-practitioner responsible for protocol implementation significantly reduced duration of stay and improved outcome. Although most data were entered prospectively, analysis was done retrospectively and results should be interpreted as such. Another limitation of the study is that the decrease in adherence cannot be explained because the reasons for protocol deviations were not registered. The increase in adherence in the latter years is explained by the introduction of a dedicated nurse-practitioner and improved training programs. The results of the regression analysis should be interpreted with regard to the method, we only used demographic characteristics, ERAS protocol items, and laparoscopic resection to determine their relative relationship with postoperative outcome. In general, duration of stay is influenced by many other factors that can have an even larger effect, like the occurrence of complications.

In conclusion, our study confirms that the ERAS protocol improves postoperative outcome. A period with less trained personnel and education lead to a decrease in ERAS adherence and a significant increase in adherence was observed when specific measures were introduced. Only postoperative items of the ERAS protocol were associated independently with a shorter duration of stay. Keeping adherence optimal remains an ongoing challenge that requires repeated training and dedicated personnel. 
We would like to thank all the members of the ERAS team in the Medical Center of Alkmaar for their efforts to sustain the ERAS protocol in colon cancer surgery. We would like to thank A. Dekker for her role in improving ERAS adherence and collection of the data. 


\section{References}

1. Varadhan KK, Lobo DN, Ljungqvist $\mathrm{O}$. Enhanced recoveryafter surgery: the future of improving surgical care. Crit Care Clin 2010;26:527-47.

2. Varadhan KK, Neal KR, Dejong $\mathrm{CH}$, Fearon KC, Ljungqvist O, Lobo DN. The enhanced recovery after surgery (ERAS) pathway for patients undergoing major elective open colorectal surgery: a meta-analysis of randomized controlled trials. Clin Nutr 2010;29:434-40.

3. Lv L, Shao YF, Zhou YB. The enhanced recovery after surgery (ERAS) pathway for patients undergoing colorectal surgery: an update of meta-analysis of randomized controlled trials. Int J Colorectal Dis 2012;27:1549-54.

4. Ahmed J, Khan S, Lim M, Chandrasekaran TV, MacFie J. Enhanced recovery after surgery protocols compliance and variations in practice during routine colorectal surgery. Colorectal Dis 2012;14:1045-51.

5. Cakir H, van Stijn MF, Lopes Cardozo AM, Langenhorst BL, Schreurs WH, van der Ploeg TJ, et al. Adherence to Enhanced Recovery After Surgery and length of stay after colonic resection. Colorectal Dis 2013;15:1019-25.

6. Greco M, Capretti G, Beretta L, Gemma M, Pecorelli N, Braga M. Enhanced recovery program in colorectal surgery: a meta-analysis of randomized controlled trials. World J Surg 2014;38:1531-41.

7. Gustafsson UO, Hausel J, Thorell A, Ljungqvist O, Soop M, Nygren J. Adherence to the enhanced recovery after surgery protocol and outcomes after colorectal cancer surgery. Arch Surg 2011;146: 571-7.

8. Bakker IS, Grossmann I, Henneman D, Havenga K, Wiggers T. Risk factors for anastomotic leakage and leak-related mortality after colonic cancer surgery in a nationwide audit. Br J Surg 2014;101:424-32.

9. Kube R, Mroczkowski P, Steinert R, Sahm M, Schmidt U, Gastinger I, et al. Anastomotic leakage following bowel resections for colon cancer: multivariate analysis of risk factors. Chirurg 2009;80:1153-9.

10. Krarup PM, Jorgensen LN, Andreasen AH, Harling H. A nationwide study on anastomotic leakage after colonic cancer surgery. Colorectal Dis 2012;14:e661-7.

11. Millan M, Biondo S, Fraccalvieri D, Frago R, Golda T, Kreisler E. Risk factors for prolonged postoperative ileus after colorectal cancer surgery. World J Surg 2012;36:179-85.

12. Vlug MS, Wind J, Hollmann MW, Ubbink DT, Cense HA, Engel AF, et al. Laparoscopy in combination with fast track multimodal management is the best perioperative strategy in patients undergoing colonic surgery: a randomized clinical trial (LAFA-study). Ann Surg 2011;254:868-75.

13. Rockall TA, Demartines N. Laparoscopy in the era of enhanced recovery. Best Pract Res Clin Gastroenterol 2014; 28:133-42.

14. Kehlet H. Multimodal approach to postoperative recovery. Curr Opin Crit Care 2009;15:355-8. 



\section{Part III}

Risk factors affecting recovery after colorectal surgery for patients treated according to an ERAS protocol 



\section{Chapter 4}

Risk of anastomotic leakage with nonsteroidal anti-inflammatory drugs within an enhanced

recovery program

N. Bakker, J.D. Deelder, M.C. Richir, H. Cakir, H.J. Doodeman, W.H. Schreurs, A.P.J. Houdijk J Gastrointest Surg 2016;20(4):776-782 


\section{Abstract}

\section{Introduction}

Anastomotic leakage is a serious complication after colorectal resection. Recent studies suggest that nonsteroidal anti-inflammatory drugs may increase the risk of anastomotic leakage. We investigated this association in our enhanced recovery population.

\section{Material and methods}

Patients undergoing an elective colon or rectal resection with primary anastomosis because of malignancy and treated within our enhanced recovery program were included. Univariate and multivariate logistic regression analyses were used to study risk factors for anastomotic leakage.

\section{Results}

Between 2006 and 2013, 856 patients were included. The anastomotic leakage rate was significantly higher in the group that received nonsteroidal anti-inflammatory drugs compared to patients who did not: 9.2 vs. $5.3 \%, P=0.038$. This higher rate was only seen in patients receiving diclofenac: for colonic resections, 11.8 vs. $6.0 \%, P=0.016$; for rectal resections, 13.1 vs. $0 \%, P=0.017$. Only male sex (odds ratio $2.20, P=0.005$ ) was also independently associated with anastomotic leakage.

\section{Conclusion}

The results of this study are in line with other comparable studies in the literature, showing an increased risk for anastomotic leakage with diclofenac. The use of diclofenac in colorectal surgery can no longer be recommended. Alternatives for postoperative analgesia need to be explored within an enhanced recovery program. 


\section{Introduction}

Anastomotic leakage ( $\mathrm{AL}$ ) is a much feared complication after colorectal resection. Reported incidence rates vary across studies from $3 \%$ in colonic resections up to $13 \%$ in low rectal resections. ${ }^{1-4} \mathrm{AL}$ increases the number of re-operations, length of stay, and morbidity and mortality rates. ${ }^{3}$ Furthermore, it has a negative impact on oncological outcome and overall, cancer-related and disease-free survival. ${ }^{3,6,8}$ Known preoperative risk factors for $\mathrm{AL}$ include the following: patients characteristics such as male sex; comorbidity such as vascular disease; American Society of Anesthesiologists (ASA) fitness grade above II, smoking; and tumor characteristics such as tumor size and an advanced stage. ${ }^{2,7}$ Intraoperative risks include factors that endanger the blood supply of the anastomosis and factors that increase surgical stress. ${ }^{6,8}$

In our institution, patients undergoing an elective colon or rectal resection are treated within an enhanced recovery program. The focus of this program lies on maintaining homeostasis and regaining mobility and oral fluid and food intake as soon as possible. ${ }^{9}$ The Enhanced Recovery after Surgery (ERAS) program reduces complications and length of stay in colorectal resections and has proven to be valuable in other surgical procedures. $^{10}$

One important component of the enhanced recovery program is multimodal pain management which involves the use of epidural analgesia and nonsteroidal antiinflammatory drugs (NSAIDs). NSAIDs are used to optimize pain control and reduce opioid use. However, several experimental and retrospective studies have linked the use of NSAIDs with an increased risk of AL. ${ }^{4,11-15}$ In the present study, we report on the $A L$ rate in a large group of patients who have undergone elective colonic and rectal resections in our institution, and the association with NSAIDs and other risk factors.

\section{Materials and methods}

\section{Study design}

In 2006, the ERAS program was introduced at the Medical Center Alkmaar for elective colon resections. In 2010, the ERAS program was introduced for elective rectal resections. The ERAS protocol as used in the Medical Center of Alkmaar is shown in Figure 4.1. All relevant clinical data were collected in a database. In this observational cohort study, we included all patients who underwent an elective colon or rectal resection with a primary anastomosis within the ERAS program. Exclusion criteria were benign disease, acute operation, colostomy closure, and any form of stoma except for 
the deviating ileostomy in rectal resection with primary anastomosis after preoperative (chemo)radiation. We excluded benign disease to increase uniformity of the patient population because only a few patients underwent elective colorectal resection because of benign disease.

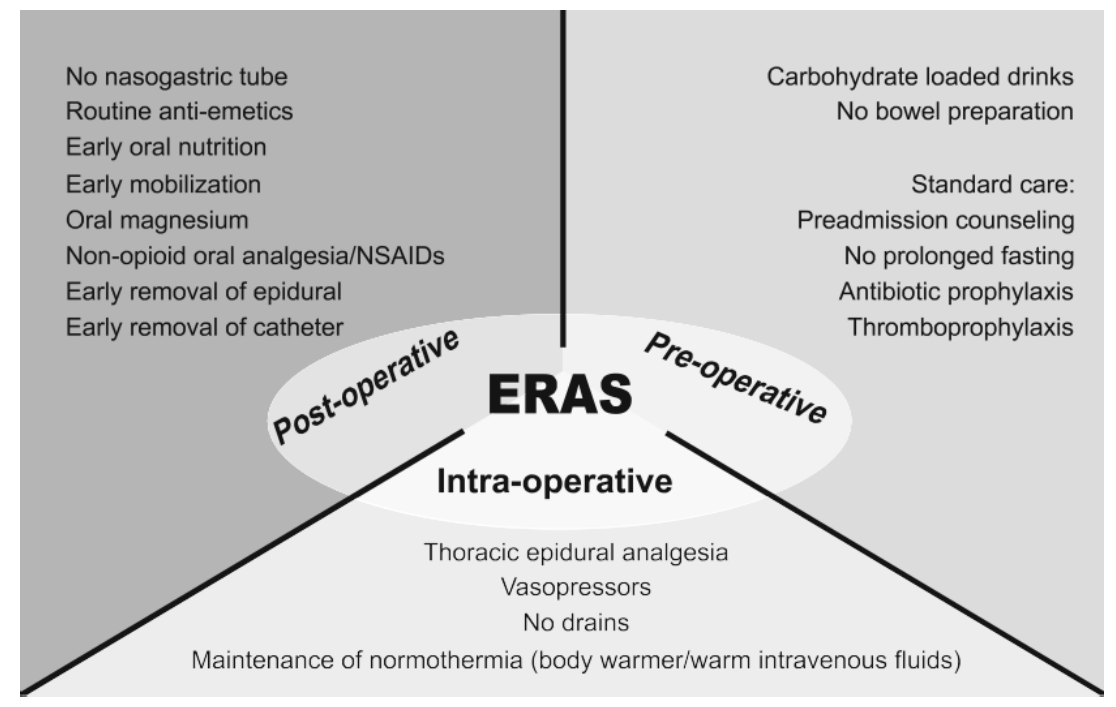

Figure 4.1 The ERAS protocol in the Medical Center of Alkmaar.

\section{Postoperative analgesia}

Patients routinely received epidural anesthesia and paracetamol. The data on the use of NSAIDs including the timing, duration, dose, and type of NSAID were extracted from the digital prescription system. According to our institutions protocol, NSAIDs were started on the second postoperative day and continued until oral analgesia could be reduced. We only recorded the use of NSAIDs during hospital stay. We defined a relevant dose of NSAIDs as a prescription of more than one consecutive day. For breakthrough pain, opioids were used. Between 2006 and 2009, ibuprofen was prescribed for patients who were 70 years of age and younger and mebutan was prescribed for patients older than 70 years of age. This distinction was made because elderly patients are at a higher risk of gastrointestinal side effects and based on working mechanism (preferential cyclo-oxygenase 2 inhibitor) mebutan is expected to cause less gastrointestinal side effects. Between 2010 and 2013, the protocol was changed and diclofenac was prescribed as NSAID for all patients. The dosage for each 
NSAID in our cohort was as follows: $400-500 \mathrm{mg}$ ibuprofen two or three times a day, $500 \mathrm{mg}$ mebutan two times a day, and $50 \mathrm{mg}$ diclofenac three times a day. The decision to prescribe NSAIDs was standardized according to the ERAS protocol. The anesthesiologist is responsible for postoperative pain management and can decide not to use NSAIDs in case of (relative) contraindications for NSAIDs based on a patient's medical history, comorbidity, and age.

\section{Patient characteristics}

The following patient characteristics were registered for this study: age, sex, BMI, ASA score, cardiac comorbidity, pulmonary comorbidity, hypertension, diabetes, steroid use, smoking, tumor stage, and neoadjuvant therapy. Steroid use was defined as prednisone use of $\geq 2.5 \mathrm{mg}$ per day within the first postoperative week.

\section{Perioperative characteristics}

All operations were performed by, or under the supervision of experienced colorectal surgeons. Laparoscopic resections were only performed by trained and experienced surgeons. During each procedure, the surgeon made sure the anastomosis was made tension free and had an adequate blood flow. Because of the long cohort period, more than ten different surgeons were represented in our cohort. The following perioperative characteristics were registered for this study: bowel preparation, type of resection, laparoscopic or open resection, technique of anastomosis, operation duration, vasopressor use, blood loss, transfusions, extended resection, drains, and deviating ileostomy. Bowel preparation with an oral laxative solution was used for rectal resections with deviating ileostomy after radiotherapy. For other rectal resections, sigmoid resections and left-sided hemi-colectomies, bowel preparation was limited to bowel enemas. For all other colon resections, bowel preparation was avoided according to the ERAS protocol. The use of vasopressors was restricted to low doses of ephedrine and phenylephrine during the surgical procedure to prevent salt and water overload. Maintenance of normothermia was achieved with the use of temperature registration, warm intravenous fluids, and a warm blanket or Bair Hugger. Extended resections were defined as additional urological, gynaecological, or other general surgical procedures, an extended resection in case of a T4 tumor necessary for radical macroscopic resection, or a secondary anastomosis. 


\section{Postoperative complications}

The following postoperative complications were registered for this study: anastomotic leakage, surgical site infection, fascial dehiscence, ileus, pneumonia, urinary tract infection, and in- hospital mortality. AL was defined as a combination of clinical signs (pain, fever, tachycardia, peritonitis, feculent, or purulent drainage) and/or radiographic signs (free abdominal fluid or gas collections on CT scan) confirmed during re-operation. We included abscess formation in the quadrant of the anastomosis requiring drainage as $\mathrm{AL}$. We did not have a time limit for the diagnosis of $A L$ because in rectal resections with deviating ileostomy clinical symptoms can take a long time to develop.

\section{Statistical analysis}

Patient and surgery characteristics were described as numbers with percentages in case of nominal variables and means with standard deviations in case of continuous variables. Groups were compared using a chi-squared test combined with a Z-test for column proportions in case of nominal variables and compared with a one-way ANOVA in case of continuous variables.

Logistic regression analysis was used to determine the independent association of all patient characteristics (Table 4.1), all perioperative characteristics (Table 4.2), and the use of NSAIDs with the risk of AL.

The variables with a significant association with anastomotic leakage in univariate analysis were entered into multivariate regression analysis. A p-value less than 0.05 was considered statistically significant in all analyses. The statistical analyses were performed using the Statistical Package for the Social Sciences (SPSS) version 20.0 (SPSS, IBM).

\section{Results}

A total of 856 patients were included in this study. Between 2006 and 2013, there were 732 patients with colon cancer who met the inclusion criteria. In this group, 282 patients $(38.5 \%)$ received no NSAIDs, 288 patients $(39.3 \%)$ received diclofenac, 93 patients $(12.7 \%)$ received mebutan, and 69 patients $(9.4 \%)$ received ibuprofen.

Between 2010 and 2013, 124 patients with rectal cancer met the inclusion criteria. In the rectum group, 40 patients (32\%) received no NSAIDs and 84 patients (68\%) received diclofenac. 
Baseline characteristics are shown in Table 4.1. The patients in the colon group receiving no NSAIDs were older, had a higher ASA score, more often had cardiac comorbidity, pulmonary comorbidity or diabetes, and more often used prednisone compared to patients receiving diclofenac or ibuprofen. For rectal cancer patients, baseline characteristics showed no differences between the group receiving no NSAIDs and the diclofenac group.

Table 4.1 Baseline characteristics

\begin{tabular}{|c|c|c|c|c|c|c|c|c|}
\hline \multicolumn{2}{|l|}{$\begin{array}{l}\text { Colon } \\
\text { No NSAIDs } \\
(n=282)\end{array}$} & \multirow{2}{*}{$\begin{array}{c}\begin{array}{c}\text { Colon } \\
\text { Diclofenac } \\
(n=288)\end{array} \\
67.8 \pm 10.4^{\mathrm{b}}\end{array}$} & \multirow{2}{*}{$\begin{array}{c}\text { Colon } \\
\text { Mebutan } \\
(n=93)\end{array}$} & \multirow{2}{*}{$\begin{array}{c}\begin{array}{c}\text { Colon } \\
\text { Ibuprofen } \\
(n=69)\end{array} \\
61.4 \pm 11.7^{c}\end{array}$} & \multirow{2}{*}{$\begin{array}{c}\begin{array}{c}P- \\
\text { value }\end{array} \\
0.000\end{array}$} & \multirow{2}{*}{$\begin{array}{c}\text { Rectum } \\
\text { No NSAIDs } \\
(n=40)\end{array}$} & \multirow{2}{*}{$\begin{array}{c}\begin{array}{c}\text { Rectum } \\
\text { Diclofenac } \\
(n=84)\end{array} \\
63.0 \pm 9.4\end{array}$} & \multirow{2}{*}{$\begin{array}{c}\begin{array}{c}P- \\
\text { value }\end{array} \\
0.089\end{array}$} \\
\hline Age & $74.7 \pm 10.6^{\mathrm{a}}$ & & & & & & & \\
\hline Male sex & $146(51.8)$ & $151(52.4)$ & $51(54.8)$ & 34 (49.3) & 0.914 & $19(47.5)$ & 49 (58.3) & 0.257 \\
\hline BMI & $25.5 \pm 4.2$ & $25.7 \pm 4.1$ & $25.5 \pm 4.3$ & $25.4 \pm 3.8$ & 0.962 & $26.0 \pm 3.9$ & $26.1 \pm 3.7$ & 0.945 \\
\hline ASA 1 & $38(13.5)^{a}$ & $99(34.4)^{b}$ & $14(15.1)^{a}$ & $29(42)^{b}$ & 0.000 & $17(42.5)$ & 35 (41.7) & 0.992 \\
\hline ASA 2 & $184(65.2)^{\mathrm{ab}}$ & $165(57.3)^{b}$ & $66(71)^{a}$ & $39(56.5)^{\mathrm{ab}}$ & & $21(52.5)$ & $44(52.4)$ & \\
\hline ASA 3 & $56(19.9)^{a}$ & $24(8.3) \mathrm{b}$ & $13(14.0)^{\mathrm{ab}}$ & $1(1.4)^{c}$ & & $2(5)$ & $5(6.0)$ & \\
\hline \multicolumn{9}{|l|}{ Comorbidity } \\
\hline Cardiac & $116(41.1)^{\mathrm{a}}$ & $77(26.7)^{b}$ & $25(26.9)^{b}$ & $12(17.4)^{b}$ & 0.000 & $10(25)$ & $12(14.3)$ & 0.144 \\
\hline Pulmonary & $45(16.0)^{a}$ & $26(9.0)^{b}$ & $7(7.5)^{b}$ & $3(4.3)^{b}$ & 0.006 & 5 (12.5) & 10 (11.9) & 0.924 \\
\hline Hypertension & $105(37.2)^{\mathrm{a}}$ & $95(33.0)^{\mathrm{a}}$ & $24(25.8)^{\mathrm{bc}}$ & $12(17.4)^{c}$ & 0.007 & $16(40)$ & $21(25.0)$ & 0.088 \\
\hline Diabetes & $49(17.4)^{a}$ & $21(7.3)^{b}$ & $10(10.8)^{\mathrm{ab}}$ & $3(4.3)^{\mathrm{b}}$ & 0.000 & 5 (12.5) & $4(4.8)$ & 0.121 \\
\hline $\begin{array}{l}\text { Hemoglobin } \\
\text { level (mmol/l) }\end{array}$ & $7.39 \pm 1.13^{\mathrm{a}}$ & $7.58 \pm 1.21^{\mathrm{ab}}$ & $7.38 \pm 1.18^{a}$ & $7.87 \pm 1.32^{b}$ & 0.010 & $8.23 \pm 0.71$ & $8.44 \pm 0.84$ & 0.194 \\
\hline Prednisone & $13(4.8)^{a}$ & $1(0.4)^{b}$ & $0(0)^{b}$ & $0(0)^{b}$ & 0.000 & $1(2.5)$ & $1(1.2)$ & 0.539 \\
\hline Smoking & $28(10.1)^{a}$ & $31(10.8)^{a}$ & $11(12.8)^{\mathrm{ab}}$ & $15(22.4)^{b}$ & 0.203 & $6(15)$ & $12(14.3)$ & 0.343 \\
\hline Former smoker & $16(5.8)$ & $17(5.9)$ & $4(4.7)$ & $4(6.0)$ & & $1(2.5$ & $0(0)$ & \\
\hline Stage 1 & $47(16.8)$ & $41(14.7)$ & $14(15.1)$ & $15(22.4)$ & 0.841 & $19(47.5)^{a}$ & $24(28.6)^{b}$ & 0.055 \\
\hline Stage 2 & $129(46.1)$ & $124(44.4)$ & $44(47.3)$ & $24(37.3)$ & & $13(32.5)$ & $18(21.4)$ & \\
\hline Stage 3 & $72(25.7)$ & 87 (31.2) & $28(30.1)$ & $20(30.3)$ & & $5(12.5)^{a}$ & $26(31.0)^{b}$ & \\
\hline Stage 4 & $29(10.4)$ & $26(9.3)$ & $7(7.5)$ & $6(9.1)$ & & $1(2.5)$ & $8(9.5)$ & \\
\hline \multicolumn{2}{|l|}{ Remission } & & & & & $2(5)$ & $6(7.1)$ & \\
\hline \multicolumn{2}{|c|}{$\begin{array}{l}\text { No neoadjuvant } 282(100) \\
\text { therapy }\end{array}$} & $288(100)$ & $93(100)$ & 69 (100) & & $3(7.5)$ & $3(3.6)$ & 0.081 \\
\hline \multicolumn{2}{|l|}{ Radiotherapy } & & & & & 31 (77.5) & $53(63.1)$ & \\
\hline \multicolumn{2}{|l|}{ Chemoradiation } & & & & & $6(15)^{\mathrm{a}}$ & $28(33.3)^{b}$ & \\
\hline
\end{tabular}

Each superscript letter denotes a subset of NSAID categories whose column proportions do not differ significantly from each other at the 0.05 level. Values in parentheses are percentages except for age, BMI, preoperative hemoglobin (mean \pm SD)

Operation characteristics are shown in Table 4.2. Patients in the colon group receiving no NSAIDs more often had an open resection, more often had a hand-sewn anastomosis and had more peroperative blood loss compared to patients receiving diclofenac. In the rectum group, patients receiving no NSAIDs more often had an open 
resection and less often had a deviating ileostomy compared to patients receiving diclofenac.

Table 4.2 Perioperative characteristics.

\begin{tabular}{|c|c|c|c|c|c|c|c|c|}
\hline & $\begin{array}{c}\text { Colon } \\
\text { No NSAIDs } \\
(n=282)\end{array}$ & $\begin{array}{c}\text { Colon } \\
\text { Diclofenac } \\
(n=288)\end{array}$ & $\begin{array}{c}\text { Colon } \\
\text { Mebutan } \\
(n=93)\end{array}$ & $\begin{array}{c}\text { Colon } \\
\text { Ibuprofen } \\
(n=69)\end{array}$ & $\begin{array}{c}P- \\
\text { value }\end{array}$ & $\begin{array}{c}\text { Rectum } \\
\text { No NSAIDs } \\
(n=40)\end{array}$ & $\begin{array}{c}\text { Rectum } \\
\text { Diclofenac } \\
(n=84)\end{array}$ & $\begin{array}{c}P \text { - } \\
\text { value }\end{array}$ \\
\hline $\begin{array}{l}\text { Bowel preparation } \\
\text { (oral) }\end{array}$ & $11(3.9)$ & $8(2.8)$ & $3(3.2)$ & $4(5.8)$ & 0.688 & $37(92.5)$ & $82(97.6)$ & 0.176 \\
\hline Type of resection & & & & & & & & \\
\hline $\begin{array}{l}\text { Right } \\
\text { hemicolectomy }\end{array}$ & $148(52.5)^{\mathrm{a}}$ & $139(48.3)^{\mathrm{a}}$ & $32(34.4)^{b}$ & $22(31.9)^{b}$ & 0.005 & & & \\
\hline Left hemi/sigmoid & & $132(45.8)^{\mathrm{ab}}$ & $48(51.6)^{b}$ & $39(56.5)^{b}$ & & & & \\
\hline Other* & $108(38.3)^{a}$ & & $13(13.9)^{\mathrm{a}}$ & $8(11.6)^{\mathrm{ab}}$ & & & & \\
\hline $\begin{array}{l}\text { Low anterior } \\
\text { resection }\end{array}$ & $26(9.2)^{\mathrm{ab}}$ & $17(5.9)^{b}$ & & & & 40 (100) & $84(100)$ & 1.000 \\
\hline $\begin{array}{l}\text { Laparoscopic } \\
\text { resection }\end{array}$ & $80(28.4)^{a}$ & $108(37.5)^{\mathrm{b}}$ & $21(22.6)^{a}$ & $21(30.4)^{\mathrm{ab}}$ & 0.029 & $10(25)$ & $37(44.0)$ & 0.041 \\
\hline $\begin{array}{l}\text { Stapled } \\
\text { Anastomosis }\end{array}$ & $124(44.0)^{\mathrm{a}}$ & $155(54.0)^{b}$ & $30(32.6)^{\mathrm{a}}$ & $30(44.8)^{\mathrm{ab}}$ & 0.002 & $39(97.5)$ & $83(98.8)$ & 0.148 \\
\hline $\begin{array}{l}\text { Operation } \\
\text { duration (h) }\end{array}$ & $1.47 \pm 1.58$ & $1.46 \pm 1.55$ & $1.44 \pm 1.62$ & $1.59 \pm 1.60$ & 0.521 & $2.55 \pm 1.39$ & $2.52 \pm 1.35$ & 0.845 \\
\hline Vasopressors & $207(73.4)^{a}$ & $218(75.7)^{a}$ & $80(86)^{b}$ & $57(84.1)^{\mathrm{ab}}$ & 0.124 & $37(92.5)$ & $76(90.5)$ & 0.216 \\
\hline Blood loss & $280 \pm 366^{\mathrm{a}}$ & $200 \pm 266^{b}$ & $242 \pm 330^{\mathrm{ab}}$ & $231 \pm 276^{\mathrm{ab}}$ & 0.031 & $338 \pm 370$ & $355 \pm 385$ & 0.822 \\
\hline Packed cells & $14(5.0)^{\mathrm{a}}$ & $5(1.7)^{b}$ & $4(4.3)^{\mathrm{ab}}$ & $0(0)^{\mathrm{ab}}$ & 0.055 & $2(5)$ & $3(3.6)$ & 0.705 \\
\hline $\begin{array}{l}\text { Extended } \\
\text { resection }\end{array}$ & $38(13.5)$ & $28(9.8)$ & 12 (13.3) & $7(10.1)$ & 0.703 & $1(2.5)$ & $5(6.0)$ & 0.048 \\
\hline Drains & $37(13.2)$ & $28(9.7)$ & $14(15.2)$ & $5(7.2)$ & 0.247 & $26(65)$ & $44(52.4)$ & 0.185 \\
\hline $\begin{array}{l}\text { Deviating } \\
\text { ileostomy }\end{array}$ & & & & & & $34(85)$ & $77(91.7)$ & 0.026 \\
\hline
\end{tabular}

Each superscript letter denotes a subset of NSAID categories whose column proportions do not differ significantly from each other at the 0.05 level. Values in parentheses are percentages except for operation duration and blood loss (geometric mean \pm SD). * Other: ileocecal resection, subtotal colectomy, segment resection, low anterior resection

Postoperative outcome is shown in Table 4.3 and Figure 4.2. There were two patients in the colon group receiving diclofenac who had an AL before the drug was started. These patients were analyzed in the no NSAIDs group. Overall, patients receiving NSAIDs had a higher AL rate compared to patients receiving no NSAIDs (9.2 vs. 5.3\%, $P=0.038)$. In the colon group, there was a significantly higher AL rate in the diclofenac group (11.8\%) compared to the control group receiving no NSAIDs $(6.0 \%)$, the mebutan group (1.1\%), and the ibuprofen group (4.3\%) $P=0.002$. In the rectum group, there were no patients with $A L$ in the no NSAIDs group and 11 patients $(13.1 \%)$ with $A L$ in the diclofenac group $(P=0.017)$. There was higher in-hospital mortality in the colon group 
receiving no NSAIDs compared to patients receiving diclofenac or ibuprofen, but there were no differences in AL-related mortality.

Table 4.3 Postoperative outcome.

\begin{tabular}{|c|c|c|c|c|c|c|c|c|}
\hline & $\begin{array}{c}\text { Colon } \\
\text { No NSAIDs } \\
(n=282)\end{array}$ & $\begin{array}{c}\text { Colon } \\
\text { Diclofenac } \\
(n=288)\end{array}$ & $\begin{array}{c}\text { Colon } \\
\text { Mebutan } \\
(n=93)\end{array}$ & $\begin{array}{c}\text { Colon } \\
\text { Ibuprofen } \\
(n=69)\end{array}$ & $\begin{array}{c}P- \\
\text { Value }\end{array}$ & $\begin{array}{c}\text { Rectum } \\
\text { No NSAIDs } \\
(n=40)\end{array}$ & $\begin{array}{c}\text { Rectum } \\
\text { Diclofenac } \\
(n=84)\end{array}$ & $\begin{array}{c}P- \\
\text { value }\end{array}$ \\
\hline $\begin{array}{l}\text { Anastomotic } \\
\text { leakage }\end{array}$ & $17(6.0)^{\mathrm{a}}$ & $34(11.8)^{b}$ & $1(1.1)^{\mathrm{a}}$ & $3(4.3)^{\mathrm{ab}}$ & 0.002 & $0(0)$ & $11(13.1)$ & 0.017 \\
\hline $\begin{array}{l}\text { Surgical site } \\
\text { infection }\end{array}$ & $21(7.4)^{a}$ & $22(7.6)^{\mathrm{a}}$ & $1(1.1)^{b}$ & $3(4.3)^{\mathrm{ab}}$ & 0.106 & $4(10)$ & $1(1.2)$ & 0.037 \\
\hline $\begin{array}{l}\text { Fascial } \\
\text { dehiscence }\end{array}$ & $5(1.8)$ & $8(2.8)$ & $2(2.2)$ & $0(0)$ & 0.509 & $0(0)$ & $0(0)$ & 1.000 \\
\hline Ileus & $44(15.6)^{a}$ & $27(9.4)^{b}$ & $8(8.6)^{\mathrm{ab}}$ & $7(10.1)^{a b}$ & 0.126 & $13(32.5)$ & $24(28.6)$ & 0.655 \\
\hline Pneumonia & $32(11.3)$ & $22(7.6)$ & $5(5.4)$ & $4(5.8)$ & 0.175 & $2(5)$ & $6(7.1)$ & 1.000 \\
\hline $\begin{array}{l}\text { Urinary tract } \\
\text { infection }\end{array}$ & $17(6.0)$ & $8(2.8)$ & $4(4.3)$ & $0(0)$ & 0.069 & $10(25)$ & 9 (10.7) & 0.039 \\
\hline $\begin{array}{l}\text { In hospital } \\
\text { mortality }\end{array}$ & $19(6.8)^{a}$ & $9(3.1)^{b}$ & $3(3.2)^{\mathrm{ab}}$ & $0(0)^{b}$ & 0.036 & $0(0)$ & $1(1.2)$ & 0.488 \\
\hline $\begin{array}{l}\text { AL related } \\
\text { mortality }\end{array}$ & $5(1.8)$ & $6(2.1)$ & $0(0)$ & $0(0)$ & 0.354 & $0(0)$ & $1(1.2)$ & 0.488 \\
\hline Length of stay & $7.6 \pm 2.1^{a}$ & $5.6 \pm 2.2^{\mathrm{b}}$ & $6.0 \pm 1.9^{b}$ & $5.4 \pm 2.0^{b}$ & 0.000 & $9.9 \pm 1.7$ & $9.4 \pm 2.1$ & 0.704 \\
\hline Re-admissions & $23(8.2)$ & $28(9.7)$ & $7(7.5)$ & $4(5.8)$ & 0.715 & $8(20)$ & 14 (16.7) & 0.650 \\
\hline
\end{tabular}

Each superscript letter denotes a subset of NSAID categories whose column proportions do not differ significantly from each other at the 0.05 level

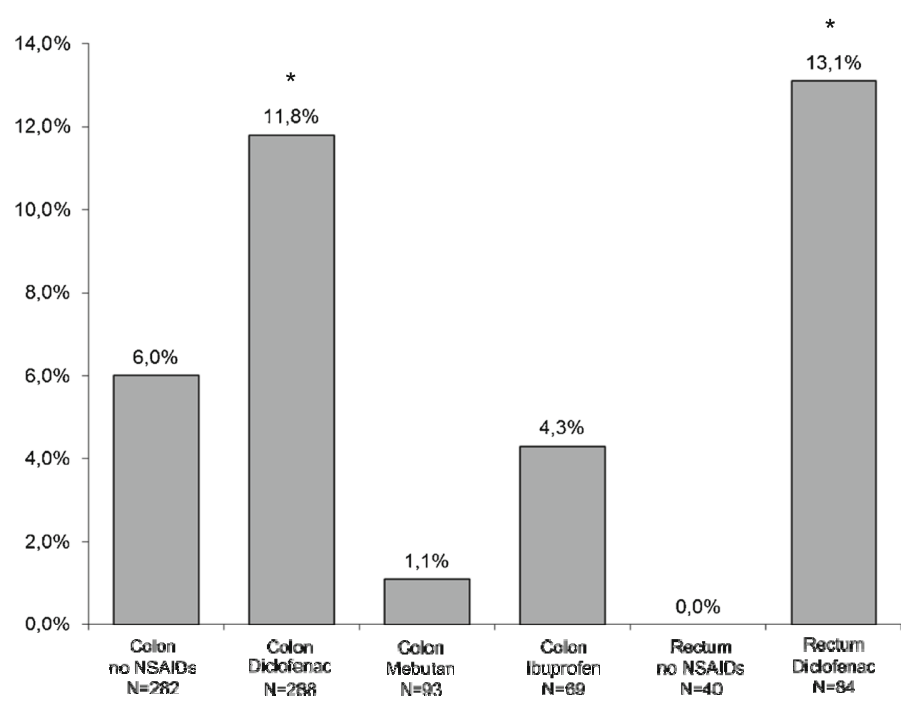

Figure 4.2 Anastomotic leakage rate (colon diclofenac vs. colon no NSAIDs, mebutan and ibuprofen, $P<0.01$; rectum diclofenac vs. no NSAIDs, $P=0.017)$. 
Outcome after AL is shown in Table 4.4. There was a high incidence of a permanent colostomy ( $40 \%$ for colonic resections and $91 \%$ for rectal resections) and a high incidence of anastomotic related mortality (20\% for colonic resections and $10 \%$ for rectal resections).

Table 4.4 Outcome after anastomotic leakage.

\begin{tabular}{lcc}
\hline & Colon & Rectum \\
& $n=55$ & $n=11$ \\
\hline Length of stay (days) & $19 \pm 2.2$ & $27 \pm 1.9$ \\
Re-anastomosis & $17(31)$ & \\
Drainage* & $2(3.6)$ & $10(91)$ \\
Permanent stoma & $22(40)$ & \\
AL after re-anastomosis & $3(5.5)$ & $1(9)$ \\
AL-related mortality & $11(20)$ & \\
\hline
\end{tabular}

* Decoupling of the anastomosis was avoided by draining the abscess near the anastomosis.

The results of the univariate and multivariate regression analyses are shown in Table 4.5. For rectal resections, multivariate regression analysis to determine independent risk factors was not possible because of absence of $A L$ in the no NSAIDs group. Therefore, we decided to analyze the colon and rectum group together to identify independent risk factors for $\mathrm{AL}$. Only diclofenac $(\mathrm{OR}=2.45)$ and male sex $(\mathrm{OR}=2.20)$ were independent predictors for AL.

Table 4.5

\begin{tabular}{lccccc}
\hline \multicolumn{2}{c}{ Univariate regression analysis } & \multicolumn{5}{c}{ Multivariate regression analysis } \\
Predictive factor & Odds ratio $(95 \% \mathrm{Cl})$ & $p$ & Predictive factor & Odds ratio $(95 \% \mathrm{Cl})$ & $p$ \\
\hline NSAIDs & $1.81(1.03-3.21)$ & 0.041 & & & \\
Diclofenac & $2.47(1.38-4.41)$ & 0.003 & Diclofenac & $2.45(1.37-4.38)$ & 0.003 \\
Mebutan & $0.20(0.03-1.49)$ & 0.115 & & & \\
Ibuprofen & $0.82(0.23-2.86)$ & 0.768 & & & \\
Male sex & $2.20(1.28-3.78)$ & 0.004 & Male sex & $2.20(1.27-3.81)$ & 0.005 \\
\hline
\end{tabular}

All baseline and perioperative characteristics shown in Tables 4.1 and 4.2 were entered into univariate regression analysis. Only factors that were independently associated with anastomotic leakage in univariate analysis were entered into multivariate regression analysis.

AL was diagnosed after a median of 6 days (range 1-25 days) in colonic resections and after a median of 10 days (range 5-79 days) in rectal resections. There was no significant relationship between the moment of starting diclofenac and the $A L$ rate: starting day 0 or $1(12.9 \%, n=224)$, day 2 or $3(10.5 \%, n=114)$ or on day 4 or later $(10.7 \%$ $\mathrm{n}=28$ ), $P=0.792$. There was also no significant relationship between the duration of 
diclofenac administration within the first five postoperative days (six including operation day) and AL rate: $1-3$ days $8.7 \%(n=126), 4-6$ days $13.8 \%,(n=240), P=0.161$.

\section{Discussion}

\section{Main findings}

In this large cohort of patients with elective colon and rectum cancer surgery, a significantly higher AL rate was found after postoperative treatment with diclofenac. Diclofenac was an independent risk factor after correction for other risk factors. The only other independent risk factor for AL was male sex. The other NSAIDs that were used in our cohort, mebutan and ibuprofen, did not increase the risk for AL. Remarkably, despite significantly more comorbidity and peroperative blood loss, the no NSAIDs group had a lower AL rate. This finding indicates the significance of the negative effect of diclofenac on anastomotic healing.

\section{Comparison with other studies}

Our results are in line with other studies reporting on increased $A L$ rate in patients treated with diclofenac or COX-2 selective NSAIDs. ${ }^{411,15}$ The AL rate in our patients receiving diclofenac was twice as high as in the control group. This difference was similar to the difference found in the study of Klein et al.. ${ }^{4}$ We noticed that the percentage of patients not receiving NSAIDs according to the ERAS protocol was particularly high, not only in our study $(37 \%)$ but also in comparable studies by Klein et al. ${ }^{4}(68 \%)$ and Gorissen et al. ${ }^{12}$ (59\%). Reasons for these protocol deviations were not documented, but they are probably explained by contraindications for the use of NSAIDS based on medical history like ischemic heart disease and decreased glomerular filtration rate. In our study, the patients receiving no NSAIDs had a higher ASA score and more cardiac comorbidity. Renal failure is a contraindication for NSAIDs and therefore likely to be more prevalent in the no NSAIDs group. However, kidney function unfortunately was not determined routinely in the perioperative phase.

\section{Possible explanations}

The mechanism by which NSAIDs may affect anastomotic healing remains unclear. However, in vitro and experimental studies have found that NSAIDs do influence leukocyte accumulation, angiogenesis, and epithelial proliferation in, which are all essential steps in wound healing and therefore may affect anastomotic healing. ${ }^{14}$ 
Another mechanism by which NSAIDs may affect anastomotic healing is by reducing anastomotic connective tissue strength. AL was significantly associated with NSAIDs in animal studies showing lower bursting pressures but not breaking strength in the NSAID group at day $7 .^{13}$ Another possible mechanism that may be involved is the cyclooxygenase-2 (COX-2) inhibition of prostaglandin expression, which contributes to local vasoconstriction and platelet aggregation. ${ }^{16}$ The resulting microthrombosis or microemboli may disturb the fragile blood supply in new anastomoses and thereby predispose to AL. The increased risk of thrombotic cardiovascular events seen in patients with long term use of selective NSAIDs supports this theory. ${ }^{17-19}$ In a study by Garcia Rodriguez et al., cardiovascular risk also showed a significant relation with treatment duration, treatment dose, and the degree of in vitro COX-2 inhibition. ${ }^{20}$ This may also explain the higher anastomotic leakage rate seen with diclofenac compared to ibuprofen and mebutan, as diclofenac has a much higher COX-2 selectivity. In a recent report by Kotagal et al. ${ }^{21}$ the preferential COX-1 inhibitor ketorolac was also associated with $A L$, which indicates that COX-2 inhibition is not the only mechanism involved.

\section{Strengths and limitations}

The main limitation of this study is its nonrandomized design. Another limitation is that information on the actual consumption of the NSAIDs by the patients was not registered. However, the registration of the exposure (NSAID prescription) and the outcome (anastomotic leakage) were registered electronically and are therefore both reliable and complete. The way in which the exposed patients differ from the nonexposed patients even strengthens the results. Another strength is that as a result of the inclusion criteria, a rather homogeneous study population was analyzed and overall, the data were more than $96 \%$ complete. As explained before, ${ }^{4}$ a well- powered randomized controlled trial would require thousands of patients, and considering the currently available evidence, we question whether such a trial would be ethically justified and if patients would give their consent.

\section{Conclusion}

In conclusion, this study contributes to the existing evidence that in colorectal cancer surgery, administration of NSAIDs in the postoperative setting in general constitutes a risk factor for AL. The use of diclofenac in particular was associated with AL in both colon and rectal cancer surgery. We therefore conclude that it is best to avoid diclofenac in the postoperative phase after colorectal resection with primary anastomosis. 


\section{References}

1. Bakker IS, Grossmann I, Henneman D, Havenga K, Wiggers T. Risk factors for anastomotic leakage and leak-related mortality after colonic cancer surgery in a nationwide audit. Br J Surg 2014;101:424-32.

2. Pommergaard HC, Gessler B, Burcharth J, Angenete E, Haglind E, Rosenberg J. Preoperative risk factors for anastomotic leakage after resection for colorectal cancer: a systematic review and meta-analysis. Colorectal Dis 2014;16(9):662-71.

3. Kube R, Mroczkowski P, Granowski D, Benedix F, Sahm M, Schmidt U et al. Anastomotic leakage after colon cancer surgery: a predictor of significant morbidity and hospital mortality, and diminished tumour-free survival. Eur J Surg Oncol 2010;36:120-4.

4. Klein M, Gogenur I, Rosenberg J. Postoperative use of non- steroidal anti-inflammatory drugs in patients with anastomotic leakage requiring reoperation after colorectal resection: cohort study based on prospective data. BMJ 2012;345:e6166.

5. Mirnezami A, Mirnezami R, Chandrakumaran K, Sasapu K, Sagar P, Finan P. Increased local recurrence and reduced survival from colorectal cancer following anastomotic leak: systematic review and metaanalysis. Ann Surg 2011;253:890-9.

6. Boccola MA, Buettner PG, Rozen WM, Siu SK, Stevenson AR, Stitz R et al. Risk factors and outcomes for anastomotic leakage in colorectal surgery: a single-institution analysis of 1576 patients. World J Surg 2011;35:186-95.

7. McDermott FD, Heeney A, Kelly ME, Steele RJ, Carlson GL, Winter DC. Systematic review of preoperative, intraoperative and postoperative risk factors for colorectal anastomotic leaks. Br J Surg 2015;102:462-79.

8. Sultan R, Chawla T, Zaidi M. Factors affecting anastomotic leak after colorectal anastomosis in patients without protective stoma in tertiary care hospital. J Pak Med Assoc 2014;64:166-70.

9. Varadhan KK, Lobo DN, Ljungqvist $O$. Enhanced recovery after surgery: the future of improving surgical care. Crit Care Clin 2010;26:527-47.

10. Varadhan KK, Neal KR, Dejong CH, Fearon KC, Ljungqvist O, Lobo DN. The enhanced recovery after surgery (ERAS) pathway for patients undergoing major elective open colorectal surgery: a meta-analysis of randomized controlled trials. Clin Nutr 2010;29:434-40.

11. Holte K, Andersen J, Jakobsen DH, Kehlet H. Cyclo-oxygenase 2 inhibitors and the risk of anastomotic leakage after fast-track colonic surgery. Br J Surg 2009;96:650-4.

12. Gorissen KJ, Benning D, Berghmans T, Snoeijs MG, Sosef MN, Hulsewe KW et al. Risk of anastomotic leakage with non-steroidal anti-inflammatory drugs in colorectal surgery. Br J Surg 2012;99:721-7.

13. Bhangu A, Singh P, Fitzgerald JE, Slesser A, Tekkis P. Postoperative nonsteroidal anti-inflammatory drugs and risk of anastomotic leak: Meta-analysis of clinical and experimental studies. World J Surg 2014;38(9):2247-57.

14. Rushfeldt CF, Sveinbjornsson B, Soreide K, Vonen B. Risk of anastomotic leakage with use of NSAIDs after gastrointestinal surgery. Int J Colorectal Dis 2011;26:1501-9.

15. Klein M, Andersen LP, Harvald T, Rosenberg J, Gogenur I. Increased risk of anastomotic leakage with diclofenac treatment after laparoscopic colorectal surgery. Dig. Surg 2009;26:27-30.

16. Antman EM, Bennett JS, Daugherty A, Furberg C, Roberts H, Taubert KA. Use of nonsteroidal antiinflammatory drugs: an update for clinicians: a scientific statement from the American Heart Association. Circulation 2007;115:1634-42.

17. Dajani EZ, Islam K. Cardiovascular and gastrointestinal toxicity of selective cyclo-oxygenase-2 inhibitors in man. J Physiol Pharmacol 2008;59 Suppl 2:117-33.

18. Kearney PM, Baigent C, Godwin J, Halls H, Emberson JR, Patrono C. Do selective cyclo-oxygenase-2 inhibitors and traditional nonsteroidal anti-inflammatory drugs increase the risk of atherothrombosis? Meta-analysis of randomised trials. BMJ 2006;332:1302-8.

19. Trelle S, Reichenbach S, Wandel S, Hildebrand P, Tschannen B, Villiger PM et al. Cardiovascular safety of non-steroidal anti-inflammatory drugs: network meta-analysis. BMJ 2011;342:c7086. 
20. Garcia Rodriguez LA, Tacconelli S, Patrignani P. Role of dose potency in the prediction of risk of myocardial infarction associated with nonsteroidal anti-inflammatory drugs in the general population. J Am Coll Cardiol 2008;52:1628-36.

21. Kotagal M, Hakkarainen TW, Simianu VV, Beck SJ, Alfonso- Cristancho R, Flum DR. Ketorolac use and postoperative complications in gastrointestinal surgery. Ann Surg 2016;236(1):71-5. 


\section{Chapter 5}

The new Body Mass Index as a predictor of postoperative complications in elective colorectal

cancer surgery

J.L.A. van Vugt*, H. Cakir*, V.N.N. Kornmann, H.J. Doodeman, J.H.M.B. Stoot, D. Boerma, A.P.J. Houdijk, K. W.E. Hulsewé * Both authors contributed equally to this article Clin Nutr ESPEN 2016;11:e71 


\section{Abstract}

\section{Background and aims}

A new Body Mass Index (BMI) formula has been developed for a better approximation of under and overweight. The aim of this study was to investigate the predictive value of this newly proposed BMI formula for postoperative complications in elective colorectal cancer surgery compared with the conventional BMI formula.

\section{Methods}

A digital database of patients undergoing elective colorectal cancer surgery was prospectively maintained in three centers and retrospectively analyzed. Data consisted of patient characteristics, surgical procedure, length of hospital stay (LOS), postoperative complications, mortality, reoperation and readmission. The BMI was calculated using both the conventional and new BMI formula. Patients were divided into four groups (BMI $<20,20-25,25-30, \geq 30 \mathrm{~kg} / \mathrm{m}^{2}$ ).

\section{Results}

A total of 1614 patients were included. There was no significant difference in mean BMI between males and females using the conventional BMI formula (26.0 versus 26.2, $P=0.347$ ), whereas a trend was observed using the new BMI formula (26.3 versus 25.6, $P=0.071)$. The proportion of overweight (BMI $\geq 25$ ) male patients was significantly higher compared with the proportion of overweight female patients using the conventional formula $(58.9 \%$ versus $51.0 \%, P=0.021)$, whereas a non-significant difference was observed using the new formula (51.7\% versus $53.4 \%, P=0.515$ ). Neither the conventional nor the new BMI were associated with postoperative complications and LOS. Higher age, higher ASA classification, male gender, and conventional surgery were independent predictors of the occurrence of postoperative complications. A longer LOS was also independently predicted by higher age, higher ASA classification and conventional surgery.

\section{Conclusions}

This study showed no superiority of the new BMI formula in predicting postoperative complications after colorectal cancer surgery. Confirmation of the results in a larger cohort is desirable. 


\section{Introduction}

Obesity represents an important and increasing health problem, especially in the western world, and its incidence is rising. ${ }^{1,2}$ Excess body weight is a risk factor for diseases such as colorectal cancer. ${ }^{1}$ Moreover, obesity (particularly visceral obesity assessed by fat volumetric measurements) is associated with postoperative complications, prolonged LOS and higher conversion rates in colorectal surgery. ${ }^{1,3-6}$ The index most frequently used to categorize overweight and obesity is the Body Mass Index (BMI), developed by the Belgian scientist Adolphe Quetelet in the 1830s as a simple measure for classifying people's weight. The BMI is easily calculated as weight in kilograms divided by height in meters squared $\left(\mathrm{kg} / \mathrm{m}^{2}\right) .^{7}$ According to the World Health Organization (WHO), overweight is defined as a $\mathrm{BMI} \geq 25 \mathrm{~kg} / \mathrm{m}^{2}$ and obesity as a BMI $\geq 30 \mathrm{~kg} / \mathrm{m}^{2}$. This BMI formula currently used (conventional formula) has been challenged for some time, since it may overestimate fat accumulation in tall people and underestimate it in short people. ${ }^{8}$ Therefore, a new BMI formula has been developed recently. As height is given a larger impact in this new formula $\left(1.3 \times \text { weight/ height }{ }^{2,5 *}\right)^{5}$, it has been considered to approximate reality better. ${ }^{9}$ The aim of this study was to investigate whether this new BMI formula is a superior predictor of postoperative complications in colorectal cancer surgery compared to the conventional BMI formula.

* Incorrectly displayed in original article

\section{Materials and methods}

\section{Patients}

All patients who underwent colorectal cancer surgery in Orbis Medical Center (Sittard, the Netherlands) between January 2010 and May 2012, Alkmaar Medical Center (Alkmaar, the Netherlands) between January 2006 and January 2012, and St Antonius Hospital (Nieuwegein, the Netherlands) between January 2009 and April 2014 were enrolled in a prospectively maintained digital database (analogous to the Dutch Surgical Colorectal Audit ${ }^{10}$ ) and retrospectively analyzed. Data consisted of patient characteristics, surgical procedure and postoperative complications. Only patients who underwent elective surgery with documented height and weight were included. All patients were treated according to the Enhanced Recovery After Surgery (ERAS) program. ${ }^{11}$ Nutritional status was assessed during preoperative consultation using nutritional screening tools, i.e. the Short Nutritional Assessment Questionnaire (SNAQ) 
and Malnutrition Universal Screening Tool (MUST). ${ }^{12,13}$ If necessary, a dietician was consulted and preoperative additional feeding was started.

\section{Postoperative complications and recovery}

Complications (within 30 days postoperative or during (re) admission) included in the database consisted of mortality, anastomotic leakage, ileus or gastroparesis, pneumonia, surgical-site infection (SSI), urinary tract infection, fascia dehiscence, and pulmonary embolism. Furthermore, reoperation, readmission, length of hospital stay (LOS), and conversion were documented. Definitions of the outcome measures are provided in Table 5.1.

Table 5.1 Definitions of outcome measures.

\begin{tabular}{|c|c|}
\hline Outcome measures & Definition \\
\hline Mortality & $\begin{array}{l}\text { Death occurring during hospital stay, within } 30 \text { days postoperative or during } \\
\text { readmission within } 30 \text { days after initial discharge. }\end{array}$ \\
\hline Anastomotic leakage & $\begin{array}{l}\text { Anastomotic dehiscence visualized during reoperation or endoscopy, } \\
\text { percutaneous/transrectal drainage of purulent fluid/enteral contents from } \\
\text { around the anastomosis or detected with radiography in combination with } \\
\text { clinical signs (e.g. abdominal pain) or the systemic inflammatory response } \\
\text { syndrome (SIRS). }\end{array}$ \\
\hline Ileus or gastroparesis & $\begin{array}{l}\text { Nausea, vomiting and/or the absence of stool requiring (prolonged) placement } \\
\text { of a gastric tube and/or a central line for feeding. }\end{array}$ \\
\hline Pneumonia & $\begin{array}{l}\text { Clinical symptoms (e.g. cough, fever, dyspnea) or consolidation on chest } \\
\text { radiography requiring antibiotic treatment with or without a positive sputum } \\
\text { culture. }\end{array}$ \\
\hline Surgical-site infection & $\begin{array}{l}\text { Purulent drainage from the surgical wound with signs of local inflammation } \\
\text { (e.g. redness, pain, tenderness requiring opening or flushing of the surgical } \\
\text { wound and/or antibiotic treatment). }\end{array}$ \\
\hline Urinary tract infection & $\begin{array}{l}\text { Clinical symptoms (e.g. fever, polyuria, stranguria) requiring the need for } \\
\text { antibiotic treatment with or without a positive urine culture. }\end{array}$ \\
\hline Fascia dehiscence & Dehiscence of the fascia with or without the need for reoperation. \\
\hline Pulmonary embolism & Clinical symptoms (e.g. dyspnea, thoracic pain) with radiologic confirmation. \\
\hline Reoperation & $\begin{array}{l}\text { During hospital stay, within } 30 \text { days postoperative or during readmission within } \\
30 \text { days after initial discharge. }\end{array}$ \\
\hline $\begin{array}{l}\text { Readmission } \\
\text { Length of hospital stay }\end{array}$ & $\begin{array}{l}\text { Within } 30 \text { days after discharge for } 24 \mathrm{~h} \text {. Hospital stay after operation until } \\
\text { discharge in days. }\end{array}$ \\
\hline Conversion & $\begin{array}{l}\text { Any incision made earlier than planned in laparoscopic procedures, but not } \\
\text { extracorporeal vessel ligation, bowel resection-anastomosis or extra trocar } \\
\text { placement. }\end{array}$ \\
\hline
\end{tabular}




\section{Body Mass Index}

Height and weight of the included patients were measured during the preoperative screening consult on the outpatient departments of the three study centers according to local standards. The conventional BMI was calculated as weight in kilograms divided by height in meters squared $\left(\mathrm{kg} / \mathrm{m}^{2}\right)$, conventional formula) and as $1.3 \mathrm{x}$ weight/height ${ }^{2,5}$ (new formula). ${ }^{7,9}$ Both the conventional and new BMI were calculated for all patients. These two groups were divided into four subgroups using the same cutoff points (BMI <20, 20-25, 25-30, $\geq 30$ ), according to the WHO definitions of normal weight, overweight, and obesity. ${ }^{2}$

\section{Statistical analysis}

Statistical analyses were performed using the Statistical Package for the Social Sciences (SPSS) version 22 (SPSS, Chicago, IL, USA). ANOVA-analysis was used for the comparison of continuous variables. Dichotomous or categorical variables were compared using Chi-square analysis. A $P$-value $<0.05$ was considered as significant. Before statistical analysis, the LOS data were log transformed, because the distribution was not normal. For the univariate analysis, linear regression analysis or logistic regression analysis were used. A $P$-value $<0.05$ was considered significant. The variables with $P$-value $<0.05$ in the univariate analysis were entered into a multivariate linear or logistic regression analysis. Regression coefficients of significant predictive parameters are given with their $95 \%$ confidence intervals $(\mathrm{Cl})$.

\section{Results}

\section{Conventional versus new BMI formula}

A total of 1614 patients were included, 719 (44.5\%) females and 895 (55.5\%) males. The mean height was $1.65 \mathrm{~m}$ (range 1.36-1.90) for females and $1.77 \mathrm{~m}$ (range 1.502.02) for males. Using the conventional BMI formula (Table 5.2), the mean BMI was 26.0 (range 14.2-56.8, SD 5.00) for females and 26.2 (range 16.8-45.5, SD 3.8) for males $(P=0.347)$. According to the WHO definition of overweight $\left(\mathrm{BMI} \geq 25 \mathrm{~kg} / \mathrm{m}^{2}\right),{ }^{2} 367$ (51.0\%) females and 527 (58.9\%) males had overweight ( $P=0.002)$. Moreover, there was a significant difference in gender $(P<0.001)$ and ASA classification $(P<0.001)$ between the four subgroups. No significant differences were found in the other parameters. Using the new BMI formula (Table 5.3), the mean BMI was 26.3 (range 14.2-58.9, SD 5.2) for females and 25.6 (range 16.4-43.4, SD 3.7) for males ( $P=0.071$ ). In total, 384 
(53.4\%) females and $463(51.7 \%)$ males had overweight $\left(\mathrm{BMI} \geq 25 \mathrm{~kg} / \mathrm{m}^{2}\right)^{2}(P=0.515)$. As for the conventional $\mathrm{BMI}$ formula, there was a significant difference in gender $(P<0.001)$ and ASA classification $(P<0.001)$ between the four subgroups. Again, there were no significant differences found in the other parameters. Finally, the four different conventional and new BMI subgroups $(<20,20-25,25-30, \geq 30)$ were compared, which showed none of the outcomes to be significantly different.

Table 5.2 Outcomes using the conventional formula for the Body Mass Index.

\begin{tabular}{|c|c|c|c|c|c|}
\hline Conventional BMI formula & $\begin{array}{c}<20 \mathrm{~kg} / \mathrm{m}^{2} \\
(n=69,4.3 \%)\end{array}$ & $\begin{array}{c}20-25 \mathrm{~kg} / \mathrm{m}^{2} \\
(\mathrm{n}=651,40.3 \%)\end{array}$ & $\begin{array}{c}25-30 \mathrm{~kg} / \mathrm{m}^{2} \\
(\mathrm{n}=636,39.4 \%)\end{array}$ & $\begin{array}{c}\geq 30 \mathrm{~kg} / \mathrm{m}^{2} \\
(\mathrm{n}=258,16.0 \%)\end{array}$ & $P$-value \\
\hline Age (mean \pm SD) & $68.9 \pm 14$ & $69.4 \pm 11$ & $68.7 \pm 10$ & $67.7 \pm 10$ & 0.594 \\
\hline Gender Female (\%) & $46(66.7)$ & $306(47.0)$ & $231(36.3)$ & $136(152.7)$ & \\
\hline Male (\%) & $23(33.3)$ & 345 (53.0) & 405 (63.7) & $122(47.3)$ & $<0.001$ \\
\hline \multicolumn{6}{|l|}{ ASA classification ${ }^{\mathrm{b}}(\%)$} \\
\hline 1 & $8(13.8)$ & $113(22.6)$ & $87(16.7)$ & $19(8.8)$ & \\
\hline 2 & 33 (56.9) & $302(60.3)$ & $324(62.2)$ & $138(63.6)$ & \\
\hline 3 & $15(25.9)$ & $82(16.4)$ & $97(18.6)$ & $57(26.3)$ & \\
\hline 4 & $2(3.4)$ & $4(0.8)$ & $13(2.5)$ & $3(1.4)$ & $<0.001$ \\
\hline Laparoscopic surgery (\%) & $25(36.2)$ & $228(35.1)$ & 260 (40.9) & $98(38.0)$ & 0.188 \\
\hline Conversion $^{\mathrm{a}}(\%)$ & $2(8)$ & $17(7.5)$ & $26(10)$ & $6(6)$ & 0.614 \\
\hline Complications (\%) & $26(37.7)$ & 207 (31.8) & $200(31.4)$ & $92(35.7)$ & 0.478 \\
\hline Anastomotic leakage (\%) & $4(5.8)$ & $52(8.0)$ & $45(7.1)$ & $20(7.8)$ & 0.871 \\
\hline Pneumonia (\%) & $8(11.6)$ & $51(7.8)$ & $46(7.2)$ & $17(6.6)$ & 0.546 \\
\hline Surgical-site infection (\%) & $3(4.3)$ & $47(7.2)$ & $51(8.0)$ & $21(8.1)$ & 0.697 \\
\hline Urinary tract infection (\%) & $7(10.1)$ & $44(6.8)$ & $40(6.3)$ & $22(8.5)$ & 0.472 \\
\hline Ileus/gastroparesis (\%) & $14(20.3)$ & 109 (16.8) & $105(16.5)$ & $48(18.6)$ & 0.774 \\
\hline Pulmonary embolism ${ }^{c}(\%)$ & $0(0)$ & $4(0.9)$ & $2(0.5)$ & $3(1.5)$ & 0.502 \\
\hline Fascia dehiscence $^{\mathrm{d}}(\%)$ & $1(1.8)$ & $5(1.1)$ & $13(2.6)$ & $8(3.8)$ & 0.123 \\
\hline Readmission (\%) & $11(15.9)$ & $80(12.3)$ & $86(13.5)$ & $35(13.6)$ & 0.803 \\
\hline Reoperation (\%) & $12(17.4)$ & $102(15.7)$ & $99(55.6)$ & $35(13.6)$ & 0.818 \\
\hline Mortality (\%) & $2(2.9)$ & $22(3.4)$ & $11(1.7)$ & $7(2.7)$ & 0.321 \\
\hline LOS (geometric mean \pm SD) & $8.2 \pm 1.9$ & $8.2 \pm 2.0$ & $7.4 \pm 1.9$ & $7.4 \pm 2.0$ & 0.766 \\
\hline
\end{tabular}

BMI: Body Mass Index; LOS: length of hospital stay; SD: standard deviation. A $P$-value $<0.05$ is considered significant. Data available from: ${ }^{a} 611$ laparoscopic procedures; ${ }^{b} 1297$ patients; ${ }^{c} 1120$ patients; ${ }^{d} 1233$ patients.

\section{Correlation of complications and length of hospital stay}

The association between the parameters (separately for the conventional and new $\mathrm{BMI}$ ) and the occurrence of complications and LOS was assessed by univariate and multivariate analysis. Multivariate analysis of complications showed a significant correlation with higher age $(P=0.025)$, male gender $(P<0.001)$, higher ASA classification 
$(P=0.030)$ and conventional (open) surgery $(P<0.001)$ (Table 5.4). Higher age $(P=0.001)$, higher ASA classification $(P=0.012)$, and conventional (open) surgery $(P<0.001)$ were also independent predictors of a longer LOS (Table 5.5). Neither the new nor the conventional BMI did influence postoperative outcomes.

Table 5.3 Outcomes using the new formula for the Body Mass Index.

\begin{tabular}{|c|c|c|c|c|c|}
\hline New BMI formula & $\begin{array}{c}<20 \mathrm{~kg} / \mathrm{m}^{2} \\
(\mathrm{n}=70,4.3 \%)\end{array}$ & $\begin{array}{c}20-25 \mathrm{~kg} / \mathrm{m}^{2} \\
(\mathrm{n}=697,43.2 \%)\end{array}$ & $\begin{array}{c}25-30 \mathrm{~kg} / \mathrm{m}^{2} \\
(\mathrm{n}=602,37.3 \%)\end{array}$ & $\begin{array}{c}\geq 30 \mathrm{~kg} / \mathrm{m}^{2} \\
(n=245,15.2 \%)\end{array}$ & $P$-value \\
\hline Age (mean \pm SD) & $68.0 \pm 14$ & $68.3 \pm 11$ & $69.1 \pm 10$ & $68.4 \pm 11$ & 0.570 \\
\hline Gender Female (\%) & $38(54.3)$ & $297(42.6)$ & $237(39.4)$ & $147(60.0)$ & \\
\hline Male (\%) & $32(45.7)$ & $400(57.4)$ & $365(60.6)$ & $98(40)$ & $<0.001$ \\
\hline \multicolumn{6}{|l|}{ ASA classification ${ }^{\mathrm{b}}(\%)$} \\
\hline 1 & $9(15.8)$ & $126(23.6)$ & 77 (15.3) & $15(7.4)$ & \\
\hline 2 & 33 (57.9) & $322(60.2)$ & $312(62.2)$ & $130(64.0)$ & \\
\hline 3 & $13(22.8)$ & $84(15.7)$ & 100 (19.9) & $54(26.6)$ & \\
\hline 4 & $2(3.5)$ & $3(0.6)$ & $13(2.6)$ & $4(2.0)$ & $<0.001$ \\
\hline Laparoscopic surgery (\%) & $27(38.6)$ & 245 (35.2) & $251(41.8)$ & $88(35.9)$ & 0.094 \\
\hline Conversion $^{\mathrm{a}}(\%)$ & $2(7.4)$ & $16(6.5)$ & $26(10.4)$ & $7(8)$ & 0.488 \\
\hline Complications (\%) & $24(34.3)$ & $223(32.0)$ & $190(31.6)$ & 88 (35.9) & 0.631 \\
\hline Anastomotic leakage (\%) & $3(4.3)$ & $56(8.0)$ & $42(7.0)$ & $20(8.2)$ & 0.629 \\
\hline Pneumonia (\%) & $6(8.6)$ & $56(8.0)$ & $43(7.1)$ & $17(6.9)$ & 0.891 \\
\hline Surgical-site infection (\%) & $3(4.3)$ & 48 (6.9) & $49(8.1)$ & $22(9.0)$ & 0.474 \\
\hline Urinary tract infection (\%) & $7(10)$ & $45(6.5)$ & $42(7.0)$ & $19(7.8)$ & 0.685 \\
\hline Ileus/gastroparesis (\%) & $13(18.6)$ & $120(17.2)$ & $101(16.8)$ & $42(17.1)$ & 0.984 \\
\hline Pulmonary embolism ${ }^{c}(\%)$ & $0(0)$ & $4(0.9)$ & $1(0.2)$ & $4(2.1)$ & 0.099 \\
\hline Fascia dehiscence $^{d}(\%)$ & $1(1.9)$ & $5(1.0)$ & $14(2.9)$ & $7(3.5)$ & 0.103 \\
\hline Readmission (\%) & 9 (12.9) & $94(13.5)$ & $75(12.5)$ & $34(13.9)$ & 0.930 \\
\hline Reoperation (\%) & $11(15.7)$ & $110(15.8)$ & $91(15.1)$ & $36(14.7)$ & 0.974 \\
\hline Mortality (\%) & $2(2.9)$ & $21(3.0)$ & $12(2.0)$ & $7(2.9)$ & 0.700 \\
\hline LOS (geometric mean \pm SD) & $8.2 \pm 1.9$ & $8.2 \pm 2.0$ & $7.4 \pm 2.0$ & $7.4 \pm 2.0$ & 0.538 \\
\hline
\end{tabular}

BMI: Body Mass Index; LOS: length of hospital stay; SD: standard deviation. A $P$-value $<0.05$ is considered significant. Data available from: ${ }^{a} 611$ laparoscopic procedures; ${ }^{b} 1297$ patients; ${ }^{c} 1120$ patients; ${ }^{d} 1233$ patients.

Table 5.4 Univariate and multivariate logistic regression analysis on the occurrence of postoperative complications.

\begin{tabular}{lcccc}
\hline & Odds ratio $(95 \% \mathrm{Cl})$ & $P$-value & Adjusted odds ratio $(95 \% \mathrm{Cl})$ & $P$-value \\
\hline Age & $1.021(1.011-1.031)$ & $<0.001$ & $1.014(1.002-1.026)$ & 0.025 \\
Gender (male) & $1.379(1.116-1.704)$ & 0.003 & $1.573(1.234-2.006)$ & $<0.001$ \\
ASA classification & $1.349(1.132-1.608)$ & 0.001 & $1.239(1.020-1.505)$ & 0.030 \\
Conventional BMI & $1.015(0.991-1.039)$ & 0.231 & & \\
New BMI & $1.010(0.986-1.033)$ & 0.419 & & $<0.001$ \\
Laparoscopic surgery & $0.452(0.360-0.569)$ & $<0.001$ & $0.424(0.331-0.544)$ & $<$ \\
\hline
\end{tabular}

BMI: Body Mass Index; 95\% Cl: 95\% confidence interval. A $P$-value $<0.05$ is considered significant. 
Table 5.5 Univariate and multivariate linear regression analysis on length of hospital stay (log transformation).

\begin{tabular}{lcccc}
\hline & Univariate B $(95 \% \mathrm{Cl})$ & $P$-value & Multivariate B $(95 \% \mathrm{Cl})$ & $P$-value \\
\hline Age & $0.008(0.005-0.011)$ & $<0.001$ & $0.006(0.002-0.009)$ & 0.001 \\
Gender (male) & $0.031(-0.034-0.097)$ & 0.345 & & \\
ASA classification & $0.121(0.066-0.175)$ & $<0.001$ & $0.071(0.016-0.127)$ & 0.012 \\
Conventional BMI & $-0.002(-0.009-0.006)$ & 0.627 & & \\
New BMI & $-0.002(-0.009-0.005)$ & 0.574 & & $<0.001$ \\
Laparoscopic surgery & $-0.420(-0.483$ to -0.245$)$ & $<0.001$ & $-0.415(-0.484$ to -0.347$)$ & \\
\hline
\end{tabular}

BMI: Body Mass Index; 95\% Cl: 95\% confidence interval; B: regression coefficient. A $P$-value $<0.05$ is considered significant.

\section{Discussion}

The present study shows no superiority of the new BMI formula compared with the conventional BMI formula in predicting postoperative complications after elective colorectal cancer surgery. Nevertheless, a trend towards a significantly lower BMI for males compared with females $(P=0.071)$ was observed using the new BMI formula. Moreover, a significant difference in the proportion of overweight males compared with overweight females in the conventional group $(P=0.002)$ became non-significant using the new formula $(P=0.515)$ and a shift of overweight males to the normal weight range was observed. Simultaneously, the ratio between overweight and normal weight females remained similar. This can be explained by the fact that the mean height in men is greater compared to women. As expected, higher age and ASA classification were associated with an impaired postoperative outcome. Nevertheless, the interest in biological age instead of chronological age, frailty, and body composition as determinants for postoperative or functional outcome and survival has greatly increased during last years and those factors are frequently considered as more relevant predictors. ${ }^{14-16}$

A previous study among patients who underwent colectomy for cancer, showed that morbid obesity (BMI $\geq 35$ ) was associated with a higher prevalence of surgical-site infections, wound dehiscence, pulmonary embolism and renal failure. No relation with other complications or mortality was found. ${ }^{17}$ Costa and colleagues found that obesity (BMI $\geq 30$ ) was associated with a higher conversion rate and longer hospital stay in laparoscopic colectomies. ${ }^{5}$ In oncologic rectal surgery, obese patients do not have a significantly increased risk to develop postoperative complications compared with nonobese patients. ${ }^{3}$ The current study, including both colon and rectal surgery patients who underwent either conventional or laparoscopic surgery following the ERAS protocol, showed neither the conventional nor the new BMI to predict postoperative 
complications or LOS. This may be due to the relatively limited number of patients in the current cohort with excessive overweight. Unfortunately, the occurrence of wound dehiscence and renal failure was not available for analysis in the current study. Furthermore, no association between BMI and conversion rate in laparoscopic procedures was found. However, the definition of conversion used in literature greatly varies and no definition of conversion was provided in the study of Costa and colleagues. ${ }^{18}$ Moreover, adequate patient selection (e.g. based on tumor size or stage) and laparoscopic experience result in lower conversion rates. ${ }^{19}$ Therefore, adequate preoperative patient selection is of utmost importance and conversion should mostly be considered as a judicious decision instead of surgical failure.

Visceral obesity, as determined by fat volumetric measurements, predicts short-term outcomes better than BMI. ${ }^{4,6}$ Nevertheless, neither BMI nor visceral obesity is associated with survival or recurrence rates after resectable colorectal cancer. ${ }^{20}$ Unfortunately, there is no meta-analysis or systematic review assessing the short-term surgical outcomes for colorectal cancer surgery in obese patients yet. ${ }^{1}$ Moreover, a variety of overweight, obesity, and morbid obesity definitions and different cut-off values have been used in previous studies, leading to difficulties in comparing literature. To our best knowledge this is the first study exploring the use of the new $\mathrm{BMI}$ formula in a patient population. Although data of three centers representing different regions of the country were combined, it should be noted that the current patient cohort might have been too small. Moreover, only a limited number of complications was available for analysis. Accordingly lack of significances may be due to a type II error. Therefore, validation of the results in a large, uniform cohort is recommended.

The new BMI formula has been developed to more accurately estimate whether a person's weight is healthy. The current study suggests that the mean BMI for males is lower, whereas the mean BMI remains similar for females using the new formula. Future studies are needed to validate these results and to confirm the equal predictive value of the new formula for health risks and postoperative complications compared with the conventional formula and visceral obesity measurements. Moreover, in this large cohort of colorectal patients of three centers, no higher complication rate could be found for obese patients compared to nonobese patients. 


\section{References}

1. Bardou M, Barkun AN, Martel M. Obesity and colorectal cancer. Gut 2013;62:933-47.

2. Ogden CL, Carroll MD, Kit BK, Flegal KM. Prevalence of obesity and trends in body mass index among us children and adolescents, 1999-2010. JAMA 2012;307:483-90.

3. Mrak K, Eberl T, Fritz J, Tschmelitsch J. Influence of body mass index on postoperative complications after rectal resection for carcinoma. South Med J 2012;105:493-9.

4. Cecchini S, Cavazzini E, Marchesi F, Sarli L, Roncoroni L. Computed tomography volumetric fat parameters versus body mass index for predicting shortterm outcomes of colon surgery. World J Surg 2011;35:415-23.

5. Costa B, Queiroz F, Lamounier P, Lacerda Filho A, Paiva R, França P, et al. Body mass index as a predictor of complications and conversion in patients undergoing laparoscopic colectomy. J Coloproctol 2011;31: 330-3.

6. Tsujinaka S, Konishi F, Kawamura YJ, Saito M, Tajima N, Tanaka O, et al. Visceral obesity predicts surgical outcomes after laparoscopic colectomy for sigmoid colon cancer. Dis Colon Rectum 2008;51:1757-65.

7. Rossner S. Adolphe quetelet (1796-1874). Obes Rev 2007;8:183.

8. Burton RF. Why is the body mass index calculated as mass $/$ height $^{2}$, not as mass/height ${ }^{3}$ ? Ann Hum Biol 2007;34:656-63.

9. Wilton P. Does my bmi look big in this?; 2013 [updated 16 January 2013]; Available from: http://www.ox.ac.uk/media/science_blog/130116.html.

10. Van Leersum NJ, Snijders HS, Henneman D, Kolfschoten NE, Gooiker GA, ten Berge MG, et al. The dutch surgical colorectal audit. Eur J Surg Oncol 2013;39: 1063-70.

11. Fearon KC, Ljungqvist $\mathrm{O}$, Von Meyenfeldt $\mathrm{M}$, Revhaug $\mathrm{A}$, Dejong $\mathrm{CH}$, Lassen $\mathrm{K}$, et al. Enhanced recovery after surgery: a consensus review of clinical care for patients undergoing colonic resection. Clin Nutr 2005;24:466-77.

12. Kruizenga HM, Seidell JC, de Vet HC, Wierdsma NJ, van Bokhorst-de van der Schueren MA. Development and validation of a hospital screening tool for malnutrition: the short nutritional assessment questionnaire (snaq). Clin Nutr 2005;24:75-82.

13. Stratton RJ, Hackston A, Longmore D, Dixon R, Price S, Stroud M, et al.Malnutrition in hospital outpatients and inpatients: prevalence, concurrent validity and ease of use of the 'malnutrition universal screening tool' ('must') for adults. Br J Nutr 2004;92:799-808.

14. Englesbe MJ, Lee JS, He K, Fan L, Schaubel DE, Sheetz KH, et al. Analytic morphomics, core muscle size, and surgical outcomes. Ann Surg 2012;256:255-61.

15. Makary MA, Segev DL, Pronovost PJ, Syin D, Bandeen-Roche K, Patel P, et al. Frailty as a predictor of surgical outcomes in older patients. J Am Coll Surg 2010;210:901-8.

16. Reisinger KW, van Vugt JL, Tegels JJ, Snijders C, Hulsewe KW, Hoofwijk AG, et al. Functional compromise reflected by sarcopenia, frailty, and nutritional depletion predicts adverse postoperative outcome after colorectal cancer surgery. Ann Surg 2015;261(2):345-52.

17. Merkow RP, Bilimoria KY, McCarter MD, Bentrem DJ. Effect of body mass index on short-term outcomes after colectomy for cancer. J Am Coll Surg 2009;208:53-61.

18. Shawki S, Bashankaev B, Denoya P, Seo C, Weiss EG, Wexner SD. What is the definition of "conversion" in laparoscopic colorectal surgery? Surg Endosc 2009;23:2321-6.

19. Neudecker J, Klein F, Bittner R, Carus T, Stroux A, Schwenk W. Short-term outcomes from a prospective randomized trial comparing laparoscopic and open surgery for colorectal cancer. Br J Surg 2009;96: 1458-67.

20. Yamamoto N, Fujii S, Sato T, Oshima T, Rino Y, Kunisaki C, et al. Impact of body mass index and visceral adiposity on outcomes in colorectal cancer. Asia Pac J Clin Oncol 2012;8:337-45. 


\section{Chapter 6}

Visceral obesity determined by CT scan and outcomes after colorectal surgery; a systematic review and meta-analysis

H. Cakir, C. Heus, T.J. van der Ploeg, A.P.J. Houdijk Int J Colorectal Dis 2015;30(7):875-882 


\section{Abstract}

\section{Background}

Visceral obesity may affect outcome after colorectal surgery. The visceral fat area as determined by CT scanning is considered the standard in the detection of visceral obesity.

\section{Method}

A systematic review was performed of trials investigating the effect of visceral obesity on outcomes of patients with colorectal cancer with no radiotherapy or chemotherapy and measured by CT scanning. The main endpoints were primary hospital stay, morbidity, operative time and blood loss. Quality assessment and data extraction were performed independently by two observers.

\section{Results}

Seven studies were eligible for analysis, including 1230 patients. Primary hospital stay (weighted mean difference 1.16 days, $95 \% \mathrm{Cl} 0.0 .05$ to 2.28 days, $P=0.04$ ), morbidity rates (RR $0.15,95 \% \mathrm{Cl} 0.10$ to $0.21, P<0.00001$ ) and operative time (weighted mean difference $20.47 \mathrm{~min}, 95 \% \mathrm{Cl} 12.76$ to $28.17 \mathrm{~min}, P<0.00001$ ) were significantly higher for visceral obese patients. No difference was found in blood loss.

\section{Conclusion}

Visceral obesity leads to a longer hospital stay, higher morbidity and longer operative time after elective colon surgery. These findings show that the preoperative CT scan for detecting disseminated disease can be used to assess visceral obesity and helps in risk profiling patients undergoing elective colon surgery. 


\section{Introduction}

Colorectal resection for cancer is one of the most frequently performed surgical procedures in the world. ${ }^{1}$ The associated complication rates are significant (15-20\%) and related to surgical and non-surgical causes. ${ }^{2}$ In recent years, visceral obesity has been recognised as one of the possible non-surgical causes of postoperative complications and longer hospital stay after colorectal surgery. ${ }^{3}$ Therefore, accurate determination of the amount of visceral fat may be of value in preoperative risk profiling in the colorectal cancer patient.

Body mass index (BMI) as a general measure of obesity is not always consistent with the amount of visceral fat and is distributed differently among various ethnic groups. ${ }^{4}$ The waist circumference and the hip to waist ratio reflect visceral fat depots better, and strong correlations with cardiovascular disease and type 2 diabetes have been found., 6 A down side to these anthropometric measurements is the low reproducibility and high variability. Using body imaging techniques, like computed tomography (CT), accurate volumetric fat measurement can be performed with high reproducibility. ${ }^{7,8}$ In the preoperative work-up of the colorectal cancer patient, CT imaging of the abdomen is standard in the search for disseminated disease and could be of value in determining visceral fat determination.

Here, we present a systematic review and meta-analysis of studies investigating the effect of visceral obesity measured only by CT on outcomes of patients with colorectal cancer who did not receive chemotherapy or radiation.

\section{Methods}

This systematic review was conducted according to the Preferred Reporting Items for Systematic Reviews and Meta-Analysis (PRISMA) guidelines. ${ }^{9}$ Inclusion criteria for article selection were clinical trials measuring visceral fat with $\mathrm{CT}$ in patients undergoing colorectal surgery.

\section{Search strategy}

A clinical librarian performed a search in MEDLINE (PubMed), EMBASE (Ovid) and the Cochrane Database of Systematic Reviews. The final search was performed on 4 April 2014. The key words and MeSH terms used for MEDLINE were ("Colorectal Neoplasms"[Mesh] OR "Colorectal Surgery"[Mesh] OR "Colectomy"[Mesh] OR "Colonoscopy"[MeSH Terms] OR "Colonic Neoplasms"[Mesh] OR "Rectal 
Neoplasms"[Mesh] OR abdominal surgery[tiab] OR colorectal surgery[tiab] OR colon surgery[tiab] OR rectal surgery[tiab] OR colectom*[tiab] OR colonic cancer*[tiab] OR colonic neoplasm*[tiab] OR colon cancer*[tiab] OR colon neoplasm*[tiab] OR rectal cancer*[tiab] OR rectal neoplasm*[tiab] OR rectal tumor*[ $\mathrm{t}$ i a b ] OR colorectal cancer*[tiab] OR colonoscopy[tiab]) AND ("Intra-Abdominal Fat"[Mesh] OR “Obesity, Abdominal"[Mesh] OR visceral fat*[tiab] OR intraabdominal fat*[tiab] OR visceral adipose tissue[tiab] OR visceral fat[tiab] OR visceral obesit*[tiab] OR abdominal obesit*[tiab] OR central obesit*[tiab] OR "Obesity"[MAJR] OR "Obesity/complications"[MeSH Terms]) AND (Prognosis/Broad[filter] OR systematic[sb] OR "Predictive Value of Tests"[MeSH Terms] OR "Cohort Studies"[Mesh] OR "Validation Studies" [Publication Type] OR "Comparative Study" [Publication Type] OR "Evaluation Studies" [Publication Type] OR "Meta-Analysis as Topic"[MeSH Terms] OR predict*[tiab] OR complication*[tiab]). For EMBASE, the combination of Emtree terms used was ((colorectal tumor/ or colorectal surgery/ or exp colon resection/ or colonoscopy/ or exp colon tumor/ or exp rectum tumor) OR (abdominal surgery or colorectal surgery or colon surgery or rectal surgery or colectom* or colonic cancer* or colonic neoplasm* or colon cancer* or colon neoplasm* or rectal cancer* or rectal neoplasm* or rectal tumor* or colorectal cancer* or colonoscopy).ti,ab.) AND ((intraabdominal fat/ or abdominal fat/ or abdominal obesity/ or *obesity/ or obesity)OR (visceral fat* or intra-abdominal fat* or visceral adipose tissue or visceral obesit* or abdominal obesit* or central obesit*).ti,ab.) AND ((predictive value/ or cohort analysis/ or exp clinical study/ or validation study/ or comparative study/ or evaluation/ or "meta analysis (topic)" / or major clinical study/ or controlled study/) OR ((predict* or complication*).ti,ab.). No hits were found in the keywords used searching the Cochrane Database.

\section{Study selection}

Two reviewers ( $\mathrm{HC}$ and $\mathrm{CH}$ ) independently selected relevant studies based on their titles and abstracts. Conference abstracts with no subsequent publication were disregarded. Full text articles were read by both reviewers. Duplicate publications and papers that reported on the same or parts of the same study population were excluded, in which case, only the largest or the most recent publication was included. Final inclusion required consensus; any differences in judgement were resolved by discussion. Only articles where the CT was used as a modality and where the patients did not receive chemotherapy or radiation were included. 


\section{Data extraction and quality assessment}

Two reviewers ( $\mathrm{HC}$ and $\mathrm{CH}$ ) independently selected relevant studies based on their titles and abstracts. The methodology of each trial was critically appraised by the two reviewers independently, using the Cochrane Collaboration's tool for assessing risk of bias as proposed by the Cochrane Collaboration. ${ }^{10}$ Studies presenting the following data were selected: age, sex, American Society of Anaesthesiologist (ASA), morbidity, mortality, readmission, primary or total hospital stay.

\section{Outcomes}

Data were extracted from original articles only. The two reviewers ( $\mathrm{HC}$ en $\mathrm{HC}$ ) both extracted the data onto a data sheet. Primary hospital stay, morbidity and operative time and blood loss were the outcomes of interest.

\section{Statistical analysis}

To determine if a meta-analysis of the data was appropriate, clinical heterogeneity was assessed by comparing inclusion and exclusion criteria per study, the outcome parameters studied and baseline characteristics of the included patients. Methodological heterogeneity was assessed using the MINORS tool. Heterogeneity was tested using the $\chi^{2}$ test and quantified with an 12 (the proportion of total variance explained by heterogeneity). For dichotomous data, a risk ratio (RR) was calculated with a 95\% confidence interval (Cl). For continuous data, a mean difference (MD) with $95 \%$ $\mathrm{Cl}$ was calculated based on the inverse variance method. A $P$ value of $<0.05$ was considered statistically significant. Statistical analysis was done using Review Manager version 5.1 (The Nordic Cochrane Centre, The Cochrane Collaboration 2011) and Comprehensive Meta-Analysis version 2.2.064 (Biostat, Inc., USA 2011).

\section{Results}

\section{Description of included studies and methodological quality}

The design of the included studies is described in Figure 6.1. Of 1064 citations reviewed, 33 met our inclusion criteria. After title and abstract review, 26 studies were excluded. The remaining seven studies were investigated in detail. All papers used in the analysis were retrospective cohort studies and in English. All studies consisted of patients of the Japanese population. These studies were published between 2005 and 2013. They reported a total of 1230 patients: a visceral obese group of 488 patients and 
a visceral nonobese group of 742 patients. In Table 6.1, the demographics, patient characteristics and reported outcome of the studies are shown. In two studies, a significant difference was seen in age. ${ }^{11,12}$ In four of the seven included studies, significantly more men were in the visceral obese group. ${ }^{4,12-14}$ Only two studies reported about the ASA classification, and one showed significant less ASA I patients in the visceral obese group. ${ }^{11}$ Tsujinaka showed a trend in amount of patients with ASA I $(P=0.066){ }^{4}$ Five studies measured the VFA at the umbilicus level or at the disc space between the third and fourth lumbar vertebral bodies during the preoperative abdominal $\mathrm{CT} .^{3,4,13-15}$ One study measured the VFA at the level of the fourth and fifth intervertebral space. ${ }^{11}$ Rickles et al. measured the VFA at the level of S1 vertebrae. ${ }^{12}$ In five studies, patients with a VFA of $\geq 100 \mathrm{~cm}^{2}$ were defined as visceral obese. ${ }^{3,12-15}$ In the other two studies, a VFA of $\geq 130 \mathrm{~cm}^{2}$ was considered as visceral obese. ${ }^{4,11}$ The methodological quality of the included studies is listed in Table 6.2. All included studies had several limitations.

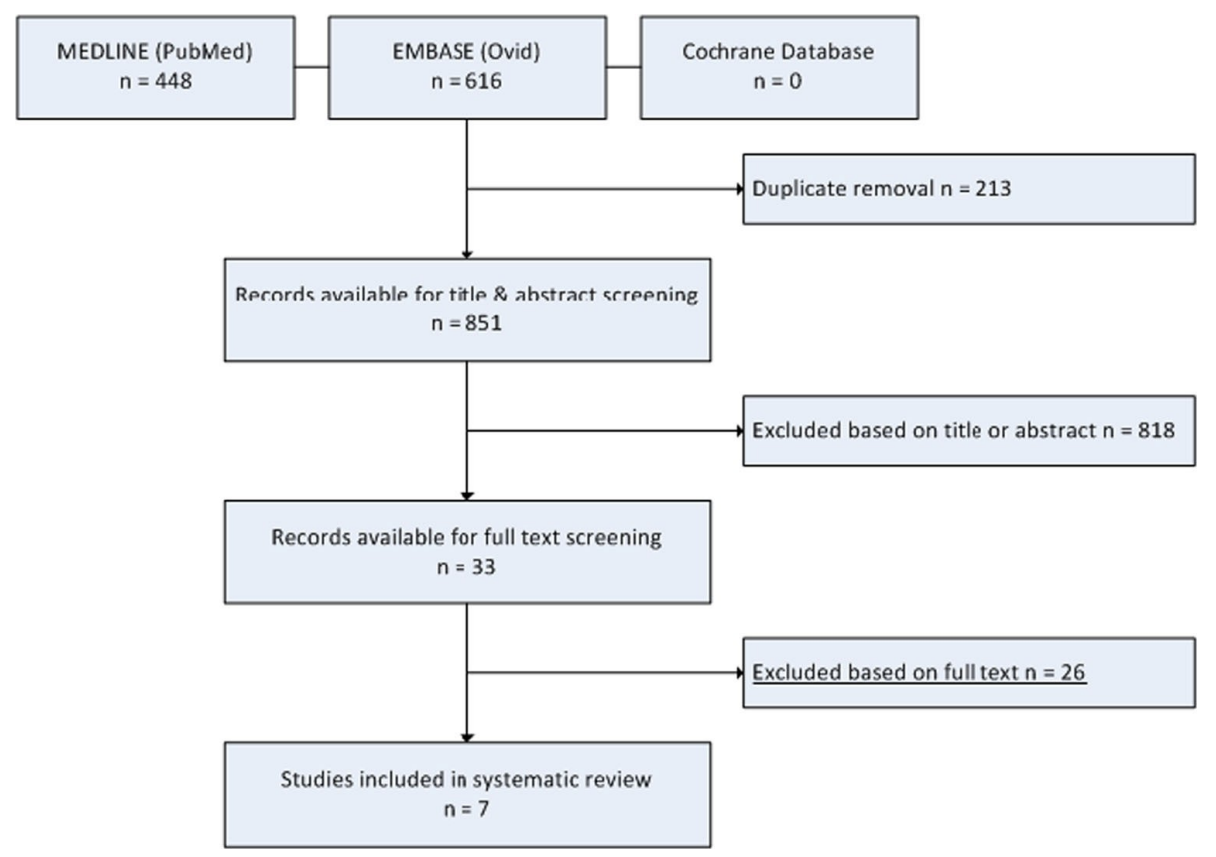

Figure 6.1 Design of the study. 


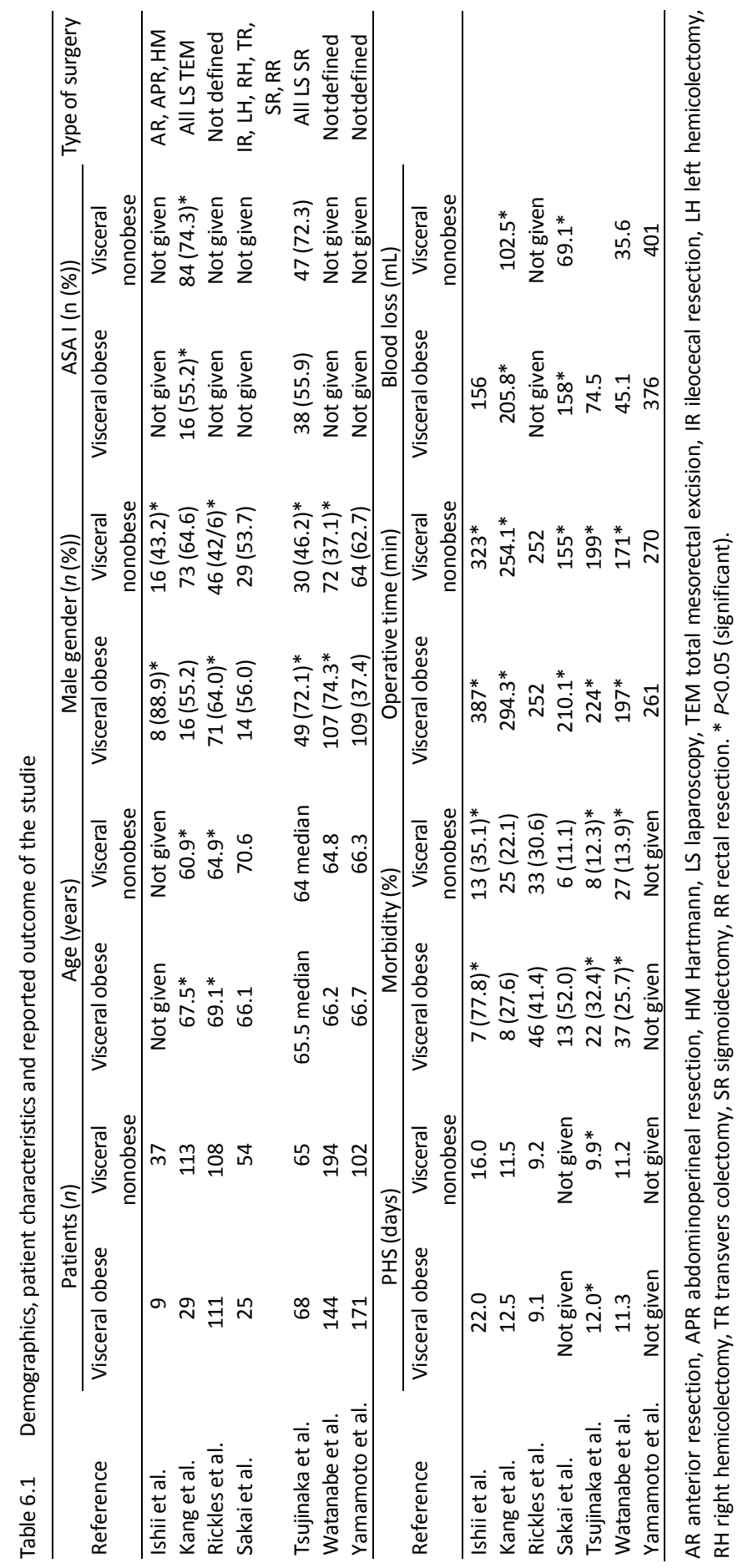


Table 6.2 Methodological quality.

\begin{tabular}{|c|c|c|c|c|c|c|}
\hline Reference & $\begin{array}{l}\text { Adequate } \\
\text { sequence } \\
\text { generation }\end{array}$ & $\begin{array}{c}\text { Allocation } \\
\text { concealment }\end{array}$ & $\begin{array}{c}\text { Blinding of } \\
\text { participants, } \\
\text { personnel and } \\
\text { outcome assessors }\end{array}$ & $\begin{array}{l}\text { Incomplete } \\
\text { outcome } \\
\text { data } \\
\text { addressed } \\
\end{array}$ & $\begin{array}{l}\text { Free of } \\
\text { selective } \\
\text { outcome } \\
\text { reporting }\end{array}$ & $\begin{array}{c}\text { Free of } \\
\text { other } \\
\text { sources of } \\
\text { bias }\end{array}$ \\
\hline Ishii et al. & + & - & - & - & - & - \\
\hline Kang et al. & + & - & - & + & - & - \\
\hline Rickles et al. & + & - & - & - & - & - \\
\hline Sakai et al. & + & - & - & - & - & - \\
\hline Tsujinaka et al. & + & - & - & - & - & - \\
\hline Watanabe et al. & + & - & - & - & - & - \\
\hline Yamamoto et al. & + & - & - & - & - & - \\
\hline
\end{tabular}

\section{Definitions of outcome measures}

Primary hospital stay (PHS) or LOS was defined as hospital stay without including rehospitalisation for complications, or no definition was given. Morbidity was defined as omplications within 30 days of the first operation, or no definition was given. Operative time was defined as the duration of surgery, or no definition was given. Blood loss was defined as blood loss during surgery, or no definition was given.

\section{Meta-analysis}

The authors of seven studies were contacted for original data reported in mean and standard deviation for the purpose of this update and meta-analysis. Two of them did not provide the data for the analysis of PHS. ${ }^{3,15}$

\section{Primary hospital stay}

Five studies reported on primary hospital stay (Table 6.1). After pooling the data, a significant higher PHS was seen for the visceral obese group (weighted mean difference 1.16 days, $95 \% \mathrm{Cl} 0.05$ to 2.28 days, $P=0.04$ ) (Figure 6.2 ).

\section{Morbidity rates}

Morbidity rates were reported in six studies and varied from 27.6 to $77.8 \%$ in the visceral obese group and 11.1 to $35.1 \%$ in the visceral nonobese group (Table 6.1 ). After pooling of the data, significantly lower morbidity rates were seen in the visceral nonobese group (RR $0.15,95 \% \mathrm{Cl} 0.10$ to $0.21, P<0.00001$ ) (Figure 6.3). 


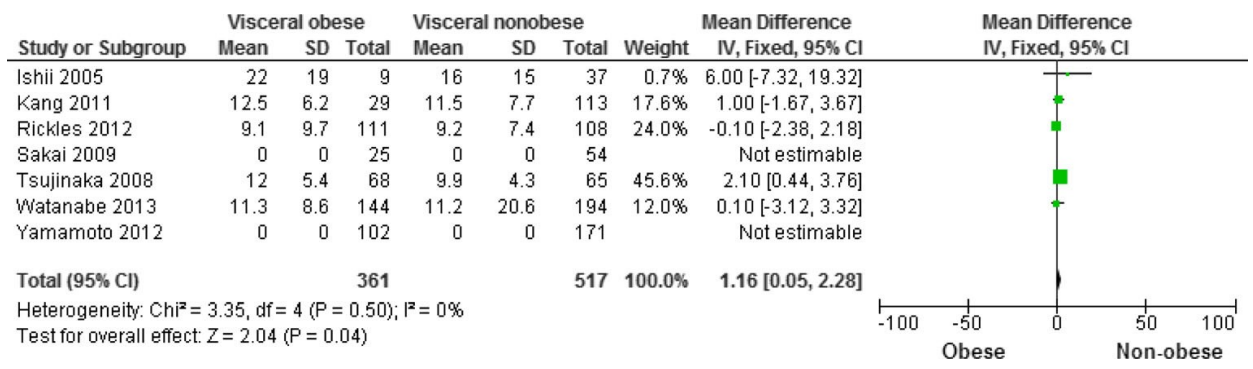

Figure 6.2 Primary hospital stay.

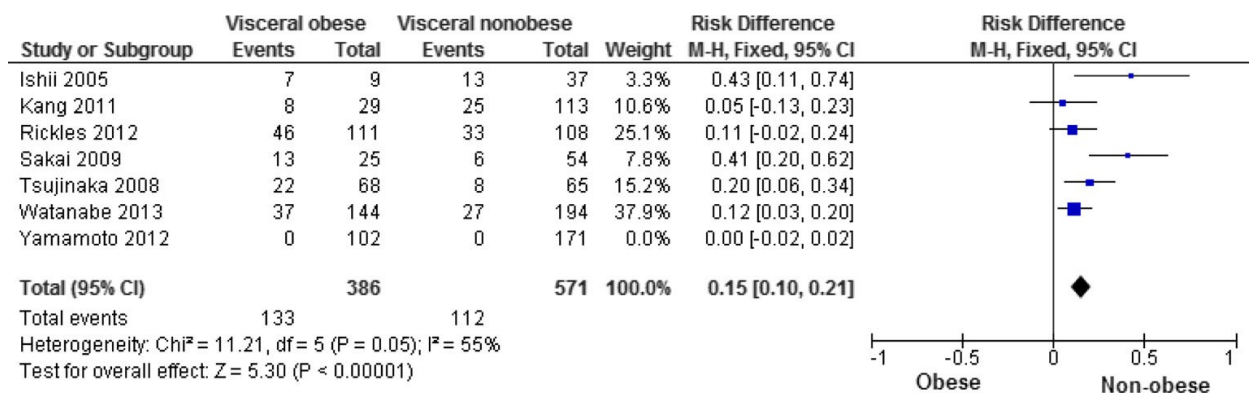

Figure 6.3 Morbidity.

\section{Operative time}

All studies reported on operative time (Table 6.1). Pooling of the data showed significantly longer operative time for the visceral obese group (weighted mean difference $20.47 \mathrm{~min}, 95 \% \mathrm{Cl} 12.76$ to $28.17 \mathrm{~min}, P<0.00001$ ) (Figure 6.4).

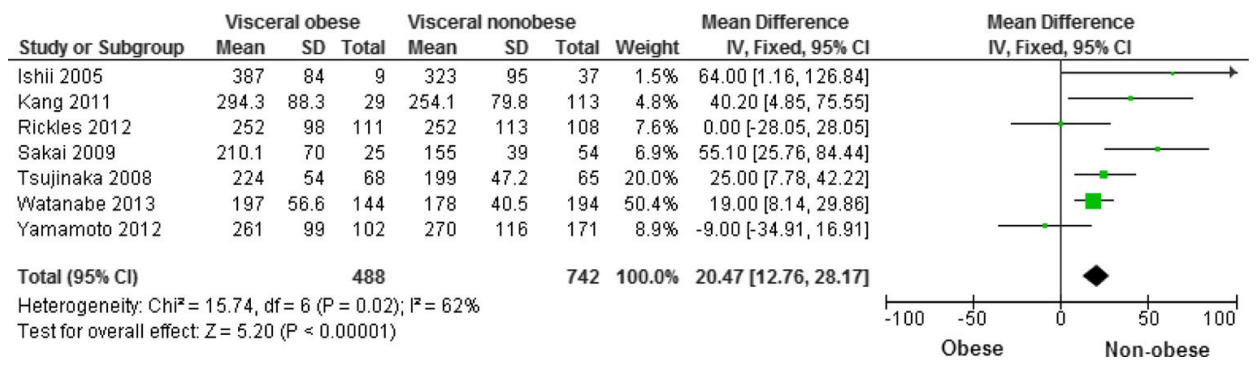

Figure 6.4 Operative time. 


\section{Blood loss}

Blood loss was reported in all included studies. The pooling of the data showed no difference in blood loss between both groups (weighted mean difference $4.64 \mathrm{~mL}, 95 \%$ $\mathrm{Cl}-16.84$ to $26.12 \mathrm{~mL}, P=0.10$ ) (Figure 6.5).

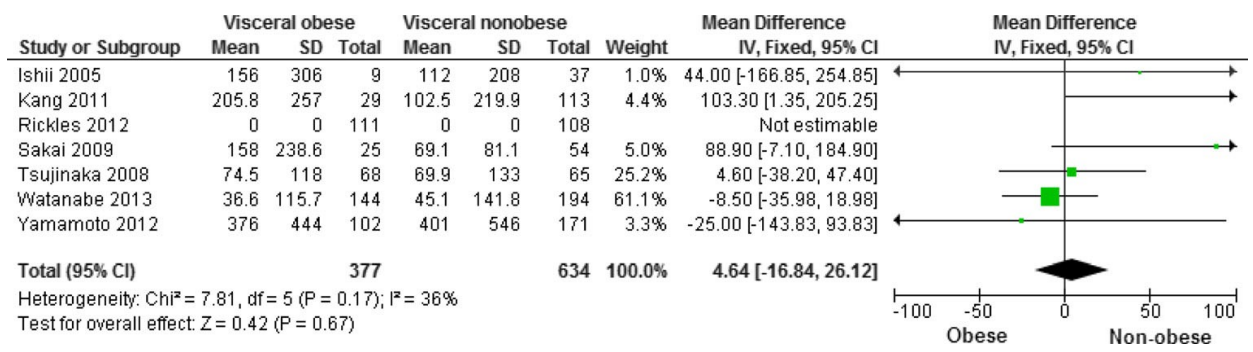

Figure 6.5 Blood loss.

\section{Discussion}

This systematic review suggests that visceral obesity as determined by CT scan results in longer PHS, higher morbidity and longer operative time after elective colon surgery. No significant difference was observed in blood loss during surgery.

Obese patients represent a significant technical and metabolic challenge for the colorectal surgeon. Visceral obesity increases the risk of developing the metabolic syndrome possibly contributing to poorer outcome. ${ }^{16,17}$ Indeed, several authors have reported that visceral obesity leads to higher numbers of wound hernia, pulmonary and cardiovascular complications, longer operative time and significantly lower disease-free survival after major colorectal surgery. ${ }^{18-20}$ Almost all earlier studies use BMI or waist circumference as an indirect index of visceral obesity. However, direct visceral fat determination using CT scan is more accurate and was shown to better predict postoperative outcome after colorectal surgery than BMI. ${ }^{21,22}$

Visceral obesity has been associated with worse outcome in other forms of surgery as well like gastrectomy, pancreatic resections and nephrectomies. For patients undergoing laparoscopy-assisted gastrectomy, VFA determined by CT scan was found to be more accurate than BMI in predicting operative time, blood loss, lower number of lymph nodes harvested and complications. ${ }^{23-25}$ For open gastrectomy, more intraabdominal infections were reported in patients with a high VFA. ${ }^{26}$ Visceral obesity has been identified as a strong predictor of postoperative pulmonary complications 
after pancreaticoduodenectomy and of perioperative outcome in patients undergoing laparoscopic radical nephrectomy. ${ }^{27,28}$

For accurate tumor staging and prognosis in rectal cancer surgery, adequate harvesting of lymph nodes in total mesorectal resection is important and more technically demanding in patients with visceral obesity. ${ }^{29-31}$ From the studies in this review, only the study of four studies reported on lymph node retrieval which was lower in the visceral obese patients. ${ }^{3,11-13}$

As stated before, BMI is not an accurate index to quantify intra-abdominal fat and thereby visceral obesity. One of the reasons is that BMI does not reflect the degree of a patients' visceral fat, because of the different fat tissue distribution between individuals and various ethnic groups. ${ }^{32}$ For this reason, we reviewed only studies that used the CT scan as a method to analyse visceral adipose tissue. Schuster et al. conducted a review in which they investigated different modalities such as BMI, bioelectrical impedance analysis, dual energy X-ray, ultrasound, CT and MRI for visceral adipose tissue analysis. ${ }^{8}$ They concluded that CT and MRI generate the most accurate, specific and comprehensive data in comparison with all other modalities. Because CT scanning is used for the preoperative determination of disseminated disease in patients with colorectal cancer, it can be used for VFA measurement as well.

Some problems however remain with the use of CT scanning for visceral fat determination. The first problem is concerned with the lack of an accepted attenuation Hounse Field Unit threshold for determining adipose tissue. In the literature, this threshold varies from -250 to $-50,-190$ to -30 or -140 to $-40 \mathrm{HFU} .^{33-35}$ In only one study, the threshold was given. ${ }^{7}$ This complicates comparison of research data, and it is in this light that the results of the present review should be interpreted. The same accounts for the differences in the level of planimetric location of the VFA measurement. Most of the levels used are the umbilicus and the L4-L5 intravertebral space. ${ }^{36-38}$ These levels are thought to correspond to the highest amount of adipose tissue accumulation. ${ }^{36-38}$

No prospective RCTs have been performed at this moment, so the available data all come from retrospective cohort studies possibly leading to selection bias. In addition, these small studies are more likely to show larger treatment effects due case-mixed differences. Due to the beneficial reports in all included studies, a publication bias is also possible. The methodological quality of the studies was low. Furthermore, no study clearly defined their outcome measures, thereby increasing heterogeneity.

According to the present systematic review, visceral obesity leads to a longer hospital stay, higher morbidity and longer operative time after elective colorectal surgery without any chemotherapy or radiation. In the preoperative work-up of the colorectal cancer patient, CT imaging of the abdomen is standard in the search for disseminated 
disease, and the assessment of visceral fat could be performed easily. This information is important in metabolic risk profiling the elective colorectal surgery patients and offers the opportunity to develop tailor-made intervention programs. Progress in this field of research is dependent on international standardisation of the technical details of VFA CT scan determination. More studies on the prognostic effects of VFA and surgical outcome are needed to further substantiate the conclusions of the present review and also the effects of chemotherapy and radiation on visceral obesity. 


\section{References}

1. Weitz J, Koch M, Debus J, Höhler T, Galle PR, Büchler MW. Colorectal cancer. Lancet 2005;365(9454):153-65.

2. Tjandra JJ, Chan MK. Systematic review on the short-term outcome of laparoscopic resection for colon and rectosigmoid cancer. Color Dis 2006;8(5):375-88.

3. Yamamoto N1, Fujii S, Sato T, Oshima T, Rino Y, Kunisaki C, Masuda M, Imada T. Impact of body mass index and visceral adiposity on outcomes in colorectal cancer. Asia Pac J Clin Oncol 2012;8(4):337-45

4. Tsujinaka S, Konishi F, Kawamura YJ, SaitoM, Tajima N, Tanaka O, Lefor AT. Visceral obesity predicts surgical outcomes after laparoscopic colectomy for sigmoid colon cancer. Dis Colon Rectum 2008;51(12):1757-65.

5. Mørkedal B, Romundstad PR, Vatten LJ. Informativeness of indices of blood pressure, obesity and serum lipids in relation to ischaemic heart disease mortality: the HUNT-II study. Eur J Epidemiol 2011;26(6):457-41.

6. Picon PX, Leitão CB, Gerchman F, Azevedo MJ, Silveiro SP, Gross JL, Canani LH. Waist measure and waist to hip ratio and identification of cardiovascular risk: multicentric study in type 2 diabetes mellitus patients. Arq Bras Endocrinol Metabol 2007;51(3):443-9.

7. Cecchini S, Cavazzini E, Marchesi F, Sarli L, Roncoroni L. Computed tomography volumetric fat parameters versus body mass index for predicting short-term outcomes of colon surgery. World J Surg 2011;35(2):415-23.

8. Shuster A, Patlas M, Pinthus JH, Mourtzakis $M$. The clinical importance of visceral adiposity: a critical review of methods for visceral adipose tissue analysis. Br J Radiol 2012;85(1009):1-10.

9. Moher D, Liberati A, Tetzlaff J, Altman DG. Preferred reporting items for systematic reviews and metaanalyses: the PRISMA statement. J Clin Epidemiol 2009;62(10):1006-12

10. Slim K, Nini E, Forestier D, Kwiatkowski F, Panis Y, Chipponi J. Methodological index for non-randomized studies (minors): development and validation of a new instrument. ANZ J Surg 2003;73(9): 712-6

11. Kang J, Baek SE, Kim T, Hur H, Min BS, Lim JS, Kim NK, Lee KY. Impact of fat obesity on laparoscopic total mesorectal excision: more reliable indicator than body mass index. Int J Color Dis 2012;27(4):497-505.

12. Rickles AS, lannuzzi JC, Mironov O, Deeb AP, Sharma A, Fleming FJ, Monson JR. Visceral obesity and colorectal cancer: are we missing the boat with BMI? J Gastrointest Surg 2013;17(1):133-43.

13. Watanabe J, Tatsumi K, Ota M, Suwa Y, Suzuki S, Watanabe A, Ishibe A, Watanabe K, Akiyama H, Ichikawa Y, Morita S, Endo I. The impact of visceral obesity on surgical outcomes of laparoscopic surgery for colon cancer. Int J Colorectal Dis 2014;29(3):343-51.

14. Ishii $\mathrm{Y}$, Hasegawa $\mathrm{H}$, Nishibori $\mathrm{H}$, Watanabe $\mathrm{M}$, Kitajima $\mathrm{M}$. Impact of visceral obesity on surgical outcome after laparoscopic surgery for rectal cancer. Br J Surg 2005;92(10):1261-2

15. Sakai T, Maekawa T, Mikami K, Kuramochi H, Noda S. Visceral fat volume and surgical outcomes of colorectal resection. Int Surg 2009;94(4):370-3

16. Després JP. Is visceral obesity the cause of the metabolic syndrome? Ann Med 2006;38(1):52-63

17. Després JP, Lemieux I. Abdominal obesity and metabolic syndrome. Nature 2006;444(7121):881-7.

18. Gendall KA, Raniga S, Kennedy R, Frizelle FA. The impact of obesity on outcome after major colorectal surgery. Dis Colon Rectum 2007;50(12):2223-37.

19. Nitori N, Hasegawa H, Ishii $\mathrm{Y}$, Endo T, Kitagawa Y. Impact of visceral obesity on short-term outcome after laparoscopic surgery for colorectal cancer: a single Japanese center study. Surg Laparosc Endosc Percutan Tech 2009;19(4):324-7.

20. Moon HG, Ju YT, Jeong CY, Jung EJ, Lee YJ, Hong SC, Ha WS, Park ST, Choi SK. Visceral obesity may affect oncologic outcome in patients with colorectal cancer. Ann Surg Oncol 2008;15(7):1918-22.

21. Ballian N, Lubner MG, Munoz A, Harms BA, Heise CP, Foley EF, Kennedy GD. Visceral obesity is associated with outcomes of total mesorectal excision for rectal adenocarcinoma. J Surg Oncol 2012;105(4):365-70.

22. Seki Y, Ohue M, Sekimoto M, Takiguchi S, Takemasa I, Ikeda M, Yamamoto H, Monden M. Evaluation of the technical difficulty performing laparoscopic resection of a rectosigmoid carcinoma: visceral fat reflects technical difficulty more accurately than body mass index. Surg Endosc 2007;21(6):929-34. 
23. Ueda J, Ichimiya $\mathrm{H}$, Okido $\mathrm{M}$, Kato $\mathrm{M}$. The impact of visceral fat accumulation on laparoscopy-assisted distal gastrectomy for early gastric cancer. J Laparoendosc Adv Surg Tech A 2009;19(2):157-62.

24. Yoshikawa K, ShimadaM, Kurita N, Iwata T, Nishioka M,Morimoto S, Miyatani T, Komatsu M, Mikami C, Kashihara H (2011) Visceral fat area is superior to body mass index as a predictive factor for risk with laparoscopy-assisted gastrectomy for gastric cancer. Surg Endosc 2011;25(12):3825-30.

25. Miyaki A, Imamura K, Kobayashi R, TakamiM,Matsumoto J. Impact of visceral fat on laparoscopyassisted distal gastrectomy. Surgeon 2013;11(2):76-81.

26. Tokunaga M, Hiki N, Fukunaga T, Ogura T, Miyata S, Yamaguchi T. Effect of individual fat areas on early surgical outcomes after open gastrectomy for gastric cancer. Br J Surg 2009;96(5):496-500.

27. Shimizu A, Tani M, KawaiM, Hirono S,MiyazawaM, Uchiyama K, Yamaue H. Influence of visceral obesity for postoperative pulmonary complications after pancreaticoduodenectomy. J Gastrointest Surg 2011;15(8):1401-10.

28. Hagiwara M, Miyajima A, Hasegawa M, Jinzaki M, Kikuchi E, Nakagawa K, Oya M. Visceral obesity is a strong predictor of perioperative outcome in patients undergoing laparoscopic radical nephrectomy. BJU Int 2012;110(11):E980-4.

29. Tepper JE, O'Connell MJ, Niedzwiecki D, Hollis D, Compton C, Benson AB 3rd, Cummings B, Gunderson L, Macdonald JS, Mayer RJ. Impact of number of nodes retrieved on outcome in patients with rectal cancer. J Clin Oncol 2011;19(1):157-63

30. Chang GJ, Rodriguez-Bigas MA, Skibber JM, Moyer VA. Lymph node evaluation and survival after curative resection of colon cancer: systematic review. J Natl Cancer Inst 2007;99(6):433-41.

31. Mekenkamp LJ, van Krieken JH, Marijnen CA, van de Velde CJ, Nagtegaal ID, Pathology Review Committee and the Co-operative Clinical Investigators. Lymph node retrieval in rectal cancer is dependent on many factors - the role of the tumor, the patient, the surgeon, the radiotherapist, and the pathologist. Am J Surg Pathol 2009;33(10):1547-53.

32. Bouchard C, Després JP, Mauriège P. Genetic and nongenetic determinants of regional fat distribution. Endocr Rev 1993;14(1):72-93.

33. Kvist H, Chowdhury B, Sjöström L, Tylén U, Cederblad A. Adipose tissue volume determination in males by computed tomography and $40 \mathrm{~K}$. Int J Obes 1988;12(3):249-66.

34. Goodpaster BH, Kelley DE, Wing RR, Meier A, Thaete FL. Effects of weight loss on regional fat distribution and insulin sensitivity in obesity. Diabetes 1999;48(4):839-47.

35. Park HS, Lee K. Greater beneficial effects of visceral fat reduction compared with subcutaneous fat reduction on parameters of the metabolic syndrome: a study of weight reduction programmes in subjects with visceral and subcutaneous obesity. Diabet Med 2005;22(3):266-72.

36. Examination Committee of Criteria for 'Obesity Disease' in Japan; Japan Society for the Study of Obesity. New criteria for 'obesity disease' in Japan. Circ J 2002;66(11):987-92

37. Yoshizumi T, Nakamura T, Yamane M, Islam AH, Menju M, Yamasaki K, Arai T, Kotani K, Funahashi T, Yamashita S, Matsuzawa Y. Abdominal fat: standardized technique for measurement at CT. Radiology 1999;211(1):283-6.

38. Rössner S, Bo WJ, Hiltbrandt E, Hinson W, Karstaedt N, Santago P, Sobol WT, Crouse JR. Adipose tissue determinations in cadavers - a comparison between cross-sectional planimetry and computed tomography. Int J Obes 1990;14(10):893-902. 


\section{Chapter 7}

Visceral obesity, body mass index and risk of complications after colon cancer resection: A retrospective cohort study 


\section{Abstract}

\section{Background}

The aim of our study was to assess the influence of visceral obesity (VO), as measured by preoperative abdominal $\mathrm{CT}$ scan, in relation to body mass index (BMI) on the incidence of postoperative complications and duration of hospital stay after colon cancer surgery.

\section{Methods}

Patients who underwent elective resection for colon cancer between January 1, 2006, and December 31, 2013, and had a preoperative CT scan were entered in the study. Visceral fat area (VFA) was determined by using the preoperative CT scan at the L3-L4 level. The effect of VO, defined as a VFA of $>100 \mathrm{~cm}^{2}$, on postoperative complications and duration of hospital stay was analyzed.

\section{Results}

Of 564 included patients, $65 \%$ had VO. VO was associated with more anastomotic leakage $(P=0.04)$, pneumonia $(P=0.02)$, wound infection $(P=0.03)$, reoperations $(P=0.04)$, and longer duration of hospital stay $(P=0.05)$. Of patients with a BMI $<25 \mathrm{~kg} / \mathrm{m}^{2}, 44 \%$ had VO. In this group, VO was associated significantly with postoperative complications, cardiac $(P<0.01)$ and pulmonary $(P=0.01)$ comorbidity, hypertension $(P<0.01)$, and diabetes $(P<0.01)$. In the overweight $\left(\mathrm{BMI} 25-30 \mathrm{~kg} / \mathrm{m}^{2}\right)$ and obese $\left(\mathrm{BMI}>30 \mathrm{~kg} / \mathrm{m}^{2}\right.$ ) groups, the rate of VO was much higher $(81 \%$ and $90 \%$, respectively), but was not associated significantly with complications or comorbidity, except for cardiac comorbidity $(P<0.02)$ in the BMI $25-30 \mathrm{~kg} / \mathrm{m}^{2}$ group. After multivariable analysis, $\mathrm{VO}$ was shown to be an independent predictor of anastomotic leakage and wound infection.

\section{Conclusion}

The association of VO with worse outcome after colon cancer surgery is most pronounced in patients with a $\mathrm{BMI}<25 \mathrm{~kg} / \mathrm{m}^{2}$. 


\section{Introduction}

Obesity is a rapidly increasing problem, complicating the surgical treatment of colorectal cancer. Apart from the technical difficulties during resection, more postoperative complications and greater costs are reported in the obese population. ${ }^{1-3}$ The way fat is distributed in the body influences the metabolic risk for the patient. Visceral fat is metabolically active and causes a chronic inflammatory status, increasing the risk of the metabolic syndrome characterized by insulin resistance, dyslipidemia, and hypertension. ${ }^{4-7}$ This may lead to an higher rate of complications after surgery in obese colon cancer patients. ${ }^{1,3}$ To determine obesity, body mass index (BMI) is normally used, and patients with a $\mathrm{BMI}$ of $>25 \mathrm{~kg} / \mathrm{m}^{2}$ are reported as at risk for developing postoperative complications. ${ }^{8}$ Recently, however, the use of $\mathrm{BMI}$ as a risk profiler for early postoperative outcome has been questioned and the focus turned to the impact of the accumulation of visceral fat. ${ }^{9-12}$ Traditionally, intra-abdominal fat is indirectly measured by waist circumference or waist-to-hip ratio. These anthropometric methods give an indication of the amount of visceral fat, but they also measure metabolically inactive subcutaneous fat. Visceral obesity (VO) is determined with far more precision if the direct visceral fat area (VFA) is measured by $\mathrm{CT} .{ }^{13}$ A VFA of $>100 \mathrm{~cm}^{2}$ is associated with the metabolic syndrome ${ }^{14}$ and is a risk factor for poor outcome and longer hospital stay after colorectal operations. ${ }^{10-12}$ Most data on VFA and postoperative outcomes come from Japanese patients, and little is known of its effect in the Western world. The aim of our study was to assess the influence of VO, as measured by preoperative abdominal $\mathrm{CT}$, in relation to $\mathrm{BMI}$, on the incidence of postoperative complications an duration of hospital stay in a large cohort of patients with colon cancer.

\section{Methods}

\section{Settings and study design}

This retrospective cohort study was conducted at the Medical Centre Alkmaar, a general teaching hospital in The Netherlands. Patients who underwent an elective resection for colon cancer between January 1, 2006, and December 31, 2013, and had a preoperative CT scan to exclude metastases. Patients were treated according to the Enhanced Recovery After Surgery (ERAS) principles, and data were prospectively entered in the ERAS database. ${ }^{15}$ Experienced gastrointestinal surgeons and their residents performed resection of colon cancer. Both open and laparoscopic resections were included in this study. Patients who underwent acute colonic resection or rectal resection were excluded. Measurement of visceral fat. In this study, all patients 
underwent an abdominal CT scan preoperatively to screen for metastatic disease. VFA was determined by a single scan at the level of the umbilicus (L3-L4), which corresponds with total abdominal fat with 99\% accuracy. ${ }^{13-16}$ The CT images were transferred electronically to a central data system and retrieved at a workstation (Syngo MMWP VE40 A, Siemens AG, Munich, Germany). Adipose tissue was determined by threshold within the range of -140 to -50 Hounsfield units. VO was defined as a VFA of $>100 \mathrm{~cm}^{2}{ }^{14}$

\section{Patient characteristics and outcome variables}

For the evaluation of the ERAS program in colorectal surgical patients, all relevant data were entered prospectively in a database. If necessary, additional information on outcome variables was obtained from the hospital administrative database and medical records. The following patient and surgery characteristics were evaluated: age, sex, type of surgery (laparoscopic or open), presence of a primary anastomosis, comorbidity (defined as cardiac or pulmonary comorbidity, hypertension, and diabetes), and BMI, divided into 3 groups: normal BMI $\left(<25 \mathrm{~kg} / \mathrm{m}^{2}\right)$, overweight $\left(25-30 \mathrm{~kg} / \mathrm{m}^{2}\right)$, and obese $\left(>30 \mathrm{~kg} / \mathrm{m}^{2}\right)$.

The outcome variables in this study were the occurrence of the postoperative complications anastomotic leakage, pneumonia, wound infection, urinary tract infection, the occurrence of reoperations within 30 days after surgery, and duration of hospital stay. The occurrence of an anastomotic leakage was evaluated only in those patients with a primary anastomosis. Duration of hospital stay was calculated from the day of surgery until the day of discharge.

\section{Statistical analysis}

Statistical analyses were performed using the Statistical Package for the Social Sciences (SPSS) version 20.0 (SPSS, Chicago, IL). Patient characteristics as well as postoperative outcomes were described as numbers with percentages in case of nominal and ordinal data, or as mean values with standard deviations in case of continuous data. Analyses for between-group differences were done for Vo versus no VO, for the $3 \mathrm{BMI}$ categories as well as for VO versus no VO within these BMI categories. Differences in nominal variables between groups (BMI categories and visceral versus no VO) were analyzed using the Chi-square or Fisher exact tests as appropriate. Differences in continuous variables between groups were analyzed using the independent samples t-test in case of a 2-group comparison and analysis of variance when $>2$ groups were compared. Continuous variables that were not distributed normally were transformed logarithmically before analysis. After analysis, back transformation of the means 
resulted in geometric means. The strength of the associations between VO, BMI categories, and VO within the BMI categories on the one hand and postoperative outcomes on the other were reported as odds ratios with $95 \% \mathrm{Cl}$ resulting from logistic regression analysis. When the logarithmically transformed duration of hospital stay was the outcome, a ratio of geometric means with a $95 \% \mathrm{Cl}$ resulting from linear regression analysis was reported. In this case, a ratio of geometric means can be interpreted as a risk ratio for prolonged hospital stay. For the comparison of the $3 \mathrm{BMI}$ categories, the category of $<25 \mathrm{~kg} / \mathrm{m}^{2}$ was chosen as the reference category.

To test the independent predictive value of VO, other patient characteristics, and laparoscopic surgery on the occurrence of any of the postoperative complications, reoperations, and duration of hospital stay, univariate and multivariate (linear and logistic) regression analyses were performed. All characteristics that were significantly associated in the univariate analysis $(P<0.05)$ were entered in a multivariate analysis. The final models incorporated all determinants with significant associations $(P<0.05)$. The risk estimates for the nominal outcomes variables are reported as odds ratios with $95 \% \mathrm{Cls}$. For the outcome duration of hospital stay, the risk estimate is a ratio of geometric means.

\section{Results}

\section{Patient characteristics: VO and BMI}

A total of 564 patients were included (Table 7.1). The mean age was 70 years (SD 11), and $51 \%$ of the patients were male. Mean BMI was $25.6 \mathrm{~kg} / \mathrm{m}^{2}$ and $65 \%$ of the patients were viscerally obese. Compared with the no VO group, more patients in the VO group were male $(P<0.01)$, were older $(P<0.01)$, and more had cardiac $(P<0.001)$ or pulmonary $(P<0.01)$ comorbidity, hypertension $(P<0.01)$, or diabetes $(P=0.01)$. A BMI of $<25 \mathrm{~kg} / \mathrm{m}^{2}$ was found in $46 \%$ of the patients, $43 \%$ had a BMI of $25-30 \mathrm{~kg} / \mathrm{m}^{2}$, and $11 \%$ had a BMI of $>30 \mathrm{~kg} / \mathrm{m}^{2}$. Cardiac comorbidity and hypertension occurred more often in higher BMI groups. More overweight patients (BMI $25-30 \mathrm{~kg} / \mathrm{m}^{2}$ ) were male. Four patients had a $\mathrm{BMI}$ of $<18.5 \mathrm{~kg} / \mathrm{m}^{2}$ without any comorbidity or complications. There was no difference in the frequency of laparoscopic surgery between groups. Figure 7.1 shows the relation between BMI and VFA.

\section{Patient characteristics: No VO versus VO within each BMI group}

VO was found in $44 \%$ of the BMI $<25 \mathrm{~kg} / \mathrm{m}^{2}$ group, in $81 \%$ of the $\mathrm{BMI} 25-30 \mathrm{~kg} / \mathrm{m}^{2}$ group, and in $90 \%$ of the patients in the $\mathrm{BMI}>30 \mathrm{~kg} / \mathrm{m}^{2}$ group. In the obese group, $10 \%$ 
had no VO. VO was associated with more advanced age in all BMI groups (Table 7.2). Significantly more patients in the VO BMI $<25 \mathrm{~kg} / \mathrm{m}^{2}$ group had comorbidity, namely, cardiac comorbidity $(P<0.01)$, pulmonary comorbidity $(P<0.01)$, hypertension $(P<0.01)$, or diabetes $(P<0.01)$. In the BMI $25-30 \mathrm{~kg} / \mathrm{m}^{2}$ group, only cardiac comorbidity occurred more often $(P<0.02)$ in the VO than in the no VO group. In the obese group, no significant differences were found. The amount of VFA (mean \pm SD) increased with higher BMI in the VO groups and no VO groups: VO group--- BMI $<25 \mathrm{~kg} / \mathrm{m}^{2}, \mathrm{VFA}=163.7$ $\pm 50 \mathrm{~cm}^{2}, \mathrm{BMI} 25-30 \mathrm{~kg} / \mathrm{m}^{2}, 195.2 \pm 68.2 \mathrm{~cm}^{2}$, and $\mathrm{BMI}>30 \mathrm{~kg} / \mathrm{m}^{2} 259.9 \pm 81.5 \mathrm{~cm}^{2}$ $(P<0.001)$; no VO group--- BMI $<25 \mathrm{~kg} / \mathrm{m}^{2}$, VFA $56.2 \pm 26.8 \mathrm{~cm}^{2}, \mathrm{BMI} 25-30 \mathrm{~kg} / \mathrm{m}^{2}, 73.5 \pm$ $21.3 \mathrm{~cm}^{2}$, and $\mathrm{BMI}>30 \mathrm{~kg} / \mathrm{m}^{2}, 86.6 \pm 13.3 \mathrm{~cm}^{2}(P<.001)$.

Table 7.1 Patient characteristics for the total study population, visceral obesity (VO) groups versus no VO groups and body mass index (BMI) categories.

\begin{tabular}{|c|c|c|c|c|c|c|c|c|}
\hline Characteristic & $\begin{array}{c}\text { Total study } \\
\text { population } \\
(n=564)\end{array}$ & $\begin{array}{l}\text { No VO } \\
(n=197)\end{array}$ & $\begin{array}{c}\text { VO } \\
(n=367)\end{array}$ & $\begin{array}{c}P- \\
\text { value }\end{array}$ & $\begin{array}{c}\mathrm{BMI}<25 \\
\mathrm{~kg} / \mathrm{m}^{2} \\
(n=260)\end{array}$ & $\begin{array}{c}\text { BMI } 25-30 \\
\mathrm{~kg} / \mathrm{m}^{2} \\
(n=241)\end{array}$ & $\begin{array}{c}\mathrm{BMI}>30 \\
\mathrm{~kg} / \mathrm{m}^{2} \\
(n=63)\end{array}$ & $\begin{array}{c}P- \\
\text { value }\end{array}$ \\
\hline Age (y), mean (SD) & $70(11)$ & $68(12)$ & $71(10)$ & $<.01$ & $71(11)$ & 70 (11) & $68(11)$ & .08 \\
\hline Male gender, $n(\%)$ & $287(51)$ & $50(25)$ & $237(65)$ & $<.01$ & $118(45)$ & 141 (59) & $28(44)$ & .01 \\
\hline \multicolumn{9}{|l|}{ Comorbidity, $n(\%)$} \\
\hline Cardiac & $176(31)$ & $33(17)$ & $143(39)$ & $<.01$ & $67(26)$ & $84(35)$ & $25(40)$ & .03 \\
\hline Pulmonary & $56(10)$ & $10(5)$ & $46(13)$ & $<.01$ & $21(8)$ & $27(11)$ & $8(13)$ & .37 \\
\hline Hypertension & 196 (35) & $49(25)$ & $147(40)$ & $<.01$ & $83(32)$ & $81(34)$ & $32(51)$ & .02 \\
\hline Diabetes & $58(10)$ & $10(5)$ & $48(13)$ & $<.01$ & $23(9)$ & $24(10)$ & $11(18)$ & \\
\hline
\end{tabular}

VO is defined as a visceral fat area of $>100 \mathrm{~cm}^{2}$.

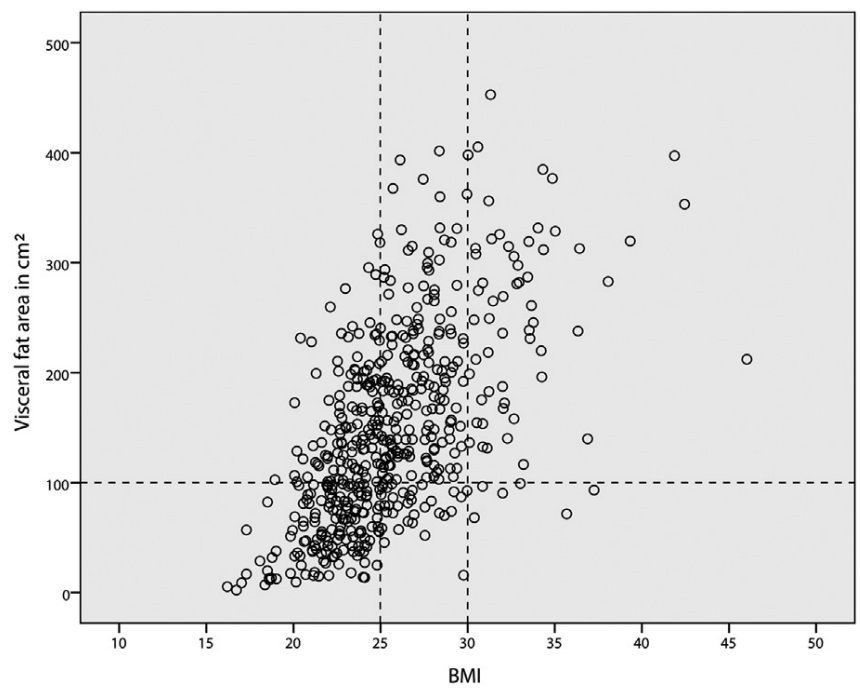

Figure 7.1 Relation between BMI and visceral fat for the 564 study patients. Dashed lines indicate thresholds for visceral obesity (VFA $>100 \mathrm{~cm}^{2}$ ), overweight $\left(\mathrm{BMI}>25 \mathrm{~kg} / \mathrm{m}^{2}\right)$ and obesity (BMI $>30 \mathrm{~kg} / \mathrm{m}^{2}$ ). 
Table 7.2 Patient characteristics for visceral obesity (VO) versus no VO per body mass index (BMI) category.

\begin{tabular}{lccccccccc}
\hline & \multicolumn{3}{c}{$B M I<25 \mathrm{~kg} / \mathrm{m}^{2}$} & \multicolumn{3}{c}{$B M I$} & $25-30 \mathrm{~kg} / \mathrm{m}^{2}$ & \multicolumn{3}{c}{$B M I>30 \mathrm{~kg} / \mathrm{m}^{2}$} \\
\cline { 2 - 9 } Characteristic & No VO & \multicolumn{2}{c}{ VO } & \multicolumn{2}{c}{ No VO } & \multicolumn{2}{c}{ VO } & No VO & \multicolumn{2}{c}{ VO } \\
& $(n=145)$ & $(\mathrm{n}=115)$ & P value & $(\mathrm{n}=46)$ & $(\mathrm{n}=195)$ & P value & $(\mathrm{n}=6)$ & $(\mathrm{n}=57)$ & P value \\
\hline Age, mean (SD) & $69(12)$ & $74(9)$ & $<.01$ & $66(14)$ & $71(10)$ & .04 & $65(13)$ & $68(11)$ & .49 \\
Male gender, $n(\%)$ & $41(28)$ & $77(67)$ & $<.01$ & $9(20)$ & $132(68)$ & $<.01$ & $0(0)$ & $28(50)$ & .03 \\
Comorbidity, $n(\%)$ & & & & & & & & & \\
$\quad$ Cardiac & $21(15)$ & $46(40)$ & $<.01$ & $9(20)$ & $75(39)$ & .02 & $3(50)$ & $22(39)$ & .67 \\
$\quad$ Pulmonary & $6(4)$ & $15(13)$ & .01 & $4(9)$ & $23(12)$ & .55 & $0(0)$ & $8(14)$ & 1.00 \\
Hypertension & $35(24)$ & $48(42)$ & $<.01$ & $11(24)$ & $70(36)$ & .12 & $3(50)$ & $29(51)$ & 1.00 \\
$\quad$ Diabetes & $6(4)$ & $17(15)$ & $<.01$ & $4(9)$ & $20(10)$ & 1.00 & $0(0)$ & $11(19)$ & .58 \\
\hline
\end{tabular}

VO defined as a visceral fat area of $>100 . \mathrm{cm}^{2}$.

\section{Postoperative outcome: VO and BMI}

VO was associated with significantly more anastomotic leakage $(P<0.04)$, pneumonia $(P<0.01)$, wound infections $(P<0.03)$ and reoperations $(P<0.04)$, and greater duration of hospital stay $(P<0.05)$. There were no differences in outcome between the BMI groups (Table 7.3).

\section{Postoperative outcome: No VO versus VO within each BMI group}

Only in the $\mathrm{BMI}<25 \mathrm{~kg} / \mathrm{m}^{2}$ group was VO associated with more postoperative complications: anastomotic leakage $(P=0.06)$, pneumonia $(P=0.01)$, and wound infections $(P<0.03)$. Duration of stay was greater in the $\mathrm{VO} B M \mathrm{Bl}<25 \mathrm{~kg} / \mathrm{m}^{2}$ group $(P=0.08$; Table 7.4).

\section{Predictive factors for postoperative outcome}

On univariate analysis, VO was associated significantly with the occurrence of anastomotic leakage, pneumonia, wound infections, and reoperations, as well as greater duration of hospital stay. On multivariate analysis, VO discriminated for anastomotic leakage (odds ratio [OR], 2.3; 95\% Cl, 1.0-5.4; $P=0.05$ ), and wound infection (OR, 2.5; $95 \% \mathrm{Cl}, 1.1-5.8 ; P=0.03$ ). For pneumonia, only pulmonary comorbidity $(\mathrm{OR}, 2.3 ; 95 \% \mathrm{Cl}, 1.1-4.8 ; P=0.03)$ remained discriminative after multivariate analysis. Pulmonary comorbidity (ratio of geometric means, $1.3 ; 95 \% \mathrm{Cl}$, 1.1-1.6; $P \leq 0.01$ ) and laparoscopic surgery (ratio of geometric means, $0.7 ; 95 \% \mathrm{Cl}$, $0.7-0.8 ; \quad P<0.01)$ were multivariately associated with duration of hospital stay (Table 7.5). 


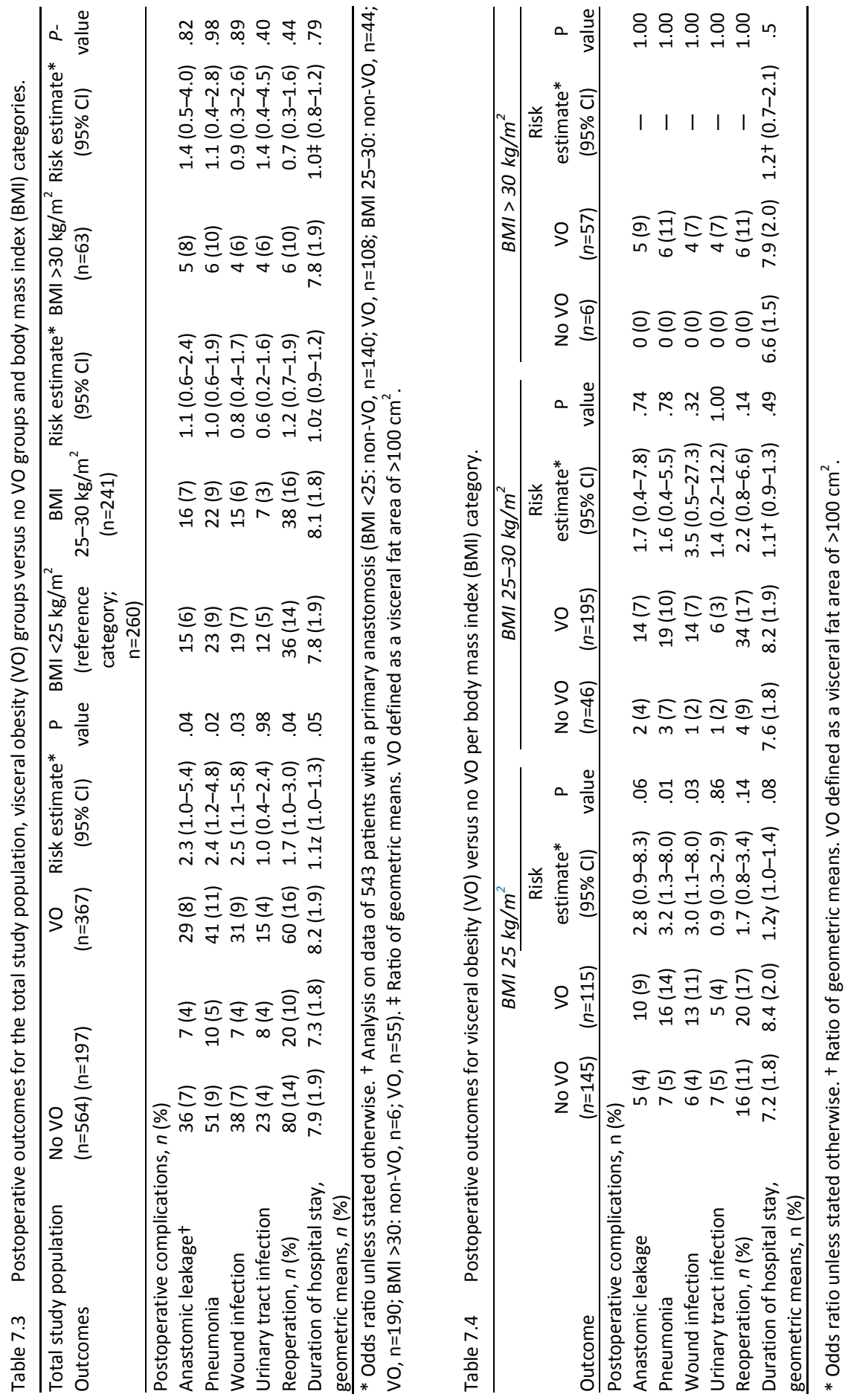


Table 7.5 Predictive factors for postoperative outcome.

\begin{tabular}{|c|c|c|c|c|c|c|}
\hline \multirow[b]{2}{*}{ Factor } & \multicolumn{2}{|c|}{ Univariate analysis } & \multicolumn{4}{|c|}{ Multivariate analysis } \\
\hline & Predictive factor & $\begin{array}{c}\text { Risk estimate* } \\
(95 \% \mathrm{Cl})\end{array}$ & $P$-value & $\begin{array}{c}\text { Predictive } \\
\text { factor }\end{array}$ & $\begin{array}{c}\text { Risk estimate* } \\
(95 \% \mathrm{Cl})\end{array}$ & $P$-value \\
\hline Anastomic leakage ${ }^{\dagger}$ & VO & $2.3(1.0-5.4)$ & .05 & VO & $2.3(1.0-5.4)$ & .05 \\
\hline \multirow[t]{4}{*}{ Pneumonia } & Age & $1.0(1.0-1.1)$ & .02 & & & \\
\hline & Male gender & $2.1(1.1-3.8)$ & .02 & & & \\
\hline & $\begin{array}{l}\text { Pulmonary } \\
\text { comorbidity }\end{array}$ & $2.9(1.4-5.9)$ & .01 & $\begin{array}{l}\text { Pulmonary } \\
\text { comorbidity }\end{array}$ & $2.3(1.1-4.8)$ & .03 \\
\hline & VO & $2.4(1.2-4.8)$ & .02 & & & \\
\hline Wound infection & VO & $2.5(1.1-5.8)$ & .03 & VO & $2.5(1.1-5.8)$ & .03 \\
\hline Urinary tract infection & Male gender & $0.3(0.1-0.8)$ & .02 & Male gender & $0.3(0.1-0.8)$ & .02 \\
\hline \multirow[t]{2}{*}{ Reoperation } & $\begin{array}{l}\text { Pulmonary } \\
\text { comorbidity }\end{array}$ & $2.8(1.5-5.2)$ & $<.01$ & $\begin{array}{l}\text { Pulmonary } \\
\text { comorbidity }\end{array}$ & $2.6(1.4-4.9)$ & $<.01$ \\
\hline & VO & $1.7(1.0-3.0)$ & .05 & & & \\
\hline \multirow[t]{4}{*}{ Length of stay } & Age & $1.0 \ddagger(1.0-1.0)$ & $<.01$ & & & \\
\hline & $\begin{array}{l}\text { Laparoscopic } \\
\text { surgery }\end{array}$ & $0.7 \mp(0.6-0.8)$ & $<.01$ & $\begin{array}{c}\text { Laparoscopic } \\
\text { surgery }\end{array}$ & $0.7 \mp(0.7-0.8)$ & $<.01$ \\
\hline & $\begin{array}{l}\text { Pulmonary } \\
\text { comorbidity }\end{array}$ & $1.4 \ddagger(1.2-1.7)$ & $<.01$ & $\begin{array}{l}\text { Pulmonary } \\
\text { comorbidity }\end{array}$ & $1.3 v(1.1-1.6)$ & $<.01$ \\
\hline & VO & $1.1 v(1.0-1.3)$ & .05 & & & \\
\hline
\end{tabular}

* Odds ratio unless stated otherwise. + Analysis on data of 543 patients with a primary anastomosis. $¥$ Ratio of geometric means. VO, Visceral obesity.

\section{Discussion}

The present data show that the negative association between $\mathrm{VO}$ and postoperative outcome in colon cancer patients was more pronounced in patients with a BMI of $<25 \mathrm{~kg} / \mathrm{m}^{2}$. Unexpectedly, an high incidence of VO was found in this group of patients (44\%), which emphasizes the relevance of this finding. In the groups of overweight and obese patients, VO was not associated significantly with postoperative outcome. Our findings shed new light on the impact of $\mathrm{VO}$ in relation to BMI, as a metabolic risk profiler for untoward postoperative outcome in colon cancer surgery.

To date, this is the largest cohort of colon cancer patients studied for the relation between VO and outcome after elective colon cancer surgery. In general, VO was associated with more comorbidity, a higher rate of postoperative complications and reoperations, and greater duration of hospital stay. These results are in line with the observations found by other authors. In colorectal surgery, vo has been related to postoperative cardiovascular and pulmonary complications, wound infections, and greater duration of hospital stay. ${ }^{3,17}$ This association was found also in patients undergoing other types of abdominal surgery, such as gastrectomy, pancreatic surgery, and nephrectomy. ${ }^{18-20}$ 
The relevance of BMI compared with $\mathrm{VO}$ in determining a metabolic risk profile in colorectal cancer has been questioned in a number of studies., ${ }^{9,17}$ Our data confirm this notion by showing that $\mathrm{BMI}$ in itself had no association with surgical outcome (Table 7.3). However, in combination with $\mathrm{VO}, \mathrm{BMI}<25 \mathrm{~kg} / \mathrm{m}^{2}$ helped to further identify a group of colon cancer patients more at risk for postoperative complications. A similar association between lower BMIs and abdominal obesity is reported for the risk of death by Pischon et al. ${ }^{21}$ in a large European cohort of participants from the general population. In their study, waist circumference and waist-to-hip ratio were used as indirect measures of central obesity and were associated positively with risk of death. This association tended to be stronger in persons with a lower BMI. Although VO was measured indirectly, the strong similarity with our study in terms of relative risk for developing postoperative complications is striking. These indirect anthropometric measures of abdominal obesity do not discriminate between the relative contributions of subcutaneous and visceral fat. Indeed, this is of importance because visceral fat and not subcutaneous fat is now considered the major predictor of adverse events. ${ }^{22}$

Nevertheless, considering the association of VO with untoward postoperative outcome, our results raise the question of why a higher rate of VO did not show a significant association with adverse outcomes in the overweight and obese groups. The differences between the lower and higher BMI groups may be related to a different immunologic response to colon cancer resection in the presence of VO. VO is characterized by a chronic inflammatory state induced by the production of adipokines by visceral fat cells and proinflammatory cytokines from fat-infiltrated macrophages. ${ }^{6,23,24}$ The mean VFA increased with higher BMI, both in the no VO groups and in the VO groups, indicating that fat had been accumulating for a longer time in the higher BMI groups. Here we hypothesize that VO-induced chronic inflammation is present more extensively and for a longer time in overweight and obese patients than in the patients with a $\mathrm{BMI}<25 \mathrm{~kg} / \mathrm{m}^{2}$. The inflammatory response to abdominal surgery in patients with a chronic inflammatory state may be blunted according to the principle of acquired tolerance, which is best described for repeated cytokine and endotoxin exposure (25). Hypothetically, the proinflammatory response may, therefore, be more pronounced in patients with $\mathrm{VO}$ and a BMI of $<25 \mathrm{~kg} / \mathrm{m}^{2}$ than in overweight and obese patients, leading to postoperative complications in patients with a lower BMI. In our multivariate analysis, VO was clearly associated with anastomotic leakage and wound infection, which suggests a link with an exaggerated inflammatory response. Further research on the principle of inflammatory tolerance in patients with VO and different BMIs is warranted.

The metabolic disturbances our patients presented with, such as cardiovascular disease, hypertension, and diabetes, were associated strongly with VO, confirming 
previous reports on the relation between the metabolic syndrome and VO. ${ }^{22}$ However, when stratified for BMI groups, these associations remained significant only in the BMI $<25 \mathrm{~kg} / \mathrm{m}^{2}$ group. Therefore, the worse outcome in the $\mathrm{VO} B M \mathrm{BM}<25 \mathrm{~kg} / \mathrm{m}^{2}$ group may have been influenced by these metabolic disturbances. However, this is contradicted by the results of the univariate and multivariate analyses, which clearly showed that the only comorbidity factor related to complications was pulmonary comorbidity, and not those associated with the metabolic syndrome. Separate multivariable analysis in the $\mathrm{BMI}<25 \mathrm{~kg} / \mathrm{m}^{2}$ group confirmed the overall analysis (data not shown). We conclude that, despite the presence of more comorbidities in the VO low BMI group, this probably was not of direct influence on the risk of postoperative complications.

A limitation of the present study is its retrospective character, and results should be interpreted in this context. Database entry, however, was done prospectively as a routine part of our ERAS quality system, which minimized the loss of data.

In conclusion, according to our results, the negative effect of $\mathrm{VO}$ on postoperative outcome after colon cancer surgery is more pronounced in patients with a BMI of $<25 \mathrm{~kg} / \mathrm{m}^{2}$ than in overweight and obese patients. The routinely performed preoperative CT scan can be used for screening the BMI $<25 \mathrm{~kg} / \mathrm{m}^{2}$ group for VO to identify a colon cancer population at significant risk for postoperative complications. Interventions need to be developed to quickly reduce visceral fat and applied in the weeks before colon cancer surgery to improve postoperative outcomes, especially in patients with a low BMI. 


\section{References}

1. Ballian N, Lubner MG, Munoz A, Harms BA, Heise CP, Foley EF, et al. Visceral obesity is associated with outcomes of total mesorectal excision for rectal adenocarcinoma. J Surg Oncol 2012;105:365-70.

2. Tapper R, Dixon L, Frampton C, Frizelle F. Impact of obesity on the cost of major colorectal surgery. Br J Surg 2013;100:293-8.

3. Gendall KA, Raniga S, Kennedy R, Frizelle FA. The impact of obesity on outcome after major colorectal surgery. Dis Colon Rectum 2007;50:2223-37.

4. Carr DB, Utzschneider KM, Hull RL, Kodama K, Retzlaff BM, Brunzell JD, et al. Intra-abdominal fat is a major determinant of the National Cholesterol Education Program Adult Treatment Panel III criteria for the metabolic syndrome. Diabetes 2004;53:2087-94.

5. Tchernof A, Despr_es J-P. Pathophysiology of human visceral obesity: an update. Physiol Rev 2013;93:359-404.

6. Patel PS, Buras ED, Balasubramanyam A. The role of the immune system in obesity and insulin resistance. J Obes 2013;2013:1-9.

7. Nakao YM, Miyawaki T, Yasuno S, Nakao K, Tanaka S, Ida M, et al. Intra-abdominal fat area is a predictor for new onset of individual components of metabolic syndrome: MEtabolic syndRome and abdominaL ObesiTy (MERLOT study). Proc Jpn Acad Ser B Phys Biol Sci 2012;88:454-61.

8. Amri R, Bordeianou LG, Sylla P, Berger DL. Obesity, outcomes and quality of care: body mass index increases the risk of wound-related complications in colon cancer surgery. Am J Surg 2014;207:17-23.

9. Kang J, Baek SE, Kim T, Hur H, Min BS, Lim JS, et al. Impact of fat obesity on laparoscopic total mesorectal excision: more reliable indicator than body mass index. Int J Colorectal Dis 2012;27:497-505.

10. Sakai T, Maekawa T, Mikami K, Kuramochi H, Noda S. Visceral fat volume and surgical outcomes of colorectal resection. Int Surg 2009;94:370-2.

11. Watanabe J, Tatsumi K, Ota M, Suwa Y, Suzuki S, Watanabe A, et al. The impact of visceral obesity on surgical outcomes of laparoscopic surgery for colon cancer. Int J Colorectal Dis 2014;29:343-51.

12. Rickles AS, lannuzzi JC, Mironov O, Deeb AP, Sharma A, Fleming FJ, et al. Visceral obesity and colorectal cancer: are we missing the boat with BMI? J Gastrointest Surg 2013;17:133-43.

13. Yoshizumi T, Nakamura T, Yamane M, Islam AH, Menju M, Yamasaki K, et al. Abdominal fat: standardized technique for measurement at CT. Radiology 1999;211:283-6.

14. Hiuge-Shimizu A, Kishida K, Funahashi T, Ishizaka Y, Oka R, Okada M, et al. Absolute value of visceral fat area measured on computed tomography scans and obesity-related cardiovascular risk factors in largescale Japanese general population (the VACATION-J study). Ann Med 2012;44:82-92.

15. Cakir H, van Stijn MF, Lopes Cardozo AM, Langenhorst BL, Schreurs WH, van der Ploeg TJ, et al. Adherence to Enhanced Recovery After Surgery and length of stay after colonic resection. Colorectal Dis 2013;15:1019-25.

16. Rossner S, Bo WJ, Hiltbrandt E, Hinson W, Karstaedt N, Santago P, et al. Adipose tissue determinations in cadavers- a comparison between cross-sectional planimetry and computed tomography. Int J Obes 1990;14:893-902.

17. Tsujinaka S, Konishi F, Kawamura YJ, Saito M, Tajima N, Tanaka O, et al. Visceral obesity predicts surgical outcomes after laparoscopic colectomy for sigmoid colon cancer. Dis Colon Rectum 2008;51:1757-65.

18. Yoshikawa K, Shimada M, Kurita N, Iwata T, Nishioka M, Morimoto S, et al. Visceral fat area is superior to body mass index as a predictive factor for risk with laparoscopyassisted gastrectomy for gastric cancer. Surg Endosc 2011; 25:3825-30.

19. Shimizu A, Tani M, Kawai M, Hirono S, Miyazawa M, Uchiyama K, et al. Influence of visceral obesity for postoperative pulmonary complications after pancreaticoduodenectomy.J Gastrointest Surg 2011;15:1401-10.

20. Hagiwara M, Miyajima A, Hasegawa M, Jinzaki M, Kikuchi E, Nakagawa K, et al. Visceral obesity is a strong predictor of perioperative outcome in patients undergoing laparoscopic radical nephrectomy. BJU Int 2012;110: E980-4.

21. Pischon T, Boeing H, Hoffmann K, Bergmann M, Schulze MB, Overvad K, et al. General and abdominal adiposity and risk of death in Europe. N Engl J Med 2008;359:2105-20. 
22. Despre's J-P, Lemieux I, Bergeron J, Pibarot $P$, Mathieu P, Larose E, et al. Abdominal obesity and the metabolic syndrome: contribution to global cardiometabolic risk. Arterioscler Thromb Vasc Biol 2008;28:1039-49.

23. Whitehead JP, Richards AA, Hickman IJ, Macdonald GA, Prins JB. Adiponectin-a key adipokine in the metabolic syndrome. Diabetes Obes Metab 2006;8:264-80.

24. Suganami T, Ogawa Y. Adipose tissue macrophages: their role in adipose tissue remodeling. J Leukoc Biol 2010;88: 33-9.

25. Lopez-Collazo E, Del Fresno C. Pathophysiology of endotoxin tolerance: mechanisms and clinical consequences. Crit Care 2013;17:242. 



\section{Chapter 8

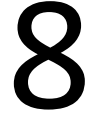

Visceral obesity, muscle mass and outcome in rectal cancer surgery after neo-adjuvant chemoradiation

C. Heus*, H. Cakir*, A. Lak, H.J. Doodeman, A.P.J. Houdijk

* Both authors contributed equally to this article

Int J Surg 2016;29:159-164 


\section{Abstract}

\section{Background}

Preoperative chemoradiation has become a routine modality in the treatment of rectal carcinoma that may impair a patients general condition. In these patients, it is important to identify factors that influence postoperative recovery. Visceral obesity (VO) as a metabolic risk factor was studied in rectal cancer patients receiving preoperative chemoradiation.

\section{Aim}

The impact of VO on post-operative outcome in rectal carcinoma surgery after preoperative chemoradiation was studied. In addition, the effect of chemoradiation on body composition was studied. Method: The visceral fat area (VFA), total fat area (TFA) and skeletal muscle area (SMA) were measured on cross-sectional CT-slides in 74 patients who underwent rectal cancer surgery after chemoradiation. CT-scans taken before and after chemoradiation were analysed. Associations between VFA, per- and post- operative complications were studied. A VFA of $100 \mathrm{~cm}^{2}$ and $130 \mathrm{~cm}^{2}$ was used to differentiate between non-VO and VO.

\section{Results}

Using a VO cut-off point of a VFA of $100 \mathrm{~cm}^{2}$, the VO patients had more per-operative blood loss ( $471 \mathrm{~mL}$ vs. $271 \mathrm{~mL}, P=0.020$ ), a higher complication rate ( $10 \%$ vs. $49 \%$, $P=0.001$ ), more ileus ( $2 \%$ vs. $28 \%, P=0.027$ ) and a longer length of stay ( 9.7 days vs. 13 days, $P=0.027)$. When a VFA of $130 \mathrm{~cm}^{2}$ was used, VO patients showed more complications ( $17 \%$ vs. $55 \%, P=0.001$ ) and ileus (10\% vs. $32 \%, P=0.017)$. During chemoradiation the SMA increased (Mean difference: $2.2 \mathrm{~cm}^{2}, P=0.024$ ), while the VFA showed no change.

\section{Conclusion}

It appears that VO is associated with co-morbidity and poor outcome in rectal cancer patients. Using different cut-off values for VO different associations with outcome were found. SMA increased during chemoradiation, a phenomenon that remains to be explained. 


\section{Introduction}

Preoperative chemoradiation followed by total mesorectal excision (TME) has become the standard treatment of locally advanced rectal cancer because of better local control and promising long-term results. ${ }^{1}$ A downside of chemoradiation however, is the possible detrimental immunological and metabolic effects that may increase the risk of postoperative complications. Therefore, in these patients, identifying metabolic risk factors is important to direct strategies to optimize preoperative condition.

In recent years, visceral obesity has been identified as a significant metabolic risk factor that negatively influences surgical outcome in colon cancer, gastric cancer and pancreatic surgery. ${ }^{2-7}$ Considering the increase in the number of obese patients, more knowledge on the effects of visceral obesity (VO) has become relevant. The negative effects of visceral adipose tissue are thought to be mediated by the state of chronic inflammation associated with cytokines such as TNF-alpha, IL-6 and IL-8 and the metabolic syndrome. ${ }^{8,9}$ In the assessment of visceral obesity, the abdominal CT scan is helpful as it enables the direct measurement of Visceral Fat Area (VFA) with far more precision than the indirect anthropometric measurements like hip to waist ratio or body mass index (BMI). In Japanese studies, a VFA of $>100 \mathrm{~cm}^{2}$ has been associated with the metabolic syndrome and an increased number of complications after colorectal surgery but little is known from other parts of the world. Another relevant metabolic tissue that can be assessed by abdominal CT is skeletal muscle from the lumbar and psoas muscles. The loss of skeletal muscle or sarcopenia is associated with more postoperative complications, increased length of stay (LOS), lower survival and reduced quality of life. ${ }^{10-12}$

In patients with locally advanced rectal cancer eligible for preoperative chemoradiation, an abdominal CT scan is performed in the search for disseminated disease before and after chemoradiation with a time interval of approximately three months. In these patients the effect of VO on surgical outcome has not been studied before. In addition, it is not known whether chemo-radiation has any effect on visceral fat or muscle mass. The aim of the present study was to assess the effects of chemoradiation on VFA and muscle mass and their relation to postoperative outcome in patients with rectal cancer. 


\section{Methods}

\section{Patients}

All patients who underwent preoperative chemoradiation and rectal resection for locally advanced carcinoma and had a pre and post chemoradiation abdominal CT scan in the period of 2006-2013 were included in this study. Chemoradiation consisted of $28 \times 1.8 \mathrm{~Gy}$ (total of $50.4 \mathrm{~Gy}$ ) and $1500 \mathrm{mg}$ Capecitabine two times a day for the duration of 5 weeks. Surgery was scheduled 6-8 weeks after completion of chemoradiation. This retrospective cohort study was conducted at the Medical Centre Alkmaar, a general teaching hospital in the Netherlands. Experienced gastrointestinal surgeons and their residents performed resection of rectal cancer. Both open and laparoscopic resections were included in this study. Patients who underwent acute rectal resection were excluded.

\section{Data collection}

The data that were collected included, age, gender, BMI, type of surgery, co-morbidity, visceral fat area, total fat area and skeletal muscle area before and after chemoradiation, length of stay (LOS), readmissions and reoperations within 30 days and the 30-day morbidity and in-hospital mortality.

Primary outcome measures were perioperative blood loss, LOS, complications, and clinical outcome. Complications were defined as wound infection, pneumonia, urinary tract infection, anastomotic leakage and ileus. Length of hospital stay (LOS) was calculated from the day of surgery until the day of discharge. Clinical outcome was defined as re-admission and re-operation in 30days. Secondary outcomes were the differences in VFA, SMA and TFA between first and second CT-scan.

\section{CT scan measurement of visceral fat area and muscle area}

For the detection of disseminated disease, all patients underwent two CT scans before and after chemoradiation prior to surgery. The images of the CT scan were electronically transferred to a centralized data system and retrieved at a workstation (Syngo MMWP VE40A, Siemens AG, München Germany). A single scan the level of the intervertebral disc of L3-L4 was selected for quantification of the degree of visceral fat and skeletal muscle. A threshold of 140 to 50 for visceral fat was used which was comparable to previous studies. ${ }^{12,13-16}$ The range of 5-60 Hounsfield units was used for muscle tissue. The VFA and the skeletal muscle area (SMA) were manually traced by trained analysts and finally calculated by the software (Figures $\mathbf{8 . 1}$ and $\mathbf{8 . 2}$ ). The 
analysts were not informed with regard to clinical outcome. The pre and post chemoradiation scans were analysed in a random order.

There is no consensus on the definition of visceral obesity as measured by abdominal CT however two cut-off points of $100 \mathrm{~cm}^{2}$ and $130 \mathrm{~cm}^{2}$ for VFA have been suggested in previous literature. $^{17-22}$ Therefore, both cut-off points were used to define visceral obesity to facilitate comparison with the known literature.

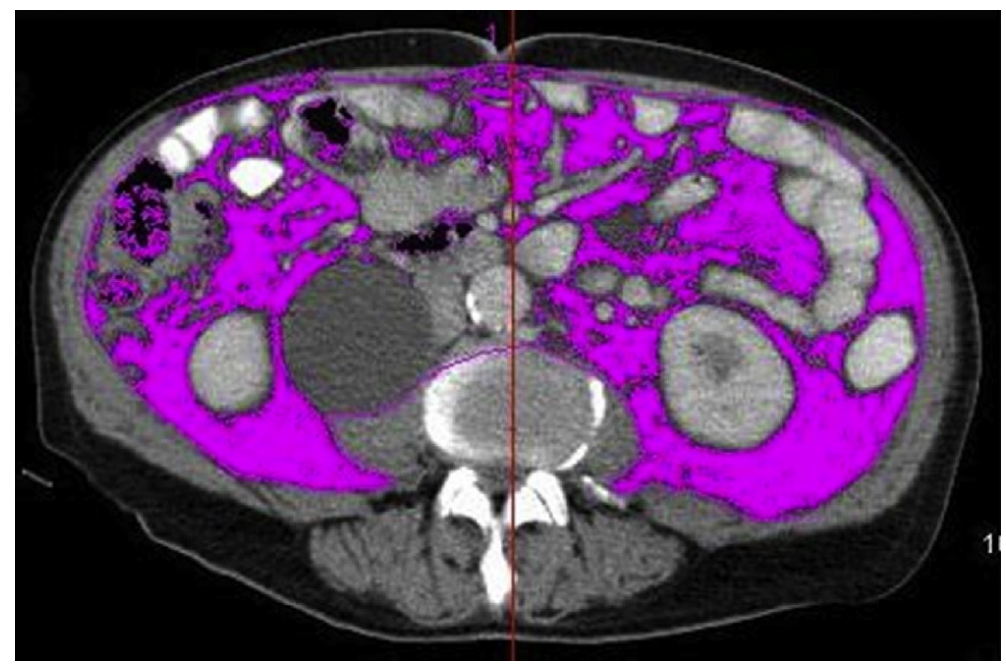

Figure 8.1 Measurement of the visceral fat area on the level of L3-L4.

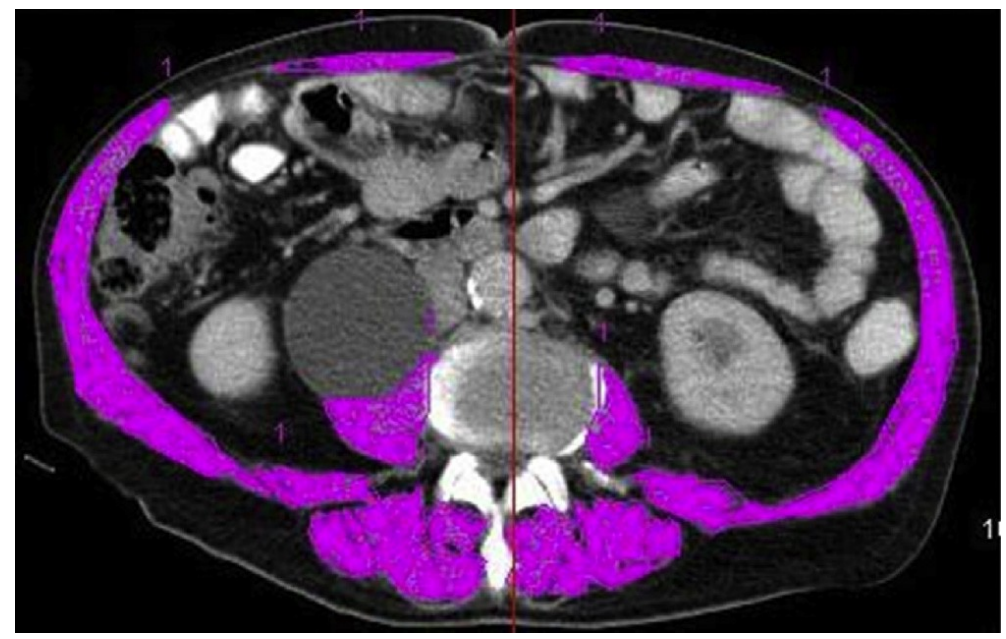

Figure 8.2 Measurement of the skeletal muscle area on the level of L3-L4. 


\section{Surgical procedure}

Experienced gastrointestinal surgeons and their residents performed rectal resection either by the open or the laparoscopic route. In the period of data collection most of the surgery was done by the open route. When an anastomosis was made a deviating loop ileostomy was constructed as well.

\section{Statistical analysis}

The statistical analyses were performed using the Statistical Package for the Social Sciences (SPSS) version 20.0 (SPSS, Chicago, IL, USA).

For the comparison of dichotomous or categorical variables between groups, we used the Chi-square test or Fisher exact test where appropriate. For the comparison of the continuous variables between groups, we used the independent samples t-test. Continuous variables that were not normally distributed (LOS, Blood loss, VFA, TFA and SMA) were logarithmically transformed before analysis. After analysis back transformation of the means resulted in geometric means. A $P$-value $<0.05$ was considered significant.

To test the independent predictive value of visceral obesity and patient characteristics on the occurrence of complications and LOS univariate and multivariate (logistic and linear) regression analysis were performed. The variables with $P$-value $<0.05$ in the univariate analysis were entered into a multivariate linear regression analysis. Effect sizes of significant predictive parameters were given with their $95 \%$ confidence intervals $(\mathrm{Cl})$.

\section{Results}

Seventy-four patients were included of who two patients eventually were not treated by surgery. However, their data were included in the analysis for preoperative comorbidity and the impact of chemoradiation on the VFA and muscle mass. A low anterior resection was performed in 39 patients and an abdominoperineal resection was performed in 26 patients. Seven patients underwent an extended Hartmann procedure. An anastomosis was made in 33 patients (45\%). Fifteen patients were treated laparoscopic. There was no significant difference between VO and non-VO patients in the number of laparoscopic procedures. 


\section{Impact of chemoradiation on VFA, TFA and muscle mass}

The mean period between the pre and post chemo-radiation CT scan was 101.0 days (SD: 23 days). There was no difference in VFA (mean difference $2.0 \mathrm{~cm}^{2}, P=0.53$ ) and total fat area (mean difference $2.4 \mathrm{~cm}^{2} P=0.80$ ) between the pre and post chemoradiation CT scan. Surprisingly, the SMA significantly increased during chemoradiation with a mean difference of $2.2 \mathrm{~cm}^{2}(P=0.024)$. As the second scan is closer to the surgical procedure this scan was used for the analysis of the impact of VFA and muscle mass on surgical outcome.

\section{Patient characteristics and postoperative outcome using VFA cut off = $100 \mathrm{~cm}^{2}$ for VO}

Table 8.1 summarizes the patient characteristics. Using VFA $100 \mathrm{~cm}^{2}$ as a cut-off, VO was found in 44 patients $(60 \%)$ of who $30(68 \%)$ were male. Of the 30 non-VO patients, $9(30 \%)$ were male. Preoperative cardiac morbidity was significantly higher in the VO than in the non-VO group $(27 \%$ and $0 \%$, resp. $P=0.001)$. Visceral obese patients had more hypertension ( $7 \%$ vs. $30 \%, P=0.016$ ) and diabetes ( $0 \%$ vs. $16 \%, P=0.037$ ).

Table 8.1 Patient characteristics per group.

\begin{tabular}{|c|c|c|c|c|c|c|c|}
\hline & $\begin{array}{l}\text { Total study } \\
\text { population } \\
(n=74)\end{array}$ & $\begin{array}{c}\text { VFA }<100 \\
\mathrm{~cm} 2 \\
(\mathrm{n}=30)\end{array}$ & $\begin{array}{c}\text { VFA }>100 \\
\mathrm{~cm} 2 \\
(\mathrm{n}=44)\end{array}$ & $P$ & $\begin{array}{c}\text { VFA }<130 \\
\mathrm{~cm} 2 \\
(\mathrm{n}=43)\end{array}$ & $\begin{array}{c}\text { VFA }>130 \\
\mathrm{~cm} 2 \\
(\mathrm{n}=31)\end{array}$ & $P$ \\
\hline Age in years, mean (SD) & $64.0(10.0)$ & $61.2(8.0)$ & $66.0(11.8)$ & $0.042^{*}$ & $61(11)$ & $68(7)$ & $0.003^{*}$ \\
\hline Male sex, n (\%) & $39(53)$ & $9(30)$ & $30(68)$ & $0.001^{*}$ & $20(47)$ & $19(61)$ & 0.209 \\
\hline $\begin{array}{l}\text { Laparoscopic surgery, } \\
\mathrm{n}(\%)\end{array}$ & $15(21)$ & $5(17)$ & $10(23)$ & 0.538 & $7(17)$ & $8(26)$ & 0.366 \\
\hline \multicolumn{8}{|l|}{ Co morbidity, n (\%) } \\
\hline - Cardiac (\%) & $12(16)$ & $0(0)$ & $12(27)$ & $0.001^{*}$ & $1(2)$ & $11(36)$ & $<0.001^{*}$ \\
\hline - Pulmonary (\%) & $7(10)$ & $5(17)$ & $2(5)$ & 0.112 & $5(12)$ & $2(7)$ & 0.692 \\
\hline - Hypertension (\%) & $15(20)$ & $2(7)$ & $13(30)$ & $0.016^{*}$ & $4(9)$ & $11(35)$ & $0.006^{*}$ \\
\hline - Diabetes (\%) & $7(10)$ & $0(0)$ & $7(16)$ & $0.037^{*}$ & $2(5)$ & $5(16)$ & 0.122 \\
\hline Mean VFA $\mathrm{cm}^{2},(\mathrm{SD})$ & $128(81)$ & $56(29)$ & $178(66)$ & NA & $73(36)$ & $206(60)$ & NA \\
\hline $\begin{array}{l}\text { Muscle mass in } \mathrm{cm}^{2} \text {, } \\
\text { mean (SD) }\end{array}$ & $58(27)$ & $48(15)$ & $66(30)$ & $0.001^{*}$ & $50(16)$ & $71(33)$ & $0.003^{*}$ \\
\hline
\end{tabular}

Table 8.2 summarizes postoperative outcome. Patients with a VFA $>100 \mathrm{~cm}^{2}$ had significantly more per-operative blood loss than the VFA group $<100 \mathrm{~cm}^{2}(471 \mathrm{~mL}$ and $271 \mathrm{~mL}$, resp. $P=0.020)$. In the VFA $>100 \mathrm{~cm}^{2}$ VO group, 21 patients $(49 \%)$ had postoperative complications and in the non-VO group only $3(10 \%)(P=0.001$, odds ratio of 8.3 (95\% Cl: $2.2-31.5)$ ). Visceral obese patients had significantly more postoperative 
ileus ( $28 \%$ vs. $7 \%, P=0.035$ ). The LOS was significantly longer in the visceral obese group (13.0 days vs. 9.7 days, $P=0.027$ ).

Table 8.2 Postoperative characteristics per group.

\begin{tabular}{lccccccc}
\hline & $\begin{array}{c}\text { Total study } \\
\text { population } \\
(\mathrm{n}=74)\end{array}$ & $\begin{array}{c}\text { VFA } \mathrm{cm}^{2} \\
(\mathrm{n}=30)\end{array}$ & $\begin{array}{c}\mathrm{VFA}>100 \\
\mathrm{~cm}^{2} \\
(\mathrm{n}=44)\end{array}$ & $\mathrm{P}$ & $\begin{array}{c}\text { VFA }<130 \\
\mathrm{~cm}^{2} \\
(\mathrm{n}=43)\end{array}$ & $\begin{array}{c}\text { VFA }>130 \\
\mathrm{~cm}^{2} \\
(\mathrm{n}=31)\end{array}$ & $\mathrm{P}$ \\
\hline Blood loss $\mathrm{mL}^{* *}$ & 400 & 271 & 471 & $0.020^{*}$ & 338 & 427 & 0.341 \\
Complications, $\mathrm{n}(\%)$ & $24(33)$ & $3(10)$ & $21(49)$ & $0.001^{*}$ & $7(17)$ & $17(55)$ & $0.001^{*}$ \\
- Anastomic leakage, $\mathrm{n}(\%)$ & $3(9)$ & $1(7)$ & $2(11)$ & 0.658 & $1(5)$ & $2(15)$ & 0.547 \\
- Pneumonia, $\mathrm{n}(\%)$ & $5(7)$ & $1(3)$ & $4(9)$ & 0.642 & $3(7)$ & $2(7)$ & 0.886 \\
- Wound infection, $\mathrm{n}(\%)$ & $8(11)$ & $1(3)$ & $7(16)$ & 0.132 & $3(7)$ & $5(16)$ & 0.278 \\
- Urinary tract infection, $\mathrm{n}(\%)$ & $5(7)$ & $1(3)$ & $4(9)$ & 0.642 & $1(2)$ & $4(13)$ & 0.158 \\
- Ileus, $\mathrm{n}(\%)$ & $14(19)$ & $2(7)$ & $12(28)$ & $0.027^{*}$ & $4(10)$ & $10(32)$ & $0.017^{*}$ \\
Readmission, $\mathrm{n}(\%)$ & $14(19)$ & $6(20)$ & $8(19)$ & 0.826 & $8(20)$ & $6(19)$ & 0.987 \\
Reoperation, $\mathrm{n}(\%)$ & $10(14)$ & $2(7)$ & $8(19)$ & 0.159 & $3(7)$ & $7(23)$ & 0.064 \\
Mortality, $\mathrm{n}(\%)$ & $4(5)$ & $2(5)$ & $2(7)$ & 0.692 & $4(9)$ & $0(0)$ & 0.135 \\
LOS, geometric mean (SD) & $12(1.8)$ & $9.7(1.6)$ & $13(1.9)$ & $0.027^{*}$ & $10.4(1.7)$ & $13.3(1.8)$ & 0.068 \\
\hline
\end{tabular}

VFA $=$ Visceral fat area. LOS = Length of stay. ${ }^{*}$ Statistically significant difference between corresponding groups $(P \leq 0.05) . * *$ Geometric mean. ns $=$ non significant $(P>0.05)$.

\section{Patient characteristics and postoperative outcome using VFA cut-off = $130 \mathrm{~cm}^{2}$ for VO}

Table 8.1 summarizes the patient characteristics. Using a VFA of $130 \mathrm{~cm}^{2}$ as a cut-off for VO, 31 patients (42\%) were categorized in the visceral obese group of which 19 were male (61\%). In the 43 non-VO patients, 20 were male (47\%).

There was significantly more cardiac co-morbidity in the VO group (36\%) than in the non-VO ( $2 \% ; P<0.001)$. A history of hypertension was more prevalent in VO patients (35\% vs. $9 \%$; $P=0.006)$.

Table 8.2 summarizes postoperative outcome. In the VO group, significantly more postoperative complications were found ( $55 \%$ vs. $17 \%, P=0.001)$. An odds ratio of 5.9 (95\% Cl: 2.0-17.3) was found for the occurrence of complications. In the VO patients more postoperative ileus occurred ( $32 \%$ vs. $10 \% ; P=0.017)$. The difference in length of hospital stay between the non-VO group and the VO group did not reach statistical significance (resp. 10.4 and 13.3 days, $P=0.068$ ).

\section{Regression analyses for LOS and complications}

Table 8.3 shows the univariate and multivariate regression analyses for the occurrence of a postoperative complication. A VFA $>100 \mathrm{~cm}^{2}$, a VFA $>130 \mathrm{~cm}^{2}$ and $\mathrm{BMI}$ were statistically significant in the univariate regression analysis. The multivariate analysis 
was performed independently for VFA $>100 \mathrm{~cm}^{2}$ and $130 \mathrm{~cm}^{2}$. VO defined as a VFA $>100 \mathrm{~cm}^{2}$ gives an odds ratio of $5.78(95 \mathrm{Cl}: 1.38-24.2 ; P=0.017)$ for the occurrence of postoperative complications in the multivariate analysis. In the multivariate analysis $\mathrm{VO}$ defined as a VFA $>130 \mathrm{~cm}^{2}$ gives an OR of 5.35 (95Cl: $\left.1.50-19.3 ; P=0.011\right)$ for the occurrence of postoperative complications. BMI did not reach statistical significance in both multivariate analyses as a predictive value for complications.

Table 8.3 Predictive factors for the occurrence of complications.

\begin{tabular}{lcccc}
\hline Predictive factor & Univariate analysis & \multicolumn{3}{c}{ Multivariate analysis } \\
\cline { 2 - 5 } & Odds Ratio $(95 \% \mathrm{Cl})$ & $P$-value & Odds ratio(95\%Cl) & $P$-value \\
\hline VFA $>100 \mathrm{~cm}^{2}$ & $8.27(2.17-31.48)$ & 0.002 & $5.78(1.38-24.2)$ & 0.017 \\
Body mass index & $1.20(1.03-1.39)$ & 0.020 & $1.10(0.93-1.29)$ & 0.265 \\
\hline
\end{tabular}

95\% Cl: 95\% Confidence Interval.

Table 8.4 shows the univariate and multivariate analyses for LOS. A VFA $>100 \mathrm{~cm}^{2}$ and a history of hypertension were statistically significant in the univariate regression analysis for LOS. Visceral obesity defined with a VFA $>130 \mathrm{~cm}^{2}$ showed no statistically significance in the univariate analysis. In the multivariate analyses no factors showed statistical significance.

Table 8.4 Predictive factors for length of stay.

\begin{tabular}{|c|c|c|c|c|c|c|}
\hline & \multicolumn{2}{|c|}{ Univariate analysis } & \multirow[b]{2}{*}{$P$-value } & \multicolumn{2}{|c|}{ Multivariate analysis } & \multirow[b]{2}{*}{$P$-value } \\
\hline & Predictive factor & $\begin{array}{l}\text { Odds Ratio } \\
(95 \% \mathrm{Cl})\end{array}$ & & Predictive factor & $\begin{array}{l}\text { Odds ratio } \\
(95 \% \mathrm{Cl})\end{array}$ & \\
\hline \multirow[t]{2}{*}{ Length of stay } & VFA $>100 \mathrm{~cm}^{2}$ & $1.33(1.02-1.74)$ & 0.039 & VFA $>100 \mathrm{~cm}^{2}$ & $1.24(0.95-1.64)$ & 0.117 \\
\hline & Hypertension & $1.47(1.06-2.05)$ & 0.023 & Hypertension & $1.37(0.98-1.93)$ & 0.070 \\
\hline
\end{tabular}

95\% Cl: 95\% Confidence Interval. * Ratio geometric means

\section{Discussion}

In this study VO is associated with more co-morbidity, a higher complication rate and longer length of stay in patients undergoing rectal resection after chemoradiation for locally advanced cancer. After chemoradiation an increase in SMA was noticed whereas no effect on VFA or subcutaneous fat was found. Skeletal muscle area was not related to co-morbidity or outcome.

Our results on co-morbidity and postoperative complications in patients with visceral obesity confirm the findings of others in colorectal but also in gastric and pancreatic surgery. ${ }^{2,4,5-7,18}$ Most of these studies, however, were performed in the Asian population and the present study is the first to report on the effect of VO on 
postoperative outcome in locally advanced rectal cancer patients after chemo-radiation in a European population. Visceral obesity, is a risk factor for the metabolic syndrome ${ }^{23-}$ ${ }^{25}$ that represents a combination of cardiovascular risk factors including type 2 diabetes, obesity, hyperlipidaemia and hypertension. ${ }^{26}$

The metabolic syndrome correlates with postoperative complications, as was demonstrated in liver transplant patients. ${ }^{27}$ The higher incidence of cardiac comorbidity and hypertension in the visceral obese rectal cancer patients is in line with these results. Clark et al. used the visceral fat/subcutaneous fat ratio to determine the effects of $\mathrm{VO}$ in rectal cancer patients after chemoradiation, showing a higher incidence of dyslipidemia and hypertension. Their study focused more on the long term effects of VO on tumor recurrence in rectal cancer patients treated with chemoradiation followed by surgery. ${ }^{28}$

When using the VFA of $100 \mathrm{~cm}^{2}$ or of $130 \mathrm{~cm}^{2}$ as different cut-off points for VO, a number of results turned out similar (Tables 8.1 and 8.2). At both cut-off points, visceral obesity was associated with significantly more cardiac co-morbidity and a higher rate of post-operative complications. In contrast, LOS was significantly longer only in the VFA $>100 \mathrm{~cm}^{2}$ group. In the regression analysis for complications both cutoff points were of predictive value. In the regression analysis for LOS only VO defined as VFA $>100 \mathrm{~cm}^{2}$ was statistically significant. This indicates that using different VFA cut-off points for $\mathrm{VO}$, the risk profile for postsurgical problems in these patients will change. These results suggest that in terms of risk profiling the cut-off of a $100 \mathrm{~cm}^{2}$ is more valuable than the cut-off of $130 \mathrm{~cm}^{2}$.

Comparison to other studies using these VFA cut-offs for VO in colorectal cancer patients show both similar and contrasting results with respect to surgical outcome. Kang et al., using the cut-off VFA $>130 \mathrm{~cm}^{2}$ investigated the influence of VO in laparoscopic rectal cancer surgery in 142 patients. They showed more blood loss in the VO group but in contrast to our results, no difference in postoperative complications. ${ }^{17}$ Using the VFA $>100 \mathrm{~cm}^{2}$ cut-off point, Ishii et al. did not find more blood loss but in line with our results a higher rate of overall complications occurred in the visceral obese patients undergoing rectal cancer surgery. ${ }^{19}$ It is of note, that in contrast to the high incidence of VO of $55.4 \%$ in our study, only 9 patients (19.5\%) had VO in their study. This underscores the notion that geographical differences may influence body composition and related postsurgical outcome. In agreement with our results, Tsujinaka et al. showed more overall complications in colon cancer patients with VO using the cut-off point of $130 \mathrm{~cm}^{2}{ }^{18}$ Sakai studied the effect of visceral obesity in 79 patients undergoing colorectal resection. More blood loss was found, when $100 \mathrm{~cm}^{2}$ was used as a cut-off point. ${ }^{21}$ From the above, we conclude that although different cut-off points will result in an altered risk profile the average result points to a significant effect of an 
excess of visceral fat on outcome after colorectal surgery. All of the above studies however were performed in the Asian population probably contributing the differences in VO incidence and related changes in outcome. Larger studies are needed to define a relevant cut-off point for $\mathrm{VO}$ in surgical patients in terms of preoperative risk profiling. This is the first study analyzing the effect of chemoradiation on preoperative body composition in rectal carcinoma patients. Because two CT scans are taken before and after chemoradiation to screen for metastatic disease, its effect on VF and muscle mass could be studied. In pancreatic cancer patients, chemoradiation is accompanied by a decrease in SMA, VFA and subcutaneous fat. ${ }^{3}$ In our rectal cancer patients, the amount of VFA was not influenced by chemoradiation. Pancreatic cancer is characterized by profound cancer cachexia that is not common in rectal cancer patients probably explaining this difference. In contrast, we found an unexpected increase in SMA after chemoradiation in our rectal cancer patients. This is an unprecedented finding and we have no clear explanation. The muscles that are measured are not in the field of radiation exposure therefore a direct influence of radiation can be discarded. One might speculate that chemoradiation decreases the inflammatory tumor state improving overall well being leading to more physical activity and muscle mass. We did not measure physical activity but this warrants further evaluation.

The CT scan was used in our study to measure visceral adipose tissue. Schuster et al. conducted a review to investigate the different modalities as BMI, bioelectrical impedance analysis, dual energy X-ray (DEXA), ultrasound, CT and MRI for visceral adipose tissue analysis. ${ }^{13}$ They concluded that $\mathrm{CT}$ and MRI generate the most accurate, specific and comprehensive data in comparison with all other modalities. The umbilical level (L3-L4) was used to measure the VFA that corresponds to total abdominal fat with 99\% accuracy and is used most frequently in the literature. ${ }^{13-20,29,30}$ Using the preoperative CT-scan that is made to screen for disseminated disease in rectal cancer patients can thus be used for the evaluation of VFA as metabolic risk factor.

The retrospective character and population bias are limitations of the present study and results should be interpreted as such. Database entry, however, was done prospectively, minimizing the loss of data. Another limitation is the small number of patients with locally advanced rectal cancer and results cannot be extrapolated to the group of rectal cancer patients as a whole.

Finally, it appears that visceral obesity is a risk factor for poor outcome after rectal carcinoma surgery in patients who underwent preoperative chemoradiation therapy. Determining the amount of visceral fat tissue using the routinely performed preoperative CT-scan is a simple method that may contribute to establish a preoperative metabolic risk profile in the rectal cancer patient. The increase in muscle mass of the psoas muscles after chemoradiation warrants further exploration. 


\section{References}

1. Schou JV, Larsen FO, Rasch L, Linnemann D, Langhoff J, Høgdall E, Nielsen DL, Vistisen K, Fromm A, Jensen BV. Induction chemotherapy with capecitabine and oxaliplatin followed by chemoradiotherapy before total mesorectal excision in patients with locally advanced rectal cancer. Ann Oncol 2012;23: 2627-33.

2. Rickles AS, lannuzzi JC, Mironov O, Deeb AP, Sharma A, Fleming FJ, Monson JR. Visceral obesity and colorectal cancer: are we missing the boat with BMI? J Gastrointest Surg 2013;17:133-43.

3. Dalal S, Hui D, Bidaut L, Lem K, Del Fabbro E, Crane C, Reyes-Gibby CC, Bedi D, Bruera E. Relationships among body mass index, longitudinal body composition alterations, and survival in patients with locally advanced pancreatic cancer receiving chemo-radiation: a pilot study. J Pain Symptom Manag 2012;44: 181-91.

4. Shimizu A, Tani M, Kawai M, Hirono S, Miyazawa M, Uchiyama K, Yamaue H. Influence of Visceral Obesity for Postoperative Pulmonary Complications After Pancreaticoduodenectomy, J. Gastrointest. Surg 2011;15:1401-10.

5. Yoshikawa K, Shimada M, Kurita N, Iwata T, Nishioka M, Morimoto S, Miyatani T, Komatsu M, Mikami C, Kashihara H. Visceral fat area is superior to body mass index as a predictive factor for risk with laparoscopy-assisted gastrectomy for gastric cancer, Surg Endosc 2011;25:3825-30.

6. Miyaki A, Imamura K, Kobayashi R, Takami M, Matsumoto J. Impact of visceral fat on laparoscopyassisted distal gastrectomy. Surgeon 2013;11:76-81.

7. Tokunaga M, Hiki N, Fukunaga T, Ogura T, Miyata S, Yamaguchi T. Effect of individual fat areas on early surgical outcomes after open gastrectomy for gastric cancer, Br J Surg 2009;96:496-500.

8. Donohoe CL, Doyle SL, Reynolds JV. Visceral adiposity, insulin resistance and cancer risk. Diabetol Metab Syndr 2011;22:3-12.

9. Matsushita Y, Nakagawa T, Yamamoto S, Kato T, Ouchi T, Kikuchi N, Takahashi Y, Yokoyama T, Mizoue T, Noda M. Adiponectin and visceral fat associate with cardiovascular risk factors. Obesity 2014;22:287-91.

10. van Vledder MG, Levolger S, Ayez N, Verhoef C, Tran TC, ljzermans JN. Body composition and outcome in patients undergoing resection of colorectal liver metastases. Br J Surg 2012;99:550-7.

11. Peng PD, van Vledder MG, Tsai S, de Jong MC, Makary M, Ng J, Edil BH, Wolfgang CL, Schulick RD, Choti MA, Kamel I, Pawlik TM. Sarcopenia negatively impacts short-term outcomes in patients undergoing hepatic resection for colorectal liver metastasis. HPB Oxf 2011;13:439-46.

12. Lieffers JR, Bathe OF, Fassbender K, Winget M, Baracos VE. Sarcopenia is associated with postoperative infection and delayed recovery from colorectal cancer resection surgery. Br J Cancer 2012;107:931-6.

13. Shuster A, Patlas M, Pinthus JH, Mourtzakis $M$. The clinical importance of visceral adiposity: a critical review of methods for visceral adipose tissueanalysis. Br J Radiol 2012;85:1-10.

14. Kvist H, Chowdhury B, Sjöström L, Tylén U, Cederblad A. Adipose tissue volume determination in males by computed tomography and 40K. Int J Obes 1988;12:249-66.

15. Borkan GA, Gerzof SG, Robbins AH, Hults DE, Silbert CK, Silbert JE. Assessment of abdominal fat content by computed tomography. Am J Clin Nutr 1982;36:172-7.

16. Goodpaster BH, Thaete FL, Simoneau JA, Kelley DE Subcutaneous abdominal fat and thigh muscle composition predict insulin sensitivity independently of visceral fat. Diabetes 1997;46:1579-85.

17. Kang J, Baek SE, Kim T, Hur H, Min BS, Lim JS, Kim NK, Lee KY. Impact of fat obesity on laparoscopic total mesorectal excision: more reliable indicator than body mass index. Int J Colorectal Dis 2012;27:497-505.

18. Tsujinaka S, Konishi MDF, Kawamura YJ, Saito MDM, Tajima N, Tanaka MDO, Levor AT. Outcomes after Laparoscopic colectomy for sigmoid colon cancer. Dis Colon Rectum 2008;51:1757-65.

19. Ishii $\mathrm{Y}$, Hasegawa $\mathrm{H}$, Nishibori $\mathrm{H}$, Watanabe $\mathrm{M}$, Kitajima $\mathrm{M}$. Impact of visceral obesity on surgical outcome after laparoscopic surgery for rectal cancer. Br J Surg 2005;92:1261-2.

20. Yamamoto N, Fujii S, Sato T, Oshima T, Rino Y, Kunisaki C, Masadu M, Imada T. Impact of body mass index and visceral adiposity on outcomes in colorectal cancer. Asia Pac J Clin Oncol 2012;8:337-45.

21. Sakai T, Maekawa T, Mikami K, Kuramochi H, Noda S. Visceral fat volume and surgical outcomes of colorectal resection. Int Surg 2009;94:370-2. 
22. Nitori N, Hasegawa H, Ishii Y, Endo T, Kitagawa Y. Impact of visceral obesity on short-term outcome after laparoscopic surgery for colorectal cancer: a single Japanese center study. Surg Laparosc Endosc Percutan Tech 2009;19:324-7.

23. Mottillo S, Filion KB, Genest J, Joseph L, Pilote L, Poirier P, Rinfret S, Schiffrin EL, Eisenberg MJ. The metabolic syndrome and cardiovascular risk a systematic review and meta-analysis. J Am Coll Cardiol 2010;56:1113-32.

24. Espinola-Klein C, Gori T, Blankenberg S, Munzel T. Inflammatory markers and cardiovascular risk in the metabolic syndrome. Front Biosci 2011;16:1663-74.

25. Pickhardt PJ, Jee Y, O'Connor SD, del Rio AM. Visceral adiposity and hepatic steatosis at abdominal CT: association with the metabolic syndrome. Am J Roentgenol 2012;198:1100-7.

26. Zimmet $P$, Magliano D, Matsuzawa $Y$, Alberti G, Shaw J. The metabolic syndrome: a global public health problem and a new definition. J Atheroscler Thromb 2005;12:295-300.

27. Bhayani NH, Hyder O, Frederick W, Schulick RD, Wolgang CL, Hirose K, Edil B, Herman JM, Choti MA, Pawlik TM. Effect of metabolic syndrome on perioperative outcomes after liver surgery: A National Surgical Quality Improvement Program (NSQIP) analysis. Surgery 2012;152:218-26.

28. Clark W, Siegel EM, Chen YA, Zhao X, Parsons CM, Hernandez JM, Weber J, THareja S, Choi J, Shibata D, Quantitative measures of visceral adiposity and body mass index in predicting rectal cancer outcomes after neoadjuvant chemoradiation. J Am Coll Surg 2013;216:1070-81.

29. Cecchini S, Cavazzini E, Roncoroni L. Computed tomography volumetric fat parameters versus body mass index for predicting short-term outcomes of colon surgery. World J Surg 2011;35:415-23.

30. Irlbeck T, Massaro JM, Babmerg F, O'Donnel CJ, Hoffman U, Fox CS. Association between songle-slice measurements of visceral and abdominal subcutaneous adipose tissue with volumetric measurements: the Framingham Heart Study. Int J Obes 2010;34:781-7. 

Part IV

Summary 



\section{Chapter 9}

General discussion and summary 



\section{Enhanced Recovery After Surgery}

In the 1990's, surgery underwent important changes due to improved surgical, anesthetic and analgesic techniques. A multidisciplinary approach to perioperative care was instituted and together with laparoscopic surgery this has led to earlier recovery in ambulatory surgery.

Programs incorporating these practice changes were called "fast track" programs and this approach converted many multi-day admission surgeries in 1-day surgery operations. In 1997, Hendrik Kehlet, a Danish surgeon, introduced a multimodal evidence-based program to fasten postoperative recovery, which was called "multimodal rehabilitation". ${ }^{1}$ Kehlet underlined that multimodal interventions in preoperative, intraoperative and postoperative care may lead to early rehabilitation after surgical procedures by maintaining pre-operative organ function and reducing the stress response following surgery. Stress-induced organ dysfunction, pain, nausea and vomiting, ileus, hypoxemia and sleep disturbances, fatigue, immobilization and semistarvation, drains and nasogastric tubes with fasting regimes were identified as key factors contributing to slow recovery. Initially, Kehlet focused on implementation of this multimodal program in colorectal surgery.

After these initial years, there was broad variation in the acceptance of this innovative approach among colorectal surgeons and most did not adhere to the program. In 2000, the Enhanced Recovery After Surgery (ERAS) study group was established as a collaboration of five specialised international departments of surgery (Denmark, UK, Norway, Sweden and the Netherlands). The ERAS group reviewed the clinical management and outcomes of colorectal surgery in these five centres of which only the Danish centre had implemented the fast track program at that time. ${ }^{2}$ The length of stay (LOS) was significantly shorter in the "fast track" centre in Denmark compared to the other "traditional care" hospitals. The ERAS care in Denmark had no influence on morbidity and 30-day mortality, but it was associated with higher re-admission rates if length of stay had been reduced to 2-3 days. Re-admission rates were not increased if LOS was around 5 days. In 2005, the group developed an evidence-based ERAS protocol for patients undergoing colonic surgery aiming at a LOS of about 5 days, which was considerably shorter than the traditional 10-11 days. ${ }^{3}$ The effects of ERAS programs on surgical outcome have been studied widely and nowadays ERAS programs are standard care after colorectal resections in many institutions. 
One of the aims of this thesis was to assess the adherence to and outcomes of implementation of an ERAS program in colonic surgery. Although the ERAS program has been successful for patients undergoing colorectal surgery as well as for many other types of surgery, in many centres the implementation of an ERAS program and adherence to its different items has been a big challenge. A retrospective analysis of patients undergoing elective colonic surgery for malignancy between 2006 and 2010 was performed and presented in this thesis (Chapter 2). From this study, it can be concluded that adherence to the ERAS program leads to a reduced length of stay (LOS) and better outcomes in elective colonic cancer surgery. Adherence rates in the first 2 years were $84 \%$ and dropped in the last 2 years to $72 \%$. The LOS in 2006 and 2007 was significantly shorter than in 2005. No significant differences were found in LOS between 2008 and 2009 compared with 2005. The benefits of shorter LOS were lost when adherence to the ERAS program was low. More urinary tract infections were seen in 2009 compared with other years. In addition, more re-operations were seen in the last 2 years than in the first 2 years. These data confirm the results of other studies performed in the first years of implementation of an ERAS program. ${ }^{2,4}$ Compliance with the ERAS program is a multidisciplinary responsibility. In our study, the loss of compliance to the ERAS program over the years was mainly found in the postoperative time period. Varadhan et al. showed that the implementation of four or more elements of the ERAS program reduced LOS and decreased complication rates in patients undergoing major colorectal surgery. ${ }^{5}$ This study failed to provide data on which of the elements were most important. In the present thesis, age, laparoscopic surgery, removal of the nasogastric tube before extubation, mobilization within $24 \mathrm{~h}$ after surgery, starting NSAIDs on day 1 and removal of thoracic epidural analgesia on day 2 were predictors of a shorter LOS. We also conducted a study on 8 years of adherence to the ERAS program and the effects on postoperative outcome in patients undergoing colonic cancer surgery (Chapter $\mathbf{3}$ ). This showed that specific measures can improve adherence and thereby the outcome in colonic surgery for malignancy in an ERAS program. Key factors include the use of a specific ward, dedicated anesthesiologists, a leader responsible for coordination of updates and training, regular auditing, and dissemination of results. Adherence to the ERAS program was inversely related to LOS. There was a shorter duration of stay in the years with high adherence (5.7 vs. 7.3 days). After specific measures, the adherence to the ERAS program improved again in 2012 and 2013 and this led to a shorter LOS. The results of this study are comparable with earlier published studies. ${ }^{6,7}$ The study reported in Chapter 3 also showed that only adherence to the postoperative items was related to a shorter LOS. From these studies, it appears that keeping adherence optimal requires repeated training and dedicated personnel. 


\section{Risk factors affecting recovery after colorectal surgery for patients treated according to an ERAS protocol}

One of the most feared complications that can occur after colorectal resection is anastomotic leakage. Incidence rates of anastomotic leakage vary from $8 \%$ in colonic resections to up to $13 \%$ in low rectal resections. ${ }^{8-11}$ Several studies have shown that the risk of anastomotic leakage may increase with the use of non-steroidal antiinflammatory drugs (NSAIDs). ${ }^{11-16}$ An important component of the ERAS program is pain management including epidural analgesia and NSAIDs. NSAIDs are supposed to be influencing essential steps in wound healing and therefore might affect anastomotic healing. ${ }^{15}$ A retrospective study was performed in this thesis to investigate the influence of postoperative NSAIDs on the occurrence of anastomotic leakage in patients undergoing colorectal surgery within an ERAS program (Chapter 4). The results of this study showed that the NSAID diclofenac leads to a higher rate of anastomotic leakage in patients undergoing colorectal surgery. These findings are in line with other studies reporting on increased anastomotic leakage rates in patients treated with diclofenac or COX-2 selective NSAIDs. ${ }^{11,16-17}$

Obesity is a rapidly increasing health problem in the Western world. Obesity has been suggested to influence outcomes of surgical procedures. ${ }^{18-24}$ Accurate assessment of body composition is therefore of major importance. Body mass index (BMI) as a general measure of obesity is not always consistent with the amount of visceral fat and visceral fat is distributed differently among various ethnic groups. Recently a new BMI formula has been developed, since the traditional BMI formula may overestimate fat accumulation in tall people and underestimate it in short people. As height is given a larger impact in this new formula $\left(1.3 \mathrm{x}\right.$ weight/height $\left.{ }^{2,5}\right)$, it has been considered to approximate reality better. ${ }^{25} \mathrm{~A}$ study was performed to investigate the predictive value of this new BMI formula for postoperative complications in colorectal cancer surgery compared to the traditional BMI formula (Chapter 5). No superiority of the new BMI formula was shown in predicting postoperative complications.

Visceral obesity, determined by volumetric fat measurements (CT scan), was shown to be a better predictor of short-term outcomes after colorectal cancer resection than $\mathrm{BMI}$ in the studies of Tsujinaka and Cecchini. ${ }^{26-27}$ Visceral obesity has been associated with worse outcomes in colorectal surgery and also in other forms of surgery. ${ }^{18-24}$ Visceral obesity is also a risk factor for longer hospital stay after colorectal surgery. ${ }^{27-}$ ${ }^{28,30}$ Most of the anthropometric methods (BMI, waist circumference or waist-to-hip ratio) give an indication of the total body fat, including visceral and subcutaneous fat. 
Assessment of obesity is important and should also include information on visceral vs. subcutaneous obesity as these may affect outcome differently. Visceral obesity can be measured accurately using CT-scans. ${ }^{30-31}$ A systematic review and meta-analysis was performed in this thesis of studies investigating the effect of visceral obesity measured by CT-scan on outcomes of patients undergoing colorectal cancer surgery (Chapter 6). From the seven studies (mostly Japanese studies) described in this meta-analysis, we concluded that visceral obesity leads to a longer LOS, higher morbidity and longer operative time in elective colon surgery. Other authors have reported that visceral obesity leads to higher numbers of wound hernia, pulmonary and cardiovascular complications, longer operative time and lower disease-free survival after major colorectal surgery. ${ }^{32-33}$

Visceral obesity increases the risk of the metabolic syndrome and this may lead to a higher rate of complications after colon cancer surgery. ${ }^{27-29}$ A visceral fat area of $>100$ $\mathrm{cm}^{2}$ is associated with the metabolic syndrome and is a risk factor for poor outcome and longer LOS after colorectal operations. ${ }^{20,34-36}$ Most of the published results until now come from Japanese studies; little is known about the importance of visceral obesity in the Western population. A study was performed in this thesis to assess the influence of visceral obesity measured by CT-scan and BMI on the incidence of complications and LOS after surgery for colon cancer (Chapter 7). This showed a higher influence of visceral obesity on outcome after colon cancer surgery in patients with a $\mathrm{BMI}<25 \mathrm{~kg} / \mathrm{m}^{2}$. In the groups of overweight and obese patients, visceral obesity was not significantly associated with worse postoperative outcomes. A similar association between lower BMIs and higher visceral obesity was found for the risk of death among a general population in the study of Pischon et al. ${ }^{38}$ In this study, visceral obesity was associated with more comorbidity, a higher rate of postoperative complications and reoperations, and longer hospital stay. These results are in line with the observations found by other authors. ${ }^{26}$

In locally advanced rectal cancer, preoperative chemo radiation has become common practice and may influence body composition. A study was conducted (Chapter 8) to identify the influence of chemo radiation on visceral obesity and its effect on postoperative outcomes. No difference was found in visceral fat area after chemo radiation. Visceral obesity was strongly associated with poor outcome in rectal cancer surgery. In this context, determining the amount of visceral fat tissue using the routinely performed preoperative CT-scan may contribute to establish a preoperative metabolic risk profile in rectal cancer patients. 


\section{Future perspectives}

After implementation of an ERAS program, it is important to maintain a good adherence to the ERAS protocol to ensure the benefits of this approach for the patient. $^{38}$ Adherence to an ERAS program is complex, because of its multidisciplinary character. It is sensitive to changes and continuous monitoring and feedback is required to ensure ongoing success. Hospital administrations should take responsibility to ensure that these multidisciplinary protocols are continuously implemented in an organization, because without adherence the care and cost benefits are easily lost. It is already proven that a structured implementation strategy can result in a good sustainability. ${ }^{39}$ The ERAS program has contributed to a standardized approach towards perioperative care in colorectal cancer surgery. This has not only improved the quality of care but also enables the study of variables that influence surgical outcome like visceral obesity and the use of NSAIDS. Ongoing efforts should be taken to improve and monitor adherence to the ERAS program to safeguard this unique effort for standardization of care for the colorectal cancer patient and also for patients with benign colorectal disease.

All recommendations by the ERAS society for colonic surgery can potentially be implemented in other patients undergoing surgery for gastric cancer or liver, pancreatic or gynaecological surgery i.e. early removal of urinary catheter, prevention of postoperative ileus, postoperative analgesia, and early mobilization and resumption of normal diet. ${ }^{40}$ In recent years efforts have been made to develop, implement and evaluate the effect of similar programs in for example gastric cancer surgery. Studies on the timing of oral intake after gastrectomy for gastric cancer are sparse. Small studies that exist have evaluated early oral feeding as safe and feasible. ${ }^{41}$ Other comparative studies showed significantly shorter LOS (e.g. 5.7 vs. 9.2 days) and earlier return of bowel function. ${ }^{42-44}$ Although the strategies for early oral feeding were different, the findings were that it is safe and potentially leads to shorter LOS. ${ }^{42-44}$ A randomized clinical trial in gastric cancer patients including 22 patients treated according to an ERAS program and 22 conventional care patients showed a shorter LOS for ERAS program patients ( 5 vs. 8 days, $P<0.001$ ) but no difference was noted for postoperative pain. ${ }^{45}$ This has resulted in the publication of a gastric cancer surgery specific ERAS guideline, but because of limited evidence for many aspects of ERAS it is largely a consensus guideline. $^{46}$

In line with these results for gastric surgery and colorectal surgery, several studies showed a reduced LOS when patients were managed within an ERAS program for liver surgery, pancreaticoduodenectomy and gynaecological surgery. ${ }^{47-50}$ LOS is reduced 
without compromising morbidity, mortality or readmission rates. This has also resulted in the publication of a liver and pancreatic cancer specific ERAS guidelines. ${ }^{51-52}$

Another promising development that may be implemented in the existing ERAS programs is the prehabilitation of patients undergoing major surgery. Optimizing preoperative physical fitness (e.g., cardiorespiratory fitness, muscle strength, and functional mobility) through prehabilitation may improve postoperative outcomes in patients undergoing major abdominal surgery. Moran et al. showed in a systematic review that prehabilitation appeared to be beneficial in decreasing the incidence of postoperative complications. ${ }^{53}$ Additionally, a systematic review of Bruns et al. reported that prehabilitation can improve the physical fitness of older patients undergoing colorectal surgery. They did not show a significant effect on reduction of complications or LOS. ${ }^{54}$ It has also been demonstrated that personalized prehabilitation reduced the number of patients with postoperative complications by $51 \%$ in high-risk patients undergoing elective major abdominal surgery. ${ }^{55}$ Currently, literature is scarce about the effect of preoperative exercise training on postoperative complications in high-risk patients with colorectal cancer. Most of the studies are underpowered, heterogeneous, and biased toward selection of patients with low risk of postoperative complications. In 2014, a well designed randomized controlled trial was started to measure the effect of a three-week prehabilitation program on postoperative complications in patients with poor cardiorespiratory fitness who were undergoing elective colorectal resection for colorectal cancer or dysplasia grade I,II, or $1 \mathrm{II}^{56}$ The inclusion is expected to be completed by the end of 2018 . 


\section{References}

1. Kehlet $\mathrm{H}$. Multimodal approach to control postoperative pathophysiology and rehabilitation. $\mathrm{Br} \mathrm{J}$ Anaesth 1997;78(5):606-17.

2. Nygren J, Hausel J, Kehlet H, Revhaug A, Lassen K, Dejong C, Andersen J, von Meyenfeldt M, Ljungqvist $\mathrm{O}$, Fearon KC. A comparison in five European Centres of case mix, clinical management and outcomes following either conventional or fast-track perioperative care in colorectal surgery. Clin Nutr 2005; 24(3):455-61.

3. Fearon KC, Ljungqvist $\mathrm{O}$, Von Meyenfeldt $\mathrm{M}$, Revhaug A, Dejong $\mathrm{CH}$, Lassen $\mathrm{K}$, Nygren J, Hausel J, Soop $\mathrm{M}$, Andersen J, Kehlet $\mathrm{H}$. Enhanced recovery after surgery: a consensus review of clinical care for patients undergoing colonic resection. Clin Nutr 2005;24(3):466-77.

4. Basse L, Thorbol JE, Lossl K, Kehlet H. Colonic surgery with accelerated rehabilitation or conventional care. Dis Colon Rectum 2004;47:271-7.

5. Varadhan KK, Neal KR, Dejong $\mathrm{CH}$, et al. The enhanced recovery after surgery (ERAS) pathway for patients undergoing major elective open colorectal surgery: a meta-analysis of randomized controlled trials. Clin Nutr 2010;29:434-40.

6. Ahmed J, Khan S, Lim M, Chandrasekaran TV, MacFie J. Enhanced recovery after surgery protocols compliance and variations in practice during routine colorectal surgery. Colorectal Dis 2012;14:1045-51.

7. Greco M, Capretti G, Beretta L, Gemma M, Pecorelli N, Braga M. Enhanced recovery program in colorectal surgery: a meta-analysis of randomized controlled trials. World J Surg 2014;38:1531-41.

8. Bakker IS, Grossmann I, Henneman D, Havenga K, Wiggers T. Risk factors for anastomotic leakage and leak-related mortality after colonic cancer surgery in a nationwide audit: Br J Surg 2014;101:424-32.

9. Pommergaard HC, Gessler B, Burcharth J, Angenete E, Haglind E, Rosenberg J. Preoperative risk factors for anastomotic leakage after resection for colorectal cancer: a systematic review and meta-analysis: Colorectal Dis 2014;16(9):662-71.

10. Kube R, Mroczkowski P, Granowski D, Benedix F, Sahm M, Schmidt U et al. Anastomotic leakage after colon cancer surgery: a predictor of significant morbidity and hospital mortality, and diminished tumour-free survival: Eur J Surg Oncol 2010;36:120-4.

11. Klein M, Gogenur I, Rosenberg J. Postoperative use of non-steroidal anti-inflammatory drugs in patients with anastomotic leakage requiring reoperation after colorectal resection: cohort study based on prospective data: BMJ 2012;345:e6166.

12. Holte $\mathrm{K}$, Andersen J, Jakobsen $\mathrm{DH}$, Kehlet $\mathrm{H}$. Cyclo-oxygenase 2 inhibitors and the risk of anastomotic leakage after fast-track colonic surgery: Br J Surg 2009;96:650-4.

13. Gorissen KJ, Benning D, Berghmans T, Snoeijs MG, Sosef MN, Hulsewe KW et al. Risk of anastomotic leakage with non-steroidal anti-inflammatory drugs in colorectal surgery: Br J Surg 2012;99:721-7.

14. Bhangu A, Singh P, Fitzgerald JE, Slesser A, Tekkis P. Postoperative Nonsteroidal Anti-inflammatory Drugs and Risk of Anastomotic Leak: Meta-analysis of Clinical and Experimental Studies: World J Surg 2014;38(9):2247-57.

15. Rushfeldt CF, Sveinbjornsson B, Soreide K, Vonen B. Risk of anastomotic leakage with use of NSAIDs after gastrointestinal surgery: Int J Colorectal Dis 2011;26:1501-9.

16. Klein M, Andersen LP, Harvald T, Rosenberg J, Gogenur I. Increased risk of anastomotic leakage with diclofenac treatment after laparoscopic colorectal surgery: Dig Surg 2009;26:27-30.

17. Holte K, Andersen J, Jakobsen DH, Kehlet H. Cyclo-oxygenase 2 inhibitors and the risk of anastomotic leakage after fast-track colonic surgery: Br J Surg 2009;96:650-4.

18. Ueda J, Ichimiya H, Okido M, Kato $M$. The impact of visceral fat accumulation on laparoscopy-assisted distal gastrectomy for early gastric cancer. J Laparoendosc Adv Surg Tech A 2009;19(2):157-62.

19. Yoshikawa K, ShimadaM, Kurita N, Iwata T, Nishioka M,Morimoto S, Miyatani T, Komatsu M, Mikami C, Kashihara H. Visceral fat area is superior to body mass index as a predictive factor for risk with laparoscopy-assisted gastrectomy for gastric cancer. Surg Endosc 2011;25(12):3825-30.

20. Miyaki A, Imamura K, Kobayashi R, TakamiM,Matsumoto J. Impact of visceral fat on laparoscopyassisted distal gastrectomy. Surgeon 2013;11(2):76-81. 
21. Tokunaga M, Hiki N, Fukunaga T, Ogura T, Miyata S, Yamaguchi T. Open gastrectomy for gastric cancer. Br J Surg 2009;96(5):496-500.

22. Shimizu A, Tani M, KawaiM, Hirono S,MiyazawaM, Uchiyama K, Yamaue H. Influence of visceral obesity for postoperative pulmonary complications after pancreaticoduodenectomy. J Gastrointest Surg 2011; 15(8):1401-10.

23. Hagiwara M, Miyajima A, Hasegawa M, Jinzaki M, Kikuchi E, Nakagawa K, Oya M. Visceral obesity is a strong predictor of perioperative outcome in patients undergoing laparoscopic radical nephrectomy. BJU Int 2011;110(11):E980-4.

24. Ballian N, Lubner MG, Munoz A, Harms BA, Heise CP, Foley EF, et al. Visceral obesity is associated with outcomes of total mesorectal excision for rectal adenocarcinoma. J Surg Oncol 2012;105:365-70.

25. Wilton P. Does my bmi look big in this?; 2013 Available from: http://www.ox.ac.uk/media/science_blog/ 130116.html

26. Tsujinaka S, Konishi F, Kawamura YJ, Saito M, Tajima N, Tanaka O, Lefor AT. Visceral obesity predicts surgical outcomes after laparoscopic colectomy for sigmoid colon cancer. Dis Colon Rectum 2008; 51(12):1757-65.

27. Cecchini S, Cavazzini E, Marchesi F, Sarli L, Roncoroni L. Computed tomography volumetric fat parameters versus body mass index for predicting short-term outcomes of colon surgery. World J Surg 2011;35(2):415-23.

28. Tapper R, Dixon L, Frampton C, Frizelle F. Impact of obesity on the cost of major colorectal surgery. Br J Surg 2013;100:293-8.

29. Gendall KA, Raniga S, Kennedy R, Frizelle FA. The impact of obesity on outcome after major colorectal surgery. Dis Colon Rectum 2007;50:2223-37.

30. Shuster A, Patlas M, Pinthus JH, Mourtzakis $M$. The clinical importance of visceral adiposity: a critical review of methods for visceral adipose tissue analysis. Br J Radiol 2012;85(1009):1-10.

31. Nitori N, Hasegawa H, Ishii Y, Endo T, Kitagawa Y. Impact of visceral obesity on short-term outcome after laparoscopic surgery for colorectal cancer: a single Japanese center study. Surg Laparosc Endosc Percutan Tech 2009;19(4):324-7.

32. Moon HG, Ju YT, Jeong CY, Jung EJ, Lee YJ, Hong SC, Ha WS, Park ST, Choi SK. Visceral obesity may affect oncologic outcome in patients with colorectal cancer. Ann Surg Oncol 2008;15(7):1918-22.

33. Sakai T, Maekawa T, Mikami K, Kuramochi H, Noda S. Visceral fat volume and surgical outcomes of colorectal resection. Int Surg 2009;94:370-2.

34. Watanabe J, Tatsumi K, Ota M, Suwa Y, Suzuki S, Watanabe A, et al. The impact of visceral obesity on surgical outcomes of laparoscopic surgery for colon cancer. Int J Colorectal Dis 2014;29:343-51.

35. Rickles AS, lannuzzi JC, Mironov O, Deeb AP, Sharma A, Fleming FJ, et al. Visceral obesity and colorectal cancer: are we missing the boat with BMI? J Gastrointest Surg 2013;17:133-43.

36. Hiuge-Shimizu A, Kishida K, Funahashi T, Ishizaka Y, Oka R, Okada M, et al. Absolute value of visceral fat area measured on computed tomography scans and obesity-related cardiovascular risk factors in largescale Japanese general population (the VACATION-J study). Ann Med 2012;44:82-92.

37. Pischon T, Boeing H, Hoffmann K, Bergmann M, Schulze MB, Overvad K, et al. General and abdominal adiposity and risk of death in Europe. N Engl J Med 2008;359:2105-20.

38. Feroci F, Lenzi E, Baraghini M, Garzi A, Vannucchi A, Cantafio S, Scatizzi M. Fast-track colorectal surgery: protocol adherence influences postoperative outcomes. Int J Colorectal Dis 2013;28(1):103-9.

39. Gillissen F, Ament SM, Maessen JM, Dejong CH, Dirksen CD, van der Weijden T, von Meyenfeldt MF. Sustainability of an enhanced recovery after surgery program (ERAS) in colonic surgery. World J Surg 2015;39(2):526-33.

40. Gustafsson UO, Scott MJ, Schwenk W, Demartines N, Roulin D, Francis N, McNaught CE, MacFie J, Liberman AS, Soop M, Hill A, Kennedy RH, Lobo DN, Fearon K, Ljungqvist O, and Enhanced Recovery After Surgery S, Guidelines for perioperative care in elective colonic surgery: Enhanced Recovery After Surgery (ERAS(R)) Society recommendations. Clin Nutr 2012;31(6):783-800.

41. Jo DH, Jeong O, Sun JW, Jeong MR, Ryu SY, and Park YK, Feasibility study of early oral intake after gastrectomy for gastric carcinoma. J Gastric Cancer 2011;11(2):101-8.

42. Hur H, Si Y, Kang WK, Kim W, and Jeon HM, Effects of early oral feeding on surgical outcomes and recovery after curative surgery for gastric cancer: pilot study results. World J Surg 2009;33(7):1454-8. 
43. Suehiro $T$, Matsumata $T$, Shikada $Y$, and Sugimachi $K$, Accelerated rehabilitation with early postoperative oral feeding following gastrectomy. Hepatogastroenterology 2004;51(60):1852-5.

44. Hur H, Kim SG, Shim JH, Song KY, Kim W, Park CH, and Jeon HM, Effect of early oral feeding after gastric cancer surgery: a result of randomized clinical trial. Surgery 2011;149(4):561-8.

45. Kim JW, Kim WS, Cheong JH, Hyung WJ, Choi SH, and Noh SH, Safety and efficacy of fast-track surgery in laparoscopic distal gastrectomy for gastric cancer: a randomized clinical trial. World J Surg 2012;36(12): 2879-87

46. Mortensen K, Nilsson M, Slim K, Schafer M, Mariette C, Braga M, Carli F, Demartines N, Griffin SM, Lassen K, and Enhanced Recovery After Surgery G, Consensus guidelines for enhanced recovery after gastrectomy: Enhanced Recovery After Surgery (ERAS(R)) Society recommendations. Br J Surg 2014; 101(10):1209-29.

47. van Dam RM, Hendry PO, Coolsen MM, Bemelmans MH, Lassen K, Revhaug A, Fearon KC, Garden OJ, Dejong $\mathrm{CH}$; Enhanced Recovery After Surgery (ERAS) Group. Initial experience with a multimodal enhanced recovery programme in patients undergoing liver resection. Br J Surg 2008;95(8):969-75.

48. Coolsen MM, Wong-Lun-Hing EM, van Dam RM, van der Wilt AA, Slim K, Lassen K, Dejong $\mathrm{CH}$. A systematic review of outcomes in patients undergoing liver surgery in an enhanced recovery after surgery pathways. HPB (Oxford) 2013;15(4):245-51.

49. Coolsen MM, van Dam RM, Chigharoe A, Olde Damink SW, Dejong CH. Improving outcome after pancreaticoduodenectomy: experiences with implementing an enhanced recovery after surgery (ERAS) program. Dig Surg 2014;31(3):177-84.

50. de Groot JJ, Ament SM, Maessen JM, Dejong CH, Kleijnen JM, Slangen BF. Enhanced recovery pathways in abdominal gynecologic surgery: a systematic review and meta-analysis. Acta Obstet Gynecol Scand 2016;95(4):382-95.

51. Melloul E, Hübner M, Scott M, Snowden C, Prentis J, Dejong CH, Garden OJ, Farges O, Kokudo N, Vauthey JN, Clavien PA, Demartines N. Guidelines for Perioperative Care for Liver Surgery: Enhanced Recovery After Surgery (ERAS) Society Recommendations. World J Surg 2016;40(10):2425-40.

52. Lassen K, Coolsen MM, Slim K, Carli F, de Aguilar-Nascimento JE, Schäfer M, Parks RW, Fearon KC, Lobo DN, Demartines N, Braga M, Ljungqvist O, Dejong $\mathrm{CH}_{\text {; ERAS }}{ }^{\circledR}$ Society; European Society for Clinical Nutrition and Metabolism; International Association for Surgical Metabolism and Nutrition. Guidelines for perioperative care for pancreaticoduodenectomy: Enhanced Recovery After Surgery (ERAS ${ }^{\circledR}$ ) Society recommendations. Clin Nutr 2012;31(6):817-30.

53. Moran J, Guinan E, Mc Cormick P, Larkin J, Mockler D, Hussey J, et al. The ability of prehabilitation to influence postoperative outcome after intra-abdominal operation: a systematic review and metaanalysis. Surgery 2016;160(5):1189-201.

54. Bruns ER, Van den Heuvel B, Buskens CJ, Van Duijvendijk P, Festen S, Wassenaar EB, et al. The effects of physical prehabilitation in elderly patients undergoing colorectal surgery: a systematic review. Color Dis 2016;18(8):0267-7.

55. Barberan-Garcia A, Ubre M, Roca J, Lacy AM, Burgos F, Risco R, et al. Personalised prehabilitation in high-risk patients undergoing elective major abdominal surgery: a randomized blinded controlled trial. Ann Surg 2018;267(1):50-6.

56. Berkel AEM, Bongers $B C$, van Kamp MS, Kotte $H$, Weltevreden $P$, de Jongh FHC, Eijsvogel MMM, Wymenga ANM, Bigirwamungu-Bargeman M, van der Palen J, van Det MJ, van Meeteren NLU, Klaase JM. The effects of prehabilitation versus usual care to reduce postoperative complications in high-risk patients with colorectal cancer or dysplasia scheduled for elective colorectal resection: study protocol of a randomized controlled trial. BMC Gastroenterol 2018;18(1):29. 

Addendum 



\section{Addendum}

In this Thesis, there are some discrepancies regarding patient numbers in the various Chapters. This addendum tries to clarify these discrepancies.

In Chapter $\mathbf{2}$ and 3, a different selection filter has been used in the same database of patients. In Chapter 2, only the patients who fully complied with the enhanced recovery after surgery program were analysed. The patients who died in this period where excluded, also because mortality was not an outcome measure in this chapter. In Chapter 3, all the patients in the database were analysed.

In Chapter 4, the risk of anastomotic leakage with NSAIDs within an enhanced recovery program was investigated. Therefore, only patients who had an anastomosis were included in this study. This explains why there are fewer patients in this study compared to Chapter $\mathbf{2}$ and $\mathbf{3}$.

In Chapter 7, the influence of visceral obesity, as measured by preoperative abdominal $\mathrm{CT}$, in relation to $\mathrm{BMI}$, on the incidence of postoperative complications and duration of hospital stay was assessed in a large cohort of patients with colon cancer. Not all colon cancer patients registered in the hospital database received a preoperative abdominal CT-scan. This explains the smaller number of patients compared with Chapter $\mathbf{3}$. The sentence "The routinely performed preoperative CT scan can be used for screening the $B M I<25 \mathrm{~kg} / \mathrm{m}^{2}$ group for visceral obesity to identify a colon cancer population at significant risk for postoperative complications" in the section discussion does not apply to the current study, but is more a recommendation for future studies.

In Chapter 8, the impact of visceral obesity on post-operative outcome in rectal carcinoma surgery after preoperative chemoradiation was studied. In this study, only the patients who received preoperatively chemoradiation were included explaining the difference in numbers between this Chapter and other chapters in the Thesis. 

Nederlandse samenvatting 



\section{Versneld herstel na operatie}

In de jaren negentig onderging chirurgie belangrijke veranderingen als gevolg van verbetering op het gebied van chirurgische, anesthetische en analgetische technieken. Een multidisciplinaire aanpak van perioperatieve zorg werd ingesteld en samen met laparoscopische chirurgie heeft dit geleid naar sneller herstel in ambulante chirurgie.

Programma's opgericht met deze praktische verandering werden "fast track" programma's genoemd en deze benadering veranderde vele meerdaagse opnameingrepen in eendaagse opname-ingrepen. In 1997 introduceerde Hendrik Kehlet, een Deense chirurg, een multimodale "evidence-based"programma om postoperatief herstel te bespoedigen, wat "multimodale rehabilitatie" genoemd werd. ${ }^{1}$ Kehlet benadrukte dat multimodale interventies in preoperatieve, intra-operatieve en postoperatieve zorg zou kunnen leiden tot sneller herstel na chirurgische procedures door de preoperatieve orgaanfunctie in stand te houden en de stress-response na chirurgie te verminderen. Stress-geïnduceerde orgaandysfunctie, pijn, misselijkheid en braken, ileus, hypoxemie en slaapstoornissen, vermoeidheid, immobilisatie en nuchter blijven, drains en maaghevels met vasten werden geïdentificeerd als belangrijkste factoren die bijdragen aan een langzaam herstel. In eerste instantie, richtte Kehlet zich op de implementatie van dit multimodale programma bij de colorectale chirurgie.

Na deze eerste jaren was er een grote variatie in het aanvaarden van deze innovatieve aanpak onder colorectale chirurgen en de meesten hielden zich niet aan het programma. In 2000, werd het versneld herstel na operatie (ERAS) studiegroep opgericht na een samenwerkingsverband van 5 gespecialiseerde internationale chirurgische afdelingen (Denemarken, Verenigd Koninkrijk, Noorwegen, Zweden en Nederland). De ERAS groep beoordeelde kritisch de klinische behandeling en uitkomsten van colorectale ingrepen in deze vijf centra waarvan op dat moment alleen het Deense centrum het "fast track" programma geïmplementeerd had. ${ }^{2}$ De ziekenhuisopname (LOS) was aanzienlijk korter in het "fast track" centrum in Denemarken vergeleken met de andere "traditionele zorg" ziekenhuizen. De ERAS zorg in Denemarken had geen invloed op morbiditeit en 30-dagen mortaliteit, maar was wel geassocieerd met een hogere heropname ratio als de ziekenhuisopname gereduceerd was tot 2-3 dagen. De heropname ratio was niet verhoogd als de ziekenhuisopname rond de 5 dagen was. In 2005 ontwikkelde de groep een evidence-based ERAS protocol voor patiënten die een coloningreep ondergingen met als doel een ziekenhuisopname van 5 dagen wat aanzienlijk korter was dan de traditionele 10-11 dagen. ${ }^{3}$ De effecten van ERAS programma's op chirurgische uitkomsten zijn uitgebreid bestudeerd en 
tegenwoordig zijn ERAS programma's standaard zorg na colorectale resecties in vele instellingen.

Een van de doelstellingen van dit proefschrift was het evalueren van de naleving en resultaten van de implementatie van een ERAS programma bij colonchirurgie. Hoewel het ERAS programma succesvol is geweest bij patiënten die een colorectale of een ander soort ingreep ondergingen, is de implementatie van een ERAS programma en de naleving van de onderdelen een grote uitdaging geweest. In dit proefschrift werd een retrospectieve analyse gepresenteerd van patiënten die tussen 2006 en 2010 een electieve coloningreep ondergingen in verband met een maligniteit (Hoofdstuk 2). De naleving in de eerste 2 jaren was $84 \%$ en daalde in de laatste 2 jaren tot $72 \%$. De LOS was in 2006 en 2007 aanzienlijk korter dan in 2005. Er werden geen significante verschillen gevonden in LOS tussen 2008 en 2009 in vergelijking met 2005. De winst van een kortere LOS ging verloren toen de naleving van het ERAS programma laag was. Meer urineweginfecties werden gezien in 2009 in vergelijking met de andere jaren. Bovendien werden in de laatste 2 jaren meer re-operaties waargenomen dan in de eerste 2 jaren. Deze data bevestigen de resultaten van andere studies die uitgevoerd zijn in de eerste jaren van implementatie van een ERAS programma. ${ }^{2,4}$ De naleving van een ERAS programma is een multidisciplinaire verantwoordelijkheid. In onze studie vond het verlies van de naleving van het ERAS programma door de jaren heen voornamelijk in de postoperatieve periode plaats. Varadhan et al. toonde aan dat de implementatie van vier of meer elementen van het ERAS programma de LOS en complicaties verlaagde van patiënten die een grote colorectale ingreep ondergingen. ${ }^{5}$ Deze studie kon niet inzichtelijk maken welke elementen het belangrijkst waren. In dit proefschrift waren leeftijd, laparoscopische chirurgie, verwijdering van de neusmaagsonde voor extubatie, mobilisatie binnen 24 uur na de operatie, het starten van NSAID's op dag 1 en verwijdering van de epidurale analgesie op dag 2 voorspellers van een kortere LOS. We hebben ook een onderzoek uitgevoerd naar 8 jaar naleving van het ERAS programma en de effecten hiervan op postoperatieve uitkomsten bij patiënten die een colon ingreep in verband met een maligniteit ondergingen (Hoofdstuk 3). Hierin werd aangetoond dat specifieke maatregelen de naleving en daarmee de uitkomsten na colonchirurgie voor een maligniteit kunnen verbeteren. Belangrijke factoren zijn onder meer het gebruik van een gespecialiseerde afdeling, toegewijde anesthesiologen, een leider die verantwoordelijk is voor coördinatie van updates en training, regelmatige audits en de disseminatie van resultaten. De naleving van het ERAS programma was omgekeerd evenredig met de LOS. Er was een kortere verblijfsduur in de jaren met een hoge naleving (5.7 vs. 7.3 dagen). Na specifieke maatregelen verbeterde de naleving van het ERAS programma opnieuw in 2012 en 
2013 en dit leidde weer tot een kortere LOS. De resultaten van deze studie zijn vergelijkbaar met andere studies. ${ }^{6,7}$ De studie die in Hoofdstuk 3 beschreven wordt, toonde ook aan dat alleen de naleving van de postoperatieve onderdelen gerelateerd was aan een kortere LOS. Uit deze studies blijkt dat het handhaven van de naleving herhaalde training en toegewijd personeel vereist.

\section{Risicofactoren die van invloed zijn op het herstel van patiënten die volgens een ERAS protocol behandeld zijn}

Een van de meer gevreesde complicaties die kan optreden na een colorectale resectie is een naadlekkage. De incidentie van een naadlekkage varieert van $8 \%$ bij colonresecties tot maximaal $13 \%$ bij lage rectumresecties. ${ }^{8-11}$ Meerdere studies hebben aangetoond dat het risico op een naadlekkage kan toenemen bij het gebruik van niet-steroïde antiinflammatoire geneesmiddelen (NSAID's). ${ }^{11-16}$ Een belangrijk onderdeel van het ERAS programma is pijnbestrijding middels epidurale analgesie en NSAID's. NSAID's worden verondersteld essentiële stappen in de wondgenezing te beïnvloeden en daarmee ook de genezing van de anastomose. ${ }^{15} \mathrm{Er}$ werd een retrospectieve studie uitgevoerd naar de effecten van postoperatief gebruik van NSAID's op het optreden van een naadlekkage bij patiënten die een colorectale ingreep binnen een ERAS programma ondergingen (Hoofdstuk 4). De resultaten van deze studie toonden aan dat de NSAID diclofenac tot meer naadlekkages leidt bij patiënten die een colorectale ingreep ondergingen. Deze bevindingen komen overeen met andere studies die een hoger percentage naadlekkage lieten zien bij het gebruik van diclofenac of COX-2 selectieve NSAID's. ${ }^{11,16-17}$

Obesitas is een snel groeiend gezondheidsprobleem in de westerse wereld. Obesitas beïnvloedt de uitkomsten van chirurgische ingrepen. ${ }^{18-24}$ Een nauwkeurige schatting van de lichaamssamenstelling is daarom van groot belang. Body Mass Index (BMI) als algemene maatstaf voor obesitas is niet altijd consistent met de hoeveelheid visceraal vet en visceraal vet is anders verdeeld onder verschillende etnische groeperingen. Onlangs is een nieuwe BMI-formule ontwikkeld, omdat de traditionele BMI-formule de vetophoping bij lange mensen kan overschatten en bij kleine mensen kan onderschatten. Aangezien de lengte van een persoon een grotere impact krijgt in deze formule $\left(1.3 \times\right.$ gewicht/lengte $\left.{ }^{2,5}\right)$, wordt er van uitgegaan dat dit de werkelijkheid beter benadert. ${ }^{25}$ Er werd een studie uitgevoerd die de voorspellende waarde van deze BMIformule voor postoperatieve complicaties na darmchirurgie i.v.m. een maligniteit in vergelijking met de traditionele BMI-formule onderzocht (Hoofdstuk 5). Er werd geen 
voordeel van de nieuwe BMI-formule aangetoond bij het voorspellen van postoperatieve complicaties.

In de studies van Tsujinaka en Cecchini bleek viscerale obesitas, vastgesteld aan de hand van volumetrische vetmetingen (CT-scan), een betere voorspeller te zijn van korte termijnresultaten na colorectale resectie vanwege een maligniteit dan BMI. $^{26-27}$ Viscerale obesitas is geassocieerd met slechtere uitkomsten na colorectale chirurgie en ook na andere vormen van chirurgie. ${ }^{18-24}$ Viscerale obesitas is ook een risicofactor voor een langer verblijf in het ziekenhuis na colorectale chirurgie. ${ }^{27-28,30}$ De meeste antropometrische methoden (BMI, middelomtrek of taille-tot-heup verhouding) geven een indicatie van het totale lichaamsvet, inclusief visceraal en subcutaan vet. Inschatting van obesitas is belangrijk en zou ook informatie moeten bevatten over viscerale vs. subcutane obesitas, omdat deze de uitkomst anders kunnen beïnvloeden. Viscerale obesitas kan nauwkeurig worden gemeten met behulp van CT-scans. ${ }^{30-31}$ Een systematische review en meta-analyse werd uitgevoerd van studies die keken naar het effect van viscerale obesitas, gemeten met CT-scan, op de uitkomsten van patiënten die een colorectale ingreep vanwege een maligniteit ondergingen (Hoofdstuk 6). Uit de zeven studies (meestal Japanse studies) beschreven in deze meta-analyse, kunnen wij concluderen dat viscerale obesitas tot een langere LOS, hogere morbiditeit en langere operatieduur bij electieve colonchirurgie leidt. Andere auteurs hebben reeds gemeld dat viscerale obesitas tot hogere aantallen wondhernia, pulmonale en cardiovasculaire complicaties, langere operatieduur en lagere ziektevrije overleving na major colorectale chirurgie kan leiden. ${ }^{32-33}$

Viscerale obesitas verhoogt het risico op het metabool syndroom en dit kan leiden tot een hoger aantal complicaties na darmkankeroperaties. ${ }^{27-29}$ Een visceraal vetgebied van $>100 \mathrm{~cm}^{2}$ is geassocieerd met het metabool syndroom en is een risicofactor voor een slechtere uitkomst en een langere LOS na colorectale operaties. ${ }^{20,34-36}$ De meeste gepubliceerde resultaten zijn tot nu toe afkomstig van Japanse studies; weinig is bekend over het belang van viscerale obesitas bij de westerse bevolking. Er is een studie uitgevoerd naar de effecten van viscerale obesitas, gemeten door CT-scan en BMI, op de incidentie van complicaties en LOS na chirurgie voor darmkanker (Hoofdstuk 7). Dit toonde een groter effect van viscerale obesitas op de uitkomst na darmkankeroperaties bij patiënten met een BMI $<25 \mathrm{~kg} / \mathrm{m}^{2}$. In de groepen met patiënten met overgewicht en obesitas was viscerale obesitas niet significant geassocieerd met slechtere postoperatieve uitkomsten. Een vergelijkbare associatie tussen lagere BMI's en hogere viscerale obesitas werd gevonden voor het risico van overlijden in een algemene populatie in de studie van Pischon et al.. ${ }^{38}$ In deze studie 
werd viscerale obesitas geassocieerd met meer comorbiditeit, een hoger aantal postoperatieve complicaties en heroperaties, en een langer verblijf in het ziekenhuis. Deze resultaten komen overeen met de bevindingen van andere auteurs. ${ }^{26}$

Bij lokaal gevorderde rectumkanker is preoperatieve chemoradiatie een van de standaard behandelingen en dit zou de lichaamssamenstelling kunnen beïnvloeden. $\mathrm{Er}$ werd een studie uitgevoerd naar de invloed van chemoradiatie op viscerale obesitas en het effect hiervan op postoperatieve uitkomsten (Hoofdstuk 8). Er werd geen verschil gevonden in visceraal vetgebied na chemoradiatie. Viscerale obesitas was sterk geassocieerd met een slechter resultaat na rectumchirurgie vanwege en maligniteit. In deze context kan het bepalen van de hoeveelheid visceraal vetweefsel, met behulp van de routinematig uitgevoerde preoperatieve CT-scan, bijdragen aan het vaststellen van een preoperatief metabool risicoprofiel bij patiënten met rectumkanker.

\section{Toekomstperspectieven}

$\mathrm{Na}$ implementatie van een ERAS programma, is het belangrijk om een goede naleving van het ERAS protocol te behouden om de voordelen van deze aanpak voor de patiënt te waarborgen. ${ }^{38}$ De naleving van een ERAS programma is complex vanwege het multidisciplinaire karakter. Het is gevoelig voor veranderingen en continue monitoring en terugkoppeling zijn vereist om een blijvend succes te garanderen. Ziekenhuisbesturen moeten de verantwoordelijkheid nemen om ervoor te zorgen dat deze multidisciplinaire protocollen in een organisatie voortdurend worden geïmplementeerd, omdat zonder naleving van zo'n protocol de voordelen m.b.t. zorg en kosten gemakkelijk verloren gaan. Het is al bewezen dat een gestructureerde implementatiestrategie kan resulteren in een goede duurzaamheid. ${ }^{39}$ Het ERAS programma heeft bijgedragen aan een gestandaardiseerde benadering van perioperatieve zorg bij colorectale kankerchirurgie. Dit heeft niet alleen de kwaliteit van zorg verbeterd, maar maakt het ook mogelijk om onderzoek te verrichten naar variabelen die van invloed zijn op de chirurgische uitkomst, zoals viscerale obesitas en het gebruik van NSAID's. Er moet voortdurend inspanning geleverd worden om de naleving van het ERAS programma te verbeteren en te monitoren om deze standaardisatie van zorg voor de patiënt met colorectale kanker en ook voor patiënten met een goedaardige colorectale aandoening te waarborgen.

Alle aanbevelingen van de ERAS sociëteit voor colonchirurgie kunnen mogelijk bij andere patiënten die worden geopereerd voor maagkanker of lever-, pancreas- of 
gynaecologische chirurgie geïmplementeerd worden, d.w.z. vroege verwijdering van de urinekatheter, preventie van postoperatieve ileus, postoperatieve pijnstilling en vroege mobilisatie en hervatting van normaal dieet. ${ }^{40}$ In de afgelopen jaren zijn pogingen gedaan om een vergelijkbaar programma in bijvoorbeeld maagkankerchirurgie te ontwikkelen, te implementeren en de effecten hiervan te evalueren. Studies over de timing van orale intake na een maagresectie voor maagkanker zijn schaars. De weinige studies die er zijn, hebben aangetoond dat vroege orale voeding veilig en haalbaar is. ${ }^{41}$ Andere vergelijkende studies toonden significant kortere LOS (bijv. 5.7 vs. 9.2 dagen) en snellere terugkeer van de darmfunctie aan. ${ }^{42-44}$ Hoewel de strategieën voor vroege orale voeding verschillend waren, waren de bevindingen dat het veilig is en dat het mogelijk tot kortere LOS leidt. ${ }^{42-44}$ Een gerandomiseerde klinische studie bij maagkankerpatiënten, waaronder 22 patiënten behandeld volgens een ERAS programma en 22 conventionele zorgpatiënten, liet een kortere LOS voor ERAS programmapatiënten ( 5 vs. 8 dagen, $P<0,001$ ) zien maar er werd geen verschil aangetoond voor postoperatieve pijn. ${ }^{45}$ Dit heeft geresulteerd in de publicatie van een maagkankerchirurgie-specifieke ERAS-richtlijn, maar vanwege het beperkte bewijs voor vele aspecten van ERAS is dit grotendeels een consensusrichtlijn. ${ }^{46}$

In lijn met deze resultaten voor maagchirurgie en colorectale chirurgie, toonden verschillende onderzoeken ook een verminderde LOS wanneer patiënten werden behandeld binnen een ERAS programma voor leverchirurgie, pancreaticoduodenectomie en gynaecologische chirurgie. ${ }^{47-50}$ LOS werd verlaagd zonder de morbiditeit, mortaliteit of het aantal heropnamen in gevaar te brengen. Dit heeft ook geresulteerd in de publicatie van lever- en pancreaskanker specifieke ERAS richtlijnen. $^{51-52}$

Een andere veelbelovende ontwikkeling die kan worden geïmplementeerd in de bestaande ERAS programma's is de prehabilitatie van patiënten die een grote operatie ondergaan. Het optimaliseren van preoperatieve fysieke fitheid (bijv. cardiorespiratoire fitness, spierkracht en functionele mobiliteit) kan namelijk de postoperatieve uitkomsten verbeteren bij patiënten die een grote buikoperatie ondergaan. Moran et al. toonde in een systematische review aan dat prehabilitatie gunstig bleek te zijn voor het verminderen van de incidentie van postoperatieve complicaties. ${ }^{53}$ Bovendien rapporteerde Bruns et al. in een systematische review dat het tevens de fysieke fitheid van oudere patiënten die een colorectale operatie ondergaan, kan verbeteren. Ze lieten geen nadelig effect zien op het aantal complicaties of LOS. ${ }^{54}$ Tevens is aangetoond dat gepersonaliseerde prehabilitatie het aantal patiënten met postoperatieve complicaties met $51 \%$ verminderde bij hoogrisicopatiënten die een electieve grote abdominale 
chirurgie ondergingen. ${ }^{55}$ Momenteel is de literatuur schaars over het effect van preoperatieve oefentraining op postoperatieve complicaties bij hoogrisicopatiënten met colorectale kanker. De meeste studies bevatten te weinig patiënten, zijn heterogeen en bevooroordeeld in de selectie van patiënten met een laag risico op postoperatieve complicaties.

In 2014 werd een goede gerandomiseerde studie gestart die keek naar de effecten van een prehabilitatie programma van drie weken op postoperatieve complicaties bij patiënten met een slechte cardiorespiratoire fitheid, die electieve colorectale resectie ondergingen voor colorectale kanker of dysplasie graad I, II of III. ${ }^{56}$ De inclusie zal naar verwachting eind 2018 afgerond zijn. 


\section{References}

1. Kehlet $\mathrm{H}$. Multimodal approach to control postoperative pathophysiology and rehabilitation. $\mathrm{Br} \mathrm{J}$ Anaesth 1997;78(5):606-17.

2. Nygren J, Hausel J, Kehlet H, Revhaug A, Lassen K, Dejong C, Andersen J, von Meyenfeldt M, Ljungqvist $\mathrm{O}$, Fearon KC. A comparison in five European Centres of case mix, clinical management and outcomes following either conventional or fast-track perioperative care in colorectal surgery. Clin Nutr 2005; 24(3):455-61.

3. Fearon KC, Ljungqvist O, Von Meyenfeldt M, Revhaug A, Dejong CH, Lassen K, Nygren J, Hausel J, Soop $\mathrm{M}$, Andersen J, Kehlet $\mathrm{H}$. Enhanced recovery after surgery: a consensus review of clinical care for patients undergoing colonic resection. Clin Nutr 2005;24(3):466-77.

4. Basse L, Thorbol JE, Lossl K, Kehlet H. Colonic surgery with accelerated rehabilitation or conventional care. Dis Colon Rectum 2004;47:271-7.

5. Varadhan $\mathrm{KK}, \mathrm{Neal} \mathrm{KR}$, Dejong $\mathrm{CH}$, et al. The enhanced recovery after surgery (ERAS) pathway for patients undergoing major elective open colorectal surgery: a meta-analysis of randomized controlled trials. Clin Nutr 2010;29:434-40.

6. Ahmed J, Khan S, Lim M, Chandrasekaran TV, MacFie J. Enhanced recovery after surgery protocols compliance and variations in practice during routine colorectal surgery. Colorectal Dis 2012;14:1045-51.

7. Greco M, Capretti G, Beretta L, Gemma M, Pecorelli N, Braga M. Enhanced recovery program in colorectal surgery: a meta-analysis of randomized controlled trials. World J Surg 2014;38:1531-41.

8. Bakker IS, Grossmann I, Henneman D, Havenga K, Wiggers T. Risk factors for anastomotic leakage and leak-related mortality after colonic cancer surgery in a nationwide audit: Br J Surg 2014;101:424-32.

9. Pommergaard HC, Gessler B, Burcharth J, Angenete E, Haglind E, Rosenberg J. Preoperative risk factors for anastomotic leakage after resection for colorectal cancer: a systematic review and meta-analysis: Colorectal Dis 2014;16(9):662-71.

10. Kube R, Mroczkowski P, Granowski D, Benedix F, Sahm M, Schmidt U et al. Anastomotic leakage after colon cancer surgery: a predictor of significant morbidity and hospital mortality, and diminished tumour-free survival: Eur J Surg Oncol 2010;36:120-4.

11. Klein M, Gogenur I, Rosenberg J. Postoperative use of non-steroidal anti-inflammatory drugs in patients with anastomotic leakage requiring reoperation after colorectal resection: cohort study based on prospective data: BMJ 2012;345:e6166.

12. Holte $\mathrm{K}$, Andersen J, Jakobsen $\mathrm{DH}$, Kehlet $\mathrm{H}$. Cyclo-oxygenase 2 inhibitors and the risk of anastomotic leakage after fast-track colonic surgery: Br J Surg 2009;96:650-4.

13. Gorissen KJ, Benning D, Berghmans T, Snoeijs MG, Sosef MN, Hulsewe KW et al. Risk of anastomotic leakage with non-steroidal anti-inflammatory drugs in colorectal surgery: Br J Surg 2012;99:721-7.

14. Bhangu A, Singh P, Fitzgerald JE, Slesser A, Tekkis P. Postoperative Nonsteroidal Anti-inflammatory Drugs and Risk of Anastomotic Leak: Meta-analysis of Clinical and Experimental Studies: World J Surg 2014;38(9):2247-57.

15. Rushfeldt CF, Sveinbjornsson B, Soreide K, Vonen B. Risk of anastomotic leakage with use of NSAIDs after gastrointestinal surgery: Int J Colorectal Dis 2011;26:1501-9.

16. Klein M, Andersen LP, Harvald T, Rosenberg J, Gogenur I. Increased risk of anastomotic leakage with diclofenac treatment after laparoscopic colorectal surgery: Dig Surg 2009;26:27-30.

17. Holte $\mathrm{K}$, Andersen J, Jakobsen $\mathrm{DH}$, Kehlet $\mathrm{H}$. Cyclo-oxygenase 2 inhibitors and the risk of anastomotic leakage after fast-track colonic surgery: Br J Surg 2009;96:650-4.

18. Ueda J, Ichimiya H, Okido M, Kato $M$. The impact of visceral fat accumulation on laparoscopy-assisted distal gastrectomy for early gastric cancer. J Laparoendosc Adv Surg Tech A 2009;19(2):157-62.

19. Yoshikawa K, ShimadaM, Kurita N, Iwata T, Nishioka M,Morimoto S, Miyatani T, Komatsu M, Mikami C, Kashihara H. Visceral fat area is superior to body mass index as a predictive factor for risk with laparoscopy-assisted gastrectomy for gastric cancer. Surg Endosc 2011;25(12):3825-30.

20. Miyaki A, Imamura K, Kobayashi R, TakamiM,Matsumoto J. Impact of visceral fat on laparoscopyassisted distal gastrectomy. Surgeon 2013;11(2):76-81. 
21. Tokunaga M, Hiki N, Fukunaga T, Ogura T, Miyata S, Yamaguchi T. Open gastrectomy for gastric cancer. Br J Surg 2009;96(5):496-500.

22. Shimizu A, Tani M, KawaiM, Hirono S,MiyazawaM, Uchiyama K, Yamaue H. Influence of visceral obesity for postoperative pulmonary complications after pancreaticoduodenectomy. J Gastrointest Surg 2011; 15(8):1401-10.

23. Hagiwara M, Miyajima A, Hasegawa M, Jinzaki M, Kikuchi E, Nakagawa K, Oya M. Visceral obesity is a strong predictor of perioperative outcome in patients undergoing laparoscopic radical nephrectomy. BJU Int 2011;110(11):E980-4.

24. Ballian N, Lubner MG, Munoz A, Harms BA, Heise CP, Foley EF, et al. Visceral obesity is associated with outcomes of total mesorectal excision for rectal adenocarcinoma. J Surg Oncol 2012;105:365-70.

25. Wilton P. Does my bmi look big in this?; 2013 Available from: http://www.ox.ac.uk/media/science_blog/ 130116.html

26. Tsujinaka S, Konishi F, Kawamura YJ, Saito M, Tajima N, Tanaka O, Lefor AT. Visceral obesity predicts surgical outcomes after laparoscopic colectomy for sigmoid colon cancer. Dis Colon Rectum 2008; 51(12):1757-65.

27. Cecchini S, Cavazzini E, Marchesi F, Sarli L, Roncoroni L. Computed tomography volumetric fat parameters versus body mass index for predicting short-term outcomes of colon surgery. World J Surg 2011;35(2):415-23.

28. Tapper R, Dixon L, Frampton C, Frizelle F. Impact of obesity on the cost of major colorectal surgery. Br J Surg 2013;100:293-8.

29. Gendall KA, Raniga S, Kennedy R, Frizelle FA. The impact of obesity on outcome after major colorectal surgery. Dis Colon Rectum 2007;50:2223-37.

30. Shuster A, Patlas M, Pinthus JH, Mourtzakis $M$. The clinical importance of visceral adiposity: a critical review of methods for visceral adipose tissue analysis. Br J Radiol 2012;85(1009):1-10.

31. Nitori N, Hasegawa H, Ishii Y, Endo T, Kitagawa Y. Impact of visceral obesity on short-term outcome after laparoscopic surgery for colorectal cancer: a single Japanese center study. Surg Laparosc Endosc Percutan Tech 2009;19(4):324-7.

32. Moon HG, Ju YT, Jeong CY, Jung EJ, Lee YJ, Hong SC, Ha WS, Park ST, Choi SK. Visceral obesity may affect oncologic outcome in patients with colorectal cancer. Ann Surg Oncol 2008;15(7):1918-22.

33. Sakai T, Maekawa T, Mikami K, Kuramochi H, Noda S. Visceral fat volume and surgical outcomes of colorectal resection. Int Surg 2009;94:370-2.

34. Watanabe J, Tatsumi K, Ota M, Suwa Y, Suzuki S, Watanabe A, et al. The impact of visceral obesity on surgical outcomes of laparoscopic surgery for colon cancer. Int J Colorectal Dis 2014;29:343-51.

35. Rickles AS, lannuzzi JC, Mironov O, Deeb AP, Sharma A, Fleming FJ, et al. Visceral obesity and colorectal cancer: are we missing the boat with BMI? J Gastrointest Surg 2013;17:133-43.

36. Hiuge-Shimizu A, Kishida K, Funahashi T, Ishizaka Y, Oka R, Okada M, et al. Absolute value of visceral fat area measured on computed tomography scans and obesity-related cardiovascular risk factors in largescale Japanese general population (the VACATION-J study). Ann Med 2012;44:82-92.

37. Pischon T, Boeing H, Hoffmann K, Bergmann M, Schulze MB, Overvad K, et al. General and abdominal adiposity and risk of death in Europe. N Engl J Med 2008;359:2105-20.

38. Feroci F, Lenzi E, Baraghini M, Garzi A, Vannucchi A, Cantafio S, Scatizzi M. Fast-track colorectal surgery: protocol adherence influences postoperative outcomes. Int J Colorectal Dis 2013;28(1):103-9.

39. Gillissen F, Ament SM, Maessen JM, Dejong CH, Dirksen CD, van der Weijden T, von Meyenfeldt MF. Sustainability of an enhanced recovery after surgery program (ERAS) in colonic surgery. World J Surg 2015;39(2):526-33.

40. Gustafsson UO, Scott MJ, Schwenk W, Demartines N, Roulin D, Francis N, McNaught CE, MacFie J, Liberman AS, Soop M, Hill A, Kennedy RH, Lobo DN, Fearon K, Ljungqvist O, and Enhanced Recovery After Surgery S, Guidelines for perioperative care in elective colonic surgery: Enhanced Recovery After Surgery (ERAS(R)) Society recommendations. Clin Nutr 2012;31(6):783-800.

41. Jo DH, Jeong O, Sun JW, Jeong MR, Ryu SY, and Park YK, Feasibility study of early oral intake after gastrectomy for gastric carcinoma. J Gastric Cancer 2011;11(2):101-8.

42. Hur H, Si Y, Kang WK, Kim W, and Jeon HM, Effects of early oral feeding on surgical outcomes and recovery after curative surgery for gastric cancer: pilot study results. World J Surg 2009;33(7):1454-8. 
43. Suehiro T, Matsumata T, Shikada $Y$, and Sugimachi K, Accelerated rehabilitation with early postoperative oral feeding following gastrectomy. Hepatogastroenterology 2004;51(60):1852-5.

44. Hur H, Kim SG, Shim JH, Song KY, Kim W, Park CH, and Jeon HM, Effect of early oral feeding after gastric cancer surgery: a result of randomized clinical trial. Surgery 2011;149(4):561-8.

45. Kim JW, Kim WS, Cheong JH, Hyung WJ, Choi SH, and Noh SH, Safety and efficacy of fast-track surgery in laparoscopic distal gastrectomy for gastric cancer: a randomized clinical trial. World J Surg 2012;36(12): 2879-87

46. Mortensen K, Nilsson M, Slim K, Schafer M, Mariette C, Braga M, Carli F, Demartines N, Griffin SM, Lassen K, and Enhanced Recovery After Surgery G, Consensus guidelines for enhanced recovery after gastrectomy: Enhanced Recovery After Surgery (ERAS(R)) Society recommendations. Br J Surg 2014; 101(10):1209-29.

47. van Dam RM, Hendry PO, Coolsen MM, Bemelmans MH, Lassen K, Revhaug A, Fearon KC, Garden OJ, Dejong $\mathrm{CH}$; Enhanced Recovery After Surgery (ERAS) Group. Initial experience with a multimodal enhanced recovery programme in patients undergoing liver resection. Br J Surg 2008;95(8):969-75.

48. Coolsen MM, Wong-Lun-Hing EM, van Dam RM, van der Wilt AA, Slim K, Lassen K, Dejong $\mathrm{CH}$. A systematic review of outcomes in patients undergoing liver surgery in an enhanced recovery after surgery pathways. HPB (Oxford) 2013;15(4):245-51.

49. Coolsen MM, van Dam RM, Chigharoe A, Olde Damink SW, Dejong CH. Improving outcome after pancreaticoduodenectomy: experiences with implementing an enhanced recovery after surgery (ERAS) program. Dig Surg 2014;31(3):177-84.

50. de Groot JJ, Ament SM, Maessen JM, Dejong CH, Kleijnen JM, Slangen BF. Enhanced recovery pathways in abdominal gynecologic surgery: a systematic review and meta-analysis. Acta Obstet Gynecol Scand 2016;95(4):382-95.

51. Melloul E, Hübner M, Scott M, Snowden C, Prentis J, Dejong CH, Garden OJ, Farges O, Kokudo N, Vauthey JN, Clavien PA, Demartines N. Guidelines for Perioperative Care for Liver Surgery: Enhanced Recovery After Surgery (ERAS) Society Recommendations. World J Surg 2016;40(10):2425-40.

52. Lassen K, Coolsen MM, Slim K, Carli F, de Aguilar-Nascimento JE, Schäfer M, Parks RW, Fearon KC, Lobo DN, Demartines N, Braga M, Ljungqvist O, Dejong $\mathrm{CH}_{\text {; ERAS }}{ }^{\circledR}$ Society; European Society for Clinical Nutrition and Metabolism; International Association for Surgical Metabolism and Nutrition. Guidelines for perioperative care for pancreaticoduodenectomy: Enhanced Recovery After Surgery (ERAS ${ }^{\circledR}$ ) Society recommendations. Clin Nutr 2012;31(6):817-30.

53. Moran J, Guinan E, Mc Cormick P, Larkin J, Mockler D, Hussey J, et al. The ability of prehabilitation to influence postoperative outcome after intra-abdominal operation: a systematic review and metaanalysis. Surgery 2016;160(5):1189-201.

54. Bruns ER, Van den Heuvel B, Buskens CJ, Van Duijvendijk P, Festen S, Wassenaar EB, et al. The effects of physical prehabilitation in elderly patients undergoing colorectal surgery: a systematic review. Color Dis 2016;18(8):0267-7.

55. Barberan-Garcia A, Ubre M, Roca J, Lacy AM, Burgos F, Risco R, et al. Personalised prehabilitation in high-risk patients undergoing elective major abdominal surgery: a randomized blinded controlled trial. Ann Surg 2018;267(1):50-6.

56. Berkel AEM, Bongers $B C$, van Kamp MS, Kotte $H$, Weltevreden $P$, de Jongh FHC, Eijsvogel MMM, Wymenga ANM, Bigirwamungu-Bargeman M, van der Palen J, van Det MJ, van Meeteren NLU, Klaase JM. The effects of prehabilitation versus usual care to reduce postoperative complications in high-risk patients with colorectal cancer or dysplasia scheduled for elective colorectal resection: study protocol of a randomized controlled trial. BMC Gastroenterol 2018;18(1):29. 
Turkse samenvatting 



\section{Cerrahi Sonrası Gelişmiş İyileştirme}

1990'lı yıllarda, cerrahi, anestezik ve analjezik tekniklerin gelişmesi nedeniyle ameliyatta önemli değişiklikler yapıldı. Perioperatif bakım için multidisipliner bir yaklaşım başlatılmış ve laparoskopik cerrahi ile birlikte bu durum ambulatuvar cerrahide hastanın daha erken iyileşmesini sağlamıştır.

Bu uygulama değişikliklerini içeren programlara "fast track" (hızlı pist) programları deniyordu. Ve bu yöntem sayesinde birçok 'bir çok uzun süre ameliyatlar' 1 günlük cerrahi operasyonlarına dönüştürdü. 1997'de Danimarkalı bir cerrah olan Hendrik Kehlet, ameliyat sonrası iyileşmeyi hızlandırmak için "multimodal rehabilitasyon" olarak adlandırılan multimodal kanıta dayalı bir program başlattı. ${ }^{1}$ Kehlet, preoperatif, intraoperatif ve postoperatif bakımdaki multimodal müdahalelerin, ameliyat öncesi organ fonksiyonunu korumak ve ameliyat sonrası stres yanıtını azaltmak cerrahi prosedürlerden sonra erken rehabilitasyona yol açabileceğinin altını çizdi. Stres kaynaklı organ disfonksiyonu, ağrı, bulantı ve kusma, ileus, hipoksemi ve uyku bozuklukları, yorgunluk, immobilizasyon ve yarı açlık, drenaj ve açlık rejimli nazogastrik tüpler yavaş iyileşmeye katkıda bulunan faktörler olarak tanımlandı. Başlangıçta, Kehlet kolorektal cerrahide bu multimodal programın uygulanması üzerinde durdu.

Bu ilk yıllardan sonra, kolorektal cerrahlar arasında bu yenilikçi yaklaşımın kabulünde geniş bir değişiklik oldu ve çoğu programa uymadı. 2000 yılında, Enhanced Recovery After Surgery (ERAS, Cerrahi Sonrası Gelişmiş İyileştirme) çalışma grubu, beş uzman uluslararası cerrahi departmanının (Danimarka, İngiltere, Norveç, İsveç ve Hollanda) işbirliği ile kuruldu. ERAS grubu, bu beş merkezde kolorektal cerrahi klinik yönetimini ve sonuçlarını gözden geçirdi. Aynı sırada sadece Danimarkalı merkezi, bu 'fast track' programını uyguluyordu. ${ }^{2}$ Danimarka'da "fast track" merkezinde diğer "geleneksel bakım" hastanelerine göre hastenede kalış süresi (LOS, Length of Stay) daha kısaydı. Danimarka'daki ERAS bakımı, hastalık ve 30 günlük ölüm oranı üzerine bir etkiye sahip değildi. Fakat eğer hastanede kalış süresi 2-3 güne azaltılamış ise, daha yüksek yeniden hastaneye kaldırılma oranları ile ilişkilendirildi. Hastenede kalış süresi (LOS) yaklaşık 5 gün ise, yeniden hastaneye kaldırılma oranlarında bir değişiklik, yükselme görünmemiştir. 2005 yılında grup, kolon ameliyatı geçiren hastalar için yaklaşık 5 günlük bir LOS'yi hedef alarak, kanıta dayalı bir ERAS protokolü geliştirdi; bu normal 10-11 günden çok daha kısaydı. ${ }^{3}$ ERAS programlarının cerrahi sonuç üzerindeki etkileri geniş bir şekilde araştırılmıştır ve günümüzde bu program birçok kurumda kolorektal rezeksiyon sonrası standart olmuştur. 
$\mathrm{Bu}$ tezin amaçlarından biri, ERAS programının kolonik cerrahide uygulanmasındaki uyumu ve sonuçlarını değerlendirmekti. ERAS programı kolorektal ameliyat geçiren hastalar için olduğu kadar diğer birçok cerrahi ameliyatları için'de başarılı olsada, birçok merkezde bir ERAS programının uygulanması ve farklı maddelere bağlı kalınması büyük bir zorluk yaşatmıştır. 2006 ve 2010 yılları arasında malignite için elektif kolon ameliyatı geçiren hastaların retrospektif analizi yapıldı ve bu tezde sunuldu (Bölüm 2). Bu çalışmadan ERAS programına bağlı kalmanın, elektif kolon kanseri ameliyatında kalış süresinin uzamasına (LOS) ve daha iyi sonuçlara yol açtığı sonucuna varılabiliriz. İlk 2 yıldaki uyum oranları $84 \%$ idi ve son 2 yılda 72\%'ye düştü. 2006 ve 2007'deki LOS, 2005 'ten anlamlı olarak daha kısaydı. 2008 ve 2009 arasında LOS'ta 2005'e bakarak anlamlı bir fark bulunmadı. Kısa LOS'un yararları, ERAS programına bağlıık düşükken kayboldu. 2009 yılında diğer yıllara göre daha fazla idrar yolu enfeksiyonu görülmüştür. Ayrıca, son 2 yılda, ilk 2 yıldan daha fazla tekrar operasyonı yaşandı. Bu veriler bir ERAS programının uygulanmasının ilk yıllarında yapılan diğer çalışmaların sonuçlarını doğrulamaktadır., ${ }^{2,4}$ ERAS programına multidisipliner bir sorumluluktur. Çalışmamızda yıllar içinde ERAS programına uyum kaybı postoperatif dönemde bulunmuştur. Varadhan ve diğ. ERAS programında dört ya da daha fazla elemanın uygulanmasının, majör kolorektal cerrahi geçiren hastalarda LOS'u azalttığını ve komplikasyon oranlarını azalttığını göstermiştir. ${ }^{5}$ Bu çalışma, hangi unsurların en önemli olduğu konusunda veri sağlayamadı. Bu tez çalışmasında yaş, laparoskopik cerrahi, ekstübasyon öncesi nazogastrik tüpün çıkarılması, ameliyat sonrası 24 saat içinde mobilizasyon, 1. günde NSAID'lerin başlatılması ve 2. günde torasik epidural analjezinin çıkarılması daha kısa bir LOS'un öngörücüsü idi. Ayrıca kolon kanseri ameliyatı geçiren hastalarda ERAS programına 8 yıllık bağlıık ve postoperatif sonuç üzerine etkileri üzerine bir çalışma yaptık (Bölüm 3). Bu, ERAS programında spesifik önlemlerin yapışmayı ve dolayısıyla kolonik cerrahide sonucu malignite açısından iyileştirebileceğini göstermiştir. Anahtar faktörler arasında özel bir koğuş kullanımı, özel anestezistler, güncelleme ve eğitim koordinasyonundan sorumlu bir lider, düzenli denetim ve sonuçların yayılması bulunmaktadır. ERAS programına bağlııı, LOS ile ters orantılıydı. Aderansı yüksek olan yıllarda kalış süreleri kısaydı (5,7 vs. 7,3 gün). Özel önlemler alındıktan sonra, 2012 ve 2013 yıllarında ERAS programına bağlılık yeniden gelişti ve bu daha kısa bir LOS'ye yol açtı. Bu çalışmanın sonuçları daha önce yayınlanmış çalışmalarla karşılaştırılabilir. ${ }^{6,7}$ Bölüm 3 'te rapor edilen çalışma ayrıca sadece postoperatif öğelere uyumun daha kısa bir LOS ile ilişkili olduğunu göstermiştir. Bu çalışmalardan, bağlılı̆ı optimal kılmanın tekrarlı eğitim ve özel personel gerektirdiği anlaşılmaktadır. 


\section{ERAS protokolüne göre tedavi edilen hastalarda kolorektal ameliyat sonrası iyileşmeyi etkileyen risk faktörleri}

Kolorektal rezeksiyon sonrası oluşabilecek en korkulan komplikasyonlardan biri anastomoz kaçağıdır. Anastomoz kaçağının insidansı, kolonik rezeksiyonlarda 8\%'den, rektal rezeksiyonlarda 13\%'e kadar değişmektedir. ${ }^{8-11}$ Birçok çalışma, steroidal olmayan antienflamatuar ilaçların (NSAID'ler) kullanılmasıyla anastomoz sızıntısı riskinin artabileceğini göstermiştir. ${ }^{11-16}$ ERAS programının önemli bir bileşeni, epidural analjezi ve NSAID'leri içeren ağrı yönetimidir. NSAID'lerin, yara iyileşmesinde temel adımları etkilediği ve bu nedenle anastomoz iyileşmesini etkileyebileceği düşünülmektedir. ${ }^{15}$ ERAS programında kolorektal ameliyat geçiren hastalarda postoperatif NSAID'lerin anastomoz kaçağı oluşumu üzerindeki etkisini araştırmak için bu tez çalışmasında retrospektif bir çalışma yapılmıştır (Bölüm 4). Bu çalışmanın sonuçları, NSAID diklofenakın, kolorektal cerrahi geçiren hastalarda daha yüksek oranda anastomoz sızıntısına yol açtığını göstermiştir. Bu bulgular, diklofenak veya COX-2 seçici NSAID'leri ile tedavi edilen hastalarda artmış anastomoz sızıntı oranlarını bildiren diğer çalışmalarla uyumludur. ${ }^{11,16-17}$

Obezite, batı dünyasında hızla artan bir sağlık sorunudur. Obezitenin cerrahi işlemlerin sonuçlarını etkilediği öne sürülmüştür. ${ }^{18-24}$ Bu nedenle vücut kompozisyonunun doğru değerlendirilmesi büyük önem taşımaktadır. Genel bir obezite ölçütü olarak vücut kitle indeksi (BMI) her zaman visseral yağ miktarı ile tutarlı değildir ve visseral yağ çeşitli etnik gruplar arasında farklı şekilde yayılmıştır. Son zamanlarda, yeni bir BMı formülü geliştirilmiştir, çünkü geleneksel BMI formülü uzun insanlarda yağ birikimini abartıp kısa insanlarda hafife alabilir. Bu yeni formülde $\left(1.3 \times\right.$ ağırlık / boy $\left.{ }^{2,5}\right)$ boy daha büyük bir etkiye sahip olduğu için, gerçeğe daha yakın olduğu düşünülmektedir. ${ }^{25}$ Kolorektal kanser cerrahisinde postoperatif komplikasyonlar için bu yeni BMI formülünün prediktif değerini geleneksel BMı formülüne göre araştırmak için bir çalışma yapıldı (Bölüm 5). Postoperatif komplikasyonları öngörmede yeni $\mathrm{BMI}$ formülünün üstünlüğü gösterilmemiştir.

Volumetrik yağ ölçümleri (CT taraması) ile belirlenen viseral obezitenin, Tsujinaka ve Cecchini ${ }^{26-27}$ çalışmalarında kolorektal kanser rezeksiyonu sonrası VKi'den kısa dönem sonuçların daha iyi bir yordayıcısı olduğu gösterilmiştir. Viseral obezite kolorektal cerrahide ve ayrıca diğer cerrahi formlarda daha kötü sonuçlarla ilişkilendirilmiştir. ${ }^{18-24}$ Viseral obezite, kolorektal cerrahi sonrası hastanede daha uzun süre kalmak için de risk faktörüdür. ${ }^{27-28,30}$ Antropometrik yöntemlerin çoğu (BMI, bel çevresi veya bel-kalça 
oranı), visseral ve subkutan yağ dahil olmak üzere toplam vücut yağının bir göstergesidir. Obezitenin değerlendirilmesi önemlidir ve sonuçları farklı bir şekilde etkileyebileceği için visseral ve subkutan obezite hakkında da bilgi içermelidir. Viseral obezite, CT taramaları kullanılarak doğru şekilde ölçülebilir. ${ }^{30-31}$ CT taraması ile ölçülen viseral obezitenin kolorektal kanser ameliyatı geçiren hastaların sonuçları üzerindeki etkisini araştıran çalışmaların tezinde sistematik bir derleme ve meta-analiz yapılmıştır (Bölüm 6). Bu meta-analizde tarif edilen yedi çalışmadan (çoğunlukla Japon çalışmaları), viseral obezitenin elektif kolon cerrahisinde daha uzun LOS, yüksek morbidite ve daha uzun ameliyat süresine yol açtığı sonucuna vardık. Diğer yazarlar viseral obezitenin büyük sayıda yara fıtığı, pulmoner ve kardiyovasküler komplikasyonlara, daha uzun operasyon süresine ve majör kolorektal cerrahi sonrası hastalıksız hayatta kalma oranına yol açtığını bildirmişlerdir. ${ }^{32-33}$

Viseral obezite metabolik sendrom riskini arttırır ve bu kolon kanseri cerrahisi sonrası daha yüksek komplikasyonlara yol açabilir. ${ }^{27-29}>100 \mathrm{~cm}^{2}$ viseral yağ bölgesi metabolik sendromla ilişkilidir ve kolorektal operasyonlardan sonra kötü sonuç ve daha uzun LOS için risk faktörüdür. ${ }^{20,34-36}$ Şimdiye kadar yayınlanan sonuçların çoğu Japonca çalışmalardan geliyor; Batı popülasyonunda viseral obezitenin önemi hakkında çok az şey bilinmektedir. Bu tez çalışmasında, CT taraması ve BMı ile ölçülen viseral obezitenin kolon kanseri için ameliyat sonrası komplikasyon ve LOS insidansı üzerine etkisini değerlendiren bir çalışma yapılmıştır (Bölüm 7). Bu, BMI $<25 \mathrm{~kg} / \mathrm{m}^{2}$ olan hastalarda kolon kanseri cerrahisi sonrası viseral obezitenin sonuca etkisi daha yüksek olduğunu göstermiştir. Aşırı kilolu ve obez hasta gruplarında viseral obezite postoperatif kötü sonuçlarla anlamlı olarak ilişkili değildi. Pischon ve arkadaşlarının çalışmasında, genel BMI popülasyonunda ölüm riski açısından düşük BMI'ler ile yüksek viseral obezite arasında benzer bir ilişki olduğu bulunmuştur. ${ }^{38}$ Bu çalışmada viseral obezite, daha fazla komorbidite, postoperatif komplikasyon ve reoperatif oranın yüksek olduğu ve hastanede kalış süreleri ile ilişkiliydi. Bu sonuçlar diğer yazarlar tarafından bulunan gözlemlerle uyumludur. ${ }^{26}$

Lokal ileri evre rektum kanserinde preoperatif kemo radyasyonu yaygın bir uygulama haline gelmiştir ve vücut bileşimini etkileyebilir. Kemo radyasyonunun viseral obezite üzerindeki etkisini ve postoperatif sonuçlara etkisini belirlemek için bir çalışma (Bölüm 8) yapılmıştır. Kemo radyasyonundan sonra viseral yağ bölgesinde bir fark bulunmadı. Viseral obezite, rektum kanseri cerrahisinde kötü sonuçlarla güçlü bir şekilde ilişkiliydi. Bu bağlamda, rutin olarak yapılan preoperatif BT taraması kullanılarak viseral yağ dokusu miktarının belirlenmesi rektal kanser hastalarında preoperatif metabolik risk profili oluşturulmasına katkıda bulunabilir. 


\section{Gelecek perspektifleri}

Bir ERAS programının uygulanmasından sonra, hastaya bu yaklaşımın yararlarını sağlamak için ERAS protokolüne iyi bir şekilde bağlı kalmak önemlidir. ${ }^{38}$ Bir ERAS programına bağııık, multidisipliner karakteri nedeniyle karmaşıktır. Değişime karşı hassastır ve devam eden başarının sağlanması için sürekli izleme ve geri bildirim gereklidir. Hastane idareleri, bu multidisipliner protokollerin bir organizasyonda sürekli olarak uygulanmasını sağlamak için sorumluluk almalıdır, çünkü uymaksızın bakım ve maliyet avantajları kolayca kaybedilir. Yapılandırılmış bir uygulama stratejisinin iyi bir sürdürülebilirliğe yol açabileceği zaten kanıtlanmıştır. ${ }^{39}$ ERAS programı, kolorektal kanser cerrahisinde perioperatif bakıma yönelik standart bir yaklaşıma katkıda bulunmuştur. Bu sadece bakım kalitesini arttırmakla kalmayıp aynı zamanda viseral obezite ve NSAiD kullanımı gibi cerrahi sonucu etkileyen değişkenlerin çalışılmasını da sağlar. Kolorektal kanser hastası ve ayrıca iyi huylu kolorektal hastalığı olan hastalar için bakımın standardizasyonu için bu eşsiz çabayı korumak için ERAS programına bağlılığı geliştirmek ve izlemek için sürekli çaba gösterilmelidir.

ERAS toplumunun kolonik cerrahi için tüm önerileri, mide kanseri veya karaciğer, pankreas veya jinekolojik cerrahi, yani idrar sondalarının erken çıkarılması, postoperatif ileusun önlenmesi, postoperatif analjezi ve erken mobilizasyonun ve normal diyetin tekrar başlatılmasının gibi diğer ameliyatlarda uygulanabilir. ${ }^{40}$ Son yıllarda, örneğin gastrik kanser cerrahisinde benzer programların etkisini geliştirmek, uygulamak ve değerlendirmek için çaba gösterilmiştir. Gastrik kanser için gastrektomi sonrası oral alımın zamanlaması üzerine yapılan çalışmalar çok azdır. Mevcut olan küçük çalışmalar, erken oral beslenmeyi güvenli ve uygulanabilir olarak değerlendirmiştir. ${ }^{41}$ Diğer karşılaştırmalı çalışmalar, anlamlı şekilde daha kısa LOS (örneğin, 5.7 vs. 9,2 gün) ve daha önce bağırsak fonksiyonunun geri dönüşünü göstermiştir. ${ }^{42-44}$ Erken oral beslenme için stratejiler farklı olmasına rağmen, bulgular güvenli olduğu ve potansiyel olarak daha kısa LOS'a yol açtığıydı. ${ }^{42-44}$ Bir ERAS programına göre tedavi edilen 22 hasta ve 22 konvansiyonel bakım hastası dahil olmak üzere mide kanseri hastalarında yapılan randomize bir klinik çalışma, ERAS program hastaları için daha kısa bir LOS göstermiştir (5'e 8 gün, $P<0.001$ ), ancak postoperatif ağrı için bir fark görülmemiştir. ${ }^{45} \mathrm{Bu}$, bir gastrik kanser ameliyatına özel ERAS kılavuzunun yayınlanmasına yol açmıştır, ancak ERAS'ın birçok yönü için sınırlı kanıt bulunduğundan, büyük ölçüde konsensüs kılavuzudur. ${ }^{46}$ Gastrik cerrahi ve kolorektal cerrahi için bu sonuçlara paralel olarak, birkaç çalışma, hastalar karaciğer cerrahisi, pankreatikoduodenektomi ve jinekolojik cerrahi için bir ERAS programında tedavi edildiğinde, LOS'un azaldığını göstermiştir. ${ }^{47-50}$ Morbidite, 
mortalite veya geri kabul oranlarından ödün vermeden LOS azalır. Bu aynı zamanda bir karaciğer ve pankreas kanserine özgü ERAS'ın yayınlanmasına neden olmuştur.

Mevcut ERAS programlarında uygulanabilecek bir diğer umut verici gelişme, büyük ameliyat geçiren hastaların ön rehabilitasyonudur. Preoperatif fiziksel sağlık (örneğin, kardiyorespiratuar sağlığlı, kas kuvveti ve fonksiyonel mobilite) ön rehabilitasyon yoluyla optimize etmek, büyük karın ameliyatı geçiren hastalarda postoperatif sonuçları geliştirebilir.

Moran ve diğ. sistematik bir incelemede, prehabilitasyonun postoperatif komplikasyonların oranlarını azaltmada yararlı olduğunu ortaya koymuştur. ${ }^{53}$ Ek olarak, Bruns ve ark. ön rehabilitasyonun, kolorektal ameliyatı geçirecek olan yaşlı hastaların, fiziksel saglığını artırabileceğini bildirdi. Fakat komplikasyonların azalması veya LOS üzerinde anlamlı bir etki göstermediler. ${ }^{54}$ Ayrıca, kişiselleştirilmiş ön rehabilitasyonun, elektif majör abdominal ameliyati geçiren yüksek riskli hastalarda, postoperatif komplikasyonlarını 51\% azalttığı gösterilmiştir. ${ }^{55}$ Günümüzde kolorektal kanserli yüksek riskli hastalarda preoperatif egzersiz eğitiminin postoperatif komplikasyonlar üzerine etkisi konusunda literatür çok azdır. Çalışmaların çoğu güçsüz, heterojen ve düşük postoperatif komplikasyon riski olan hastaları üzerinedir. 2014 yılında, kardiyo solunumu zayıf olan ve kolorektal kanser, displazi I, II veya III için seçmeli kolorektal rezeksiyon yapılan hastalarla, üç haftalık bir ön rehabilitasyon programının etkisini öğrenmek için, iyi tasarlanmış, randomize, ve kontrollü bir deneme yapıldı. ${ }^{56} \mathrm{Bu}$ deneme 2018 'in sonunda tamamlanması bekleniyor. 


\section{References}

1. Kehlet H. Multimodal approach to control postoperative pathophysiology and rehabilitation. $\mathrm{Br} \mathrm{J}$ Anaesth 1997;78(5):606-17.

2. Nygren J, Hausel J, Kehlet H, Revhaug A, Lassen K, Dejong C, Andersen J, von Meyenfeldt M, Ljungqvist $\mathrm{O}$, Fearon KC. A comparison in five European Centres of case mix, clinical management and outcomes following either conventional or fast-track perioperative care in colorectal surgery. Clin Nutr 2005; 24(3):455-61.

3. Fearon KC, Ljungqvist $\mathrm{O}$, Von Meyenfeldt $\mathrm{M}$, Revhaug A, Dejong $\mathrm{CH}$, Lassen $\mathrm{K}$, Nygren J, Hausel J, Soop $\mathrm{M}$, Andersen J, Kehlet $\mathrm{H}$. Enhanced recovery after surgery: a consensus review of clinical care for patients undergoing colonic resection. Clin Nutr 2005;24(3):466-77.

4. Basse L, Thorbol JE, Lossl K, Kehlet H. Colonic surgery with accelerated rehabilitation or conventional care. Dis Colon Rectum 2004;47:271-7.

5. Varadhan $\mathrm{KK}, \mathrm{Neal} \mathrm{KR}$, Dejong $\mathrm{CH}$, et al. The enhanced recovery after surgery (ERAS) pathway for patients undergoing major elective open colorectal surgery: a meta-analysis of randomized controlled trials. Clin Nutr 2010;29:434-40.

6. Ahmed J, Khan S, Lim M, Chandrasekaran TV, MacFie J. Enhanced recovery after surgery protocols compliance and variations in practice during routine colorectal surgery. Colorectal Dis 2012;14:1045-51.

7. Greco M, Capretti G, Beretta L, Gemma M, Pecorelli N, Braga M. Enhanced recovery program in colorectal surgery: a meta-analysis of randomized controlled trials. World J Surg 2014;38:1531-41.

8. Bakker IS, Grossmann I, Henneman D, Havenga K, Wiggers T. Risk factors for anastomotic leakage and leak-related mortality after colonic cancer surgery in a nationwide audit: Br J Surg 2014;101:424-32.

9. Pommergaard HC, Gessler B, Burcharth J, Angenete E, Haglind E, Rosenberg J. Preoperative risk factors for anastomotic leakage after resection for colorectal cancer: a systematic review and meta-analysis: Colorectal Dis 2014;16(9):662-71.

10. Kube R, Mroczkowski P, Granowski D, Benedix F, Sahm M, Schmidt U et al. Anastomotic leakage after colon cancer surgery: a predictor of significant morbidity and hospital mortality, and diminished tumour-free survival: Eur J Surg Oncol 2010;36:120-4.

11. Klein M, Gogenur I, Rosenberg J. Postoperative use of non-steroidal anti-inflammatory drugs in patients with anastomotic leakage requiring reoperation after colorectal resection: cohort study based on prospective data: BMJ 2012;345:e6166.

12. Holte $\mathrm{K}$, Andersen J, Jakobsen DH, Kehlet H. Cyclo-oxygenase 2 inhibitors and the risk of anastomotic leakage after fast-track colonic surgery: Br J Surg 2009;96:650-4.

13. Gorissen KJ, Benning D, Berghmans T, Snoeijs MG, Sosef MN, Hulsewe KW et al. Risk of anastomotic leakage with non-steroidal anti-inflammatory drugs in colorectal surgery: Br J Surg 2012;99:721-7.

14. Bhangu A, Singh P, Fitzgerald JE, Slesser A, Tekkis P. Postoperative Nonsteroidal Anti-inflammatory Drugs and Risk of Anastomotic Leak: Meta-analysis of Clinical and Experimental Studies: World J Surg 2014;38(9):2247-57.

15. Rushfeldt CF, Sveinbjornsson B, Soreide K, Vonen B. Risk of anastomotic leakage with use of NSAIDs after gastrointestinal surgery: Int J Colorectal Dis 2011;26:1501-9.

16. Klein M, Andersen LP, Harvald T, Rosenberg J, Gogenur I. Increased risk of anastomotic leakage with diclofenac treatment after laparoscopic colorectal surgery: Dig Surg 2009;26:27-30.

17. Holte K, Andersen J, Jakobsen DH, Kehlet H. Cyclo-oxygenase 2 inhibitors and the risk of anastomotic leakage after fast-track colonic surgery: Br J Surg 2009;96:650-4.

18. Ueda J, Ichimiya H, Okido M, Kato $M$. The impact of visceral fat accumulation on laparoscopy-assisted distal gastrectomy for early gastric cancer. J Laparoendosc Adv Surg Tech A 2009;19(2):157-62.

19. Yoshikawa K, ShimadaM, Kurita N, Iwata T, Nishioka M,Morimoto S, Miyatani T, Komatsu M, Mikami C, Kashihara H. Visceral fat area is superior to body mass index as a predictive factor for risk with laparoscopy-assisted gastrectomy for gastric cancer. Surg Endosc 2011;25(12):3825-30.

20. Miyaki A, Imamura K, Kobayashi R, TakamiM,Matsumoto J. Impact of visceral fat on laparoscopyassisted distal gastrectomy. Surgeon 2013;11(2):76-81. 
21. Tokunaga M, Hiki N, Fukunaga T, Ogura T, Miyata S, Yamaguchi T. Open gastrectomy for gastric cancer. Br J Surg 2009;96(5):496-500.

22. Shimizu A, Tani M, KawaiM, Hirono S,MiyazawaM, Uchiyama K, Yamaue H. Influence of visceral obesity for postoperative pulmonary complications after pancreaticoduodenectomy. J Gastrointest Surg 2011; 15(8):1401-10.

23. Hagiwara M, Miyajima A, Hasegawa M, Jinzaki M, Kikuchi E, Nakagawa K, Oya M. Visceral obesity is a strong predictor of perioperative outcome in patients undergoing laparoscopic radical nephrectomy. BJU Int 2011;110(11):E980-4.

24. Ballian N, Lubner MG, Munoz A, Harms BA, Heise CP, Foley EF, et al. Visceral obesity is associated with outcomes of total mesorectal excision for rectal adenocarcinoma. J Surg Oncol 2012;105:365-70.

25. Wilton P. Does my bmi look big in this?; 2013 Available from: http://www.ox.ac.uk/media/science_blog/ 130116.html

26. Tsujinaka S, Konishi F, Kawamura YJ, Saito M, Tajima N, Tanaka O, Lefor AT. Visceral obesity predicts surgical outcomes after laparoscopic colectomy for sigmoid colon cancer. Dis Colon Rectum 2008; 51(12):1757-65.

27. Cecchini S, Cavazzini E, Marchesi F, Sarli L, Roncoroni L. Computed tomography volumetric fat parameters versus body mass index for predicting short-term outcomes of colon surgery. World J Surg 2011;35(2):415-23.

28. Tapper R, Dixon L, Frampton C, Frizelle F. Impact of obesity on the cost of major colorectal surgery. Br J Surg 2013;100:293-8.

29. Gendall KA, Raniga S, Kennedy R, Frizelle FA. The impact of obesity on outcome after major colorectal surgery. Dis Colon Rectum 2007;50:2223-37.

30. Shuster A, Patlas M, Pinthus JH, Mourtzakis $M$. The clinical importance of visceral adiposity: a critical review of methods for visceral adipose tissue analysis. Br J Radiol 2012;85(1009):1-10.

31. Nitori N, Hasegawa H, Ishii Y, Endo T, Kitagawa Y. Impact of visceral obesity on short-term outcome after laparoscopic surgery for colorectal cancer: a single Japanese center study. Surg Laparosc Endosc Percutan Tech 2009;19(4):324-7.

32. Moon HG, Ju YT, Jeong CY, Jung EJ, Lee YJ, Hong SC, Ha WS, Park ST, Choi SK. Visceral obesity may affect oncologic outcome in patients with colorectal cancer. Ann Surg Oncol 2008;15(7):1918-22.

33. Sakai T, Maekawa T, Mikami K, Kuramochi H, Noda S. Visceral fat volume and surgical outcomes of colorectal resection. Int Surg 2009;94:370-2.

34. Watanabe J, Tatsumi K, Ota M, Suwa Y, Suzuki S, Watanabe A, et al. The impact of visceral obesity on surgical outcomes of laparoscopic surgery for colon cancer. Int J Colorectal Dis 2014;29:343-51.

35. Rickles AS, lannuzzi JC, Mironov O, Deeb AP, Sharma A, Fleming FJ, et al. Visceral obesity and colorectal cancer: are we missing the boat with BMI? J Gastrointest Surg 2013;17:133-43.

36. Hiuge-Shimizu A, Kishida K, Funahashi T, Ishizaka Y, Oka R, Okada M, et al. Absolute value of visceral fat area measured on computed tomography scans and obesity-related cardiovascular risk factors in largescale Japanese general population (the VACATION-J study). Ann Med 2012;44:82-92.

37. Pischon T, Boeing H, Hoffmann K, Bergmann M, Schulze MB, Overvad K, et al. General and abdominal adiposity and risk of death in Europe. N Engl J Med 2008;359:2105-20.

38. Feroci F, Lenzi E, Baraghini M, Garzi A, Vannucchi A, Cantafio S, Scatizzi M. Fast-track colorectal surgery: protocol adherence influences postoperative outcomes. Int J Colorectal Dis 2013;28(1):103-9.

39. Gillissen F, Ament SM, Maessen JM, Dejong CH, Dirksen CD, van der Weijden T, von Meyenfeldt MF. Sustainability of an enhanced recovery after surgery program (ERAS) in colonic surgery. World J Surg 2015;39(2):526-33.

40. Gustafsson UO, Scott MJ, Schwenk W, Demartines N, Roulin D, Francis N, McNaught CE, MacFie J, Liberman AS, Soop M, Hill A, Kennedy RH, Lobo DN, Fearon K, Ljungqvist O, and Enhanced Recovery After Surgery S, Guidelines for perioperative care in elective colonic surgery: Enhanced Recovery After Surgery (ERAS(R)) Society recommendations. Clin Nutr 2012;31(6):783-800.

41. Jo DH, Jeong O, Sun JW, Jeong MR, Ryu SY, and Park YK, Feasibility study of early oral intake after gastrectomy for gastric carcinoma. J Gastric Cancer 2011;11(2):101-8.

42. Hur H, Si Y, Kang WK, Kim W, and Jeon HM, Effects of early oral feeding on surgical outcomes and recovery after curative surgery for gastric cancer: pilot study results. World J Surg 2009;33(7):1454-8. 
43. Suehiro $T$, Matsumata $T$, Shikada $Y$, and Sugimachi $K$, Accelerated rehabilitation with early postoperative oral feeding following gastrectomy. Hepatogastroenterology 2004;51(60):1852-5.

44. Hur H, Kim SG, Shim JH, Song KY, Kim W, Park CH, and Jeon HM, Effect of early oral feeding after gastric cancer surgery: a result of randomized clinical trial. Surgery 2011;149(4):561-8.

45. Kim JW, Kim WS, Cheong JH, Hyung WJ, Choi SH, and Noh SH, Safety and efficacy of fast-track surgery in laparoscopic distal gastrectomy for gastric cancer: a randomized clinical trial. World J Surg 2012;36(12): 2879-87

46. Mortensen K, Nilsson M, Slim K, Schafer M, Mariette C, Braga M, Carli F, Demartines N, Griffin SM, Lassen K, and Enhanced Recovery After Surgery G, Consensus guidelines for enhanced recovery after gastrectomy: Enhanced Recovery After Surgery (ERAS(R)) Society recommendations. Br J Surg 2014; 101(10):1209-29.

47. van Dam RM, Hendry PO, Coolsen MM, Bemelmans MH, Lassen K, Revhaug A, Fearon KC, Garden OJ, Dejong $\mathrm{CH}$; Enhanced Recovery After Surgery (ERAS) Group. Initial experience with a multimodal enhanced recovery programme in patients undergoing liver resection. Br J Surg 2008;95(8):969-75.

48. Coolsen MM, Wong-Lun-Hing EM, van Dam RM, van der Wilt AA, Slim K, Lassen K, Dejong $\mathrm{CH}$. A systematic review of outcomes in patients undergoing liver surgery in an enhanced recovery after surgery pathways. HPB (Oxford) 2013;15(4):245-51.

49. Coolsen MM, van Dam RM, Chigharoe A, Olde Damink SW, Dejong CH. Improving outcome after pancreaticoduodenectomy: experiences with implementing an enhanced recovery after surgery (ERAS) program. Dig Surg 2014;31(3):177-84.

50. de Groot JJ, Ament SM, Maessen JM, Dejong CH, Kleijnen JM, Slangen BF. Enhanced recovery pathways in abdominal gynecologic surgery: a systematic review and meta-analysis. Acta Obstet Gynecol Scand 2016;95(4):382-95.

51. Melloul E, Hübner M, Scott M, Snowden C, Prentis J, Dejong CH, Garden OJ, Farges O, Kokudo N, Vauthey JN, Clavien PA, Demartines N. Guidelines for Perioperative Care for Liver Surgery: Enhanced Recovery After Surgery (ERAS) Society Recommendations. World J Surg 2016;40(10):2425-40.

52. Lassen K, Coolsen MM, Slim K, Carli F, de Aguilar-Nascimento JE, Schäfer M, Parks RW, Fearon KC, Lobo DN, Demartines N, Braga M, Ljungqvist O, Dejong $\mathrm{CH}_{\text {; ERAS }}{ }^{\circledR}$ Society; European Society for Clinical Nutrition and Metabolism; International Association for Surgical Metabolism and Nutrition. Guidelines for perioperative care for pancreaticoduodenectomy: Enhanced Recovery After Surgery (ERAS ${ }^{\circledR}$ ) Society recommendations. Clin Nutr 2012;31(6):817-30.

53. Moran J, Guinan E, Mc Cormick P, Larkin J, Mockler D, Hussey J, et al. The ability of prehabilitation to influence postoperative outcome after intra-abdominal operation: a systematic review and metaanalysis. Surgery 2016;160(5):1189-201.

54. Bruns ER, Van den Heuvel B, Buskens CJ, Van Duijvendijk P, Festen S, Wassenaar EB, et al. The effects of physical prehabilitation in elderly patients undergoing colorectal surgery: a systematic review. Color Dis 2016;18(8):0267-7.

55. Barberan-Garcia A, Ubre M, Roca J, Lacy AM, Burgos F, Risco R, et al. Personalised prehabilitation in high-risk patients undergoing elective major abdominal surgery: a randomized blinded controlled trial. Ann Surg 2018;267(1):50-6.

56. Berkel AEM, Bongers $B C$, van Kamp MS, Kotte $H$, Weltevreden $P$, de Jongh FHC, Eijsvogel MMM, Wymenga ANM, Bigirwamungu-Bargeman M, van der Palen J, van Det MJ, van Meeteren NLU, Klaase JM. The effects of prehabilitation versus usual care to reduce postoperative complications in high-risk patients with colorectal cancer or dysplasia scheduled for elective colorectal resection: study protocol of a randomized controlled trial. BMC Gastroenterol 2018;18(1):29. 

Valorisation 



\section{Valorisation}

In this thesis we contributed evidence for the importance of adherence after implementation of an ERAS program. In short, the ERAS program is a multidisciplinary approach to reduce surgical stress leading to early recovery and shorten postoperative length of stay (LOS) in patients undergoing major surgery. ${ }^{1}$ The ERAS program consists of evidence-based changes in preoperative, intra-operative and postoperative treatments. ${ }^{1}$ Nowadays, the ERAS program is the standard care after colorectal surgery. Higher adherence to the ERAS program led to a reduced LOS and better outcome in elective colonic cancer surgery. ${ }^{2-4}$ Therefore, compliance with the ERAS elements is crucial for a shorter LOS and fewer complications in patients undergoing elective colon resections for malignancy. ${ }^{5}$ Despite the obvious benefits of the ERAS program, its implementation and adherence to the protocol remain a challenge. Adherence to an ERAS program is complex because of its multidisciplinary character; it is sensitive to change, and continuous monitoring and feedback are required to ensure ongoing success. ${ }^{5}$ In this era of increasing numbers of protocols and regulations, hospital administrations should take responsibility to ensure these multidisciplinary protocols are continuously implemented in an organization, because without adherence the care and cost benefits are easily lost. ${ }^{5}$ Key factors include repeated training sessions and the presence of trained nurse-practitioners at all stages in perioperative care. ${ }^{5}$ It is useful to continuously monitor barriers and facilitators for implementation and adherence. ${ }^{5}$ In addition, the nationwide introduction of the ERAS protocol has resulted in an unprecedented equalization of perioperative care for the colorectal cancer patient increasing the quality of multicenter scientific programs on surgical outcome

Another item affecting the outcome of colorectal surgery was visceral obesity. In short, obesity is an increasing health problem in the Western world. Visceral obesity has been associated with worse outcome in colorectal surgery and other forms of surgery. ${ }^{6-13}$ The measurement of visceral fat contributes to the risk assessment of postoperative problems in patients undergoing colonic surgery ${ }^{14,15}$ and should be investigated in a larger context where it is conceivable that the measurement becomes a standard part of the preoperative work-up for patients with a colonic malignancy. In the preoperative work-up of the colorectal cancer patient, the assessment of visceral fat could be performed easily with CT imaging of the abdomen. ${ }^{16}$ This information is also important in metabolic risk profiling the elective colorectal surgery patients and offers the opportunity to develop tailor-made intervention programs. ${ }^{16}$ In this thesis, the worse outcome seems even more present in patients with a $\mathrm{BMI}<25 \mathrm{~kg} / \mathrm{m}^{2}$ in combination 
with visceral obesity undergoing colon cancer surgery and this group may deserve more preoperative attention. ${ }^{16}$ 


\section{References}

1. Kehlet H. Multimodal approach to control postoperative pathophysiology and rehabilitation. $\mathrm{Br} \mathrm{J}$ Anaesth 1997;78(5):606-17. Review.

2. Ahmed J, Khan S, Lim M, Chandrasekaran TV, MacFie J. Enhanced recovery after surgery protocols compliance and variations in practice during routine colorectal surgery. Colorectal Dis 2012;14: 1045-51.

3. Gustafsson UO, Hausel J, Thorell A, Ljungqvist O, Soop M, Nygren J. Adherence to the enhanced recovery after surgery protocol and outcomes after colorectal cancer surgery. Arch Surg 2011;146: 571-7.

4. Vlug MS, Wind J, Hollmann MW, Ubbink DT, Cense HA, Engel AF, et al. Laparoscopy in combination with fast track multimodal management is the best perioperative strategy in patients undergoing colonic surgery: a randomized clinical trial (LAFA-study). Ann Surg 2011; 254(6): 868-75.

5. Cakir H, van Stijn MF, Lopes Cardozo AM, Langenhorst BL, Schreurs WH, van der Ploeg TJ, et al. Adherence to Enhanced Recovery After Surgery and length of stay after colonic resection. Colorectal Dis 2013;15:1019-25.

6. Dai Z, Xu YC, Niu L. Obesity and colorectal cancer risk: a meta-analysis of cohort studies. World J Gastroenterol 2007;13 (31):4199-206.

7. Tsujinaka S, Konishi F, Kawamura YJ, SaitoM, Tajima N, Tanaka O, Lefor AT. Visceral obesity predicts surgical outcomes after laparoscopic colectomy for sigmoid colon cancer. Dis Colon Rectum 2008; 51(12):1757-65.

8. Ueda J, Ichimiya $\mathrm{H}$, Okido $\mathrm{M}$, KatoM. The impact of visceral fat accumulation on laparoscopy-assisted distal gastrectomy for early gastric cancer. J Laparoendosc Adv Surg Tech A 2009;19(2):157-62.

9. YoshikawaK, ShimadaM, Kurita N, Iwata T, Nishioka M,Morimoto S, Miyatani T, Komatsu M, Mikami C, Kashihara $\mathrm{H}$. Visceral fat area is superior to body mass index as a predictive factor for risk with laparoscopy-assisted gastrectomy for gastric cancer. Surg Endosc 2011;25(12):3825-30.

10. MiyakiA, Imamura K, Kobayashi R, TakamiM,Matsumoto J. Impact of visceral fat on laparoscopyassisted distal gastrectomy. Surgeon 2013;11(2):76-81.

11. Tokunaga M, Hiki N, Fukunaga T, Ogura T, Miyata S, Yamaguchi T. Effect of individual fat areas on early surgical outcomes after open gastrectomy for gastric cancer. Br J Surg 2009;96(5):496-500.

12. Shimizu A, Tani M, KawaiM, Hirono S,MiyazawaM, Uchiyama K, Yamaue H (2011) Influence of visceral obesity for postoperative pulmonary complications after pancreaticoduodenectomy. J Gastrointest Surg 2011;15(8):1401-10.

13. Hagiwara M, Miyajima A, Hasegawa M, Jinzaki M, Kikuchi E, Nakagawa K, Oya M. Visceral obesity is a strong predictor of perioperative outcome in patients undergoing laparoscopic radical nephrectomy. BJU Int 2012;110(11): E980-E984

14. Ballian N, Lubner MG, Munoz A, Harms BA, Heise CP, Foley EF, Kennedy GD. Visceral obesity is associated with outcomes of total mesorectal excision for rectal adenocarcinoma. J Surg Oncol 2012;105(4):365-70.

15. Seki Y, Ohue M, Sekimoto M, Takiguchi S, Takemasa I, Ikeda M, Yamamoto H, Monden M. Evaluation of the technical difficulty performing laparoscopic resection of a rectosigmoid carcinoma: visceral fat reflects technical difficulty more accurately than body mass index. Surg Endosc 2007;21(6):929-34.

16. Cakir H, Heus C, Verduin WM, Lak A, Doodeman HJ, Bemelman WA, Houdijk AP. Visceral obesity, body mass index and risk of complications after colon cancer resection: A retrospective cohort study. Surgery 2015;157(5):909-15. 

Dankwoord 



\section{Dankwoord}

$\mathbf{P h}$ (inally)D(one). Eindelijk is het af!

Bij deze wil ik iedereen bedanken die op de één of andere manier een bijdrage heeft geleverd aan dit proefschrift.

Een aantal personen zou ik graag in het bijzonder willen bedanken.

Dr. A.P.J. Houdijk, beste Lex: Ondanks het feit dat ons initiële onderzoek niet is gelopen zoals wij het graag hadden gezien, hebben we dit proefschrift tot een mooi eind kunnen brengen. Ik heb ontzettend veel van je geleerd en heb respect voor de manier hoe jij onderzoek combineert met een baan in een perifeer ziekenhuis. Het was een plezier om met je samen te werken.

Prof. dr. C.H.C. Dejong, beste Kees: dank je wel dat jij mij de kans hebt geboden om bij jou te kunnen promoveren. Jouw toevoegingen hebben bijgedragen aan een verbetering van mijn proefstuk. Tevens zal ik jouw steun voor mijn aanname tot de opleiding Heelkunde nooit vergeten. Ik waardeer je manier van werken enorm en je bent een voorbeeld voor velen. Eén ding is zeker, voor mij ben je meer een FOS dan een FNOS.

Prof. dr. W.A. Bemelman en Dr. M.J.M. Serlie, beste Willem en Mireille: jullie waren beide in het begin betrokken bij mijn onderzoek. Graag wil ik jullie bedanken voor alle input die jullie hebben geleverd.

De hoofdstukken in dit proefschrift zouden niet tot stand gekomen zijn zonder de inbreng van alle co-auteurs. Bij deze wil ik alle auteurs bedanken die hier een bijdrage hebben geleverd.

De nurse-practitioner van het Noordwest Ziekenhuisgroep (voormalig Medisch Centrum Alkmaar), Anneke Dekker, wil ik bedanken voor het verzamelen van alle patiëntengegevens.

Deze promotie had niet tot stand kunnen komen zonder de leescommissie die dit proefschrift heeft beoordeeld. Ik wil dan ook de leden van de leescommissie: Prof. dr. L.P.S. Stassen, Prof. dr. H.J. Bonjer, Prof. dr. M.W. de Haan, Dr. A.G.M. Hoofwijk en 
Dr. J. Melenhorst hartelijk bedanken voor hun bereidheid dit proefschrift te beoordelen.

De overige leden van de promotiecommissie, Prof. dr. W.G. van Gemert, Prof. dr. G.L. Beets, Prof. Dr. I.H.J.T. de Hingh en Prof. dr. W.F.F.A. Buhre, wil ik bedanken voor het optreden als opponent tijdens mijn verdediging.

Mijn paranimfen, Claire Leenarts en Ruben Visschers. Lieve Claire, vanaf het moment dat wij collega's werden in het voormalig Orbis Medisch Centrum hebben we altijd al een speciale klik gehad. En zoals vanaf dag één al werd gezegd: jij zou mijn paranimf worden! Ondanks het feit dat ik het jammer en zonde vind dat je geen chirurgie bent gaan doen, hoop ik echt dat je gelukkig wordt in datgene wat je uiteindelijk wel gaat doen.

Beste Ruben, mijn broeder, abi, mijn partner in crime. We hebben vele jaren van de opleiding samen doorlopen en veel congressen bezocht. In jouw boekje gaf je aan dat je blij was dat ik vanuit het westen naar het zuiden gekomen was om hier de boel samen "onveilig" te maken. Dat gevoel is wederzijds en ik hoop dat wij nog vele jaren samen zullen werken. En de "positieve tuuter" houden we erin.

Ik vind het een eer dat jullie paranimf bij mijn promotie willen zijn, heel erg bedankt voor jullie steun.

Lieve Litza Mitalas en Nelleke Schouten: jullie horen natuurlijk ook apart vermeld te worden in dit proefschrift. Samen als ANIOS begonnen in het Reinier de Graaf Gasthuis te Delft en nu alle drie de opleiding volbracht in regio VIII. We hebben samen veel meegemaakt, zowel op het werk als privé. Jullie staan altijd voor mij klaar en daarmee hebben jullie een speciaal plekje in mijn leven.

Na mijn verhuizing naar het zuiden in 2013 kwam ik in een warm bad terecht door de assistenten van het voormalig Orbis Medisch Centrum. De volgende personen wil ik daarvoor bedanken (in willekeurige volgorde): Jarno Melenhorst, Femke Hellenthal, Michiel de Maat, Ruben Visschers, Litza Mitalas, Nelleke Schouten, Thomas Douchy, Casper Sommeling, Robert-Jan Coelen, Claire Leenarts, Job Alberga en Merel van Gelderen.

Graag wil ik alle chirurgen en assistenten van het Zuyderland Medisch Centrum en het MUMC+ bedanken voor de leerzame periode en steun tijdens mijn opleidingsjaren. 
Dr. A.G.M. Hoofwijk, beste Ton: mede door jouw steun en vertrouwen als voormalig opleider ben ik aangenomen voor de opleiding Heelkunde. "Ho, halt, stop" zullen veel assistenten zich herinneren als zij aan jou denken. Ik heb veel van je kunnen leren en hoop dat ik jouw verwachtingen waargemaakt heb.

Dr. L.H.J.M. van den Akker, beste Luc: ook jou wil ik apart noemen in mijn proefschrift. Ik vind het nog steeds jammer dat jij gestopt bent als chirurg, maar ik weet dat jij heel gelukkig bent in datgene wat jij nu doet. We hebben vaak gesprekken gevoerd over de chirurgie, maar ook over de vele dingen buiten de chirurgie. We blijven contact houden.

Beste Maud Rameckers, Denny Stoekenbroek en Claire Leenarts, mijn festivalmaatjes, mijn eetclubje. Wat hebben wij veel tijd doorgebracht op verschillende festivals en tijdens onze vele diners. Jullie zijn vrienden voor het leven geworden en ik hoop dat wij nog lang samen kunnen genieten van alle leuke/hippe/gezellige festivals, ook al praten wij dan vaak over het werk.

Denny, jou wil ik apart nog bedanken voor het ontwerpen van de kaft van dit boek.

Beste Jerrel Bechan, Waqas Raghoebar, Ferdi Doekhi: "The Wolfpack", al jaren vrienden voor het leven. Altijd staan jullie klaar voor mij tijdens de goede en de minder leuke tijden. Ondanks het feit dat wij de laatste tijd wat minder contact hebben, weet ik dat jullie er altijd zijn voor mij. Binnenkort maar weer snel afspreken.

De volgende vrienden (in willekeurige volgorde) Yusuf Ozbay, Ersin Kiris, Metin Ateş, Murat Ateş, Cihan Çolakoğlu, Ozcan Kuk, Serdal Gulhan en Inder Jagessar wil ik bedanken voor hun steun de afgelopen jaren. Jullie hebben allemaal een belangrijke rol gespeeld in mijn leven. Jullie worden één voor één zeer gewaardeerd.

Antonio Braucci; "my Italian brother from another mother". Gewoon in het Nederlands omdat jij altijd klaagt dat ik te weinig Nederlands spreek met jou. We zijn samen begonnen aan het promotieonderzoek in Alkmaar en we hebben zelfs een tijdje samengewoond in Den Haag. Helaas ben je eerder dan gepland teruggekeerd naar Napels. Desondanks hebben wij nog steeds een hechte band. Grazie di tutto!

Graag wil ik het bourgondische leven in Limburg bedanken voor al de extra kilo's die ik nu bij mij draag.

Paul, Marjo, Frank, Yvette, Koen, Carla, Stijn, Noud, Jasper, Boris en Isabel; mijn schoonfamilie. Vanaf dag één dat ik jullie heb leren kennen, heb ik mij direct welkom 
gevoeld binnen de familie. De rust die jullie hadden binnen de familie, is sindsdien ver te zoeken. En dit allemaal dankzij deze "Schwarze". Ik kijk uit naar de volgende vakanties samen. En Marjo, je gaat nog een keer mee naar het land van Erdoğan: jouw visum is al geregeld.

Graag wil ik al mijn ooms, tantes, neefjes, nichtjes en in het bijzonder mijn neef Ayhan Yildiz bedanken voor hun steun tijdens mijn studie en promotie.

En nu is het de beurt aan mijn 5 zussen, mijn "Kardesians". Fadime Gundoğdu-Çakir, Fatma Ossendrijver-Çakir, Dondu Çakir, Gulustan Cengiz-Çakir en Eda Çakir.

Fadime; je bent een tweede moeder voor ons allemaal, maar een geheim bewaren dat lukt je niet. Met de vele vragen die je stelt, maakt je ons af en toe gek. Je bent altijd tot laat aan het werk in je eigen zaak, maar op zondag maak je tijd voor de familie. Creëer wat meer vrije tijd voor jezelf.

Fatma; als kind waren wij water en vuur. Misschien is het wel goed dat jij in Almere bent gaan wonen en ik in Sittard $(;)$. Door de jaren heen zijn wij meer naar elkaar toe gegroeid en zitten we vaker op één lijn. Ik kom binnenkort wel langs om wat spullen in te slaan.

Dondu, ook al ben je soms eigenwijs, je weet altijd je doel te bereiken. Na een vervelende periode heb je de kracht gevonden om alles weer op orde te krijgen. Je hebt nu een nieuwe baan, een eigen huis en je bent de rijkste van ons allemaal.

Gulustan ofwel Gul; de kleinste van ons allemaal. Ik vind het heel knap dat je geprobeerd hebt om te emigreren naar Istanbul, maar ben stiekem wel blij dat je toch weer terug bent gekomen naar Nederland (de heer Wilders waarschijnlijk niet).

Eda; jongste van het gezin, nakomertje. Wat heb ik je hiermee vaak gepest! Nu ben je een volwassen vrouw en sta je altijd voor iedereen klaar in de familie. Ik heb veel respect voor alles wat je voor onze ouders doet, maar denk ook af en toe meer aan jezelf.

Jullie hebben ieder een speciaal plekje in mijn hart, ik hou van jullie en ik ben trots op jullie allemaal. Maar hoe goed jullie je best ook doen, als enige zoon in het gezin sta ik lekker toch altijd op nummer één bij papa en mama.

Mijn zwagers Kerim Gundoğdu, Erik Mark Ossendrijver en Muhammed Cengiz. Jullie houden mijn zussen in het gareel en daarvoor ben ik jullie dankbaar. Ik wil jullie bedanken voor alle steun de afgelopen jaren. 
Mijn neefjes Osman, Oğuzhan, Semih, Atilla en mijn nichtje Safiye; de next generation. $\mathrm{Er}$ is altijd leven in de brouwerij met jullie. Ik geniet stuk voor stuk van jullie aanwezigheid.

Mijn ouders, Tahir Çakir en Safiye Çakir-Cetiz: jullie staan altijd klaar voor de familie en de deur staat altijd open. Ik heb respect voor hoe jullie zes kinderen groot hebben gebracht. leder van ons heeft de mogelijkheid en vrijheid gekregen om zich te ontwikkelen en daarvoor zal ik jullie altijd dankbaar blijven. Blijf vooral genieten van al het moois dat het leven nog te bieden heeft. Bu sozlerinizi hic unutmayacağim: "Kimse senin dalgalarla nasıl boğuştuğuna bakmaz, gemiyi limana getirip getirmediğine bakar". Ik hou van jullie, sizi cok seviyorum!

Mehmet Aslan en Timur, mijn twee prachtige zonen. Jullie zijn de zonnetjes in mijn leven en brengen mij iedere dag vreugde.

Mehmet Aslan: jij bent mijn oudste zoon, mijn grote trots. Jij bent slim, grappig en sterk. Volg altijd je hart en weet dat jij alles kan worden wat jij maar wil. Inmiddels heb je een broertje en zijn jullie onafscheidelijk.

Timur, mijn jongste telg: sinds een jaar ben jij in ons gezin en maak je alles compleet. Jouw lach laat mij alle ellende vergeten.

Ik hou ontzettend veel van jullie!

Kim Gubbels: sinds 2014 (kort na het starten van mijn opleiding tot chirurg) zijn wij bij elkaar. Al die jaren stond jij naast mij en zonder jouw steun zou het nooit gelukt zijn om mijn promotie af te ronden. Jij geeft mij de ruimte om te zijn wie ik ben en ik kijk uit naar de nieuwe avonturen die wij samen zullen beleven. Jij brengt rust in mijn leven! Nu de promotie afgerond is, hebben wij meer tijd voor ons gezin. Ik hou van je, lief! 
List of publications 



\section{List of publications}

van Dijk DPJ, van Woerden V, Cakir H, den Dulk M, Olde Damink SWM, Dejong CHC. ERAS: Improving outcome in the cachectic HPB patient. J Surg Oncol. 2017 Oct;116(5):617-622. doi: 10.1002/jso.24767. Epub 2017 Aug 2. Review.

Heus C, Cakir H, Lak A, Doodeman HJ, Houdijk AP. Visceral obesity, muscle mass and outcome in rectal cancer surgery after neo-adjuvant chemo-radiation. Int J Surg. 2016 May;29:159-64. doi: 10.1016/j.ijsu.2016.03.066. Epub 2016 Apr 6.

Reply on: The new Body Mass Index as a predictor of postoperative complications in elective colorectal cancer surgery - Letter to Editor. van Vugt JLA, Cakir H, Kornmann VNN, Doodeman HJ, Stoot JHMB, Boerma D, Houdijk APJ, Hulsewé KWE. Clin Nutr ESPEN.

Bakker N, Deelder JD, Richir MC, Cakir H, Doodeman HJ, Schreurs WH, Houdijk AP. Risk of anastomotic leakage with nonsteroidal anti-inflammatory drugs within an enhanced recovery program. J Gastrointest Surg. 2016 Apr;20(4):776-82. doi: 10.1007/s11605015-3010-1. Epub 2015 Nov 4.

Bakker N, Cakir H, Doodeman HJ, Houdijk AP. Eight years of experience with Enhanced Recovery After Surgery in patients with colon cancer: Impact of measures to improve adherence. Surgery. 2015 Jun;157(6):1130-6. doi: 10.1016/j.surg.2015.01.016. Epub 2015 Mar 16.

Cakir H, Heus C, van der Ploeg TJ, Houdijk AP. Visceral obesity determined by CT scan and outcomes after colorectal surgery; a systematic review and meta-analysis. Int J Colorectal Dis. 2015 Jul;30(7):875-82. doi: 10.1007/s00384-015-2174-1. Epub 2015 Mar 14. Review.

Cakir H, Heus C, Verduin WM, Lak A, Doodeman HJ, Bemelman WA, Houdijk AP. Visceral obesity, body mass index and risk of complications after colon cancer resection: A retrospective cohort study. Surgery. 2015 May;157(5):909-15. doi: 10.1016/j.surg.2014.12.012. Epub 2015 Feb 21. 
van Vugt JL, Cakir H, Kornmann VN, Doodeman HJ, Stoot JH, Boerma D, Houdijk AP, Hulsewé KW. The new Body Mass Index as a predictor of postoperative complications in elective colorectal cancer surgery. Clin Nutr. 2015 Aug;34(4):700-4. doi: 10.1016/j.clnu.2014.08.006. Epub 2014 Aug 15.

Daams F, Wu Z, Cakir H, Karsten TM, Lange JF. Identification of anastomotic leakage after colorectal surgery using microdialysis of the peritoneal cavity. Tech Coloproctol. 2014 Jan;18(1):65-71. doi: 10.1007/s10151-013-1020-0. Epub 2013 Apr 30.

Cakir H, van Stijn MF, Lopes Cardozo AM, Langenhorst BL, Schreurs WH, van der Ploeg TJ, Bemelman WA, Houdijk AP. Adherence to Enhanced Recovery After Surgery and length of stay after colonic resection. Colorectal Dis. 2013 Aug;15(8):1019-25. doi: 10.1111/codi.12200.

Van Vliet-Koppert ST, Cakir H, Van Lieshout EM, De Vries MR, Van Der Elst M, Schepers T. Demographics and functional outcome of toe fractures. J Foot Ankle Surg. 2011 MayJun;50(3):307-10. doi: 10.1053/j.jfas.2011.02.003. Epub 2011 Mar 25.

Cakir H, van der Pol CC. [A man with a big tumour on his back]. Ned Tijdschr Geneeskd. 2011;155(18):A1081. Dutch.

Cakir H, Van Vliet-Koppert ST, Van Lieshout EM, De Vries MR, Van Der Elst M, Schepers T. Demographics and outcome of metatarsal fractures. Arch Orthop Trauma Surg. 2011 Feb;131(2):241-5. doi: 10.1007/s00402-010-1164-6. Epub 2010 Aug 17.

de Weert TT, Cretier S, Groen HC, Homburg P, Cakir H, Wentzel JJ, Dippel DW, van der Lugt A. Atherosclerotic plaque surface morphology in the carotid bifurcation assessed with multidetector computed tomography angiography. Stroke. 2009 Apr;40(4):133440. doi: 10.1161/STROKEAHA.108.538439. Epub 2009 Mar 5.

de Weert TT, Cakir H, Rozie S, Cretier S, Meijering E, Dippel DW, van der Lugt A.Intracranial internal carotid artery calcifications: association with vascular risk factors and ischemic cerebrovascular disease. AJNR Am J Neuroradiol. 2009 Jan;30(1):177-84. doi: 10.3174/ajnr.A1301. Epub 2008 Oct 8. 


\section{Curriculum Vitae}





\section{Curriculum Vitae}

Hamit Cakir was born on the 4th of January 1980 in Darende, Turkey. In September 1981 he moved with his family to the Netherlands. He obtained his Gymnasium degree at the Segbroek College in The Hague in 1998. After being several times eliminated by lottery, he started in $\mathbf{2 0 0 2}$ his medical study at the Faculty of Medicine at the Erasmus University in Rotterdam where he received his medical doctor degree in 2008. After his graduation, he started working as a surgical resident not in training at

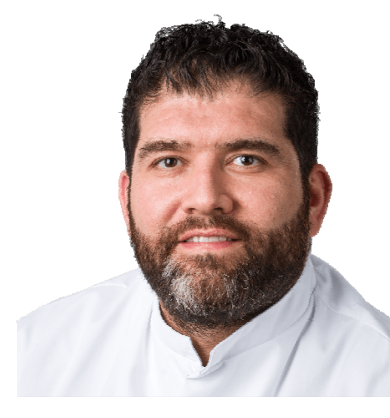
Reinier de Graaf Gasthuis in Delft. In 2010, he started as a PhD student in Medical Centre Alkmaar (nowadays Noordwest Ziekenhuisgroep) under the supervision of Dr. A.P.J. Houdijk and Prof. dr. C.H.C. Dejong. After 3 years of research, he started as a surgical resident not in training at Orbis Medical Centre (nowadays Zuyderland Medical Centre) in Sittard-Geleen. In January 2014, he started his surgical training at Orbis Medical Centre (nowadays Zuyderland Medical Centre) in Sittard-Geleen under the supervision of Dr. A.G.M. Hoofwijk and Dr. M.N. Sosef. In January 2017, he continued his training at the Maastricht University Medical Centre under the guidance of Prof. dr. L.P.S. Stassen and Prof. dr. C.H.C. Dejong. In October 2018, he returned back to the Zuyderland Medical Centre (Dr. M.N. Sosef and Drs. E.R. de Loos). He plans to finish his residency in January 2020. He lives happily together with Kim Gubbels, and is the proud father of two sons (Mehmet Aslan and Timur). 
